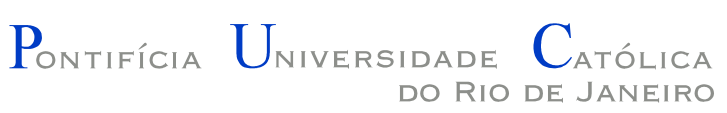

Marcus Vinicius Comodo Lauria de Faria

\title{
Potencial de aplicação de uma liga Fe-C-Ni em conexão flangeada de conectores de dutos flexíveis sob condição criogênica
}

Dissertação de Mestrado

Dissertação apresentada como requisito parcial para obtenção do grau de Mestre pelo Programa de Pós-graduação em Engenharia de Materiais e de Processos Químicos e Metalúrgicos do Departamento de Engenharia Química e de Materiais do Centro Técnico Científico da PUCRio.

Orientador: Prof. Marcos Venicius Soares Pereira 
Marcus Vinicius Comodo Lauria de Faria

\author{
Potencial de aplicação de uma liga Fe-C-Ni em conexão \\ flangeada de conectores de dutos flexíveis sob condição \\ criogênica
}

Dissertação apresentada como requisito parcial para obtenção do grau de Mestre pelo Programa de Pósgraduação em Engenharia de Materiais e de Processos Químicos e Metalúrgicos do Departamento de Engenharia Química e de Materiais do Centro Técnico Científico da PUC-Rio. Aprovada pela Comissão Examinadora abaixo assinada.

Prof. Marcos Venicius Soares Pereira

Orientador e Presidente

Departamento de Engenharia Química e de Materiais - PUC-Rio

Prof. Arnaldo Freitas Camarão

Co-Orientador

SAE Brasil

Prof. Fathi Aref Ibrahim Darwish Universidade Federal Fluminense

Prof. Carlos Alberto de Almeida Departamento de Engenharia Química e de Materiais - PUC-Rio

Prof. Marcio da Silveira Carvalho

Coordenador Setorial do Centro Técnico Científico da PUC-Rio

Rio de Janeiro, 05 de Abril de 2016 
Todos os direitos reservados. É proibida a reprodução total ou parcial do trabalho sem autorização da universidade, do autor e do orientador.

\section{Marcus Vinicius Comodo Lauria de Faria}

Cursou técnico em Mecânica no CEFET-RJ entre os anos 1966 e 1999. Entre os anos de 2001 e 2006, cursou graduação de Engenharia Metalúrgica na Universidade Federal do Rio de Janeiro e entre os anos de 2002 e 2009 cursou graduação em Ciências Contáveis na Universidade Estadual do Rio de Janeiro. Nos anos de 2008 e 2009 finalizou a Pós-graduação em Engenharia de Tubulação na PUC-Rio. Iniciou o curso de Mestrado em 2014, defendendo a Dissertação em 2016.

Ficha Catalográfica

Faria, Marcus Vinicius Comodo Lauria de

Potencial de aplicação de uma liga Fe-C-Ni em conexão flangeada de conectores de dutos flexíveis sob condição criogênica / Marcus Vinicius Comodo Lauria de Faria ; orientador: Marcos Venicius Soares Pereira. - 2016.

143 f. : il. ; $30 \mathrm{~cm}$

Dissertação (mestrado)-Pontifícia Universidade Católica do Rio de Janeiro, Departamento de Engenharia Química e de Materiais, 2016.

Inclui bibliografia

1. Engenharia Química - Teses. 2. Engenharia de Materiais - Teses. 3. Indústria do petróleo. 4. Integridade estrutural. 5. Propagação de trincas. 6. Conector de dutos flexíveis. 7. Criogenia. I. Pereira, Marcos Venicius Soares. II. Pontifícia Universidade Católica do Rio de Janeiro. Departamento de Engenharia Química e de Materiais. III. Título. 
Dedico este trabalho a minha esposa Marcia, ao meu filho Matheus e a toda minha família pelo que sei pelo que sou e por todo o amor, apoio e confiança incondicionais. 


\section{Agradecimentos}

Ao professor Marcos Venícius Pereira, pelo profundo acompanhamento, ensino, orientação e constante estímulo transmitido durante todo o trabalho. Ao Doutor Arnaldo Camarão pelo ensinamento e orientação transmitido durante o trabalho.

Ao CAPES, pelo auxílio concedido, sem o qual este trabalho não poderia ter sido realizado.

Aos meus amigos e colegas de trabalho que me apoiaram e sempre me incentivaram a continuar me esforçando e a todos que colaboraram direta ou indiretamente na concepção deste trabalho. 


\section{Resumo}

Faria, Marcus Vinicius Comodo Lauria de; Pereira, Marcus Venicius Soares. Potencial de aplicação de uma liga Fe-C-Ni em conexão flangeada de conectores de dutos flexíveis sob condição criogênica. Rio de Janeiro, 2016. 143p. Dissertação de Mestrado - Departamento de Engenharia Química e de Materiais, Pontifícia Universidade Católica do Rio de Janeiro.

Durante o tempo em serviço, estruturas e componentes de equipamentos podem falhar e causar acidentes. Isto geralmente conduz a danos materiais podendo, ainda, causar perda de vidas humanas e danos ambientais. Frequentemente, os eventos danosos são originários de falhas de materiais e de fabricação, sobrecargas não previstas ou outros problemas oriundos do tempo de operação ou deficiência de manutenção de um componente. Neste estudo, com base numa análise de propagação de trinca superficial submetida a carregamento, se avaliou a integridade de um flange da conexão de topo de uma linha flexível, sob condições criogênicas de operação. Quando em serviço, a falha deste conector pode ocasionar interrupções na produção, dano a equipamentos e meio ambiente, bem como fatalidades em plataformas offshore de petróleo. As linhas (dutos) flexíveis utilizadas para injetar gás $\mathrm{CO}_{2}$ nos reservatórios de petróleo no país trabalham submetidas a elevadas pressões internas (da ordem de 10.000 psi), o que aumenta o risco de falha do componente. Além disto, a selagem da conexão flangeada pode falhar e provocar um vazamento de fluido gasoso, proporcionando uma queda acentuada da temperatura local e potencializando a fratura frágil do componente. O cenário proposto para o estudo foi relacionado a possível falha na vedação do anel BX, localizado entre a conexão da linha flexível e a plataforma de petróleo. A metodologia foi dividida em duas etapas: a primeira corresponde à análise global linear elástica do conector na ausência de trincas e baseada no método de elementos finitos (MEF). Na segunda etapa da análise, se introduziu uma trinca no conector na região com os maiores níveis de tensão e onde é possível realizar ensaio por líquido penetrante. Assim, o estudo se concentrou na conexão flangeada do conector, adotando como um aço com 9\% de níquel em sua 
composição química, liga ferrosa de larga aplicação em tanques de armazen de GNL. Se buscou avaliar a resistência à fratura do material através da associação de condições severas de carregamento, baixas temperaturas e tamanho de trinca em flanges de dutos flexíveis, conforme critério severizado da norma API 6A. Desta maneira, se espera contribuir para que a indústria offshore de petróleo tenha mais uma opção de material para ser adotado na fabricação de conectores de topo das linhas flexíveis que trabalhem em condição criogênica.

\section{Palavras-chave}

indústria do petróleo; integridade estrutural; propagação de trincas;

conector de dutos flexíveis 


\section{Abstract}

Faria, Marcus Vinicius Comodo Lauria de; Pereira, Marcus Venicius Soares. Application potential of an $\mathrm{Fe}-\mathrm{C}-\mathrm{Ni}$ alloy in flanged connection of end fitting of flexible pipe under cryogenic conditions. Rio de Janeiro, 2016. 143p. MSc. Dissertation - Departamento de Engenharia Química e de Materiais, Pontifícia Universidade Católica do Rio de Janeiro.

During the time in service, structures and equipment components can fail and cause accidents. This usually leads to damage and may also cause loss of human lives and environmental damages. Often, harmful events are originated from materials and manufacturing faults, unforeseen overloads or other problems arising from the operation time or component maintenance deficiencies. In this study, based on the analysis of surface crack propagation under loading, was assessed the integrity of a top connecting flange of a flexible line operation under cryogenic conditions. When in service, the failure of this connector may cause production disruptions, damages to the equipment and the environment, as well as human fatalities on offshore oil platforms. In Brazil, flexibles lines (ducts) used to inject $\mathrm{CO} 2$ gas in oil reservoirs work subjected to high internal pressures (of the order of 10,000 psi), which increases the risk of a component failure. Moreover, the damaged flange may cause leakage of gaseous fluid resulting in very low local temperatures and resulting in brittle fracture enhancing of the component. The scenario proposed in this study is related to a possible seal BX ring failure which is located between the flexible line connection and the oil platform. The methodology was divided into two stages: the first corresponds to the linear elastic global analysis of the connector in the absence of cracks and based on the finite element method (FEM). In the second stage of analysis, it introduced a crack on the connector in the region with the highest stress levels and where it is possible to test for penetrant. Thus, the study focused on the flange connection connector, adopting as a steel with $9 \%$ nickel in its chemical composition, ferrous alloy wide application in LNG storage tanks. He sought to evaluate the fracture resistance of the material through the combination of severe loading conditions, low temperatures and 
cracks in flanges of flexible ducts as severe criteria standard API 6A standard. Thus, it is expected to contribute to the offshore oil industry has one more material option to be adopted in the manufacture of top connectors of the flexible lines working in cryogenic condition.

\section{Keywords}

oil industry; structural integrity; crack propagation; end fitting of flexible pipe 


\section{Sumário}

1. INTRODUÇÃO 20

2. REVISÃO DA LITERATURA 23

2.1. Petróleo 23

2.2. Acidente em planta de GNL e a consequência na indústria de petróleo 28

2.3. Sistema Submarino de Produção 32

2.4. Risers flexíveis 33

2.5. Propriedade Mecânica do Inconel UNS N06625 40

2.6. Propriedade mecânica do aço $9 \% \mathrm{Ni}$

2.7. Mecânica da fratura $\quad 45$

2.7.1. Mecânica da fratura linear-elástica 45

2.7.2 Mecânica da fratura elasto-plástica (MFEP) 50

2.7.2.1 Método de abertura crítica da trinca - CTOD 52

2.7.2.2. Integral J 54

2.8. Cálculo por Elementos Finitos 56

2.8.1. Método Elementos Finitos 56

2.8.2. Malha de elementos finitos: nós e elementos $\quad 59$

2.8.3. Elementos isoparamétricos 64

2.8.4. Abordagem por elementos 3D sólidos 67

2.8.5. Mecânica da fratura no Método dos Elementos Finitos 69

2.9. Norma BS: 7910 (antiga PD11:6493) 72

3. MATERIAIS E MÉTODOS 83

3.1. Componentes 84

3.2. Materiais 85

3.2.1. Material dos Flanges $\quad 85$

3.2.2. Material do anel BX $156 \quad 87$

3.2.3. Material dos Estojos e porcas 90

3.3. Avaliação numérica do conjunto sem defeito 92

3.3.1. Malha 93

3.3.2. Regiões de avaliações 96 
3.3.3. Premissas térmicas $\quad 97$

3.3.4. Premissas Estruturais 98

3.4. Avaliação Analítica do Conjunto com o defeito 100

3.5. Avaliação Numérica do Conjunto com o defeito 103

3.5.1. Malha 103

3.5.2. Regiões de Avaliação 106

3.5.3. Premissas Térmicas 106

3.5.4. Premissas Estruturais 107

3.5.5. ANSYS: Calcular o K 108

4. RESULTADOS E DISCUSSÕES 112

4.1. Avaliação numérica do conjunto sem defeito 112

4.1.1. Análise Térmica 112

4.1.2. Análise Estrutural 112

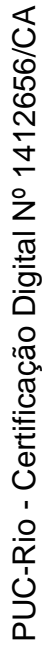

4.2. Avaliação Analítica do Conjunto com o defeito 114

4.3. Avaliação Numérica do Conjunto com o defeito 115

4.3.1. Análise Térmica 115

4.3.2. Análise Estrutural 116

4.3.3. Análise Mecânica da Fratura 118

5. CONCLUSÕES 120

6. Referências bibliográficas 122

7. Anexo A 128

8. Anexo B 136 


\section{Lista de figuras}

Figura 1 - Acumulação de petróleo devido às relações discordantes nas rochas [2]. 20

Figura 2 - Acumulação de petróleo devido às relações discordantes nas rochas 23

Figura 3 - FPSO P-50 (Fonte: Acervo de imagem da Petrobras) 26

Figura 4 - Esquema simplificado de injeção contínua de $\mathrm{CO}_{2}$ (acervo Technip) 27

Figura 5 - Fotos da planta de GNL em Shangai após o acidente [4].......29

Figura 6 - Fotos da conexão flangeada onde iniciou a explosão [4]. 29

Figura 7 - Esquema de conexão entre uma linha flexível e uma plataforma de petróleo.

Figura 8 - Esquema de uma conexão flangeada API.

Figura 9 - Sistema Submarino de Produção. (Fonte: Modificada.

Acervo de imagem da Petrobras).

Figura 10 - Riser e flowline flexíveis. (Fonte: Acervo de imagem da Petrobras).

Figura 11 - Estruturas de tubos flexíveis utilizadas para exploração de petróleo [http://www.defesaaereanaval.com.br/?p=29972] .................35

Figura 12 - Estrutura flexível (Fonte: acervo Petrobras)...........................36

Figura 13 - Armadura de pressão (Perfil Zeta e Teta) ..............................38

Figura 14 - Conector de um tubo flexível [10]..........................................39

Figura 15 - Montagem de conector de um tubo flexível [11] ...................40

Figura 16 - Resistência a corrosão da liga UNS N06625 em meio de $\mathrm{H}_{2} \mathrm{~S} / \mathrm{CO}_{2}$ com altas concentrações de $\mathrm{Cl}$ e ausência de enxofre. Taxa de corrosão de Q.05 mm/ano (2 mpy) e sem mecanismo de SSC e SCC [13].

Figura 17 - Representação esquemática de uma chapa de dimensões relativamente infinitas com uma trinca central de formato elíptico de comprimento 2a, HERTZBERG (1989) [28].

Figura 18 - Os três modos de carregamento que podem ser aplicados em uma trinca, ANDERSON (2005) [27]. 
Figura 19 - Faixa de aplicação da MFLE, MFEP E MFP para descrever o comportamento da fratura. Adaptado de EWALDS \& WANHILL (1993) [33].

Figura 20 - Representação esquemática de abertura na ponta da trinca [31].

Figura 21 - Definição da Integral J para um entalhe agudo submetido a um estado plano de tensões e o contorno de integração. .55

Figura 22 - Resumo de um processo de solução pelo MEF. 59

Figura 23 - Exemplo de problema 2D com detalhe para um elemento triangular de primeira ordem.

Figura 24 - Elemento triangular plano: (a) para elemento de primeira ordem e (b) de segunda ordem.

Figura 25 - Comparativo de discritização de erro para três abordagens diferentes em relação à ordem do elemento. 64

Figura 26 - Elemento isoparamétrico de um elemento quadrilátero de primeira ordem [43].

Figura 27 - Elemento sólido 3D: Estado tridimensional de tensões (a). Contento 8 nós (b) e seus graus de liberdade por nó (b).

Figura 28 - Elementos 3D sólidos: Tetraédrico de primeira ordem (a), tetraédrico de segunda ordem (b), hexaédrico de primeira ordem (c) e hexaédrico de segunda ordem (d) [45]

Figura 29: Alteração de um elemento quadrilátero em um elemento triangular na ponta da trinca

Figura 30 - Transformação de um elemento tipo bloco em uma cunha ...71

Figura 31 - Elemento singular 8-nós quadrático isoparamétrico plano (a) e elemento isoparamétrico de origem (b) [51] 71

Figura 32 - Elemento singular prismático de 20-nós sólido [45] ...............72

Figura 33 - Modelo semi-simétrico de uma trinca plana ...........................72

Figura 34 - Caracterização das trincas [52]..........................................78

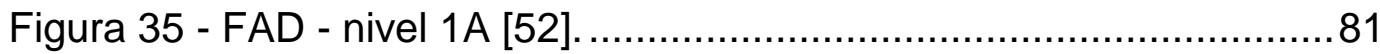

Figura 36 - Diagrama FAD utilizado na BS:7910, incorporando a influência do escoamento descontínuo na ductilidade do material [52]....82 
Figura 37 - Esquema simplificado da metodologia usado na pesquisa....83 Figura 38 - Esquema do flange 7 1/16" API 6BX 10.000 psi, anel BX e estojos e porcas

Figura 39 - Conexão flangeada de uma terminação de topo de um duto flexível de uma linha de injeção de gás. 85

Figura 40 - Propriedades do material Aço 9\%Ni [25]. 86

Figura 41 - Coeficiente térmico de expansão do material Aço 9\%Ni [25]. 86 Figura 42 - Variação da condutividade térmica em relação a temperatura do material Aço 9\% Ni [25].

Figura 43 - Variação de calor específico em relação a temperatura do material Aço 9\%Ni [25].

Figura 44 - Propriedades do material Inconel UNS N06625 [12]. 88

Figura 45 - Coeficiente térmico de expansão do material Inconel UNS N06625 [12].

Figura 46 - Variação da condutividade térmica em relação a temperatura do material Inconel UNS N06625 [12]. 89

Figura 47 - Variação do calor específico em relação a temperatura do material Inconel UNS N06625 [12].

Figura 48 - Curva Tensão x Deformação do material Inconel UNS

N06625 de forma simplificada [12]. 90

Figura 49 - Propriedades do material Inconel UNS N06625 [12]. .90

Figura 50 - Coeficiente térmico de expansão do material Inconel UNS N06625 [12].

Figura 51 - Variação da condutividade térmica em relação a temperatura do material Inconel UNS N06625 [12].

Figura 52 - Variação do calor específico em relação a temperatura do material Inconel UNS N06625 [12]. .92

Figura 53 - Curva Tensão x Deformação do material Inconel

UNS N06625 de forma simplificada [12] .92

Figura 54 - Região de interesse do estudo no flange 7 1/16" API 6BX 10.000 psi

Figura 55 - Modelo com a malha. 94

Figura 56 - Modelo com a malha 94

Figura 57 - Modelo com a malha. 95 


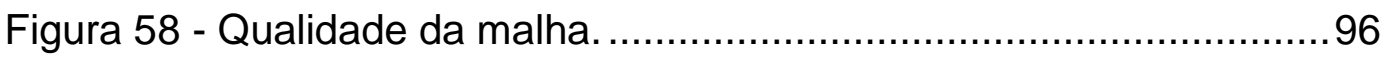

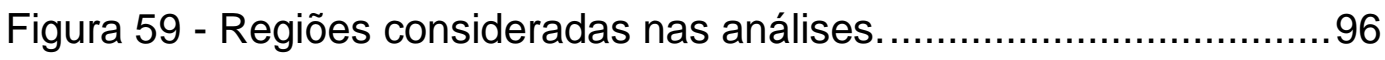

Figura 60 - Regiões consideradas nas análises.....................................97

Figura 61 - Condições de contorno térmico. .........................................97

Figura 62 - Condição de contorno estrutural. ........................................98

Figura 63 - Condição de contorno estrutural .........................................98

Figura 64 - Condições de contorno da análise estrutural. .........................99

Figura 65 - Pressão aplicada nos flanges ............................................99

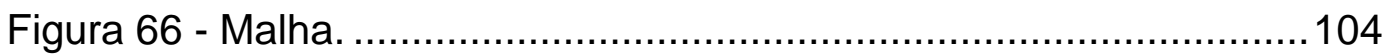

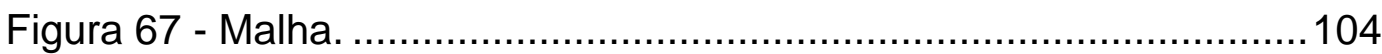

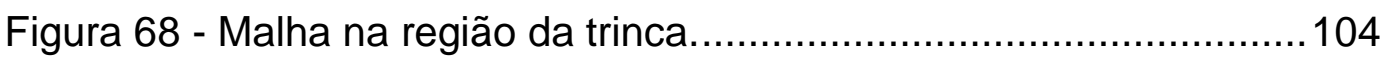

Figura 69 - Malha na região da trinca................................................ 105

Figura 70 - Malha na região da trinca................................................105

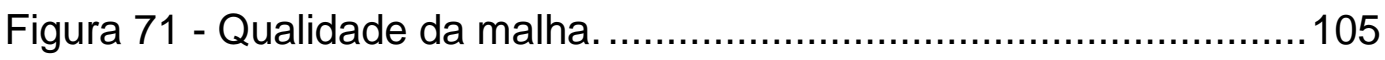

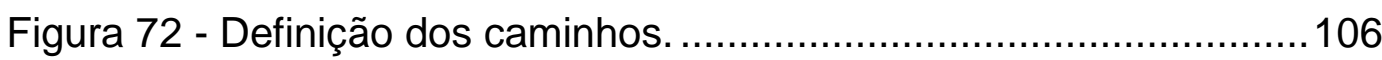

Figura 73 - Condições de contorno térmico. ......................................106

Figura 74 - Premissas estruturais.................................................... 107

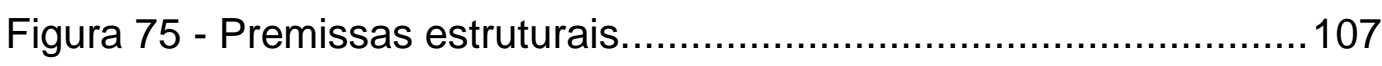

Figura 76 - Trinca de $34,9 \mathrm{~mm}$ de abertura e $6,5 \mathrm{~mm}$ de profundidade em chapa de aço $9 \% \mathrm{Ni}$. 109

Figura 77 - Trinca feita pelo comando Fracture $\rightarrow$ Crack de de

$34,9 \mathrm{~mm}$ de abertura e $6,5 \mathrm{~mm}$ de profundidade em chapa de aço $9 \% \mathrm{Ni}$.

Figura 78 - Malha da trinca feita pelo comando Fracture $\rightarrow$ Crack de

$34,9 \mathrm{~mm}$ de abertura e 6,5 mm de profundidade em chapa de aço

$9 \% \mathrm{Ni}$

Figura 79 - Tensão principal máxima na chapa $(34,9 \times 6,5 \mathrm{~mm}) \ldots \ldots \ldots \ldots \ldots . .109$

Figura 80 - Fator Intensidade de Tensão na trinca $(34,9 \times 6,5 \mathrm{~mm}) \ldots \ldots \ldots .110$

Figura 81 - Esquema de trinca superficial semielíptica em chapa.

Valores: a =6,5 mm, 2c=34,9 mm. [27]

Figura 82 - Resultado da Análise térmica............................................ 112

Figura 83 - Resultado da Análise térmica.............................................112

Figura 84 - Resultado da análise estrutural..........................................113

Figura 85 - Resultado análise estrutural..............................................113 
Figura 86 - Resultado da análise estrutural (Tensão de Membrana e

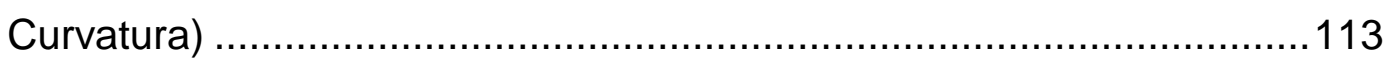

Figura 87 - Resultado da análise térmica........................................116

Figura 88 - Resultado da análise térmica.........................................116

Figura 89 - Resultado da Análise Estrutural........................................117

Figura 90 - Resultado da Análise Estrutural........................................117

Figura 91 - Resultado da Análise Estrutural.......................................117

Figura 92 - Resultado da Análise Estrutural......................................118

Figura 93 - Resultado da Análise Estrutural.....................................118

Figura 94 - Resultado da análise mecânica de fratura..........................119

Figura 95 - Resultado da análise mecânica de fratura..........................119 


\section{Lista de gráficos}

Gráfico 1 - Diagrama FADNível $2 \quad 102$

Gráfico 2 - Resultado avaliação analítica através da ferramenta Mathcad para trinca de $6,5 \mathrm{~mm}$

Gráfico 3 - Resultado avaliação analítica através da ferramenta Mathcad para trinca de $31,5 \mathrm{~mm}$ 


\section{Lista de tabelas}

Tabela 1 - Composição química nominal do Inconel UNS N06625

(\% em peso) [12]

Tabela 2 - Propriedades mecânicas da liga de Inconel

UNS N06625 [12]

Tabela 3 - Propriedades mecânicas da liga de Inconel UNS N06625 na temperatura ambiente [12]

Tabela 4 - Efeitos nas propriedades da liga a partir de alterações na composição química [15] 43

Tabela 5 - Composição química nominal do A353 e A553 tipo I [25] ....... 44

Tabela 6 - Propriedades mecânicas da liga 9\% Ni [25] ........................... 44

Tabela 7 - Módulos de Elasticidades em função da Temperatura [25].....44

Tabela 8 - Média dos coeficientes de expansão do A353 e A553

tipo I [25].

Tabela 9 - Condutividade Térmica do A353 e A553 tipo I [25].

Tabela 10 - Média dos coeficientes de expansão do A353 e A553

tipo I [26]. 45

Tabela 11 - Seções do documento BS-7910 [52] 74

Tabela 12 - Materiais empregados e descrição dos equipamentos 85

Tabela 13 - Pré-carregamento dos estojos 99

Tabela 14 - Propriedades Mecânicas para análise analítica do material aço $9 \% \mathrm{Ni}$ 100

Tabela 15 - Pré-carregamento dos estojos. 


\section{Lista de abreviaturas}

MEF Método dos Elementos Finitos

MEF 2D Método dos Elementos Finitos Bidimensional

MEF 3D Método dos Elementos Finitos Tridimensional

Offshore Estação Marítima

API American Petroleum Institute

GNL Gás Natural Liquefeito

ESDV Emergency Shut Down Valve

Manifold Receptor de dutos

PLEM Pipeline end manifold

PLET Pipeline end terminator

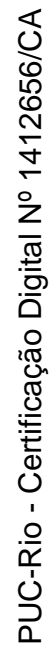

FPSO Floating Production, Storage and Offloading

End Fitting Conector/Terminação de tubos flexíveis

INCO Nickel Company International

NSSMC Nippon Steel e Sumitomo Metal Corporation

NSC Nippon Steel Corporation

SMI Sumitomo Metal Industries

EUA Estados Unidos da América

MFLE Mecânica Fratura Linear Elástica

MFEP Mecânica Fratura Elasto-Plástica

CTOD Crack Tip Opening Displacement

BS British Standard

FEA Finite Element Analysis

FAD Failure Assessment Diagram

END Ensaio Não Destrutivo

SSC Stress Sulfide Crack

SCC Stress Corrosion Crack

$\mathrm{CO}_{2} \quad$ Dióxido de Carbono 


\section{INTRODUÇÃO}

O petróleo, do latim petroleum, "óleo da pedra", no sentido de óleo bruto, consiste em uma substância oleosa e inflamável, de coloração geralmente negra e menos densa que a água. Dentre as diversas teorias a respeito de seu surgimento, a mais aceita confere suas origens aos restos orgânicos de animais e vegetais, os quais, depositados no fundo de lagos e mares ao longo de milhares de anos, sofreram transformações químicas, devido às elevadas taxas de pressão e temperatura [1].

O petróleo é gerado em uma rocha conhecida como fonte ou geradora e na sequência passa pelo processo de acumulação. Para ocorrer essa acumulação é necessário que aconteça a expulsão do petróleo da rocha geradora (migração primária) e que ele continue seu percurso através de uma rocha porosa e permeável até ser interceptado por uma rocha selante (impermeável). A rocha em que o petróleo fica acumulado denomina-se reservatório (migração secundária). $\mathrm{Na}$ Figura 1 observa-se o detalhe desse processo geológico que envolve o acúmulo de petróleo.

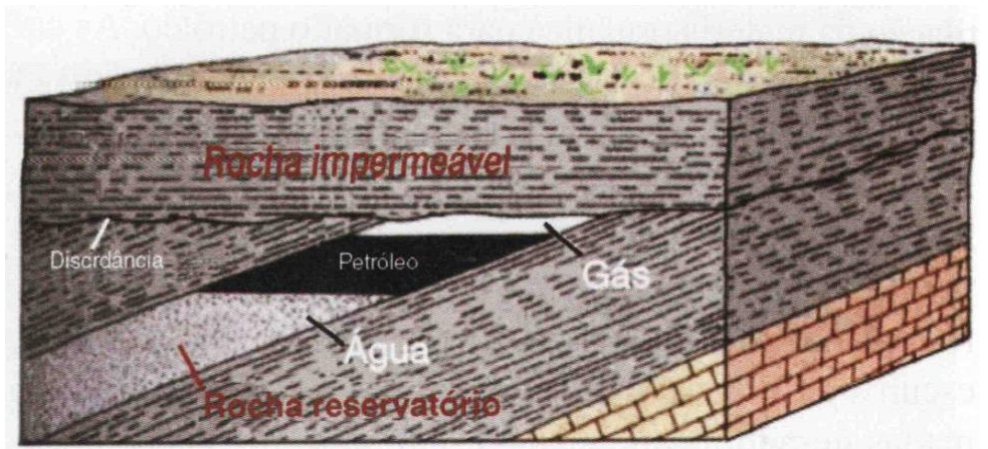

Figura 1 - Acumulação de petróleo devido às relações discordantes nas rochas [2].

Atualmente a indústria do petróleo atua nas mais diversas regiões do planeta, principalmente em plataformas oceânicas. As plataformas oceânicas de extração de petróleo constituem estruturas, fixas ou móveis, pavimentadas em concreto, flutuantes com ancoragem ou braços tensores, podendo, ainda, se tratar de plataformas distribuidoras. Todas, entretanto, possuem em comum o fato de poderem utilizar tubos flexíveis tanto para produção de óleo e gás como para injeção de fluido no reservatório. 
As novas descobertas de petróleo em águas brasileiras ultra profundas tornam o país um dos maiores produtores de hidrocarbonetos no mundo, passando de 200 milhões de barris de petróleo em 2014 [3].

Com isso, os projetos para sistemas submarinos de produção tornaram-se cada vez mais aprimorados e desafiantes, tendo em vistas a complexidade dessas operações. A elaboração de um bom projeto de produção em águas brasileiras abrange desde o conhecimento minucioso sobre o arranjo submarino até a definição e instalação dos equipamentos e dutos que devem garantir a produção e assegurar seu escoamento.

No caso da existência dos eventos danosos, é de grande importância analisálos de modo a obter informações valiosas para o melhoramento de um equipamento ou estrutura. A análise de falha é um processo que determina a causa de um dano. Este processo é complexo, baseia-se em diversas disciplinas, e usa uma variedade de técnicas de inspeção e laboratório. A Mecânica da Fratura é uma das ferramentas utilizadas na análise de falhas, e iniciou o seu desenvolvimento a partir da ocorrência de fraturas e inúmeros acidentes na indústria ferroviária, naval e aeronáutica.

Colaborando com a necessidade de conhecer os mecanismos de falhas na indústria de petróleo, destaca-se um acidente ocorrido no dia 24/02/2009, na ilha Ximentang, Shanghai/China, no Terminal de GNL operado pela Shanghai LNG Co Ltd [4].

A explosão ocorreu durante a execução de teste pneumático de equipamentos no Terminal de Gás Natural Liquefeitos (GNL), que estava previsto para iniciar suas operações com recebimento de cerca de 3 milhões toneladas/ano de GNL, nesta primeira fase.

A causa da explosão foi atribuída a uma falha catastrófica de um flange, localizado no final da seção de teste.

$\mathrm{Na}$ ocasião, este acidente provocou uma preocupação para as empresas exploradoras de petróleo que usam como técnica a injeção de $\mathrm{CO}_{2}$ nos reservatórios, pois qualquer falha em um sistema de risers pode causar sérios danos a todo o ambiente marinho, além de provocar altos gastos no reparo do sistema e na recuperação do meio ambiente e provocar a indesejada interrupção da produção de óleo e perdas de vidas. Este movimento da indústria que foi o grande motivacional para que este trabalho fosse desenvolvido. 
Este trabalho estuda a aplicação de uma liga de aço no conector de topo de um tubo flexível de injeção de gás calculando os valores da intensidade de tensão por dois métodos: Método de Elementos Finitos e Método Analítico conforme a norma BS 7910. Serão utilizados os dados relativos à geometria do componente em estudo, o comprimento de uma trinca e os valores máximos da intensidade de tensão correspondente às situações extremas de carregamento e mínimas de temperatura, além das propriedades dos materiais. Será avaliado como o material se comportará nesta condição com a presença de uma trinca de 6,5 milímetros em todo o perímetro do pescoço de um conector.

Esta pesquisa tem como objetivo estudar o potencial de aplicação de uma liga metálica da família do aço $9 \% \mathrm{Ni}$, usualmente adotada em tanques de armazenamento de GNL, na fabricação de flanges de conectores de linhas flexíveis. O estudo se torna relevante, uma vez que em caso de falha da conexão flangeada, o componente ter de trabalhar em temperaturas abaixo daquela de transição dúctilfrágil do material hoje comumente usado (4130). 


\section{REVISÃO DA LITERATURA}

\subsection{Petróleo}

O petróleo, do latim petroleum, "óleo da pedra", no sentido de óleo bruto, consiste em uma substância oleosa e inflamável, de coloração geralmente negra e menos densa que a água. Dentre as diversas teorias a respeito de seu surgimento, a mais aceita confere suas origens aos restos orgânicos de animais e vegetais, os quais, depositados no fundo de lagos e mares ao longo de milhares de anos, sofreram transformações químicas, devido a elevadas taxas de pressão e temperatura [1].

O petróleo é gerado em uma rocha conhecida como fonte ou geradora e na sequência passa pelo processo de acumulação. Para ocorrer essa acumulação é necessário que aconteça a expulsão do petróleo da rocha geradora (migração primária) e que ele continue seu percurso através de uma rocha porosa e permeável até ser interceptado por uma rocha selante (impermeável). A rocha em que o petróleo fica acumulado denomina-se reservatório (migração secundária). Na Figura 2 observa-se o detalhe desse processo geológico que envolve o acúmulo de petróleo.

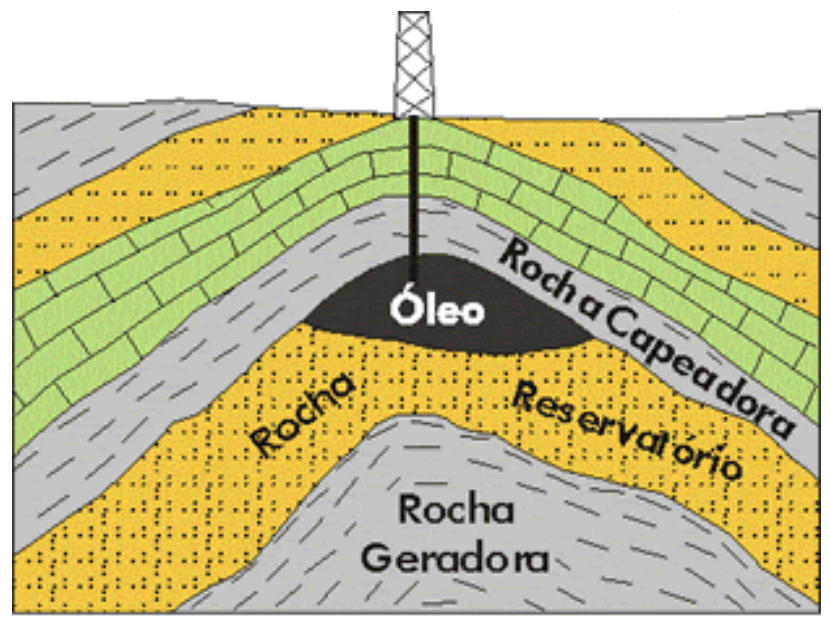

Figura 2: Acumulação de petróleo devido às relações discordantes nas rochas

A rocha selante cria as condições necessárias para acumulação do petróleo, que é um ambiente de pouca permeabilidade, inibindo a ação de água circulante e diminuindo a quantidade de oxigênio existente. A migração primária da rocha, onde 
o petróleo foi gerado tem várias explicações e ainda é uma polêmica entre os geólogos. Pode ser por micro fraturamento existentes nessas rochas ou através de altas pressões de compactação existentes.

Para ocorrer a acumulação do petróleo a rocha reservatório tem que ser porosa no seu interior, e que esses poros estejam interconectados. As rochas reservatório podem ser arenitos, calcarenitos e todas as rochas sedimentares que contenham essas características [1] [5].

Registros históricos apontam como marco inicial de sua utilização a exploração de afloramentos no Oriente Médio (por volta de 1.000 a.C.) e, posteriormente, as perfurações feitas com hastes de bambu na China. Ao longo de muitos anos, as principais utilidades do petróleo consistiram na iluminação e no aquecimento de água [6].

A moderna indústria petrolífera, por sua vez, desenvolveu-se a partir de meados do século XIX, quando poços de pequena profundidade começaram a ser perfurados ao redor do mundo. O primeiro poço comercial com elevada produção foi perfurado nos Estados Unidos, no estado da Pensilvânia, por Edwin Laurentine Drake, também conhecido por Coronel Drake, por meio de uma técnica elaborada para a exploração das minas de sal, em 1859.

A descoberta de suas vantagens e a crescente necessidade de aumento da produção e transporte desse precioso material contribuiu para a elaboração e aprimoramento de técnicas de soldagem, de laminação de tubos e de metalurgia, as quais possibilitaram a construção de longas redes de tubulação. A partir de então, a humanidade pôde observar um desenvolvimento industrial sem precedentes.

Diante da escassez de jazidas tradicionais, foi necessário buscar o petróleo em bacias sedimentares de difícil acesso, tais como as localizadas em zonas árticas e marítimas. Atualmente a indústria do petróleo atua nas mais diversas regiões do planeta, principalmente em plataformas oceânicas. Para tanto, investimentos expressivos são feitos com intuito de aprimorar as técnicas de extração, transporte e refino do petróleo, bem como minimizar as perdas durante o processo.

As plataformas oceânicas de extração de petróleo constituem estruturas, fixas ou móveis, pavimentadas em concreto, flutuantes com ancoragem ou braços tensores, podendo, ainda, se tratar de plataformas distribuidoras. Todas, entretanto, possuem em comum o fato de poderem utilizarem tubos flexíveis tanto para produção de óleo e gás como para injeção de fluido no reservatório. 
Em 1968, a Petrobras iniciou as atividades de prospecção em alto mar. No ano seguinte foi descoberto o campo de Guaricema, em Sergipe. Entretanto, foi em Campos, no Estado do Rio de Janeiro, que a Petrobras encontrou a bacia que se tornou a maior produtora de petróleo do país.

O campo inicial foi o de Garoupa, em 1974, seguido pelos campos gigantes de Marlim, Albacora, Barracuda e Roncador. A partir de 2002, a Petrobras ampliou sua área de prospecção buscando novas frentes exploratórias nas Bacias de Santos e Espírito Santo e em bacias ainda pouco exploradas em suas águas profundas, como as da costa sul da Bahia, Sergipe, Alagoas e da margem equatorial brasileira.

O ano de 2003 foi considerado um marco na história da Petrobras. Além do expressivo volume de petróleo descoberto, foram identificadas novas províncias de óleo de excelente qualidade, gás natural e condensado, permitindo que as reservas da companhia mudassem para um perfil de maior valor no mercado mundial de petróleo.

Em 2006 foi alcançada a auto suficiência do Petróleo no Brasil. Com o início das operações da P-50 no campo de Albacora Leste, no norte da Bacia de Campos, a Petrobras alcançou a marca de 2 milhões de barris por dia, o suficiente para cobrir o consumo do mercado interno de 1,8 milhões de barris diários.

A P-50, indicada na Figura 3, foi o marco inicial da sustentabilidade, destacando a retomada estratégica do crescimento econômico e tecnológico nacional. Aliada as descobertas recentes, dos campos de petróleo sob a camada de Pré-Sal, a sustentabilidade indica que os anos seguintes seriam marcados por grandes desenvolvimentos tecnológicos, possibilitando a extração, processamento e transporte do petróleo brasileiro, elevando a qualidade de vida nacional.

A decisão de explorar petróleo em alto mar foi um marco na história nacional. A partir disto, a Petrobras tem trilhado um caminho de inúmeras descobertas, alcançando o título de líder mundial em tecnologia de exploração de petróleo em águas profundas e ultra profundas.

As novas descobertas de petróleo em águas brasileiras ultra profundas tornam o país um dos maiores produtores de hidrocarbonetos no mundo, passando de 200 milhões de barris de petróleo em 2014 [3]. 


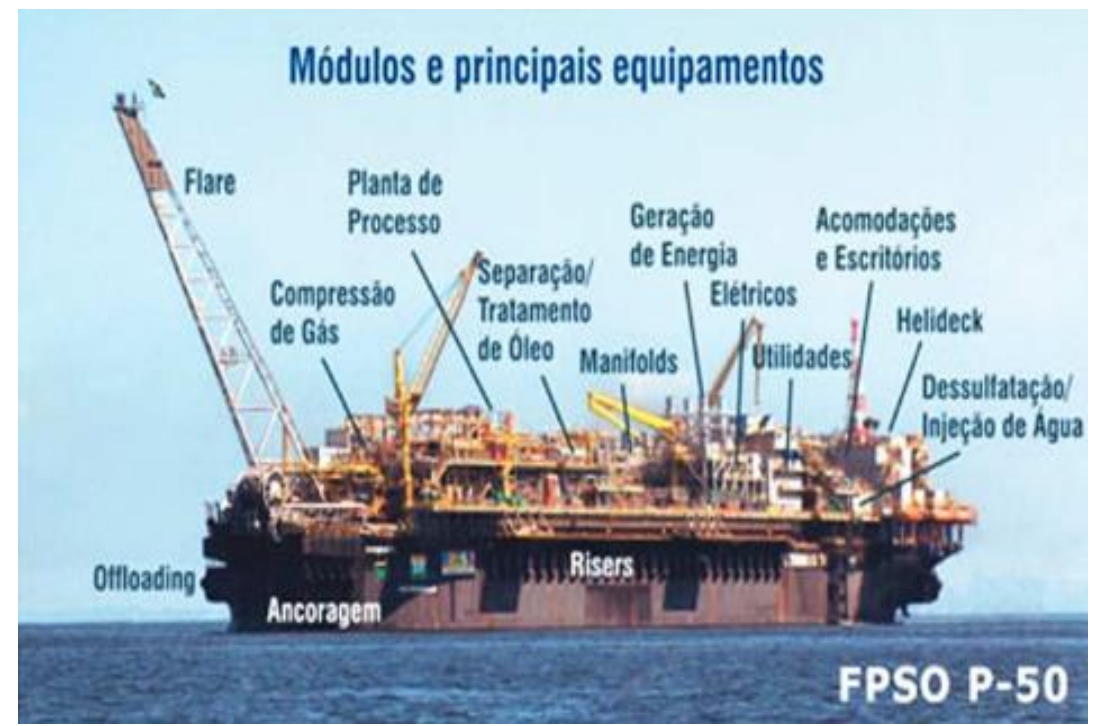

Figura 3: FPSO P-50 (Fonte: Acervo de imagem da Petrobras)

Com isso, os projetos para sistemas submarinos de produção tornaram-se cada vez mais aprimorados e desafiantes, tendo em vistas a complexidade dessas operações. A elaboração de um bom projeto de produção em águas brasileiras abrange desde o conhecimento minucioso sobre o arranjo submarino até a definição e instalação dos equipamentos e dutos que devem garantir a produção e assegurar seu escoamento.

O sistema submarino de produção é subdividido em sistema de coleta, que é composto pelos dutos e equipamentos que coletam a produção do poço interligando-a a unidade estacionária de produção, e o de exportação, que compreende os dutos e equipamentos submarinos, monobóias e navios off-loading que transferem a produção de uma ou mais unidade estacionária de produção até um ponto de recebimento (terminal oceânico ou terrestre). Por sua vez, os dois sistemas variam de acordo com a unidade de exploração/produção e de acordo com alguns fatores como característica do fluido e tipo de escoamento.

No caso das plataformas de petróleo, os tubos flexíveis prestam-se a conexão da plataforma as bombas submersas de extração de petróleo ou injeção de $\mathrm{CO}_{2}$ ou água, com comprimento na ordem de quilômetros em águas profundas, sob constante pressão e esforços mecânicos intensos (Figura 4).

Em 2009, a Petrobras utilizou uma técnica de injeção de gás $\mathrm{CO}_{2}$ em alta pressão que pode contribuir para os projetos de desenvolvimento da região do Pré- 
Sal da Bacia de Santos, uma vez que alguns dos reservatórios ali encontrados revelaram a presença de $\mathrm{CO}_{2}$ natural associado ao petróleo. $\mathrm{O}$ gás carbônico produzido nos campos do pré-sal é reinjetado nos próprios reservatórios para aumentar o fator de recuperação, além dos ganhos ambientais. $\mathrm{O} \mathrm{CO}_{2}$ atua como uma espécie de solvente que altera as propriedades do petróleo e facilita o escoamento no sistema poroso da rocha-reservatório.

Algumas vantagens observadas do processo de injeção de $\mathrm{CO}_{2}$ são a possibilidade de que seja alcançada a miscibilidade para baixas pressões, além de ter também para baixos valores de pressão o deslocamento eficiente para a maioria dos reservatórios, sendo a saturação de óleo reduzida a cerca de $5 \%$ do volume poroso original. Sob determinadas condições, a densidade do $\mathrm{CO}_{2}$ é semelhante a do óleo e aproxima-se da densidade da água, minimizando os efeitos de segregação gravitacional. Comparado ao metano, a viscosidade do dióxido de carbono é de 2 a 4 vezes maior no intervalo de pressões comumente encontradas nos reservatórios, fato esse que melhora a eficiência em comparação ao mesmo processo utilizando hidrocarbonetos. A utilização de $\mathrm{CO}_{2}$ também é capaz de reduzir a viscosidade do óleo, melhorando a recuperação [7].

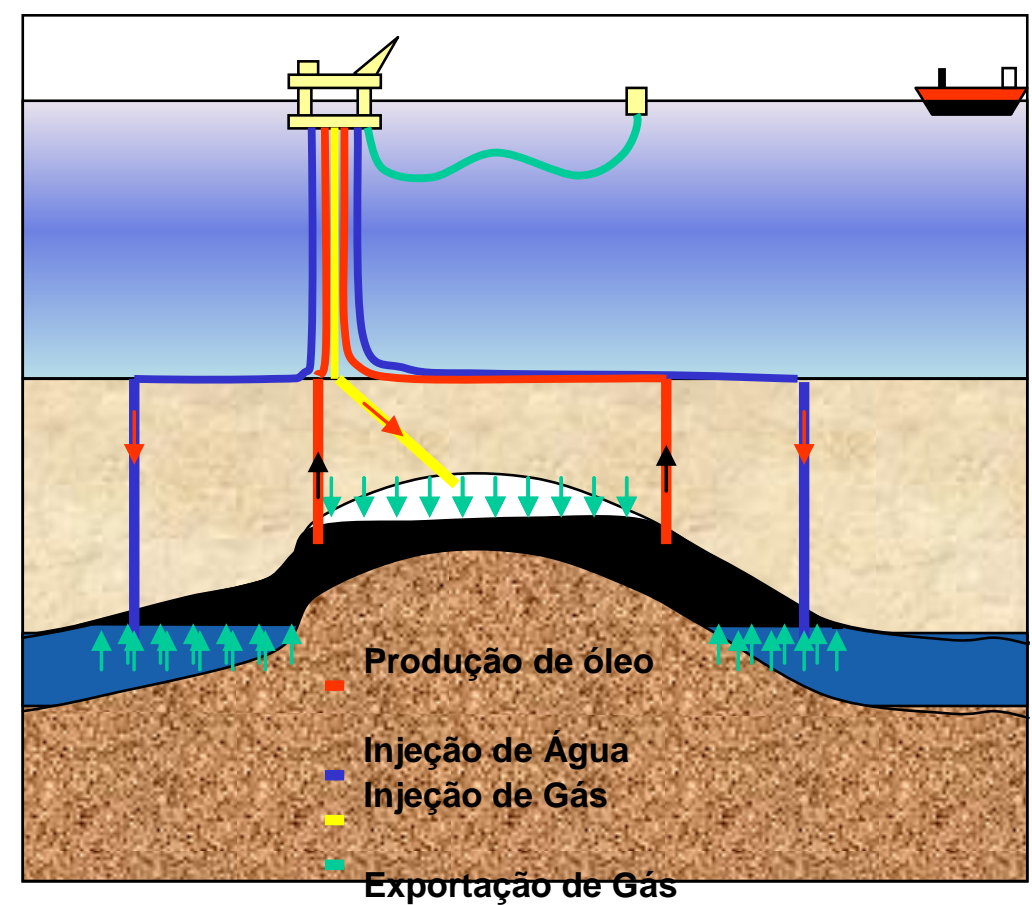

Figura 4: Esquema simplificado de injeção contínua de $\mathrm{CO}_{2}$ (acervo Technip)

Nestes ambientes operacional e marítimo hostis e durante o tempo em 
serviço, estruturas e componentes de equipamentos podem falhar e causar acidentes. Isto geralmente conduz a perdas econômicas e vidas, além de gerar efeitos ambientais negativos. Frequentemente os eventos danosos são originários de falhas de materiais e de fabricação, sobrecargas não previstas ou outros problemas oriundos do tempo de operação ou deficiência de manutenção de um componente.

\subsection{Acidente em planta de GNL e a consequência na indústria de petróleo}

Colaborando com a necessidade de conhecer os mecanismos de falhas na indústria de petróleo, destaca-se um acidente ocorrido no dia 24/02/2009, na ilha Ximentang, Shanghai/China, no Terminal de Gás Natural Liquefeitos (GNL) operado pela Shanghai LNG Co Ltd [4].

A explosão ocorreu durante a execução de teste pneumático de equipamentos no Terminal de Gás Natural Liquefeitos (GNL), que estava previsto para iniciar suas operações com recebimento de cerca de 3 milhões toneladas/ano de GNL, nesta primeira fase. Quando terminado, o GNL importado da Malásia seria transportado por dutos de gás natural até o centro de Shanghai.

Os trabalhadores estavam comprimindo ar no sistema quando houve a ruptura catastrófica de um trecho de aproximadamente 600 metros de tubulação, gerando a projeção de fragmentos ao redor de toda área. Este acidente gerou uma fatalidade e 16 feridos, todos pelo atingimento por fragmentos de equipamentos. $\mathrm{O}$ trabalhador que faleceu, atingido por uma tubulação de andaime, estava próximo a porta de entrada do dormitório, cerca de 350 metros de distância do local do acidente. Estima-se que o acidente tenha causado um atraso no início das operações em 6 meses (Figura 5).

A causa da explosão foi atribuída a uma falha catastrófica de um flange, localizado no final da seção de teste (Figura 6). A falha ocorreu durante a pressurização de uma linha de 36", com cerca de 600 metros de comprimento, para condução do teste pneumático. Este flange seria usado para conexões futuras. A pressão de teste era de $15,6 \mathrm{MPa}\left(159 \mathrm{kgf} / \mathrm{cm}^{2}\right)$ e a explosão ocorreu quando a pressão no sistema atingiu $12,3 \mathrm{MPa}\left(125 \mathrm{kgf} / \mathrm{cm}^{2}\right)$. 
A ruptura ocorreu no corpo do flange, de 30 a 40 milímetros de distância entre o flange e a solda da tubulação. Há relatos de ocorrência de fratura frágil do corpo do flange.

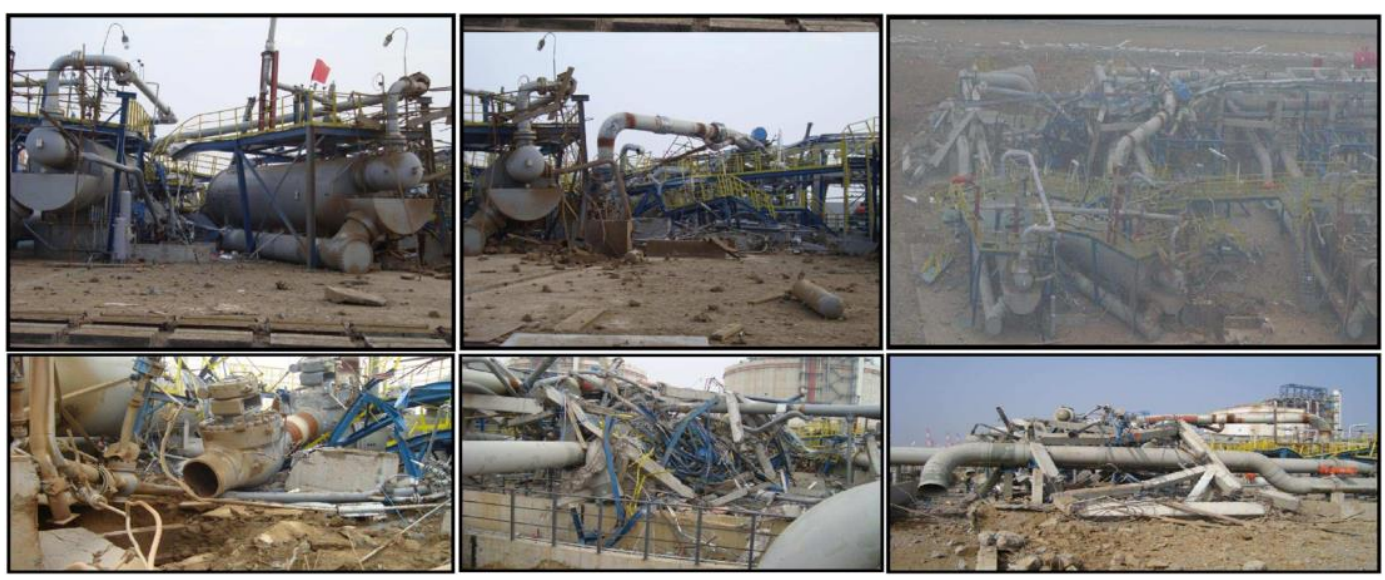

Figura 5: Fotos da planta de GNL em Shangai após o acidente [4].

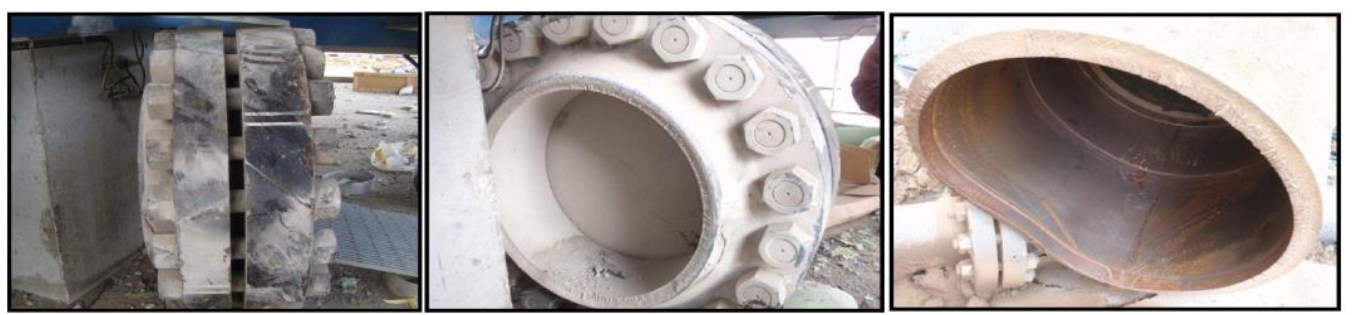

Figura 6: Fotos da conexão flangeada onde iniciou a explosão [4].

A fratura frágil é aquela que ocorre de maneira catastrófica, sem que haja tempo suficiente para a liberação de energia de deformação plástica. Pode ser causada por fatores internos (como a presença de inclusões não metálicas fragilizantes dentro do material) ou externos (como agentes ambientais fragilizantes tais como hidrogênio, gás sulfídrico, dióxido de carbono e outros).

Os testes hidrostáticos ou testes pneumáticos são aplicados em equipamentos de pressão para aferir se haverá ocorrência de vazamentos ou ruptura. São realizados com os equipamentos fora de serviço, através de sua pressurização com água (teste hidrostático), ar comprimido (teste pneumático) ou outro fluido disponível, em pressões superiores às pressões operacionais. Normalmente essas pressões situam-se na ordem de 1,5 vezes a Pressão Máxima de Trabalho Admissível. Simula-se então uma condição operacional mais rigorosa, para garantir 
que em serviço normal (a pressões mais baixas) não ocorrerão falhas ou vazamentos.

Devido às características inerentes aos fluidos de teste, há algumas diferenças significativas na aplicação de testes hidrostáticos e pneumáticos:

No caso de testes hidrostáticos, o fluido de teste, a água, é considerado incompressível, ou seja, a pressão não exerce influência no volume ocupado; podese aumentar ou diminuir a pressão que a densidade permanecerá constante. Neste caso, se houver um vazamento durante o teste há uma rápida queda de pressão interna e os danos potenciais são relativamente mais fáceis de controlar do que quando comparados ao teste pneumático.

No caso dos testes pneumáticos, a grande compressibilidade e a excessiva capacidade de expansão, que compreendem as fundamentais características físicas dos gases, contribuem para que, nestes testes, o acúmulo de energia no sistema seja bem superior do que quando comparado ao teste hidrostático. Portanto, em caso de falha durante a execução, os testes pneumáticos apresentariam maior potencial de danos do que os testes hidrostáticos.

Por serem testes aplicados em pressões acima das de operação, sua realização está muitas vezes sujeita a falhas, desde o aparecimento de pequenos vazamentos, crescimento de descontinuidades de soldas, até rupturas catastróficas durante a sua realização. Desta forma, sua execução deve ser cercada de controles de forma a garantir a segurança.

$\mathrm{Na}$ ocasião, este acidente provocou uma preocupação para as empresas exploradoras de petróleo que usam como técnica a injeção de $\mathrm{CO}_{2}$ nos reservatórios, pois qualquer falha em um sistema de risers pode causar sérios danos a todo o ambiente marinho, além de provocar altos gastos no reparo do sistema e na recuperação do meio ambiente e provocar a indesejada interrupção da produção de óleo e perdas de vidas. Este movimento da indústria que foi o grande motivacional para que este trabalho fosse desenvolvido.

Assim, esta dissertação estudou um componente mecânico conhecido como flange e utilizado em conexão de topo de uma linha flexível de injeção de $\mathrm{CO}_{2}$. A falha deste pode ocasionar interrupções na produção, dano a equipamentos ou mortes. As linhas flexíveis utilizadas para injetar gás $\mathrm{CO}_{2}$ nos reservatórios de petróleo no Brasil trabalham com pressões internas muito elevadas, proporcionando um alto risco em caso de falha do componente. O cenário considerado para o estudo 
está relacionado a falha na vedação do anel BX entre a conexão da linha flexível e a plataforma de petróleo (Figura 7 e Figura 8).

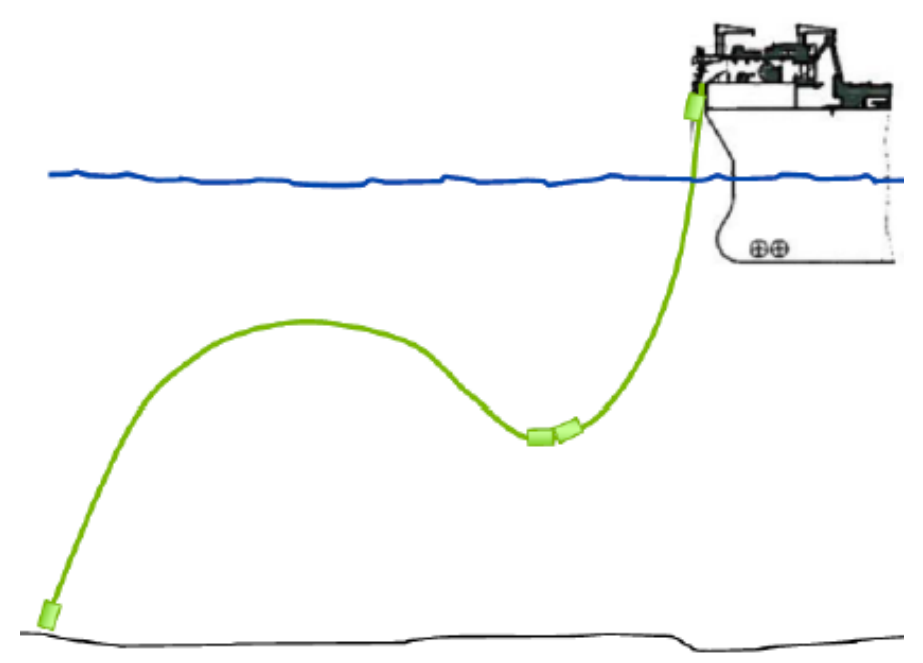

Figura 7: Esquema de conexão entre uma linha flexível e uma plataforma de petróleo.

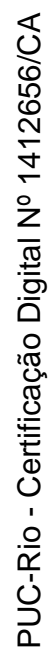
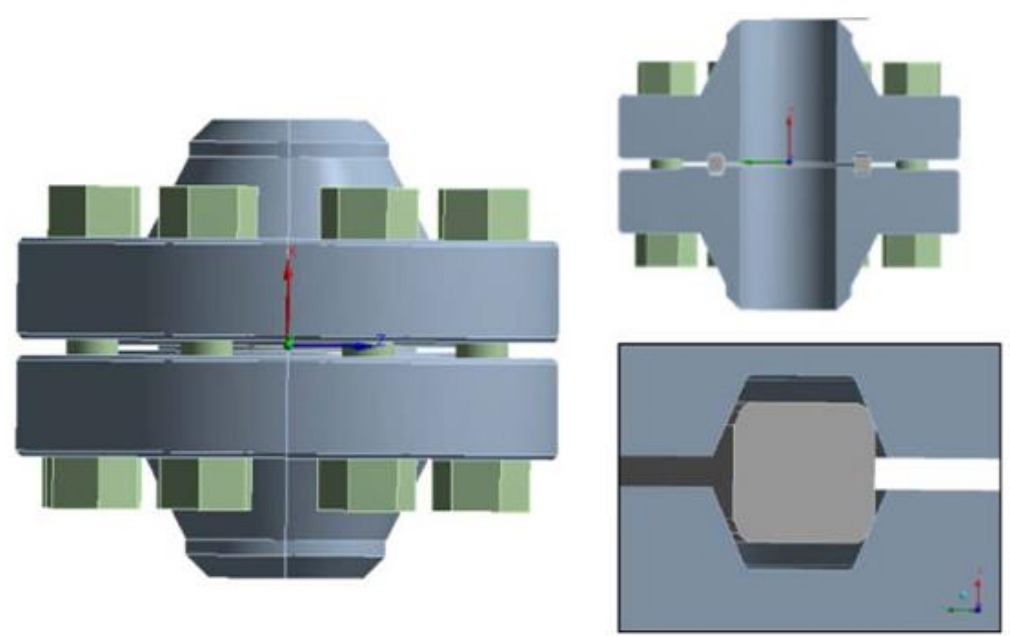

Figura 8: Esquema de uma conexão flangeada API. 


\subsection{Sistema Submarino de Produção}

Pode-se definir um sistema submarino de produção como sendo um conjunto de instalações submersas destinadas à elevação, injeção e escoamento dos fluidos produzidos e/ou movimentados em um campo de petróleo ou gás natural. O projeto de desenvolvimento de um campo visa à maximização da recuperação de petróleo e um custo mínimo operacional e de investimento de capital.

Conceitua-se como arranjo submarino de produção, a escolha dos equipamentos que serão utilizados e de que maneira eles estarão dispostos. $\mathrm{O}$ arranjo final de um campo é o resultado de um processo de otimização que envolve diversas variáveis, tais como:

Número de poços e posicionamento dos mesmos;

Comprimento e diâmetro dos dutos de produção;

Posicionamento da unidade produção flutuante;

Tipo de ancoragem;

Meios de instalação;

Perfil de produção desejado;

Necessidade de utilização de meios de elevação artificial e outros.

Em um Sistema Submarino de Produção, basicamente encontramos os seguintes equipamentos, conforme Figura 9:

Cabeça de Poço;

Árvore de Natal Molhada;

Dutos Submarinos;

ESDV (Emergency Shut Down Valve) Submarina;

Manifold;

PLEM (pipeline end manifold);

PLET (pipeline end terminator). 


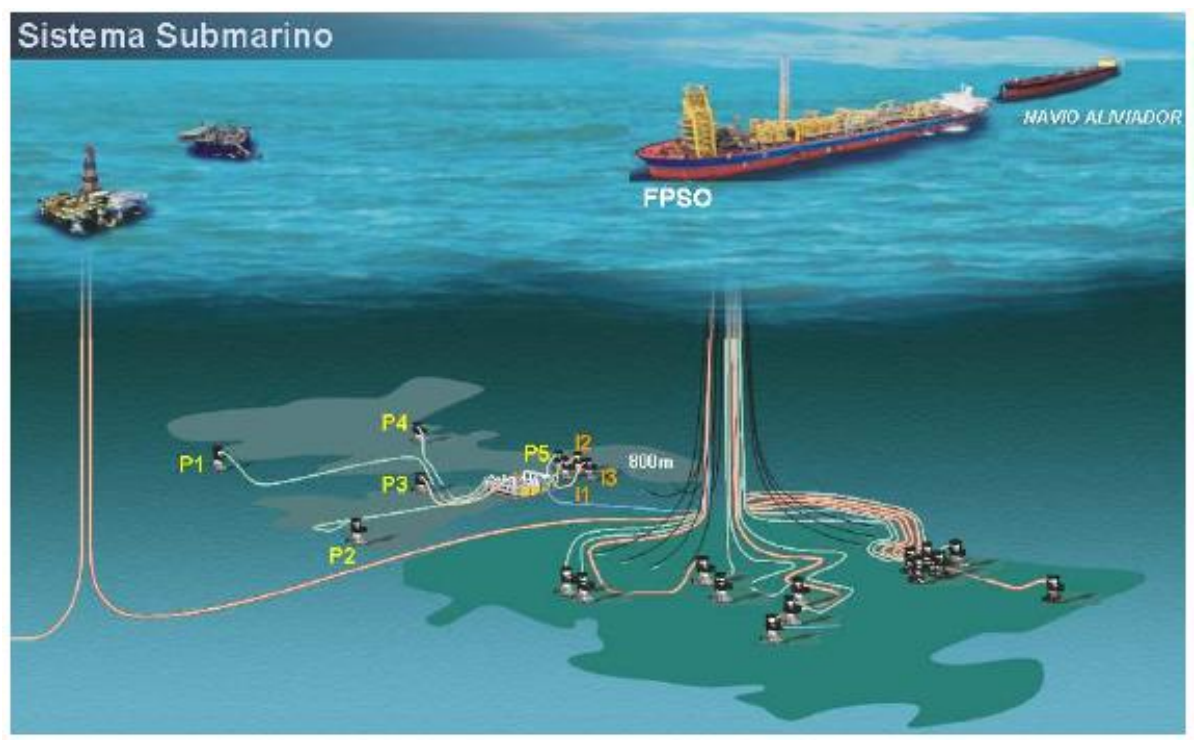

Figura 9: Sistema Submarino de Produção. (Fonte: Modificada. Acervo de imagem da Petrobras).

Neste cenário os risers flexíveis são dutos que transportam o petróleo e o gás produzidos dos poços até a plataforma e daí, após o processamento, para navios e/ou para terra. A produção de petróleo em águas profundas no Brasil utiliza em larga escala os dutos flexíveis, pois eles possuem várias vantagens em relação a outras soluções, em especial a grande versatilidade de uso.

\subsection{Risers flexíveis}

Na Indústria do Petróleo, especificamente na produção de petróleo e gás no ambiente marítimo, os dutos flexíveis submarinos são amplamente empregados tanto no Sistema de Coleta e Injeção (poços à plataforma) quanto no Sistema de Escoamento (plataforma a terra). Os dutos flexíveis são classificados quanto ao tipo e aplicação em risers e flowlines, como pode ser visto na Figura 10.

Chama-se de riser o trecho suspenso do duto que conecta a unidade de exploração e produção a um equipamento no fundo do leito marinho. O riser desempenha um papel fundamental dentro do sistema de exploração e produção de óleo e gás, devendo-se garantir sua integridade e confiabilidade em suas diferentes aplicações [8]. 


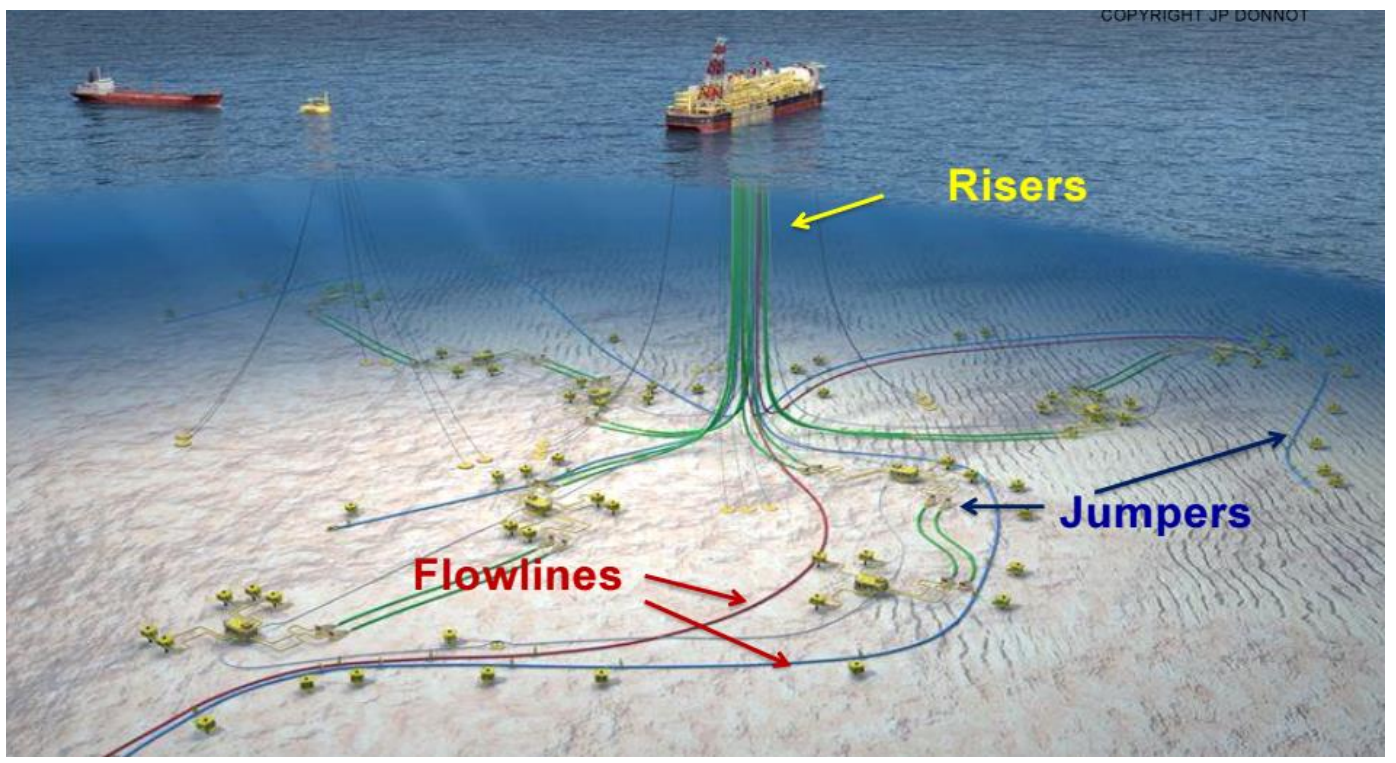

Figura 10: Riser e flowline flexíveis. (Fonte: Acervo de imagem da Petrobras)

Esse trecho suspenso dos dutos de coleta sujeito a esforços dinâmicos deverá ser dimensionado para resistir a dobramentos, tensões e torções. As várias cargas que agem em dutos submarinos são classificadas em cargas funcionais (pressão interna e externa, forças térmicas, peso do duto e forças residuais e de lançamento), cargas ambientais (de onda, de corrente e vão livre em solos irregulares e de instabilidade no solo) e cargas acidentais (impacto de âncora, impactos de queda de objetos, impactos devido a pesca de fundo, impactos de embarcações etc.) [9].

A escolha do tipo de riser mais adequado para desenvolvimento da produção será baseada em critérios como condições ambientais, perfil de correntes submarinas, profundidade e arranjo do campo, excursão e movimento da unidade flutuante, número de risers, carga máxima do sistema de suspensão do riser, facilidade e custo de instalação.

Eles podem ser definidos classificando-se a sua funcionalidade como: riser de produção, utilizado na transferência dos fluidos produzidos (óleo e gás) do poço à plataforma, riser de injeção, para injetar gás ou água no reservatório e ajudar a manter sua pressão e melhorar o escoamento do óleo, riser de exportação, utilizado na transferência do fluido processado da plataforma até a terra ou outra unidade e riser de perfuração que é utilizado principalmente para proteger a coluna da broca de perfuração do poço (Figura 11) [8]. 


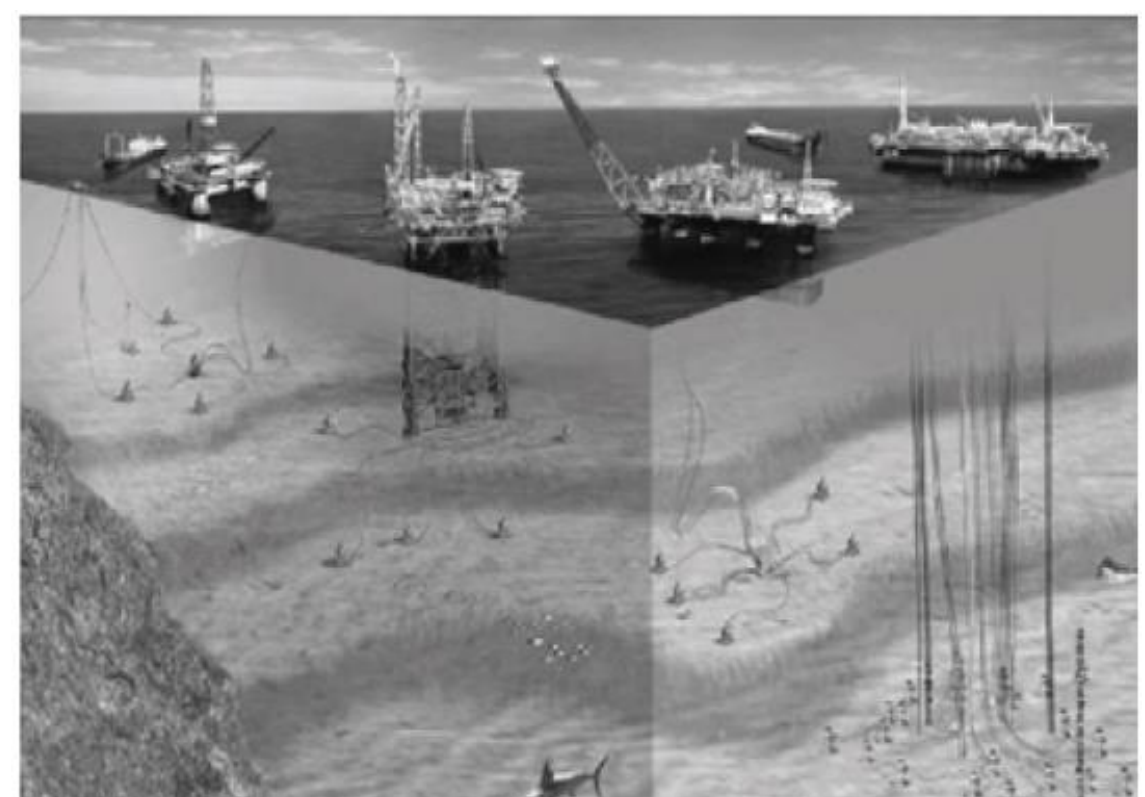

Figura 11: Estruturas de tubos flexíveis utilizadas para exploração de petróleo [http://www.defesaaereanaval.com.br/?p=29972]

Segundo Silva [8], os risers flexíveis são dutos compostos pela superposição de camadas plásticas e metálicas que lhes conferem respectivamente estanqueidade e resistência mecânica, caracterizando-se pela baixa rigidez à flexão.

O mercado de dutos flexíveis no Brasil é crescente devido ao uso dos sistemas de produção flutuantes que atendem as demandas em águas ultra profundas, porém os centros de pesquisa ainda enfrentam desafios para obtenção de dutos flexíveis mais resistentes e com menor peso. Essas estruturas compostas têm sido utilizadas na maioria dos campos da Petrobras, seus diâmetros variam de 2,5" a 18 " e pressões de 200 a 10.000 psi.

A seleção dos tubos flexíveis deve levar em consideração fatores como:

Propriedade e composição do fluido interno (quantidade de $\mathrm{CO}_{2}, \mathrm{H}_{2} \mathrm{~S}$ e água);

Taxa de escoamento requerida;

Pressão e temperatura do fluido;

Vida útil do duto e lamina d'água;

Necessidade de isolamento térmico;

Método e navio para instalação.

A composição do riser flexível por diferentes materiais possui como objetivo combinar as melhores propriedades de cada um deles formando uma estrutura ideal. Como mostra a Figura 12, suas camadas são nomeadas como carcaça, camada de 
pressão, armadura de pressão, armaduras de tração e camada externa. Vale ainda ressaltar que existe um espaço anular no tubo que se limita ao espaço radial que vai do diâmetro externo da camada de vedação ao diâmetro interno da camada externa do tubo.

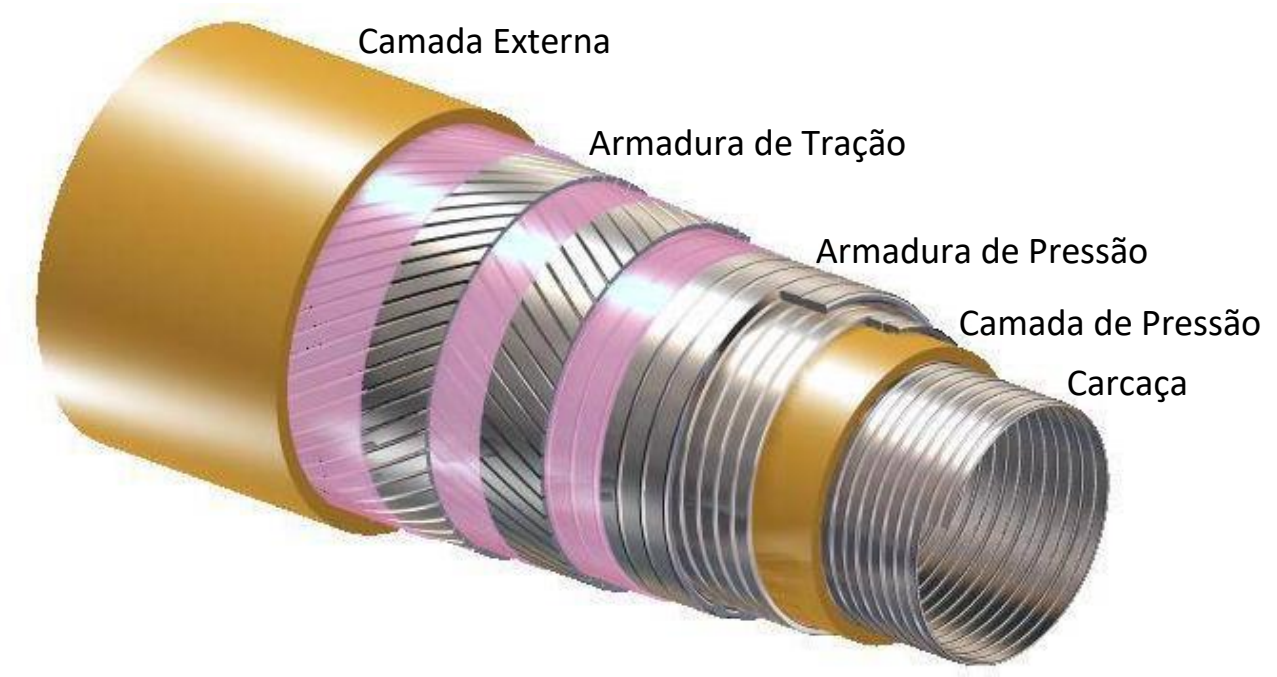

Figura 12: Estrutura flexível (Fonte: acervo Petrobras)

a) Carcaça

Essa camada mais interna do tubo é feita com estrutura de aço inter travado e torna-se obrigatória quando o fluido possui gás. Em caso de fluido sem gás, essa camada poderá ser substituída por uma camada anticolapso. A principal função da carcaça é evitar o colapso da camada seguinte (camada de pressão) nos casos de aumento da pressão externa ou do anular do duto. Devido ao seu modelo estrutural, como pode ser visto na Figura 12, essa camada não foi elaborada com propósito de impedir o fluxo de fluido para as camadas adjacentes, portanto ela não resiste ao aumento da pressão interna do duto.

O material metálico dessa carcaça também deverá suportar as cargas radiais das armaduras de tração quando o duto estiver sob tração, suportar as cargas radiais de equipamentos como boias, colar, restritores de flexão e enrijecedores montados no tubo, e por fim, deverá suportar, também, o esforço radial gerado pelos tensionadores durante o aperto de instalação. O conhecimento prévio do fluido 
interno que estará em contato direto com a carcaça é indispensável, pois a presença de $\mathrm{CO}_{2}, \mathrm{H}_{2} \mathrm{~S}$, cloretos ou areia, por exemplo, podem corroer o duto e causar graves danos à produção.

b) Camada de pressão:

Camada plástica elaborada a partir de materiais como polietileno, gammaflex ou poliamida, cuja principal função é garantir estanqueidade do riser e transmitir os esforços oriundos do aumento da pressão interna para as armaduras seguintes. Em dutos smooth bore, onde não existe a carcaça, essa camada é o próprio tubo interno, onde sua espessura deve ser dimensionada para resistir ao colapso em caso de despressurização emergencial.

É de grande relevância o conhecimento do fluido interno e sua compatibilidade química com o material da camada de pressão, além do conhecimento de fatores como pressão e temperatura que irão influenciar diretamente na vida útil dessa camada.

c) Armadura de pressão:

São perfis de aço de diferentes formatos (zeta, teta ou psi) e espessuras que devem resistir aos esforços radiais causados principalmente pela pressão interna, além daqueles causados pelas armaduras de tração, pelos tensionadores e pelos equipamentos auxiliares. Essa armadura, como pode ser vista na Figura 13, também, auxilia a carcaça a resistir ao aumento de pressão externa causada por dano à camada mais externa do riser. A previsão de difusão do gás do fluido interno pela camada de pressão, também, deve ser considerada, pois isso poderá ocasionar um ambiente corrosivo dentro do anular do riser, danificando todas as outras camadas, inclusive as metálicas. O conhecimento prévio desse possível ambiente corrosivo irá contribuir para escolha do material das armaduras de pressão e tração.

Geralmente essa armadura de pressão poderá ser seguida por uma camada espiral que irá aumentar a resistência à pressão interna sem precisar aumentar a armadura, 

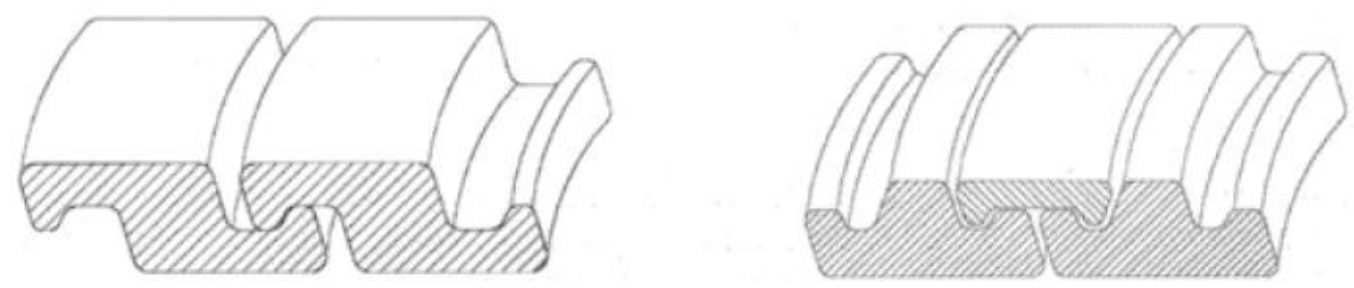

Figura 13: Armadura de pressão (Perfil Zeta e Teta)

isso minimiza o peso do duto e as dificuldades para instalação.

d) Armadura de tração:

São fios chatos de aço fabricados em pares e aplicados de forma helicoidal, de modo que sua resistência e funcionalidade irão variar de acordo com o ângulo de aplicação dessas hélices. Sua principal função é resistir à tração e às cargas compressivas, além de suportar as cargas radiais de pressão interna e resistir aos esforços de torção. Para evitar desorganização desses arranjos helicoidais, fitas são aplicadas sobre essas armaduras beneficiando o processo de fabricação.

e) Camada externa:

É a camada mais externa do tubo feita a partir de material plástico, tendo como função garantir a estanqueidade externa do duto e proteger as camadas mais internas do riser do contato com a água do mar e entrada de areia. Além disso, em caso de difusão do gás pela camada de pressão, essa camada externa irá impedir a difusão desse gás contido internamente no anular do duto. Para solucionar isso existem válvulas de alívio nos conectores da extremidade, evitando problemas de aumento da pressão interna do anular e corrosão das armaduras.

f) Camadas auxiliares:

Existem camadas que somam funcionalidade as camadas básicas de um duto flexível, como por exemplo: camada antiatrito, fitas de alta resistência, camada anticolapso e isolamento térmico.

Os riser flexíveis possuem um raio limite de curvatura, acima do qual poderá 
ocorrer o destravamento da armadura de pressão ou o rasgo da camada externa. Por isso esses dados, também, devem estar presentes na configuração dos dutos a serem utilizados. Em águas profundas o comprimento do riser pode ser dividido em duas seções. A seção de topo será projetada para resistir aos esforços de tração e fadiga, enquanto que a seção do fundo será projetada para pressão de colapso, cargas de instalação e efeito de fundo negativo.

As terminações de um riser flexível, ver Figura 14, são conhecidas como conectores (end fittings), sendo utilizadas para conectar os tubos a plataformas e a outras estruturas e atendem a norma API 6A e a API 17J.

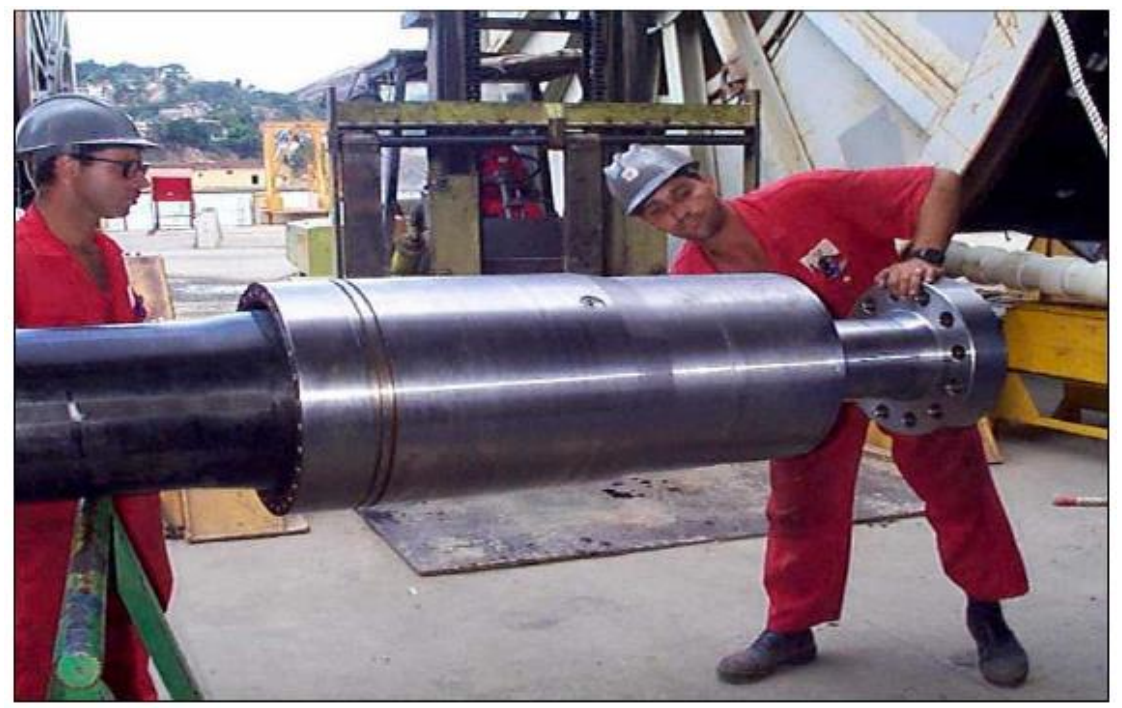

Figura 14: Conector de um tubo flexível [10].

Os conectores são montados na estrutura flexível e têm como propósitos principais:

Terminar todos os elementos de força na construção do tubo de modo que cargas axiais e momentos fletores possam ser transmitidos para o conector sem afetar as camadas contentoras de fluidos;

Fornecer uma transição de pressão entre o corpo do tubo e o conector.

A montagem do conector pode ser vista na Figura 15. Uma das pontas do riser é descascada até se chegar as armaduras de tração mais externas. As armaduras de tração são então dobradas e encaixadas no conector de acordo com um procedimento que muda de acordo com a configuração do conector. 
Uma vez que as armaduras de tração foram presas à terminação, uma resina é vazada de modo a preencher os vazios entre os fios.

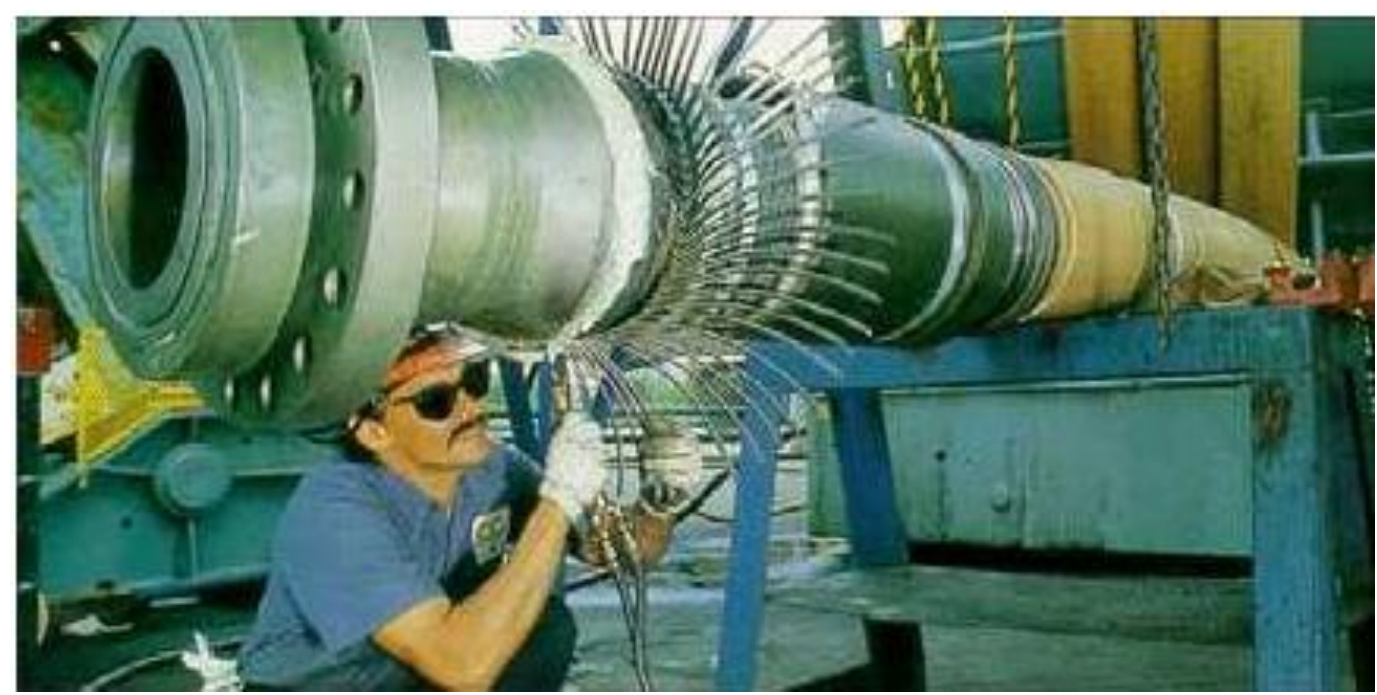

Figura 15: Montagem de conector de um tubo flexível [11].

O grande desafio da exploração e produção de petróleo no Brasil é o desenvolvimento de tecnologia e conhecimento suficientes para alcançar maiores profundidades de lâminas d'água, onde se encontra a maior parte da reserva nacional. Maiores profundidades significam maiores carregamentos nos dutos flexíveis em operação, maiores custos de instalação e operação, e maiores cargas de instalação.

Deste modo, o conhecimento das propriedades mecânicas dos materiais que compõem um duto flexível torna-se ponto crítico na compreensão do seu comportamento estrutural.

\subsection{Propriedade Mecânica do Inconel UNS N06625}

Visto o acidente no terminal de GNL na China, a Petrobras começou a exigir dos fornecedores de tubos flexíveis que os conectores fossem fabricados com um material de alta tenacidade a condições de baixa temperatura. Assim, chegou-se ao material UNS N06625 para substituir os aços carbono 4130. Aquele atendia às características mecânicas exigidas pela operadora. No entanto, trazia um elevado custo de projeto para a aplicação de injeção de $\mathrm{CO}_{2}$ em campos de petróleo no Brasil.

O Inconel UNS N06625 é uma liga a base de níquel que oferece boas 
propriedades mecânicas, resistência a corrosão e soldabilidade. As temperaturas de operação variam de criogênicas até $982^{\circ} \mathrm{C}$ [12].

Essa liga possui alta resistência a corrosão em ambientes em que há presença de níveis elevados de $\mathrm{CO}_{2}$ e $\mathrm{H}_{2} \mathrm{~S}$. Na Figura 16 é possível observar que com o aumento da temperatura eleva-se a resistência a corrosão em meios ricos em $\mathrm{H}_{2} \mathrm{~S}$. Essas ligas geralmente não apresentam corrosão pelo $\mathrm{CO}_{2}$ e sua seleção limitada aos níveis de concentração de $\mathrm{H}_{2} \mathrm{~S}$ e de temperatura. A presença de enxofre livre na composição do produto que possa vir a circular no interno do componente pode levar a um mecanismo severo de corrosão por pite e (ou) fragilização do material sob certas condições de operação [13].

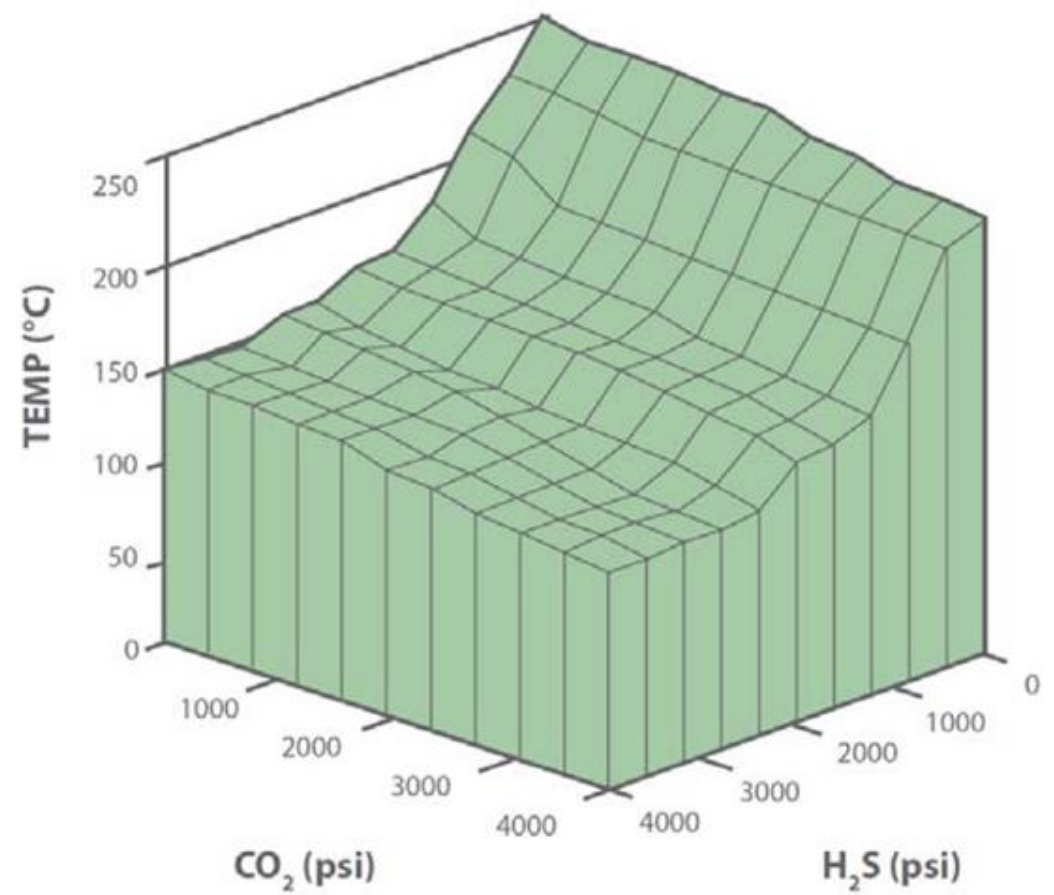

Figura 16: Resistência a corrosão da liga UNS $\mathrm{N} 06625$ em meio de $\mathrm{H}_{2} \mathrm{~S} / \mathrm{CO}_{2}$ com altas concentrações de $\mathrm{Cl}$ e ausência de enxofre. Taxa de corrosão de Q.05 mm/ano (2 mpy) e sem mecanismo de SSC e SCC [13].

A composição química nominal da liga Inconel UNS N06625 e suas propriedades mecânicas estão apresentadas, na Tabela 1 e na Tabela 2, respectivamente [12].

Tabela 1: Composição química nominal do Inconel UNS N06625 (\% em peso) [12]

\begin{tabular}{l|l|l|l|l|l}
\hline $\mathbf{N i}$ & $\mathbf{C r}$ & $\mathbf{F e}$ & $\mathbf{M o}$ & $\mathbf{N b}$ & $\mathbf{C}$ \\
\hline 58,0 min. & $20,0-23,0$ & 5,0 max. & $8,0-10,0$ & $3,15-4,15$ & 0,10 max. \\
\hline $\mathbf{M n}$ & $\mathbf{S i}$ & $\mathbf{P}$ & $\mathbf{S}$ & $\mathbf{A l}$ & $\mathbf{T i}$ \\
\hline 0,50 max. & 0,50 max. & 0,015 max. & 0,015 max. & 0,40 max. & 0,40 max. \\
\hline
\end{tabular}


Tabela 2: Propriedades mecânicas da liga de Inconel UNS N06625 [12]

\begin{tabular}{|c|c|c|c|c|c|}
\hline $\begin{array}{ll}\text { Formato } & \mathrm{e} \\
\text { condição } & \end{array}$ & $\begin{array}{l}\text { Limite de } \\
\text { Resistência } \\
\text { a Tração } \\
(\mathrm{MPa})\end{array}$ & $\begin{array}{l}\text { Limite de } \\
\text { Escoamento } \\
\text { (MPa) }\end{array}$ & $\begin{array}{l}\text { Alongamento } \\
\text { (\%) }\end{array}$ & $\begin{array}{l}\text { Estricção } \\
(\%)\end{array}$ & $\begin{array}{l}\text { Dureza } \\
\text { (HBW) }\end{array}$ \\
\hline \multicolumn{6}{|c|}{ Chapa / Barra / Haste } \\
\hline Laminado & $827-1103$ & $414-758$ & $60-30$ & $60-40$ & $175-240$ \\
\hline Recozido & $827-1034$ & $414-655$ & $60-30$ & $60-40$ & $145-220$ \\
\hline Solubilizado & $724-896$ & $290-414$ & $65-40$ & $90-60$ & $116-194$ \\
\hline \multicolumn{6}{|l|}{ Folha / Fita } \\
\hline Recozido & $827-1034$ & $414-621$ & $55-30$ & & $145-240$ \\
\hline \multicolumn{6}{|c|}{ Tubo / Deformado a frio } \\
\hline Recozido & $827-965$ & $414-517$ & $55-30$ & & \\
\hline Solubilizado & $689-827$ & $276-414$ & $60-40$ & & \\
\hline
\end{tabular}

A Tabela 3 apresenta, de forma simplificada, mais algumas propriedades mecânicas da liga Inconel UNS N06625.

Tabela 3: Propriedades mecânicas da liga de Inconel UNS N06625 na temperatura ambiente [12]

\begin{tabular}{l|l}
\hline Propriedades Mecânicas $\left(\mathbf{2 5}^{\circ} \mathbf{C}\right)$ & Inconel UNS N06625 \\
\hline \hline Módulo de Elasticidade (E) & $205 \mathrm{GPa}$ \\
\hline Coeficiente de Poison (v) & 0,297 \\
\hline
\end{tabular}

A microestrutura do Inconel UNS N06625 é formada por uma matriz de níquel com estrutura cúbica de face centrada endurecível por mecanismo de solução sólida. Diferentemente da liga Inconel 718, esta liga não requer tratamentos térmicos para atingir níveis superiores de resistência mecânica através da precipitação de fases secundárias.

Os carbonetos mais frequentemente encontrados em ligas de níquel são: $\mathrm{MC}$, $\mathrm{M}_{6} \mathrm{C}, \mathrm{M}_{7} \mathrm{C}_{3}$ e $\mathrm{M}_{23} \mathrm{C}_{6}$, nos quais $\mathrm{M}$ é o elemento metálico formador de carboneto. Os do tipo $\mathrm{MC}$, por terem uma distribuição não-uniforme e aspecto grosseiro, não são desejados. Os $\mathrm{M}_{6} \mathrm{C}$ quando precipitados nos contornos de grão podem ser utilizados para controle do tamanho de grão, mas se estiverem dispersos em padrão de Widmanstatten podem prejudicar a ductilidade e a vida em fadiga [14].

As fases Laves $\left(\mathrm{A}_{2} \mathrm{~B}\right)$ e os carbonetos $\mathrm{MC}$ formados durante o processo de solidificação e as fases Laves e delta formadas durante tratamentos térmicos devem ser evitadas devido aos seus efeitos deletérios as propriedades mecânicas do material. No entanto, certos tipos e distribuições de carbonetos ao longo dos contornos de grão podem possuir efeitos benéficos a resistência a corrosão sob tensão [15]. 
A Tabela 4 relaciona os efeitos da presença de alguns elementos de liga. Os elementos de liga $\mathrm{Fe}, \mathrm{Co}, \mathrm{W}, \mathrm{Va}, \mathrm{Ti}, \mathrm{Al}, \mathrm{Cr}$ e $\mathrm{Mo}$ agem como elementos endurecedores por solução sólida nas ligas de níquel. A adição de $\mathrm{Al}$ e Ti são principalmente para o refino do grão e são mantidos baixos para melhorar a soldabilidade da liga. O Cr e o Mo também contribuem para a resistência a corrosão por fresta e pite e o $\mathrm{Nb}$ age estabilizando a liga contra efeitos de sensitização durante a soldagem, prevenindo desta forma a formação de trincas intergranulares. $\mathrm{O}$ alto teor de níquel elimina o efeito de corrosão sob tensão em meios clorados [15].

Tabela 4: Efeitos nas propriedades da liga a partir de alterações na composição química [15]

\begin{tabular}{|c|c|c|c|}
\hline $\begin{array}{l}\text { Redução de Teor do } \\
\text { Elemento }\end{array}$ & $\begin{array}{l}\text { Resistência } \\
\text { Mecânica } \\
\end{array}$ & $\begin{array}{ll}\begin{array}{l}\text { Resistência } \\
\text { Corrosão }\end{array} & \text { a } \\
\end{array}$ & Soldabilidade \\
\hline $\mathrm{Nb}$ & Diminui & $\mathrm{N}$ & Aumenta \\
\hline $\mathrm{Fe}$ & Diminui & $\mathrm{N}$ & Aumenta \\
\hline Mo & Diminui & Diminui & Aumenta \\
\hline Ti e Al & $\operatorname{Diminui}^{(1)}$ & $\mathrm{N}$ & Diminui $^{(2)}$ \\
\hline C & $\mathrm{N}$ & Diminui $^{(3)}$ & Aumenta \\
\hline $\mathrm{Si}$ & $\mathrm{N}$ & $\operatorname{Diminui}^{(3)}$ & Aumenta \\
\hline
\end{tabular}

$N$ - Sem efeito significativo ou não verificado; (1) - Ti e Al são importantes para a resistência mecânica apenas se mecanismo de endurecimento por precipitação forem empregados; (2) Certas quantidades de $\mathrm{Ti}$ e Al são benéficas a soldabilidade da liga; (3) - Se carbonetos intergranulares forem responsáveis por conferir a liga resistência a corrosão, quantidades mínimas de $C$ e Si são necessárias.

\subsection{Propriedade mecânica do aço $9 \% \mathrm{Ni}$}

A liga de aço $9 \% \mathrm{Ni}$ que foi desenvolvida pela Nickel Company International (INCO) em 1946 [16] e possui excelente resistência à baixas temperaturas [17] [18]. Este material tornou-se amplamente utilizado em tanques de armazenamento de GNL após uma extensa avaliação, denominada "Operação Criogênia" [19], a qual mostrou que o tratamento alívio do estresse é desnecessário para o aço $9 \% \mathrm{Ni}$. Nippon Steel e Sumitomo Metal Corporation (NSSMC) foi formada através da fusão da Nippon Steel Corporation (NSC) e Sumitomo Metal Industries, Ltd. (SMI) em 2012. Ela possui um longo histórico de fabricação do aço $9 \%$ Ni. No total, 260.000 toneladas de aço 9\% Ni foram fabricados.

No que diz respeito à segurança da falha de tanques de GNL, apenas análises referentes à iniciação de trincas frágeis foram levadas em conta até a década de 1970, nas quais só havia tanques de contenção simples. No entanto, alguns 
acidentes de falhas envolvendo tanques de GNL, na segunda metade da década de 1970, desencadearam o conceito de um tanque com dupla parede, a qual tem a capacidade de conter qualquer vazamento em tanques [20]. Nos anos 1980 outras investigações para aplicação em tanques de GNL foram feitas [21]. Quanto ao aço $9 \% \mathrm{Ni}$, suas propriedades ainda não eram de total domínio e, com isso, seu uso foi questionado na época. No entanto, vários projetos de pesquisas foram desenvolvidos pelos EUA, Europa e Japão [22] [23] e o Instituto de Pesquisa de Gás concluiu que o aço 9\% Ni com uma energia absorvida de 60 Joules a uma temperatura de $-196^{\circ} \mathrm{C}$ tem adequada propriedades mecânicas de serviço [24]. Em seguida, a reputação da confiabilidade de aço ao níquel $9 \%$ foi divulgada. Atualmente, aço níquel 9\% tem um histórico de aplicação, e tornou-se um dos materiais mais dominantes para uso em tanques internos de tanques de armazenamento de GNL em terra.

$\mathrm{Na}$ Tabela 5 tem-se a composição química dos aços $9 \% \mathrm{Ni}$.

Tabela 5: Composição química nominal do A353 e A553 tipo I [25]

\begin{tabular}{|l|l|l|l|l|l|}
\hline $\mathbf{N i}$ & $\mathbf{P}$ & $\mathbf{S}$ & $\mathbf{M G}$ & $\mathbf{S i}$ & $\mathbf{C}$ \\
\hline $8,50-9,50$ & 0,035 & 0,035 & 0,90 & $0,15-0,40$ & 0,13 max. \\
\hline
\end{tabular}

Já na Tabela 6 têm-se as propriedades mecânicas.

Tabela 6: Propriedades mecânicas da liga 9\% Ni [25]

\begin{tabular}{|l|lr|l|l|}
\hline Formato e Condição & $\begin{array}{l}\text { Limite de } \\
\text { Resistência } \\
\text { Tração Ksi [MPa] }\end{array}$ & $\begin{array}{l}\text { Limite } \\
\text { Escoamento } \\
\text { [MPa] }\end{array}$ & $\begin{array}{r}\text { de } \\
\text { Ksi }\end{array}$ & $\begin{array}{l}\text { Alongamento em 2"' } \\
\text { [50mm] (\%) }\end{array}$ \\
\hline A353 & $100-120[690-825]$ & $75[515]$ & 20 \\
\hline A553 tipo I & $100-120[690-825]$ & $85[585]$ & 20 \\
\hline
\end{tabular}

Nas Tabelas Tabela 7, Tabela 8 e Tabela 9 têm as propriedades físicas.

Tabela 7: Módulos de Elasticidades em função da Temperatura [25]

\begin{tabular}{|l|l|}
\hline em 21ํㅡ & em $-196^{\circ} \mathrm{C}$ \\
\hline $27 \times 10^{6} \mathrm{psi}(185.000 \mathrm{MPa})$ & $30 \times 10^{6} \mathrm{psi}(209.000 \mathrm{MPa})$ \\
\hline
\end{tabular}

Tabela 8: Média dos coeficientes de expansão do A353 e A553 tipo I [25].

\begin{tabular}{|l|l|l|l|}
\hline-196 a $21^{\circ} \mathrm{C}$ & -129 a $21^{\circ} \mathrm{C}$ & -73 a $21^{\circ} \mathrm{C}$ & -73 a 200ㅇ \\
\hline $8,8 \times 10^{6} \mathrm{~K}^{-1}$ & $9,9 \times 10^{6} \mathrm{~K}^{-1}$ & $10,6 \times 10^{6} \mathrm{~K}^{-1}$ & $11,2 \times 10^{6} \mathrm{~K}^{-1}$ \\
\hline
\end{tabular}


Tabela 9: Condutividade Térmica do A353 e A553 tipo I [25].

\begin{tabular}{l|l}
\hline Temperatura $\left({ }^{\circ} \mathbf{C}\right)$ & Condutividade Térmica $(\mathbf{W} /(\mathbf{m} . \mathbf{K}))$ \\
\hline \hline-196 & 13,1 \\
\hline-176 & 16,1 \\
\hline-170 & 17,3 \\
\hline-153 & 19,3 \\
\hline-122 & 21,0 \\
\hline-72 & 24,8 \\
\hline-22 & 27,4 \\
\hline 27 & 29,2 \\
\hline 128 & 32,5 \\
\hline 228 & 34,0 \\
\hline 328 & 34,3 \\
\hline 428 & 33,4 \\
\hline 528 & 32,3 \\
\hline
\end{tabular}

$\mathrm{Na}$ Tabela 10 tem os valores de $\mathrm{K}_{\mathrm{C}}$.

Tabela 10: Média dos coeficientes de expansão do A353 e A553 tipo I [26].

\begin{tabular}{l|l|l|l}
\hline Material & Temperatura $\left({ }^{-} \mathbf{C}\right)$ & K médio $\left(\mathbf{M P a} \cdot \mathbf{m}^{1 / 2}\right)$ & $\mathbf{K}$ mín (MPa.m \\
\hline \hline A353 & -191 & 136 & 134 \\
\hline A353 & -175 & 185 & 185 \\
\hline A353 & -162 & 176 & 170 \\
\hline A353 & -162 & 330 & 301 \\
\hline A553 & -196 & 186 & 178 \\
\hline A553 & -175 & 176 & 174 \\
\hline A553I & -196 & 228 & 213 \\
\hline A553I & -196 & 307 & 304 \\
\hline A553I & -196 & 228 & 213 \\
\hline A553I & -196 & 307 & 304 \\
\hline A553I & -196 & 261 & 252 \\
\hline A553I & -196 & 258 & 208 \\
\hline A553I & -196 & 250 & 210 \\
\hline A553I & -196 & 271 & 234
\end{tabular}

\subsection{Mecânica da fratura}

A tenacidade à fratura de um material se caracteriza pela sua capacidade de resistir à propagação de uma trinca. Esta pode ser iniciada por carregamentos estáticos ou dinâmicos, bem como por defeitos de fabricação e interferências do meio externo, como por exemplo, impacto de detritos, entre outros.

\subsubsection{Mecânica da fratura linear-elástica}

A abordagem tradicional da Resistência dos Materiais em projetos de estruturas considera basicamente duas variáveis: a tensão máxima aplicada e a resistência mecânica do material. Esta é uma abordagem mais tradicional e mais 
largamente empregada, tratando o material como um meio continuo, isotrópico e homogêneo. Assume-se que o material seja adequado para utilização caso sua resistência mecânica (representada por um critério de escoamento apropriado) seja superior a solicitação externa, considerando um fator de segurança.

A abordagem da Mecânica da Fratura permitiu considerar que os materiais estruturais não são contínuos e incorporou uma variável adicional na análise: o tamanho da descontinuidade na estrutura. A partir de tal, definiu-se a propriedade a tenacidade a fratura como aquela que descreve a resistência a propagação de um defeito (tipo trinca) e representa a capacidade do material em absorver energia mecânica sem fraturar. Neste contexto, a tenacidade a fratura é uma propriedade tão relevante do material quanto a própria tensão limite de escoamento [27].

Conforme GODEFROID (1985), a tenacidade a fratura de um material representa a sua habilidade inerente de resistir a certo valor de intensidade de tensão na ponta de uma trinca nele presente sem que ocorra fratura.

Para caracterizar o comportamento mecânico de um material com trinca, Griffith em 1921, fazendo um balanço entre mudanças de energia elástica de deformação e de superfície, propôs que para ocorrer o avanço de uma trinca sob uma tensão aplicada, a queda na energia potencial do sistema deve ser no mínimo igual ao aumento da energia de superfície devido a extensão de uma trinca.

Em 1913, usando as análises de Inglis de tensões para uma trinca de formato elíptico numa chapa de comportamento elástico de dimensões infinitas, Figura 17, Griffith deduziu que a mudança da energia potencial da chapa é dada pela equação 2.1 .

$$
w_{p}=\frac{\pi a^{2} \sigma^{2} B}{E^{\prime}} \quad \text { Eq. } 2.1
$$

onde B é a espessura da chapa, E' e o modulo de Young adaptado $\left(E^{\prime}=E\right.$ para o estado de tensão plana e $E^{\prime}=E 1\left(1-v^{2}\right)$ para o estado de deformação plana), e a é metade do comprimento da trinca.

A energia de superfície do sistema é dada pela equação 2.2 . 


$$
w_{s}=4 a B \gamma_{s} \text { Eq. } 2.2
$$

onde $\gamma_{\mathrm{s}}$ é a energia de superfície livre por unidade de área de superfície. Sendo assim, a energia total do sistema, devido a trinca será dado pela equação 2.3.

$U=w_{p}+w_{s}=-\frac{\pi a^{2} \sigma^{2} B}{E^{\prime}}+4 a B \gamma_{s} \quad$ Eq. 2.3

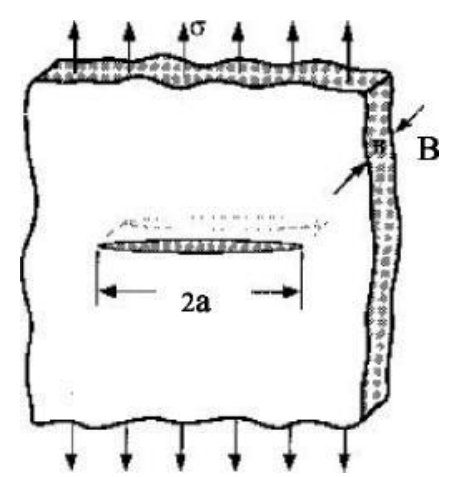

Figura 17: Representação esquemática de uma chapa de dimensões relativamente infinitas com uma trinca central de formato elíptico de comprimento 2a, HERTZBERG (1989) [28].

Griffith notou que a condição crítica para iniciar o crescimento da trinca era dada pela equação 2.4 .

$$
\frac{d U}{d A}=-\frac{\pi a \sigma^{2}}{E^{\prime}}+2 \gamma_{s} \quad \text { Eq. } 2.4
$$

onde $\mathrm{A}=2 \mathrm{aB}$, é a área da trinca.

Griffith concluiu sua teoria baseado no comportamento frágil de um vidro na temperatura ambiente, considerando que a tensão na ponta da trinca excede a resistência de coesão do material (tensão necessária para superar a força das ligações inter atômicas).

Na maioria dos materiais de engenharia, contudo, há deformação plástica nas proximidades da ponta da trinca, induzida pela concentração de tensão no local. Por isso, Orowan em 1952 aplicou o conceito de Griffith para metais, simplesmente complementando a energia de superfície com a dissipação de energia de deformação plástica do material, obtendo-se a equação 2.5. 
$W_{s}=4 a B\left(\gamma_{s}+\gamma_{p}\right)$

Eq. 2.5

onde $y_{p}$ é o trabalho de deformação plástica por unidade de área de superfície criada. Vale lembrar que geralmente $\gamma_{\mathrm{p}}$ e muito maior que $\gamma_{\mathrm{s}}$.

Enfim, a teoria de Griffith diz que a trinca se propaga se a energia total do sistema diminuir ou permanecer constante. Com essa proposição foi possível obter ferramentas matemáticas para a Mecânica de Fratura. Em 1956 Irwin definiu a taxa de liberação de energia do material G, como sendo a equação 2.6.

$G=\frac{d \Pi}{d A}=\left(\frac{\pi \sigma^{2} a}{E}\right) \quad$, sendo $\pi$ a energia potencial

Esta taxa de liberação de energia, quando assume um valor crítico, leva a propagação instável da trinca e, portanto, é uma medida da tenacidade a fratura do material. Seja $\mathrm{G}$ a força de crescimento da trinca, e $\mathrm{R}_{\mathrm{T}}$ a resistência a propagação da mesma. Enquanto $G$ assume valores menores ou iguais a $R_{T}$, o crescimento é estável. Quando $\mathrm{G}$ excede o valor de $\mathrm{R}_{\mathrm{T}}$, a propagação da trinca é instável. A resistência a propagação da trinca $\mathrm{R}_{\mathrm{T}}$ está definida pela Equação 2.7.

$R_{T}=2\left[w_{s}+w_{p}\right]$ Eq. 2.7

onde $\mathrm{w}_{\mathrm{s}}$ é a energia para formação de superfície no material, e $\mathrm{w}_{\mathrm{p}}$, é a energia de deformação plástica em torno da trinca.

Posteriormente, em 1957, Irwin aperfeiçoou os conceitos da Mecânica de Fratura com a introdução do parâmetro K, chamado de intensidade de tensão. A intensidade do campo de tensão-deformação, localizado, nas vizinhanças da ponta da trinca é descrita em função de K, RICARDO, 2003 [29]. Frequentemente o fator $\mathrm{K}$ inclui um subscrito, tal como I, II ou III. Estes subscritos referem-se aos três modos diferentes de carregamento de um corpo trincado, Figura 18. O modo I, também chamado de modo de abertura ou trativo, é caracterizado por uma solicitação no plano da chapa, normal ao plano das faces da trinca. É considerado 
tecnicamente o modo mais importante, pois é encontrado com frequência nos problemas básicos de fratura, desta forma, a maior parte dos estudos de Mecânica de Fratura é baseada neste modo. O modo II é denominado modo de deslizamento ou cisalhamento planar, onde o deslocamento das superfícies da trinca se dá no plano da trinca e perpendicular a aresta frontal da trinca. Por fim, o modo III, chamado de modo de rasgamento, é causado por um cisalhamento fora do plano da trinca, sendo que o deslocamento das superfícies da trinca se dá no plano da trinca e paralelo a aresta frontal da mesma, RICARDO, 2003 [29].

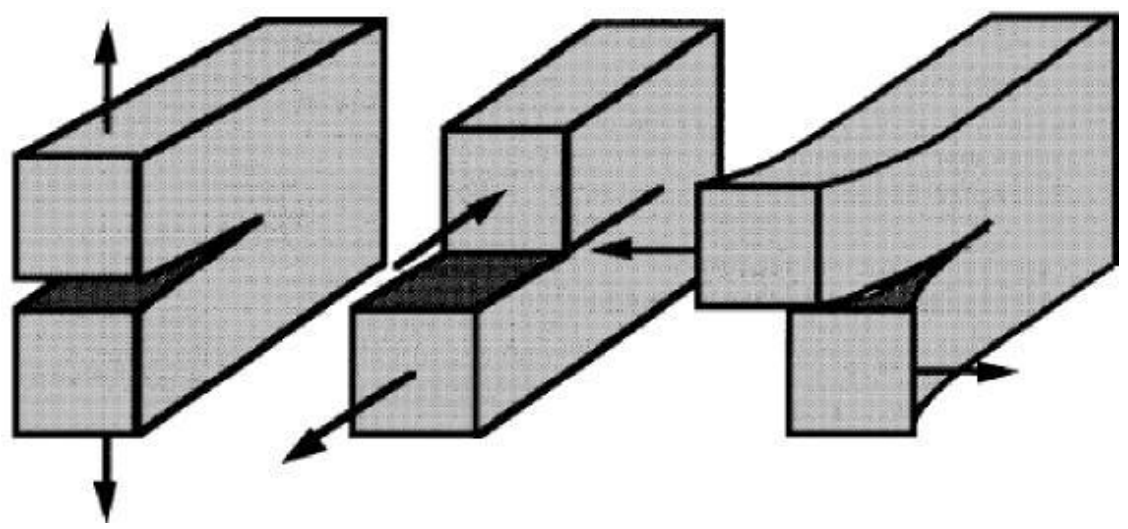

Figura 18: Os três modos de carregamento que podem ser aplicados em uma trinca, ANDERSON (2005) [27].

Cada trinca tem um fator $\mathrm{K}_{\mathrm{I}}$ singular, que depende diretamente do comprimento a da mesma, da tensão aplicada ao material $\sigma$, e de um fator de forma Y. Este fator K vem caracterizar o crescimento da trinca como estável ou instável. A Equação 2.8 mostra uma relação entre o fator de intensidade de tensão, segundo o modo trativo (I) de carregamento, e suas variáveis.

$K_{I}=Y \sigma \sqrt{\pi a} \quad$ Eq. 2.8

A trinca se torna instável quando $\mathrm{K}_{\mathrm{I}}$ assume um valor critico, que é chamado de $\mathrm{K}_{\mathrm{IC}}$. Este fator $\mathrm{K}_{\mathrm{IC}}$ mede a tenacidade a fratura do material. Seu valor é obtido experimentalmente, e é numericamente proporcional a G. O parâmetro K descreve o comportamento do material na Mecânica de Fratura Linear Elástica (MFLE). 
Segundo EWALDS \& WANHIL (1993) a Mecânica de Fratura Linear Elástica (MFLE) foi originalmente desenvolvida para descrever crescimento de trinca e fratura sob condições essencialmente elásticas, como o nome já diz. No entanto tais condições são encontradas somente para fratura em deformação plana de materiais metálicos de alta resistência mecânica e para fratura de materiais com comportamento frágil, como vidros, cerâmicos, rochas e gelo.

Mais tarde foi demonstrado que o conceito de Mecânica da Fratura Linear Elástica (MFLE) poderia ser levemente alterado de forma a incluir materiais com plasticidade limitada na ponta da trinca. Nesta categoria é tratado o problema de fratura sob tensão plana. No entanto, existe uma importante classe de materiais de engenharia que são mais dúcteis do que o comportamento permitido para a análise: a zona plástica na ponta da trinca muito grande. Para esses casos é utilizada a Mecânica de Fratura Elasto-Plástica (MFEP). Para o comportamento elastoplástico, HUTCHINSON (1968) e RICE \& ROSENGREN (1968) mostraram que o campo de tensão e de deformação na frente de uma trinca estacionária, pode ser descrito por um fator único denominado integral-J, ou através do CTOD.

\subsubsection{Mecânica da fratura elasto-plástica (MFEP)}

A Mecânica da Fratura Elasto-Plástica (MFEP) é uma extensão natural da MFLE (Mecânica da Fratura Linear Elástica), sendo a condição em que provavelmente ocorre a maioria das rupturas de componentes mecânicos e estruturas [30].

A MFLE (Mecânica da Fratura Linear Elástica) é aplicável a materiais que apresentam fratura predominantemente no regime elástico. Isso acontece nos materiais estruturais que apresentam elevada resistência mecânica, porém, baixa tenacidade. Em materiais que possuem uma elevada tenacidade e resistência mecânica moderada, a estrutura apresenta plasticidade considerável durante o processo de fratura, as soluções elásticas não são mais aplicáveis e a MFEP deve ser aplicada. Dois são os parâmetros amplamente utilizados para descrever o comportamento em fratura de materiais em regime elasto plástico: o CTOD (Crack Tip Opening DisplacementI) e a Integral J [30] [31].

A MFEP estende o campo da Mecânica de Fratura para descrever o 
comportamento da fratura além do regime elástico, mas ela também é limitada. Logo MFEP não pode tratar de todos os casos dos chamados colapsos plásticos. Para materiais com comportamento linear elástico, a tenacidade a fratura pode ser descrita em termos do fator de intensidade de tensão K, nas seguintes condições:

$\mathrm{K}_{\mathrm{C}}=$ Carregamento estático sob condição de tensão plana;

$\mathrm{K}_{\mathrm{IC}}=$ Carregamento estático sob condição de deformação plana;

$\mathrm{K}_{\mathrm{d}}=$ Carregamento dinâmico sob condição de deformação plana;

$\mathrm{K}_{\mathrm{R}}=$ Resistencia ao crescimento estável da trinca.

Para materiais com comportamento elasto-plástico, a tenacidade a fratura é descrita pelos seguintes parâmetros:

$\delta_{\mathrm{c}}=$ Deslocamento crítico de abertura de trinca (CTOD);

$\mathrm{J}_{\mathrm{IC}}=$ Valor crítico da integral $\mathrm{J}$;

$\mathrm{J}_{\mathrm{R}}$ ou $\varsigma_{\mathrm{R}}=$ Resistência ao crescimento estável da trinca.

Para os materiais com comportamento plástico, um número significativo de pesquisadores tem procurado estender a teoria da Mecânica de Fratura além dos limites impostos pela utilização de um parâmetro, KIRK, DODDS, Apud ANDERSON; DOWD. A maior parte destas aproximações envolve a introdução de um segundo parâmetro para caracterizar as condições na ponta da trinca, conforme visto na Figura 19 [27] [32]. 


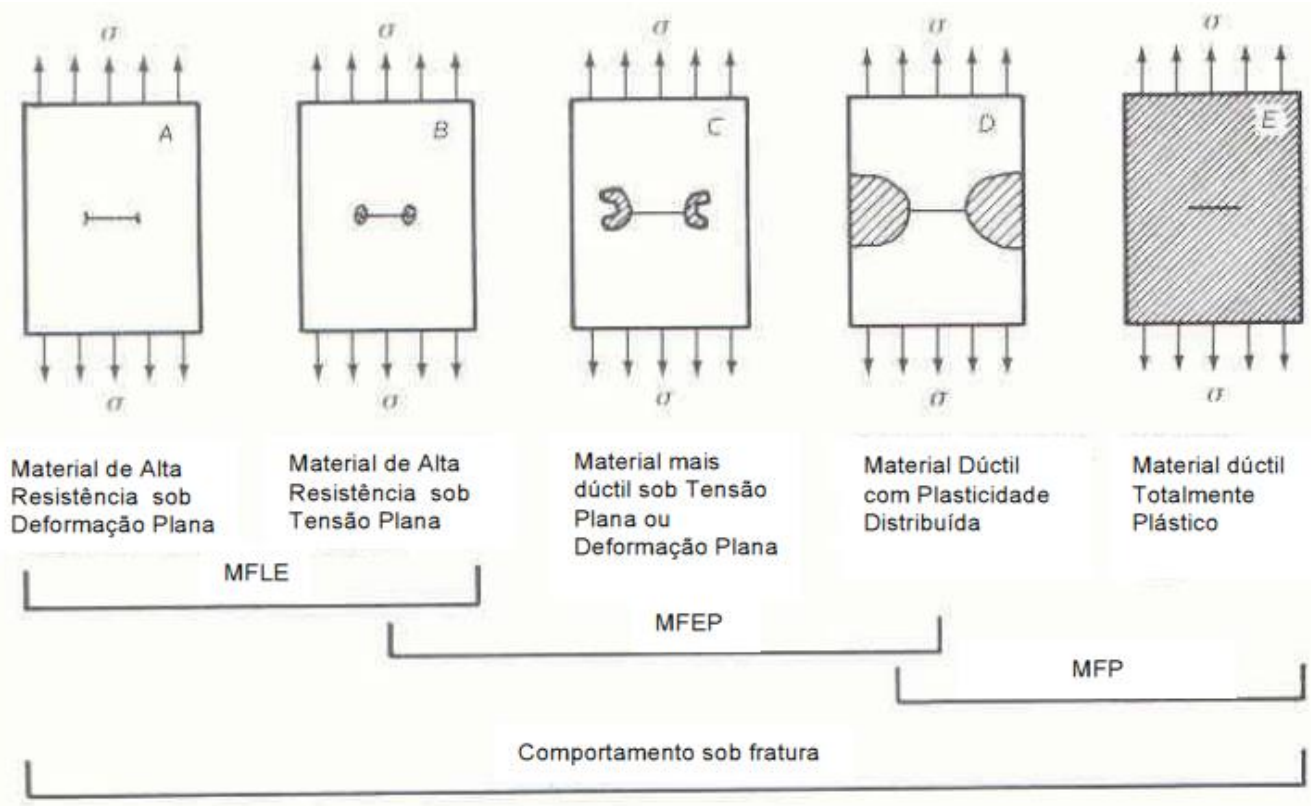

Figura 19: Faixa de aplicação da MFLE, MFEP E MFP para descrever o comportamento da fratura. Adaptado de EWALDS \& WANHILL (1993) [33].

\subsubsection{Método de abertura crítica da trinca - CTOD}

Este método foi introduzido primeiramente por WELLS [34] e baseia-se na hipótese que quando ocorre plasticidade significativa, o processo de fratura é controlado primeiramente pela intensa deformação adjacente à ponta da trinca e que a separação das superfícies da trinca, na ponta da mesma ou abertura da ponta da trinca, é uma medida desta deformação. A propagação da trinca inicia-se, assim, em um valor crítico dessa abertura na ponta da trinca. Daí o nome em inglês Crack Tip Opening Displacement - CTOD, representado pela grandeza $\delta$, conforme representado na Figura 20.

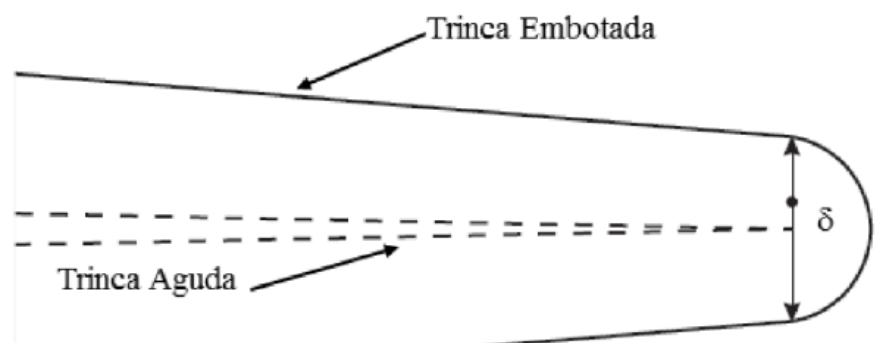

Figura 20: Representação esquemática de abertura na ponta da trinca [31]. 
Diante do exposto, fica evidente a necessidade de se conhecer o valor crítico de abertura $\left(\delta_{\mathrm{C}}\right)$ que um determinado material possa suportar sem romper, ou seja, qualquer carregamento que provoque uma abertura da trinca a um valor superior ao crítico, promoverá a ruptura da estrutura. Para que o modelo possa prever se uma determinada trinca provocará a ruptura de uma estrutura submetida a um dado carregamento, é necessário que através desse modelo seja possível o cálculo do valor de $\delta$ correspondente a esse tipo particular de carregamento e valor de tensão aplicada. A fratura da estrutura ocorrerá quando $\delta_{\text {aplicado }}$ exceder a $\delta_{\mathrm{C}}$.

A determinação tradicional do CTOD foi padronizada pela British Standard Institution, através da BS 5762/79 [30]. Posteriormente, a ASTM publicou a primeira versão americana para o teste: ASTM E1280 [35]. Em ambos os métodos, o cálculo do CTOD se dá pela separação da componente elástica e da componente plástica (Equação 2.9).

$\delta=\delta_{e l}+\delta_{p l} \quad$ Eq. 2.9

Antes do desenvolvimento da parte elástica do cálculo do CTOD, faz-se necessário a apresentação de alguns conceitos relacionados com a Mecânica da Fratura Linear Elástica (MFLE). Griffith, em 1920, propôs uma abordagem baseada no balanço energético, que residia na formulação de um sistema para a trinca e análise em termos de um processo termodinâmico, postulando que uma trinca só irá se propagar, de modo instável, quando a taxa de liberação de energia elástica armazenada pelo carregamento do material for ao menos igual ao aumento de energia superficial resultante do crescimento da trinca. Por outro lado, Irwin fundamentou um desenvolvimento baseado no comportamento mecânico nas vizinhanças da ponta da trinca e utilizando o fator de intensidade de tensão $\mathrm{K}$. Como o fator $\mathrm{K}$ possui uma ampla aplicação na mecânica da fratura, além do fato de se poder relacionar a teoria energética de Griffith com o fator de intensidade de tensão $\mathrm{K}$ com equações simples, é comum a representação da unidade de energia $\mathrm{G}$ em termos de K como visto na equação 2.10 para o modo I de fratura [30].

$G_{I}=\frac{K_{I}^{2}}{E^{*}} \quad$ Eq. 2.10 
onde $\mathrm{E}^{*}=\mathrm{E}$ para um estado plano de tensões, $\mathrm{E}^{*}=\mathrm{E} /\left(1-\mathrm{v}^{2}\right)$ para um estado plano de deformações e v é a razão de Poisson.

\subsubsection{Integral J}

As integrais independentes do contorno considerado, são utilizadas na física para calcular a intensidade de uma singularidade de um determinado campo, sem a necessidade de conhecer a exata forma do campo na proximidade da singularidade [36]. Essas integrais foram introduzidas na mecânica da fratura inicialmente por RICE [37], com um enfoque puramente mecânico (não considera aspectos metalúrgicos e microestruturais) da fratura [30]. A Integral J é definida como visto na equação 2.11 .

$$
J=\int_{\Gamma} W d y-T \frac{\partial u}{\partial x} d s \quad \text { Eq. } 2.11
$$

onde J é a Integral J, $\Gamma$ é o caminho da integração percorrido no sentido antihorário entre a borda inferior e superior da trinca, W é a energia de deformação por unidade de volume, calculada conforme equação 2.12 , T é o vetor tração normal a $\Gamma$ orientado para fora, definido pela equação 2.13 , u é o deslocamento na direção x e ds é o elemento infinitesimal do arco ao longo de $\Gamma$.

$$
W=\int_{0}^{\varepsilon} \sigma_{i j} d \varepsilon_{i j} \quad \text { Eq. } 2.12
$$

$$
T_{i}=\sigma_{i j} n_{j} \quad \text { Eq. } 2.13
$$

onde $\mathrm{W}$ é a deformação total do material, $\sigma i j$ é o tensor de tensão, $\varepsilon i j$ o tensor de deformação, $T i$ o componente do vetor $\mathrm{T}$ na direção i e nj o vetor unitário normal a $\Gamma$ na direção $\mathrm{j}$.

Por definição de equilíbrio, a equação 2.14 é não nula quando o volume de integração não contém uma singularidade. Assumindo que os caminhos FA e CD na 
Figura 21, nas faces da trinca, são retos e com tensões nulas, logo FA e CD não contribuem para o cálculo da integral.

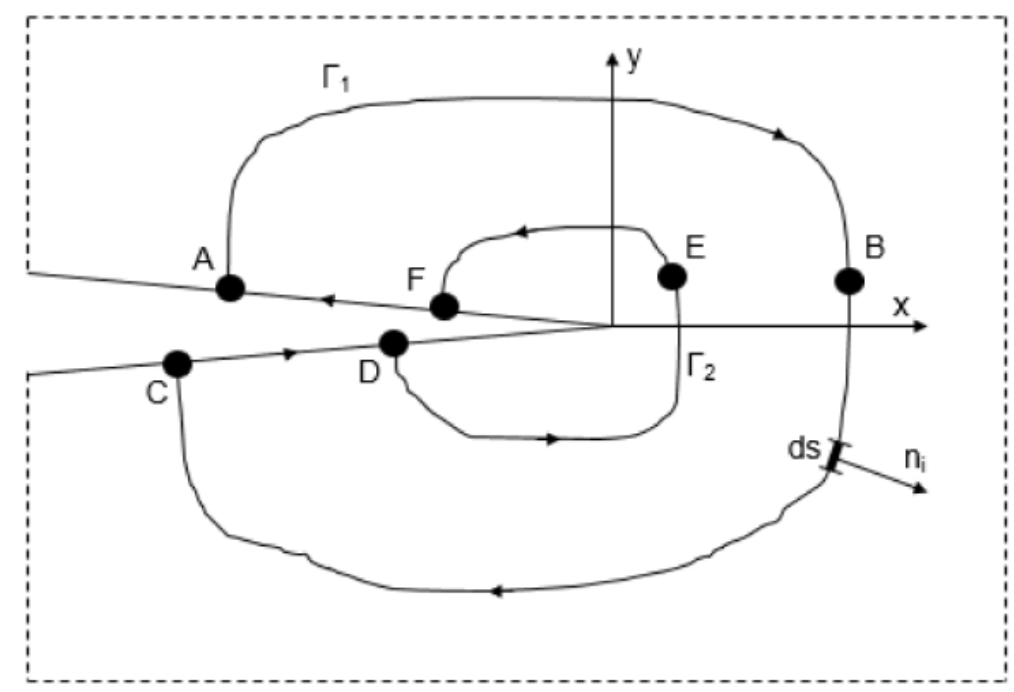

Figura 21: Definição da Integral $\mathrm{J}$ para um entalhe agudo submetido a um estado plano de tensões e o contorno de integração.

Assim, as contribuições devido a ABC e DEF são (Equação 2.14):

$J_{A B C}+J_{D E F}=0 \leftrightarrow J_{D E F}=-J_{A B C} \quad$ Eq. 2.14

Considerando então as integrais calculadas pelos contornos $\Gamma 1$ e $\Gamma 2$, tem-se a equação 2.15 .

$J_{\Gamma_{1}}=J_{\Gamma_{2}} \quad$ Eq. 2.15

A definição da Integral J, mostra uma independência em relação ao contorno considerado. Esta é uma das vantagens do método, pois J pode ser obtida selecionando-se o percurso mais adequado para realizar a integração (por exemplo o contorno do corpo de prova), facilitando desta forma os cálculos [30] e podendo a mesma ser calculada para diferentes geometrias e estado de tensões [31].

A definição proposta por RICE supõe um material elástico, linear ou nãolinear, i.e. com comportamento reversível. No caso dos campos de tensão puramente elásticos, foi apresentado que a quantidade $J$ da equação 2.16 é igual a 
taxa de energia dissipada na propagação dinâmica de uma trinca (Equação 2.16):

$J=-\frac{\partial U}{\partial a}=G \quad$ Eq. 2.16

onde U representa a energia potencial e a o comprimento da trinca.

\subsection{Cálculo por Elementos Finitos}

Outro método de cálculo numérico importante é o Método dos Elementos Finitos (MEF). O MEF foi inicialmente divulgado por volta dos anos 1960 (HUEBNER, 1976), já então tendo sido utilizado na área aeroespacial (CLOUGH, 1960). Estudos a respeito da discretização de funções continuas, por sua vez, iniciaram-se apenas em 1943, pelo matemático Courant, seguindo a ideia de utilização de elementos triangulares e da minimização de energia potencial em estudos de torção em pegas mecânicas.

O Método dos Elementos Finitos é um método matemático para a solução de equações diferenciais parciais, tais como as equações de Poisson e Laplace [38]. O conceito mais fundamental do Método dos Elementos Finitos é o de que toda função continua, seja ela de temperatura, pressão ou deslocamento, pode ser aproximada por um modelo composto de um conjunto de funções continuas (dentro de um intervalo) definidas sobre um número finito de subdomínios, denominados por elementos finitos [39].

O maior problema do Método dos Elementos Finitos é a dificuldade de geração de malha. Por esse motivo, sua utilização tornou-se mais popular apenas na década de 80, a partir do avanço tecnológico dos computadores e dos vários métodos de geração automática de malhas.

Até então, a utilização do método era restrita ao mundo acadêmico, passando a ser utilizado posteriormente pelas empresas, com o objetivo principal de aumentar a precisão de projetos e minimizar os custos com modelos reais e com perdas na produção.

\subsubsection{Método Elementos Finitos}

Quando utiliza-se da modelagem computacional para solução de problemas 
de engenharia, a primeira etapa consiste na identificação dos fatores que influenciam de maneira relevante no problema, implicando na escolha adequada dos princípios físicos e das variáveis que descrevem o problema, resultando em um modelo matemático constituído por um conjunto de equações diferenciais. A segunda etapa do processo consiste em obter a solução do modelo matemático. Essa tarefa pode ser atribuída aos métodos numéricos [40].

A definição matemática do Método dos Elementos Finitos pode ser atribuída a uma equação principal polinomial de interpolação dentro de um domínio finito que apresenta diferentes sub-funções, cada uma aplicada a certos subdomínios, i.e. ao longo de um elemento, o campo de uma determinada quantidade contínua, como por exemplo o campo de deslocamento, é uma interpolação dos valores dessa quantidade contínua calculada em um número finito de pontos dentro do subdomínio, i.e. os nós. Quando os elementos são conectados, esse campo se torna interpolado ao logo de toda a estrutura por várias equações polinomiais diretamente relacionadas ao número de elementos [41]. A determinação das quantidades contínuas nos nós está associada à minimização de uma grandeza integral que está relacionada a cada problema particular, gerando um conjunto de equações algébricas que podem ser expressas de maneira matricial pela equação 2.17 .

\section{$K_{F E M} D=F \quad$ Eq. 2.17}

onde D é o vetor das variáveis não conhecidas (valores do campo da quantidade contínua), F é o vetor dos carregamentos conhecidos e KFEM a matriz das constantes conhecidas (em uma análise de tensões, conhecida como matriz de rigidez).

Matematicamente, diz-se que a solução é obtida através da ponderação da solução aproximada em todo o domínio, com o que se minimiza o erro.

COOK [41] atribuiu à versatilidade como a grande vantagem do método. A estrutura analisada pode possuir uma forma, condições de contorno e de carregamentos arbitrários. Generalidades estas que não existem nas teorias analíticas clássicas.

Como apresentado anteriormente, o MEF é usado para solucionar problemas 
físicos na engenharia. Segundo BATHE [42], o processo de uma análise de elementos finitos (FEA em sua sigla em inglês) pode ser resumido conforme a Figura 5. O problema físico tipicamente envolve a estrutura atual ou o componente estrutural submetido a uma determinada condição de carregamento. A idealização do problema físico em um modelo matemático requer assumir algumas premissas que juntas levam às equações diferenciais que governam o modelo matemático. $\mathrm{O}$ Método dos Elementos Finitos soluciona estas equações diferenciais.

Como o Método dos Elementos Finitos é um procedimento matemático, torna-se necessário verificar a acuracidade da solução. Se o critério de acuracidade da solução não for atendido, a solução numérica deve ser repetida com parâmetros mais refinados, como por exemplo refino da malha de elementos finitos, que nada mais é que o refino da discretização do domínio finito, até que uma suficiente acurácia seja atingida. É importante ressaltar que o Método dos Elementos Finitos simplesmente resolve um modelo matemático e requer definição de premissas associadas a fase de pré-processamento. A resposta da solução é diretamente associada à seleção dessas premissas, portanto, a escolha do modelo matemático apropriado é essencial para determinar a acurácia em relação ao modelo físico que a análise irá obter. 


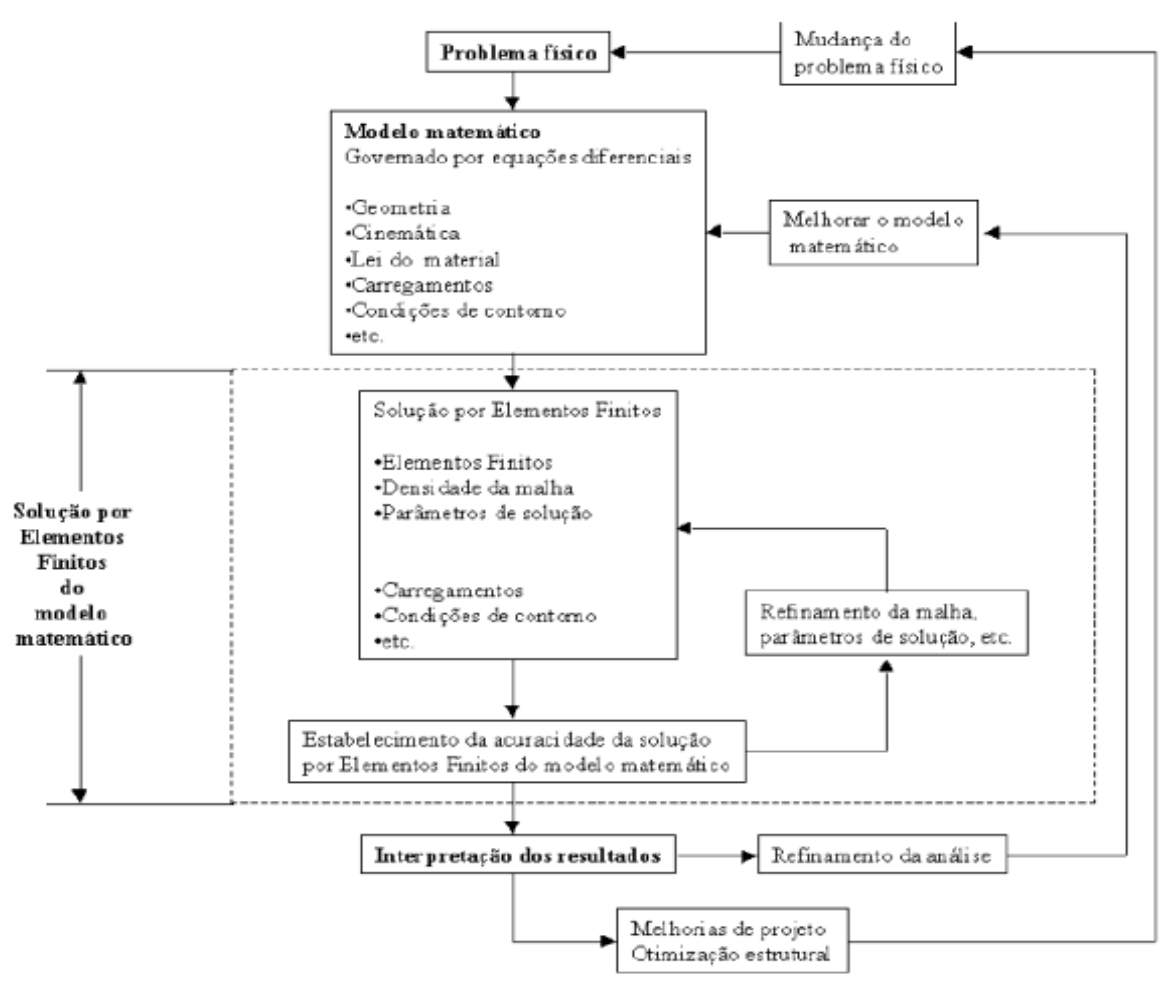

Figura 22: Resumo de um processo de solução pelo MEF.

Uma vez estabelecida a solução das equações pelo Método dos Elementos Finitos, torna-se necessária a interpretação dos resultados de forma a identificar mudanças nas premissas de pré-processamento que podem melhorar a acurácia em relação ao modelo físico. Além disso, alterações estruturais no modelo físico podem ser necessárias dependendo da interpretação dos resultados, induzindo mais uma interação dentro do ciclo de processamento.

\subsubsection{Malha de elementos finitos: nós e elementos}

A malha de elementos finitos é composta pelos contornos contínuos do domínio finito, chamado de elementos. Os nós são pontos que aparecem nos contornos dos elementos que servem para conectá-los. Na Figura 23 os elementos são representados pelas áreas triangulares e os nós pelos pontos. Neste exemplo,

Figura 5: Resumo de um processo de solução pelo MEF.

todos os nós com exceção dos pontos $\mathrm{A}$ e $\mathrm{C}$ compartilham um ou mais elementos, onde estes elementos possuem o mesmo campo de deslocamento nestes nós 
compartilhados.

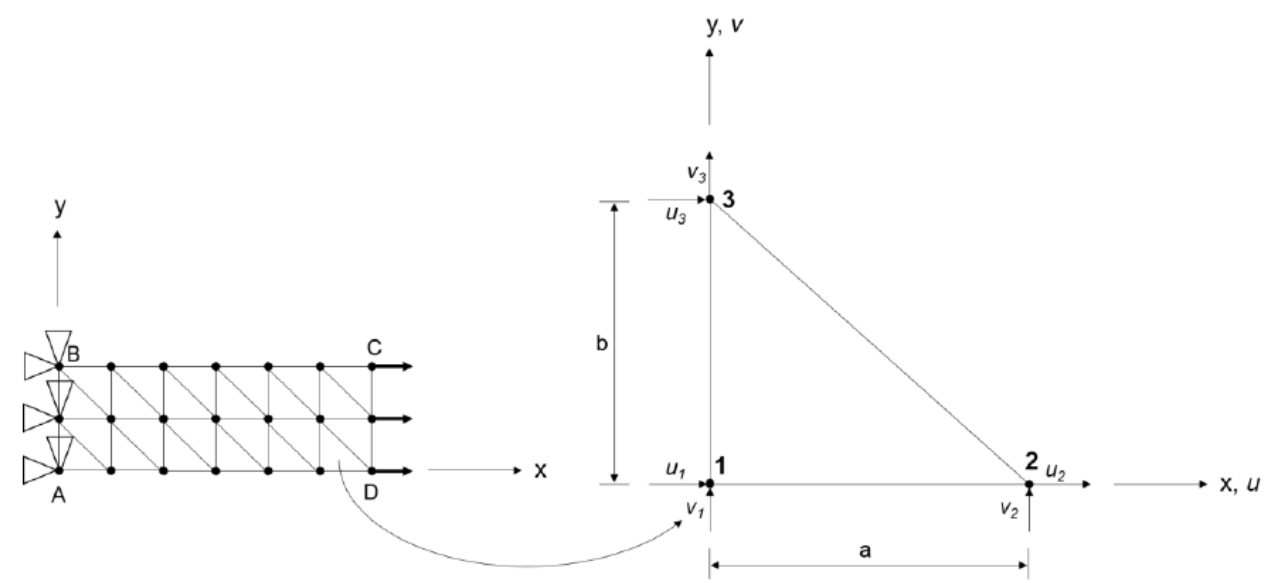

Figura 23: Exemplo de problema 2D com detalhe para um elemento triangular de primeira ordem.

Considerando o elemento plano triangular detalhado na Figura 23, o campo de deslocamento nas coordenadas locais do elemento ( $\mathrm{u}$ e v), podem ser expressas pelas equações 2.18 e 2.19 polinomiais em x e y.

$$
u=\beta_{1}+\beta_{2} x+\beta_{3} y \quad \text { Eq. } 2.18
$$

$v=\beta_{4}+\beta_{5} x+\beta_{6} y \quad$ Eq. 2.19

onde $\beta i$ podem ser relacionadas às amplitudes de deslocamento. Para o exemplo em questão, considerando o deslocamento $u, \beta_{1}$ é a amplitude de deslocamento de corpo rígido e $\beta_{2}$ e $\beta_{3}$ são as amplitudes do deslocamento de variação linear, todas na direção $\mathrm{x}$.

Conhecendo que:

$$
\begin{array}{lllllll}
\mathrm{u}=\mathrm{u}_{1} & \text { e } & \mathrm{v}=\mathrm{v}_{1} & \text { em } & \mathrm{x}=0 & \text { e } & \mathrm{y}=0 \\
\mathrm{u}=\mathrm{u}_{2} & \text { e } & \mathrm{v}=\mathrm{v}_{2} & \text { em } & \mathrm{x}=\mathrm{a} & \text { e } & \mathrm{y}=0
\end{array}
$$


$\mathrm{u}=\mathrm{u}_{3} \quad \mathrm{e} \quad \mathrm{v}=\mathrm{v}_{3} \quad$ em $\quad \mathrm{x}=0 \quad$ e $\quad \mathrm{y}=\mathrm{b}$

Podemos reescrever $\beta$ em função de $\mathrm{u}_{1}, \mathrm{v}_{1}, \mathrm{u}_{2}, \mathrm{v}_{2}, \mathrm{u}_{3}$ e $\mathrm{v}_{3}$, uma vez que substituindo as equações acima em 2.18 e 2.19 temos um sistema de seis equações e seis incógnitas:

$$
\begin{aligned}
& u=\left(1-\frac{x}{a}-\frac{y}{b}\right) u_{1}+\left(\frac{x}{a}\right) u_{2}+\left(\frac{y}{b}\right) u_{3} \quad \text { Eq. } 2.20 \\
& v=\left(1-\frac{x}{a}-\frac{y}{b}\right) v_{1}+\left(\frac{x}{a}\right) v_{2}+\left(\frac{y}{b}\right) v_{3} \quad \text { Eq. } 2.21
\end{aligned}
$$

Escrevendo o campo de deslocamentos do elemento pelas equações 2.18 e 2.19 ou pelas equações 2.20 e 2.21, observa-se que seis variáveis são necessárias ( $\beta i$ ou ui e vi) para a representação da interpolação linear dentro do domínio do elemento, o que caracteriza um problema de seis graus de liberdade, i.e. dois graus de liberdade por nó.

Generalizando as equações 2.20 e 2.21, pode-se escrever as equações 2.22 e 2.23 .

$$
\begin{aligned}
& u^{e}=\sum_{i=1}^{3} N_{i} u_{i}=N_{1} u_{1}+N_{2} u_{2}+N_{3} u_{3} \quad \text { Eq. } 2.22 \\
& v^{e}=\sum_{i=1}^{3} N_{i} v_{i}=N_{1} v_{1}+N_{2} v_{2}+N_{3} v_{3} \quad \text { Eq. } 2.23
\end{aligned}
$$

onde $N i$ são chamadas de função de interpolação, definidas por:

$$
N_{i}^{e}(x, y)=\left\{\begin{array}{l}
0 \text { se }(x, y) \neq\left(x_{i}, y_{i}\right) \\
1 \text { se }(x, y)=\left(x_{i}, y_{i}\right)
\end{array}\right.
$$

O que matematicamente define uma equação polinomial de interpolação no domínio do elemento. Fisicamente, as equações 2.22 e 2.23 significam a contribuição do deslocamento de cada nó ponderada por uma função de interpolação em uma determinada posição x e y dentro do domínio do elemento. 
Resolvendo o campo de deformações no domínio do elemento, temos as equações $2.24,2.25$ e 2.26 :

$$
\begin{aligned}
& \varepsilon_{x}=\frac{\partial u}{\partial x}=\beta_{2}=\frac{\left(u_{2}-u_{1}\right)}{a} \quad \text { Eq. } 2.24 \\
& \varepsilon_{y}=\frac{\partial v}{\partial y}=\beta_{6}=\frac{\left(v_{3}-v_{1}\right)}{b} \quad \text { Eq. } 2.25 \\
& \gamma_{x y}=\frac{\partial u}{\partial y}+\frac{\partial v}{\partial x}=\beta_{3}+\beta_{5}=\frac{u_{3}-u_{1}}{b}-\frac{v_{2}-v_{1}}{a} \quad \text { Eq. } 2.26
\end{aligned}
$$

Este elemento triangular é chamado de constant strain triangle devido ao fato de nenhum dos três componentes de deformação variarem ao longo do elemento. $\mathrm{O}$ que mostra uma limitada aplicação deste tipo de elemento, que não consegue representar uma variação linear da deformação em uma condição de flexão pura. Em adição a isso, através das equações 2.20 e 2.21, pode-se observar que a condição deformada do elemento irá manter sempre as arestas retas. Essas características se dão pelo fato da função de interpolação $N i$ ser linear, o que define o elemento como de primeira ordem.

Para o caso apresentado na Figura 23, onde não há flexão, elementos de primeira ordem possibilitarão uma boa resposta para o modelo, porém, para casos onde faz-se necessária a representação de uma resposta linear da deformação, elementos de segunda ordem são mais indicados. Para que o elemento seja de segunda ordem, faz-se necessária a utilização de funções de interpolação parabólicas mantendo a definição de $N i$, ou seja, a utilização de nós intermediários às arestas.

$$
\begin{aligned}
& u=\beta_{1}+\beta_{2} x+\beta_{3} y+\beta_{4} x^{2}+\beta_{5} x y+\beta_{6} y^{2} \quad \text { Eq. } 2.27 \\
& v=\beta_{7}+\beta_{8}+\beta_{9} y+\beta_{10} x^{2}+\beta_{11} x y+\beta_{12} y^{2} \quad \text { Eq. } 2.28
\end{aligned}
$$

Utilizando o elemento triangular plano como exemplo, o número de nós passaria de três para seis e os graus de liberdade de seis para doze, como apresentado nas equações 2.27 e 2.28 . 


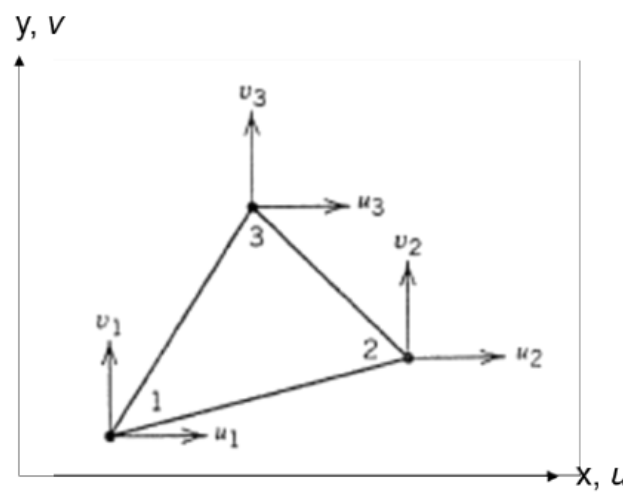

(a)

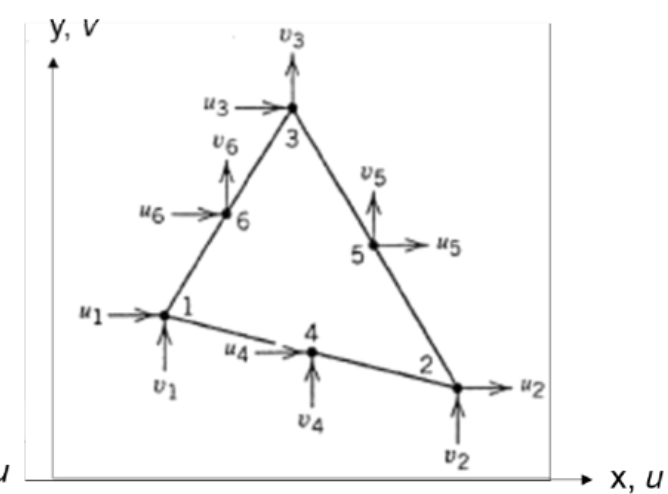

(b)

Figura 24: Elemento triangular plano: (a) para elemento de primeira ordem e (b) de segunda ordem.

Aplicando as mesmas equações $2.24,2.25$ e 2.26 no elemento de segunda ordem regido pelas equações 2.27 e 2.28 , observa-se que a resposta da deformação passa a ser linear ao longo do elemento, conhecido por linear strain triangle. Claramente é um elemento mais competente do que o triângulo de seis nós, porém, depende de um maior custo computacional para a solução das suas equações. Essa relação entre acurácia de solução e tempo computacional pode ser exemplificada pela Figura 25, onde é mostrada uma comparação de discretização do erro da solução numérica em relação a ordem do elemento selecionado.

Os elementos triangulares resumidos acima são utilizados para problemas de estados planos, no qual a variação de deformação ou tensão são desprezíveis na direção z, i.e. direção perpendicular ao plano de análise. Se os deslocamentos e tensões podem variar com as três coordenadas, a estrutura deve ser acessada por elementos sólidos 3D, chamados de problemas de estado sólido 3D. Uma chapa reta submetida a carregamentos in-plane são problemas de estado plano, porém, se são submetidas a carregamentos laterais e consequentemente à flexão, são chamados de problemas de placa e acessados por elementos de placa. Se a placa é curva, se transformam em problemas de casca. Os elementos de casca podem ser submetidos à carregamentos in-plane e laterais, além disso, deformações planas e de flexão normalmente aparecem simultaneamente. Portanto, existem elementos planos, sólidos, de placa, de casca, além de elementos especiais, como para fundações elásticas, ponta de trincas, tubulações curvas, dentre outros [41]. 
Equações como as equações 2.18 e 2.19 e as equações 2.27 e 2.28 constituem a base do MEF. Considerando a solução de um problema de análise de tensões, resta-se a base de manipulação para gerar a matriz de rigidez $\left(\mathrm{K}_{\mathrm{FEM}}\right)$ que descreve o comportamento do elemento, conectar os elementos para produzir o MEF, aplicar as condições de carregamento, impor as condições de contorno, resolver os resultados nodais através das equações gerais 2.20 e 2.21 e usar os resultados nodais para calcular as deformações e finalmente as tensões.

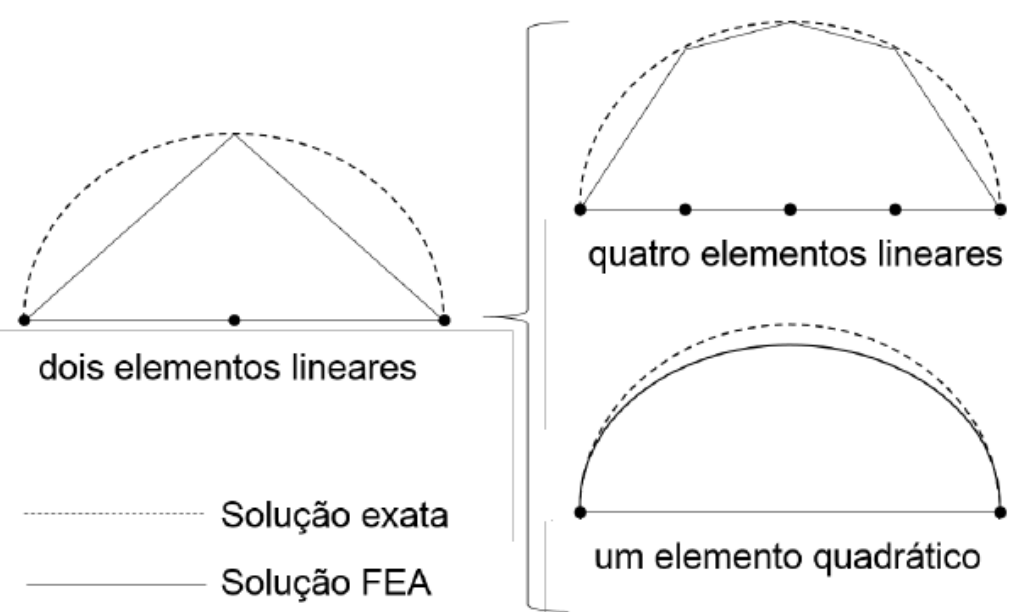

Figura 25: Comparativo de discritização de erro para três abordagens diferentes em relação à ordem do elemento.

\subsubsection{Elementos isoparamétricos}

Em alguns casos é necessária uma integração no interior do domínio do elemento. Essa integral típica, resultante da discretização por elementos finitos, tem a equação 2.29 .

$$
K_{e}=\int B^{T^{T}} D_{c} B^{\prime} d V \quad \text { Eq. } 2.29
$$

onde $\mathrm{B}^{\prime}$ é o operador diferencial aplicado às funções de interpolação $N_{i}, D_{\mathrm{c}}$ é a matriz constitutiva do material e $\mathrm{V}$ o volume de integração do elemento. Essa integral pode ser aplicada no domínio real do problema, porém, na prática, os elementos encontram-se distorcidos e/ou inclinados em relação aos eixos de coordenadas, como por exemplo elementos singulares aplicados na mecânica da 
fratura que serão discutidos mais a frente, o que torna complicado sistematizar o cálculo da integral. Este é o motivo pelo qual a utilização de elementos isoparamétricos se tornou padrão.

A ideia principal deste tipo de elemento é mapear a geometria em um sistema local de coordenadas naturais, onde as integrais podem ser facilmente efetuadas, analítica ou numericamente. Para isto, a solução aproximada e suas derivadas devem ser escritas em função dessas coordenadas naturais. O termo isoparamétrico (parâmetros iguais) vem do fato de que o mapeamento da geometria é feito através do uso dos mesmos parâmetros utilizados na interpolação da solução aproximada. Deve-se observar que, embora os parâmetros sejam os mesmos, não há nenhuma restrição quanto ao uso de interpolações diferentes para a geometria e para a aproximação da solução [43].

O mapeamento isoparamétrico consiste em mapear um elemento em um domínio regular de coordenadas naturais $\xi \eta$ onde o contorno do elemento é sempre definido por $\xi= \pm 1$ e $\eta= \pm 1$. O mapeamento é dado pelas funções polinomiais de interpolação idênticas às utilizadas na aproximação da solução, i.e. mesma parametrização para a geometria e parametrização. Tomando como exemplo um elemento 2D plano quadrilátero com deformação constante, Figura 26, a aproximação do campo de deslocamentos u escrito em termos das coordenadas naturais $\xi \eta$ é dada pela equação 2.30 .

$\hat{u}_{e}(\xi, \eta)=\sum_{i=1}^{4} N_{i}(\xi, \eta) u_{i} \quad$ Eq. 2.30

onde $N i(\xi, \mathrm{X})$ é a função de interpolação do nó $j$ nas coordenadas naturais do elemento.

A posição dos nós no sistema natural de coordenadas é dada pelas equações 2.31 e 2.32 .

$$
\begin{aligned}
& x(\xi, \eta)=\sum_{i=1}^{4} N_{i}(\xi, \eta) x_{i} \quad \text { Eq. } 2.31 \\
& y(\xi, \eta)=\sum_{i=1}^{4} N_{i}(\xi, \eta) y_{i} \quad \text { Eq. } 2.32
\end{aligned}
$$



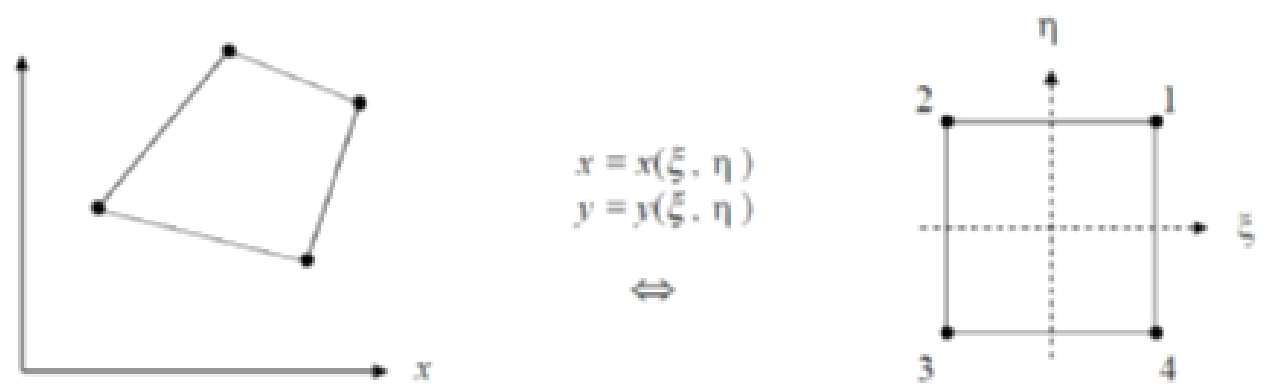

Figura 26: Elemento isoparamétrico de um elemento quadrilátero de primeira ordem [43].

O nome isoparamétrico deriva do uso da mesma função de interpolação para interpolar coordenadas e deslocamentos [41].

Com essa aproximação em termos das coordenadas naturais $\xi \eta$, a integral da equação 2.29 passa a ser a equação 2.33 .

$$
K_{e}=\int B^{\prime T}(\xi, \eta) D_{c} B(\xi, \eta) d V \quad \text { Eq. } 2.33
$$

Para a representação da matriz B em termos das coordenadas naturais, tornase necessária estabelecer uma relação entre os gradientes nos dois sistemas de coordenadas. Portanto, torna-se necessária a definição de uma matriz de transformação de coordenadas. Sabendo que para um elemento bidirecional:

$$
\begin{aligned}
& x=f_{1}(\xi, \eta) \\
& y=f_{2}(\xi, \eta)
\end{aligned}
$$

Aplicando a regra da cadeia, para uma função $f(x, y)$ pode-se escrever:

$$
\begin{aligned}
& \frac{\partial f(x, y)}{\partial \xi}=\frac{\partial f \partial x}{\partial x \partial \xi}+\frac{\partial f \partial y}{\partial y \partial \xi} \quad \text { Eq. } 2.34 \\
& \frac{\partial f(x, y)}{\partial \eta}=\frac{\partial f \partial x}{\partial x \partial \eta}+\frac{\partial f \partial y}{\partial y \partial \eta} \quad \text { Eq. } 2.35
\end{aligned}
$$


Matricialmente:

$$
\left[\begin{array}{c}
\frac{\partial}{\partial \xi} \\
\frac{\partial}{\partial \eta}
\end{array}\right]=\underbrace{\left[\begin{array}{ll}
\frac{\partial x}{\partial \xi} & \frac{\partial y}{\partial \xi} \\
\frac{\partial x}{\partial \eta} & \frac{\partial y}{\partial \eta}
\end{array}\right]}_{j b}\left[\begin{array}{c}
\frac{\partial}{\partial x} \\
\frac{\partial}{\partial y}
\end{array}\right]
$$

onde $\mathrm{J}^{\mathrm{b}}$ é chamada de matriz Jacobiana de transformação de coordenadas.

Consequentemente, as derivadas em relação à x e y de uma função $f(\xi, \eta)$ é dada por:

$$
\left[\begin{array}{c}
\frac{\partial}{\partial x} \\
\frac{\partial}{\partial y}
\end{array}\right]=J b^{-1}\left[\begin{array}{c}
\frac{\partial}{\partial \xi} \\
\frac{\partial}{\partial \eta}
\end{array}\right]
$$

onde a matriz Jacobiana é determinada pelas derivadas das equações $2.31 \mathrm{e}$ 2.32 .

Com isso, como já definida a matriz Jacobiana de transformação de coordenadas, aplicando a transformação do domínio $\mathrm{dV}=\mathrm{t} d \mathrm{dx} d \mathrm{y}=|\mathrm{Jb}| \mathrm{d} \xi \mathrm{d} \eta$, onde t representa a espessura do elemento, podemos reescrever a equação 2.29 , obtendo a equação 2.36 .

$$
K_{e}=\int B^{\prime^{T}} D_{c} B^{\prime} d V=\iint_{-1} B^{\prime^{T}}(\xi, \eta) D_{c} B^{\prime}(\xi, \eta) t|J b| d \xi d \eta \quad \text { Eq. } 2.36
$$

A aplicação do mapeamento isoparamétrico pode ser extrapolada para qualquer tipo de elemento, a diferença ficará acerca do número de linhas e colunas da matriz $\mathrm{B}^{\prime}$ que varia de acordo com o número de nós e seus graus de liberdade. A matriz Jacobiana continua dois por dois para elementos planos com mais nós, virando três por três para um caso 3D com elementos sólidos.

\subsubsection{Abordagem por elementos 3D sólidos}

Os elementos 3D sólidos, pela própria definição significa um sólido tridimensional não restrito à forma, condição de carregamento, propriedade mecânica e condições de contorno [44]. A sua generalidade permite a obtenção de 
um estado tri-axial de tensões expressos em seis componentes: três normais e três cisalhamentos. Diferente dos elementos de casca, os elementos sólidos possuem somente três graus de liberdade por nó: translação em x, y e z. O que cobre qualquer característica de deslocamento dentro do espaço devido à sua forma $\mathrm{e}$ possuem tipicamente duas formas: hexaédrica e tetraédrica. A Figura 27 apresenta um elemento sólido 3D de oito nós, com destaque para seu estado tridimensional de tensões e graus de liberdade por nó.

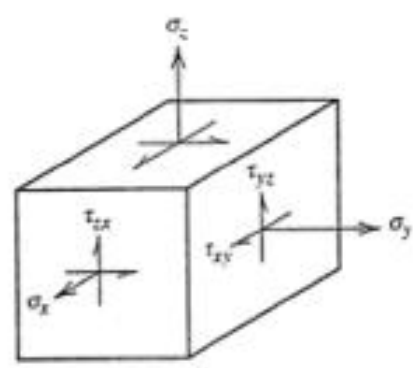

(a)

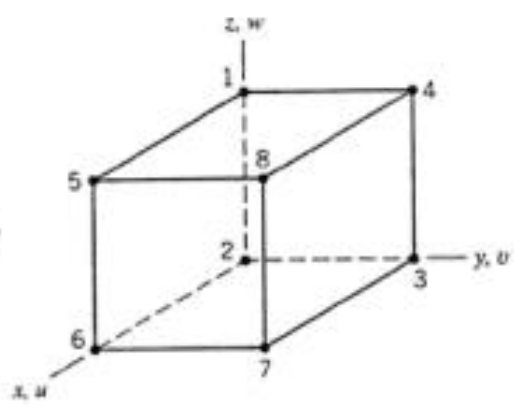

(b)

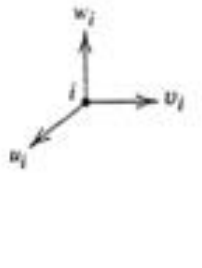

(c)

Figura 27: Elemento sólido 3D: Estado tridimensional de tensões (a). Contento 8 nós (b) e seus graus de liberdade por nó (b).

Os elementos sólidos 3D são uma extensão dos elementos planos. Esta extensão se dá na adição de um eixo de coordenadas e de um componente de deslocamento. Fazendo um paralelo ao campo de deslocamento do elemento triangular plano de primeira ordem, apresentado na Figura 23, a equação polinomial de elemento 3D sólido tetraédrico de primeira ordem, i.e. com comportamento de deformação constante (Figura 28a), pode ser expressa pelas equações 2.37, 2.38 e 2.39. Como pode ser observado, o elemento 3D sólido tetraédrico de primeira ordem possui um total de 12 graus de liberdade, o que significa um elemento de quatro nós com três graus de liberdade por nó.

$u=\beta_{1}+\beta_{2} x+\beta_{3} y+\beta_{4} z \quad$ Eq. 2.37

$v=\beta_{5}+\beta_{6} x+\beta_{7} y+\beta_{8} z \quad$ Eq. 2.38 
$w=\beta_{9}+\beta_{10} x+\beta_{11} y+\beta_{12} z \quad$ Eq. 2.39

O variante com comportamento de deformação linear (segunda ordem) de forma tetraédrica possui dez nós (Figura 28b), com um total de 30 graus de liberdade. O seu campo de deslocamento em termos de um sistema de coordenadas generalizado por ser expresso com a adição de seis modos quadráticos, $\mathrm{x}^{2}, \mathrm{y}^{2}, \mathrm{z}^{2}, \mathrm{xy}$, yz e zx em cada equação polinomial de deslocamento: u, v e w. Esse elemento pode representar campos de deformação pura com precisão.

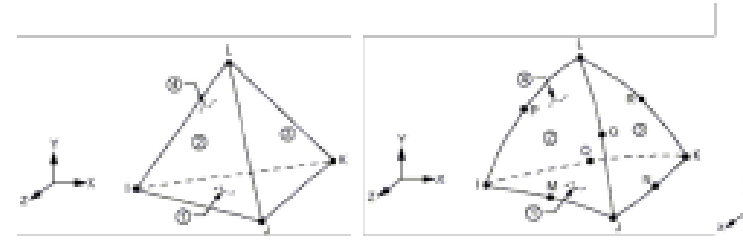

(a) (b)

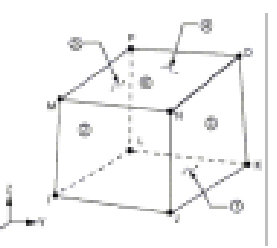

(c)

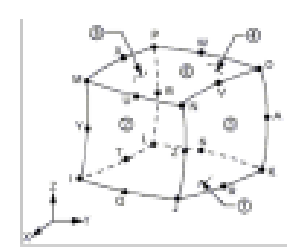

(d)

Figura 28: Elementos 3D sólidos: Tetraédrico de primeira ordem (a), tetraédrico de segunda ordem (b), hexaédrico de primeira ordem (c) e hexaédrico de segunda ordem (d) [45].

\subsubsection{Mecânica da fratura no Método dos Elementos Finitos}

Alheio à mecânica da fratura, existem diversos problemas no qual, em um determinado ponto do domínio, chamado de $\mathrm{P}$, a função da solução, chamada de $\mathrm{Fu}$, irá ter uma singularidade em sua primeira derivada. Se R é a distância radial medida a partir do ponto $\mathrm{P}$, a função de solução $\mathrm{Fu}$ poderá ser dependente de $\mathrm{R}^{\lambda}$, onde $\lambda$ pode de maneira geral ser complexo e a sua parte real menor que a unidade, assim, a primeira derivada de Fu tenderá ao infinito [46].

Agora, retornando para os conceitos da mecânica da fratura, os campos de tensões e deformações nas proximidades da ponta da trinca, permitem uma correlação da ordem $r^{\lambda}$, onde $\lambda$ é sempre menor que a unidade e dependente do comportamento do material: $\sigma_{i \mathrm{j}} \propto r^{-1 / \mathrm{n}+1} \mathrm{e} \xi_{i j} \propto r^{-\mathrm{n} / \mathrm{n}+1}$. Do ponto de vista da MFLE, onde $\mathrm{n}=1$, o campo de tensões e deformações ficam proporcionais à $1 / \sqrt{ } r$, enquanto que na Mecânica da Fratura Elasto-Plástica ficam dependente do parâmetro $\mathrm{n}$ do material sempre maior que a unidade, ambas indicando uma 
tendência ao infinito quando $r \rightarrow 0$, mostrando que a mecânica da fratura é uma área onde a singularidade assume um papel dominante. Sendo assim, sabendo que o grande interesse se concentra em analisar a segurança de operação em estruturas trincadas, fica evidente a necessidade de uma correta representação do campo de tensões e deformações na ponta da trinca, mostrando a necessidade de métodos especiais para o tratamento de problemas com singularidades no Método dos Elementos Finitos.

O desenvolvimento de elementos especiais, chamados de elementos singulares, para contemplar uma determinada precisão no cálculo do campo de tensões e deformações foi proposta por BARSOUM [47]. Estes elementos foram criados incorporando uma singularidade do tipo $r^{-1 / 2}$ para o cálculo do fator de intensidade de tensões para a Mecânica da Fratura Elasto-plástica. A singularidade dessa ordem no estado de deformações foi imposta na matriz Jacobiana de transformações de coordenadas, através do colapso de elementos de segunda ordem, onde o nó intermediário foi modificado para $1 / 4$ da sua posição, mais próximo à ponta da trinca (Figura 31 e Figura 32). Segundo o autor, a aplicação destes elementos para trincas com contornos simétricos, submetidas a carregamentos mecânicos ou térmicos e para trincas tri-dimensionais, mostraram um alto grau de convergência com as soluções analíticas.

Destaca-se que na ponta da trinca, em problemas bidimensionais, os elementos de quatro lados são frequentemente alterados para triângulos, conforme mostrado na Figura 29. Observe que os nós 1, 2 e 3 ocupam o mesmo ponto no espaço. Na Figura 30 apresenta-se uma situação análoga para problemas tridimensionais, na qual o elemento tridimensional tipo bloco é alterado para uma cunha.

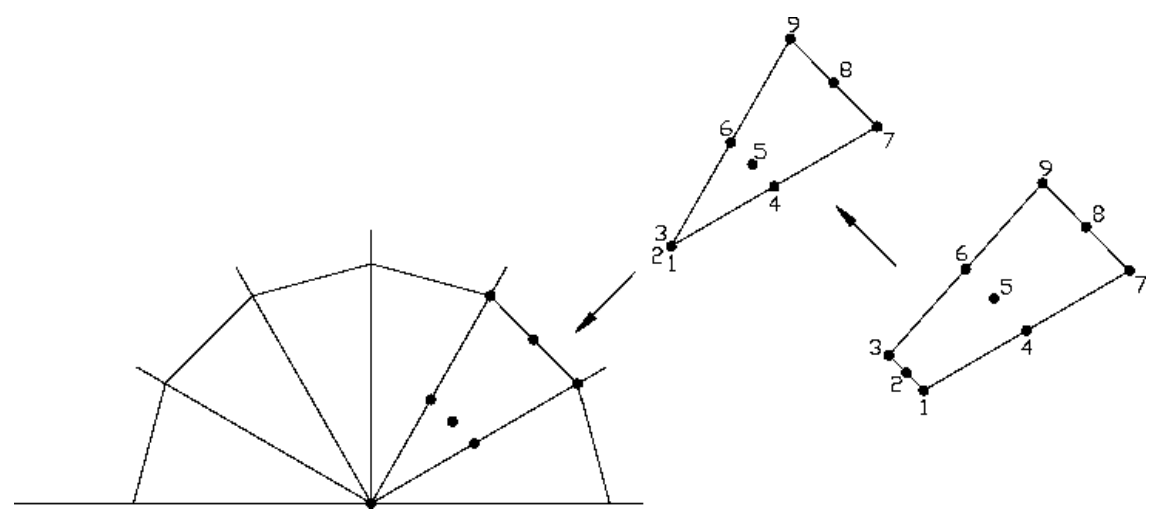

Figura 29: Alteração de um elemento quadrilátero em um elemento triangular na ponta da trinca 


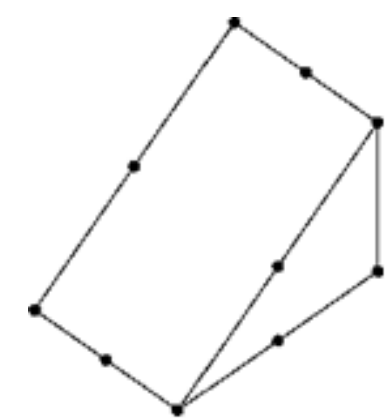

Figura 30: Transformação de um elemento tipo bloco em uma cunha

Segundo BROCKS et. al. [48], se os elementos ao redor da ponta da trinca não possuírem os nós intermediários transladados para $1 / 4 \mathrm{e}$ as posições dos nós da ponta não estiverem restritos a terem o mesmo deslocamento, uma singularidade do tipo $r^{-1}$ é obtida no campo de deformações do elemento, o que representaria o comportamento de um material elástico perfeitamente plástico (n 》1). Estudos numéricos mostraram, em destaque MCMEEKING et. al. [49] e BROCKS et. al. [50], que elementos triangulares ou prismáticos de oito e 20 nós com uma singularidade no campo de deformações na ordem de $r^{-1}$ em conjunto com mudança na formulação para contemplar não-linearidades geométricas, apresentaram bons resultados para problemas elasto-plásticos.

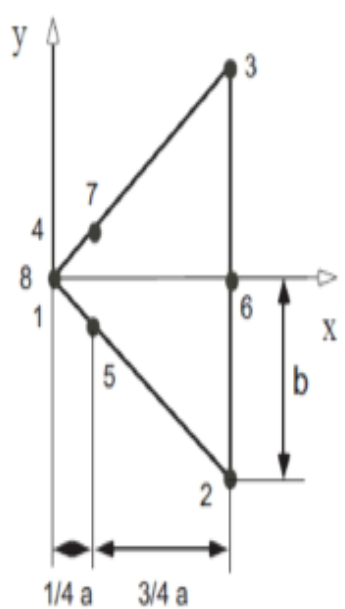

(a)

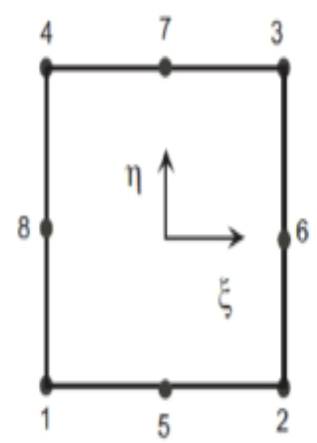

(b)

Figura 31: Elemento singular 8-nós quadrático isoparamétrico plano (a) e elemento isoparamétrico de origem (b) [51]. 


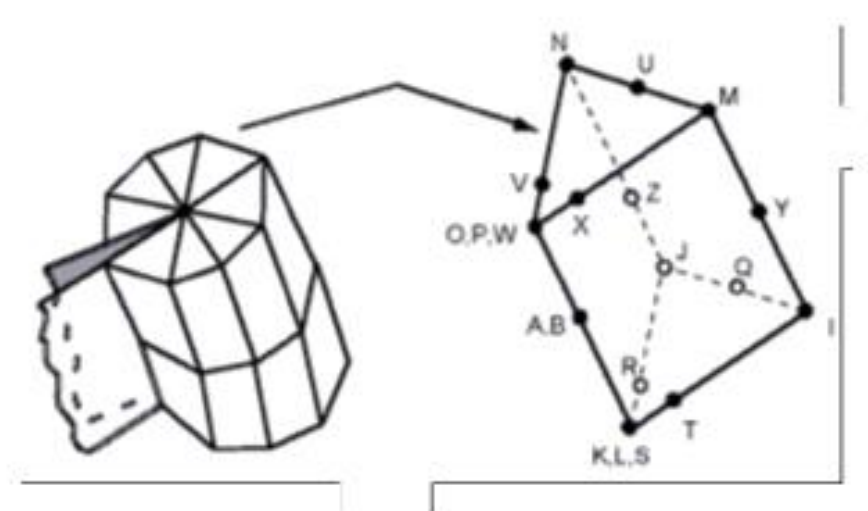

Figura 32: Elemento singular prismático de 20-nós sólido [45].

O presente trabalho aborda apenas a situação de uma trinca estacionária estática e elástica, não sujeita a deformações plásticas.

Em muitos problemas, o desenho de uma malha eficiente para a região na ponta da trinca tem provado ser a configuração da teia de aranha, que consiste em circunferências concêntricas que são direcionadas para a ponta da trinca (Anderson, 1995). Os elementos da circunferência interna são modificados para elementos triangulares, conforme mostrado na Figura 33. A região da ponta da trinca apresenta concentrações de tensão e deformação, desta forma, a malha deve ser mais refinada. O desenho da teia de aranha propicia uma transição suave da malha fina na ponta da trinca até uma malha mais grossa distante da ponta da trinca.

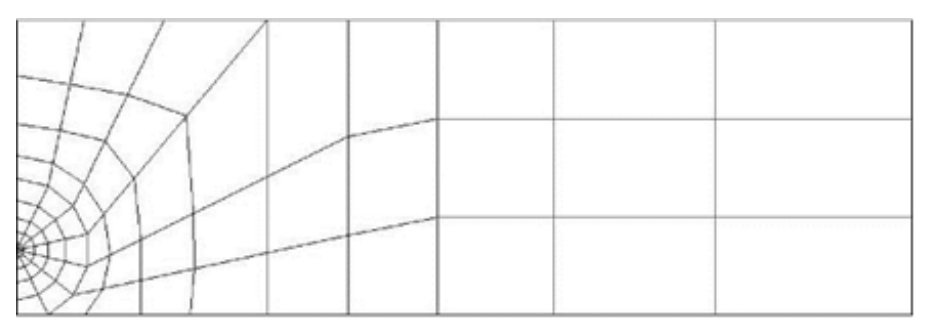

Figura 33: Modelo semi-simétrico de uma trinca plana

\subsection{Norma BS: 7910 (antiga PD11:6493) [52]}

Em 1968, Harrison \& Burdekin defendiam que, àquela época, já haveria informação suficiente para se elaborar um documento técnico capaz de considerar defeitos encontrados em soldas de acordo com a abordagem fitness-for-purpose. A partir do início dos anos 1970 a British Standard Institute iniciou as atividades de 
um comitê cujo objetivo era elaborar um procedimento técnico que permitisse avaliar imperfeições de solda, e substituísse os critérios arbitrários e empíricos de muitos códigos de projeto e de fabricação utilizados até então. A primeira edição do procedimento técnico PD:6493 foi lançada em 1980, e considerava a avaliação de defeitos em relação a ocorrência de fratura frágil e fadiga, baseada em valores de tenacidade expressos em parâmetros $\mathrm{K}_{\mathrm{i}}$ e CTOD. A falha por colapso plástico do ligamento remanescente de uma estrutura contendo defeito era tratada de forma bastante sucinta, e totalmente desacoplada do modo de falha por fratura frágil. Apesar destas limitações, a publicação da PD:6493 foi um marco porque, a partir dela, estabeleceu-se uma estrutura de avaliação técnica que facilita as relações entre fabricantes, construtores e agências de certificação, permitindo avaliar imperfeições estruturais durante a fabricação e operação do equipamento.

Em 1991 foi lançada a segunda edição do procedimento PD:6493. Neste documento foram incorporadas diversas alterações em relação a versão original, principalmente a metodologia FAD introduzida pelo procedimento R6. A vantagem desta nova edição da PD:6493 é que os dois modos de falha (frágil e dúctil) são tratados explicitamente de forma conjugada através da metodologia FAD.

Mais dez anos, e em 2001 o procedimento PD:6493 alcançou o status de norma técnica e foi publicado como norma BS:7910. Sua estrutura geral está organizada em função dos modos de falha de materiais, em seções referentes a fratura, a fadiga, aos danos por fluência e, finalmente, uma sessão geral referente a falhas por corrosão, flambagem, erosão e colapso plástico.

A BS-7910 destina-se à avaliação de equipamentos construídos a partir de diferentes códigos e materiais, fornecendo metodologias para avaliação de descontinuidades para todos os tipos de estruturas e componentes. A BS-7910 compreende 10 seções e 21 anexos conforme Tabela 11. 
Tabela 11: Seções do documento BS-7910 [52]

\begin{tabular}{|c|c|}
\hline Seções & Descrição \\
\hline 1 & Escopo \\
\hline 2 & Referências normativas \\
\hline 3 & Símbolos e definições \\
\hline 4 & Tipo de descontinuidade \\
\hline 5 & Modos de falha e mecanismos de danos \\
\hline 6 & Informações requeridas para avaliação \\
\hline 7 & Avaliação de resistência a fratura \\
\hline 8 & Avaliação de fadiga \\
\hline 9 & Avaliação de descontinuidades sob a condição de fluência \\
\hline 10 & Avaliação de outros modos de falha \\
\hline Anexos & Descrição \\
\hline A & $\begin{array}{l}\text { Avaliação em condição de tensões normal e de cisalhamento combinadas ou } \\
\text { modos de carregamento I, II e III combinados }\end{array}$ \\
\hline $\mathbf{B}$ & $\begin{array}{l}\text { Procedimentos de avaliação em juntas soldadas em estruturas tubulares } \\
\text { offshore }\end{array}$ \\
\hline $\mathbf{C}$ & Procedimentos para avaliação de fratura para vasos de pressão e dutos \\
\hline $\mathbf{D}$ & Tensões devido ao desalinhamento \\
\hline $\mathbf{E}$ & Re-categorização de descontinuidades \\
\hline$\overline{\mathbf{F}}$ & Um procedimento para avaliação "leak-before-break" \\
\hline G & Avaliação de corrosão em dutos e vasos de pressão \\
\hline $\mathbf{H}$ & Registro das avaliações de fratura, fadiga e fluência \\
\hline I & $\begin{array}{l}\text { A significância de soldas de resistências dissimilares sobre a tenacidade a } \\
\text { fratura de juntas soldadas }\end{array}$ \\
\hline $\mathbf{J}$ & Uso do teste de impacto Charpy-V para estimar a tenacidade a fratura \\
\hline K & $\begin{array}{l}\text { Confiabilidade, fatores de segurança parciais, } n^{\circ} \text { de ensaios e fatores de } \\
\text { reserva }\end{array}$ \\
\hline $\mathbf{L}$ & Determinação da tenacidade a fratura para soldas \\
\hline $\mathbf{M}$ & Soluções para fatores de intensidade de tensão \\
\hline $\mathbf{N}$ & $\begin{array}{l}\text { Procedimentos simplificados para definição de critérios de aceitação para } \\
\text { descontinuidades conhecidas ou para estimativa do tamanho aceitável da } \\
\text { descontinuidade pelo nível } 1\end{array}$ \\
\hline 0 & Considerações sobre teste de pressão e "warm prestressing" \\
\hline $\mathbf{P}$ & Calculo da tensão de referencia \\
\hline $\mathbf{Q}$ & Distribuições de tensão residual em juntas soldadas \\
\hline $\mathbf{R}$ & $\begin{array}{l}\text { Determinação dos efeitos da interação de plasticidade para tensões primaria } \\
\text { e secundaria combinadas }\end{array}$ \\
\hline $\mathbf{S}$ & Métodos de integração numérica para estimativa de vida a fadiga \\
\hline $\mathbf{T}$ & Informações para avaliação de propagação de trincas a alta temperatura \\
\hline $\mathbf{U}$ & $\begin{array}{l}\text { Exemplo para demonstração do procedimento de avaliação de falha a alta } \\
\text { temperatura }\end{array}$ \\
\hline
\end{tabular}

As seções de 7 a 10 contêm os procedimentos de avaliação por tipo de defeito ou mecanismo de dano. Os anexos contêm procedimentos normativos e informativos, dados atualizados, que são utilizados nos procedimentos de avaliação das seções de 7 a 10.

Os tipos de descontinuidades que podem ser avaliadas por estes documentos são:

Descontinuidades planares;

Descontinuidades volumétricas;

Imperfeições de forma; 
Os modos de falha considerados são:

Falha por fratura e colapso plástico (Seção 7)

Danos por fadiga (Seção 8);

Danos por fluência e fluência-fadiga (Seção 9);

Danos por vazamento de contaminantes (Seção 10.2);

Danos por erosão/corrosão (Seção 10.3.2);

Danos por trincamento assistido pelo meio (Seção 10.3.3);

Falha por instabilidade (Seção 10.4);

Os dados relevantes que podem ser requeridos na avaliação estão listados abaixo:

Natureza, posição e orientação da descontinuidade;

Geometria da estrutura, da solda e o procedimento de fabricação;

Tensões (devido à pressão do fluido, tensões térmicas, residuais), temperaturas e transientes;

Propriedades mecânicas do material;

Dados de fadiga, corrosão-fadiga e dados sobre a propagação de trinca;

Dados de tenacidade a fratura do material;

Dados sobre fluência;

Dados sobre corrosão-sob-tensão;

Informações requeridas dos ensaios não destrutivos - END:

Comprimento da descontinuidade;

Profundidade da descontinuidade;

Posição da descontinuidade;

Orientação da descontinuidade em relação as tensões principais;

Se a descontinuidade for planar ou volumétrica;

A seção de análise de fratura está subdividida em três níveis, separados em função da quantidade de informação envolvida e do grau de complexidade das análises. O primeiro nível de avaliação da BS7910 (Simplified Assessment) 
permanece inalterado em relação as versões anteriores da PD:6493, e é o nível de análise mais conservativo. Este nível incorpora a metodologia FAD e apresenta um diagrama em função de $\mathrm{K}_{\mathrm{r}}$, razão entre o fator de intensificação de tensões aplicado e a tenacidade do material, e $\mathrm{Sr}$, razão entre a tensão aplicada e a tensão de referência do material.

O nível 2 de análise (Normal Assessment) é utilizado quando se conhece os dados de tenacidade do material $\left(\mathrm{K}_{\mathrm{ip}}, \mathrm{J}_{\mathrm{ig}}, \delta_{\mathrm{mat}}\right)$. Este nível apresenta duas vertentes (2A e 2B), dependendo de se ter disponível a curva tensão-deformação completa do material da estrutura. $\mathrm{O}$ nível $2 \mathrm{~B}$ permite aumentar a área de região segura no diagrama FAD, porque considera o efeito de patamar de carga no escoamento descontinuo em aços-carbono estruturais e, consequentemente, assume maior ductilidade do material e maior deformação plástica anterior a falha (Figura 36). Para materiais com escoamento contínuo, que não apresentem patamar na região do limite de escoamento, a curva no diagrama FAD é semelhante àquela utilizada para a avaliação em nível 3.

O nível 3 de análise considera a instabilidade devida ao rasgamento dúctil e permanece inalterado desde a versão da PD:6493 de 1991, com vertentes 3A e 3B semelhantes ao nível 2 , em virtude de se ter ou não a curva completa de tensão-deformação do material da estrutura. Este nível de análise é totalmente baseado em analises numéricas pelo método de elementos finitos, e fornece a avaliação menos conservadora.

Finalmente, a norma BS7910 incorpora 21 anexos, que incluem procedimentos para diversas etapas do processo de avaliação. Um destes procedimentos refere-se a categorização de trincas, que é uma etapa extremamente importante em procedimentos de fitness-for-purpose porque permite transformar uma configuração real de trincas, detectada fisicamente na estrutura, em uma configuração geométrica idealizada tratável analiticamente. A norma inglesa incorpora ainda anexos referentes a considerações sobre carregamentos multiaxiais, fatores de segurança nas análises, soluções analíticas para distribuição de tensões em corpos trincados, equações e ábacos para correlação entre tenacidade a fratura e energia de impacto Charpy para diversos materiais, entre outros.

Abaixo é apresentado um passo-a-passo para aplicação do procedimento para avaliação de trincas nível 1. Este passo-a-passo é apenas um resumo de parte do conteúdo da Seção 7 da BS-7910 e maiores informações deverão ser consultadas 
naquele documento.

PASSO 1- Definir as tensões atuantes

Determinar a distribuição de tensões no local da trinca devido aos carregamentos e classificar as tensões resultantes dentro das seguintes categorias:

Tensões primárias;

Tensões secundárias;

Tensões residuais;

A distribuição de tensão é determinada supondo a estrutura sem a presença de trinca. A distribuição de tensão real poderá ser utilizada na avaliação. Contudo, a linearização dessa distribuição torna-se mais conveniente para a avaliação. Para mais detalhes sobre linearização de tensões, vide figura 1 na Seção 6 da BS-7910.

PASSO 2 - Determinar ou estimar a tenacidade a fratura do material

A tenacidade a fratura, $K_{\text {mat }}$ ou $\delta_{\text {mat }}$, poderá ser determinada a partir de ensaios conforme exigências constantes no parágrafo 7.1.5 da BS-7910 ou conforme o Anexo L da mesma para a determinação da tenacidade a fratura para soldas.

Caso a medida da tenacidade a partir de ensaios não seja uma possibilidade, então pode-se estimar $K_{\text {mat }}$ a partir de dados do teste de impacto Charpy- $\mathrm{V}$, conforme o Anexo J da BS-7910:2005.

PASSO 3 - Determinar as propriedades do ensaio de tração do material

As propriedades mecânicas do material requerida na avaliação são:

$\sigma_{\mathrm{y}}$ : tensão limite de escoamento mínima;

$\sigma_{\mathrm{u}}$ : tensão limite de resistência;

E: módulo de elasticidade; 
PASSO 4 - Caracterização da trinca

Uma trinca deve ser caracterizada por um comprimento e uma altura (ou profundidade no caso de trincas superficiais) que são as medidas dos lados de um retângulo imaginário que envolve completamente a trinca. A depender da posição da trinca, suas dimensões são caracterizadas conforme a Figura 34.
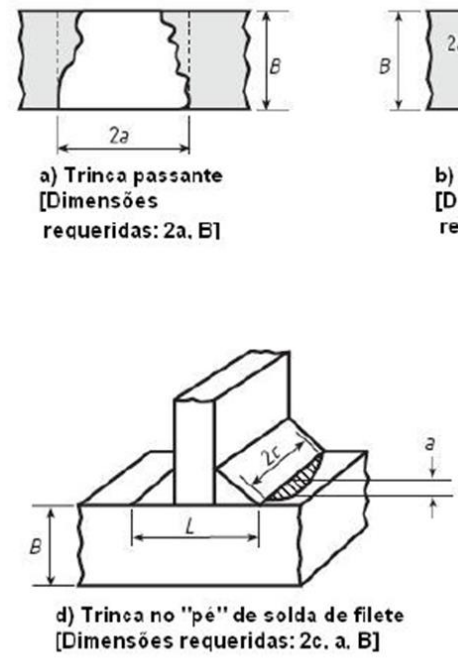

Figura 34: Caracterização das trincas [52].

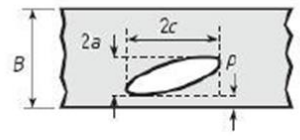

b) Trinca interna [Dimensôes requeridas: 2c, p, 2a, B]

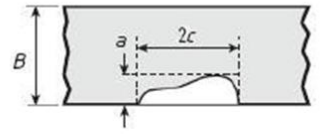

c) Trinca superficial [Dimensôes requeridas: $a, 2 c, B]$

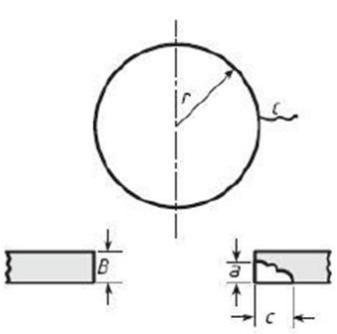

e) Trinca em orificios [Dimensöes requeridas: $c, a, B$ ]

Quando várias trincas estão presentes em uma mesma seção transversal, a possibilidade de interação entre as mesmas pode causar, contra a integridade estrutural, efeitos mais severos que a soma dos efeitos causados por cada uma em separado. A figura 9 na Seção 7 da BS-7910:2005 estabelece os critérios de interação de trincas e suas dimensões efetivas após interação quando múltiplas trincas estão presentes em uma mesma seção do material.

PASSO 5 - Escolher a metodologia de avaliação

Dentro do nível 1 da BS-7910, escolher entre os níveis 1A e 1B para avaliação da trinca. Se o nível 1A for o escolhido, então continuar a sequência de passos abaixo. Se for escolhido o nível 1B, que trata de um procedimento simplificado sem o uso do FAD e que define uma dimensão limite para a trinca, então utiliza o Anexo N da BS-7910:2005. 
PASSO 6 - Cálculo da tensão máxima

Calcular a máxima tensão trativa, $\sigma_{\text {máx }}$ que é dada como a soma dos componentes das tensões. Este valor irá depender se a tensão nominal de membrana e (ou) flexão forem conhecidos. Os valores de concentração de tensão devido as tensões de membrana, concentração de tensão devido as tensões de flexão e fator de concentração de tensão devido ao desalinhamento podem ser obtidos no anexo D da BS-7910:2005.

As variações dos componentes das tensões na seção transversal não são levadas em consideração levando a uma estimativa conservativa para a tensão total aplicada.

PASSO 7 - Cálculo das tensões residuais

a) Para estruturas soldadas sem Tratamento Térmico Alívio de Tensões:

Para trincas situadas num plano transversal a solda: a tensão residual uniforme é determinada pela tensão de escoamento do material na temperatura ambiente onde a trinca estiver localizada.

Para trinca situada num plano paralelo a solda: a tensão residual deverá ser igual ao valor da tensão de escoamento a temperatura ambiente da solda ou do metal base, o que for menor.

b) Para estruturas soldadas submetidas a Tratamento Térmico Alívio de Tensões

Se o valor da tensão residual não for conhecido, então pode-se estimar, para aços ao manganês e aços baixa liga tratados termicamente em forno na faixa de temperatura entre $580{ }^{\circ} \mathrm{C}$ a $620{ }^{\circ} \mathrm{C}$, como sendo $30 \%$ da tensão de escoamento do material na temperatura ambiente onde a trinca estiver localizada.

Para a tensão transversal a solda, a tensão residual deverá ser assumida como sendo igual a $20 \%$ da tensão de escoamento da solda ou do metal base, o que for 
menor.

Tratamentos Térmicos Alívio de Tensões localizados e não controlados podem induzir altos níveis de tensão residual na estrututura; neste caso deve-se assumir valores de tensão residual na condição sem Tratamento Térmico Alívio de Tensões após a solda.

Teste de pressão ou outra forma de carregamento mecânico podem reduzir os níveis de tensão residual da estrutura (ver Anexo O da BS-7910).

PASSO 8 - Calcular $\mathrm{K}_{\mathrm{I}}$

Calcular o fator de intensidade de tensão aplicado. Os fatores de correção para curvatura (bulging factor), fator de correção para largura finita do componente e fator geométrico para as tensões de membrana são obtidos a partir do Anexo $\mathrm{M}$ da BS-7910:2005, em função da geometria considerada e do tipo de descontinuidade.

Se a informação de tenacidade a fratura do material não estiver disponível, então uma estimativa desta poderá ser realizada a partir de dados de ensaio de impacto Charpy-V (ver Anexo J da BS-7910:2005).

PASSO 9 - Calcular $\mathrm{K}_{\mathrm{r}}$

$\mathrm{K}_{\mathrm{r}}$ é a razão entre o fator de intensidade de tensões aplicado, $\mathrm{K}_{1}$, e a tenacidade fratura do material, $\mathrm{K}_{\mathrm{mat}}$.

PASSO 10 - Calcular o fator de intensidade de tenções aplicado $\left(\delta_{\mathrm{I}}\right)$

O CTOD aplicado, $\delta_{\mathrm{I}}$, é determinado a partir de $\mathrm{K}_{\mathrm{I}}$.

PASSO 11 - Calcular

O coeficiente $\delta_{\mathrm{r}}$ é a razão entre $\delta_{I}$ e a tenacidade a fratura do material, $\delta_{\text {mat }}$.

PASSO 12 - Calcular a razão de colapso plástico $\left(\mathrm{S}_{\mathrm{r}}\right)$

A razão de colapso plástico, $\mathrm{S}_{\mathrm{r}}$, é calculada a partir da tensão de referência 
calculada a partir de formulas do ANEXO P da BS-7910:2005 e o valor assumido como a média aritmética entre a tensão de escoamento e o limite de resistência do material até um máximo de $1,2 \sigma_{\mathrm{y}}$.

\section{PASSO 13 - Plotar o FAD}

A Figura 35 mostra o FAD genérico utilizado pelo nível 1A da BS-7910. Plotar

sobre esse diagrama um ponto cujas coordenadas são os valores $K_{r}$ e $S_{r}$ obtidos nos PASSOS 10, 11 e 12 respectivamente.

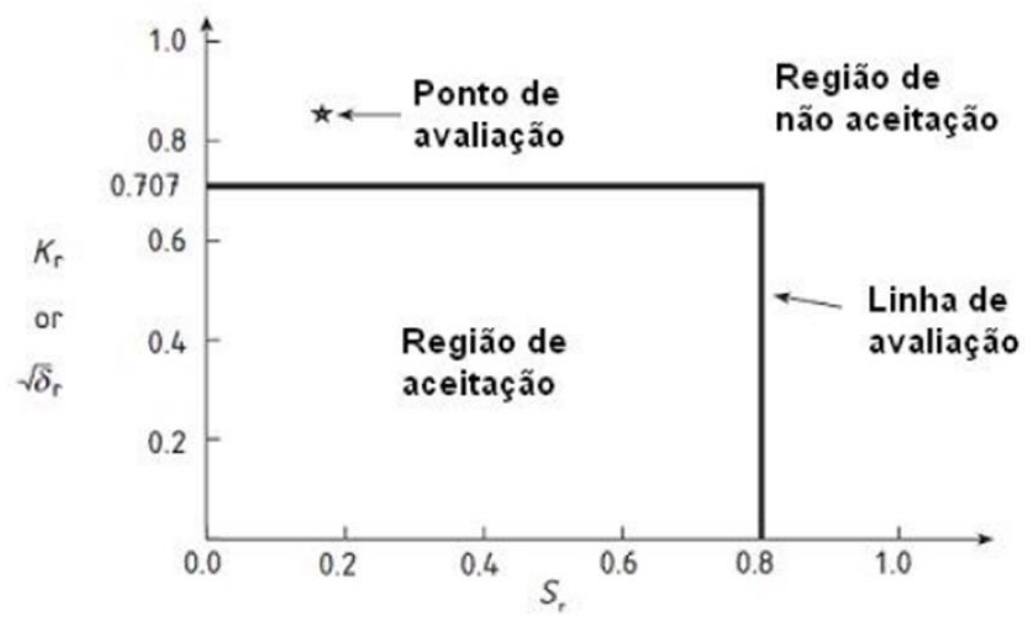

Figura 35: FAD - nivel 1A [52].

Se o ponto, plotado no diagrama, situar-se no interior do retângulo delimitado pelos eixos coordenados e as linhas de avaliação, então a trinca é aceitável pelo nível 1 desta norma.

Se o ponto localizar-se fora do retângulo ou, se o ponto localizar-se sobre uma das linhas do FAD então a trinca em avaliação não é aceitável. Neste caso, uma das seguintes ações, ou combinação delas, devem ser avaliadas:

Os dados utilizados na análise devem ser refinados e a avaliação de nível 1 deve ser repetida, isto é, pode se refinar a análise das tensões atuantes e/ou pode-se 
recaracterizar a(s) trinca(s) em análise.

Realizar avaliação pelos níveis 2 ou 3 .

Reparar ou substituir o componente trincado.

O nível 1 da BS-7910 não requer a aplicação de fatores de segurança adicionais já que no próprio $F A D$ está embutido um fator de segurança (aproximadamente igual a 2 para o tamanho de trinca). Contudo, as piores estimativas, isto é, os valores das variáveis de entrada nas condições mais críticas, deverão ser adotados neste nível.

As avaliações nos níveis 2 e 3 são semelhantes e um exemplo de um gráfico FAD no nível 2 é mostrado na Figura 36.

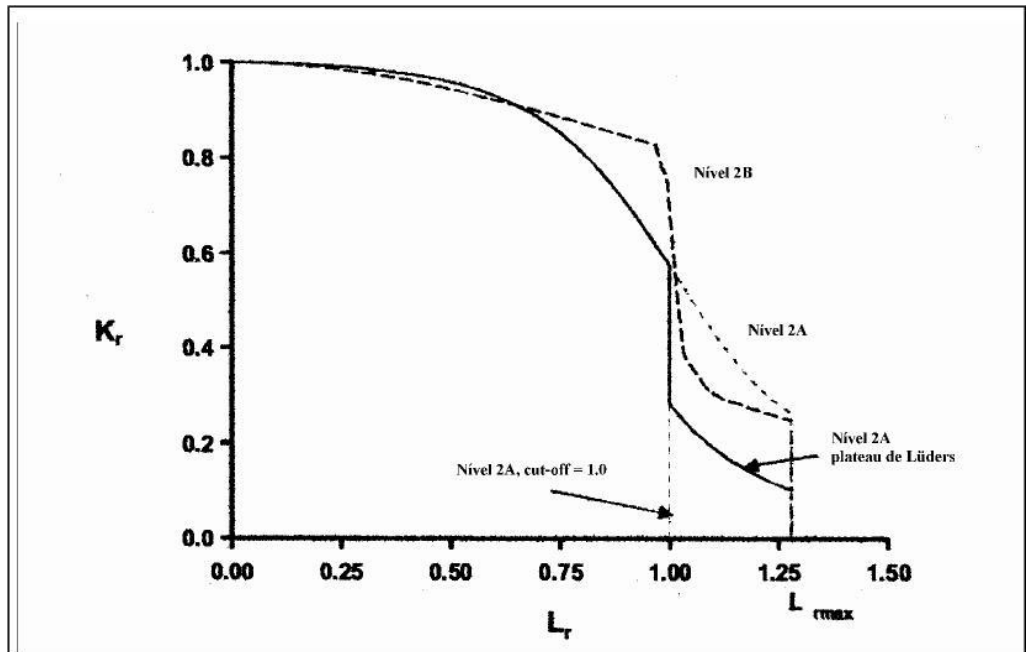

Figura 36: Diagrama FAD utilizado na BS:7910, incorporando a influência do escoamento descontínuo na ductilidade do material [52]. 


\section{MATERIAIS E MÉTODOS}

Neste capítulo estão descritos os componentes mecânicos, seus materiais e as duas metodologias (analítica e numérica) que foram utilizadas para avaliar a integridade de um conector de topo de um tubo flexível de injeção de gás com aço 9\% Ni atendendo aos critérios severizados de presença de trincas e inclusões da norma API 6A. O método utilizado está mostrado simplificadamente na Figura 37.

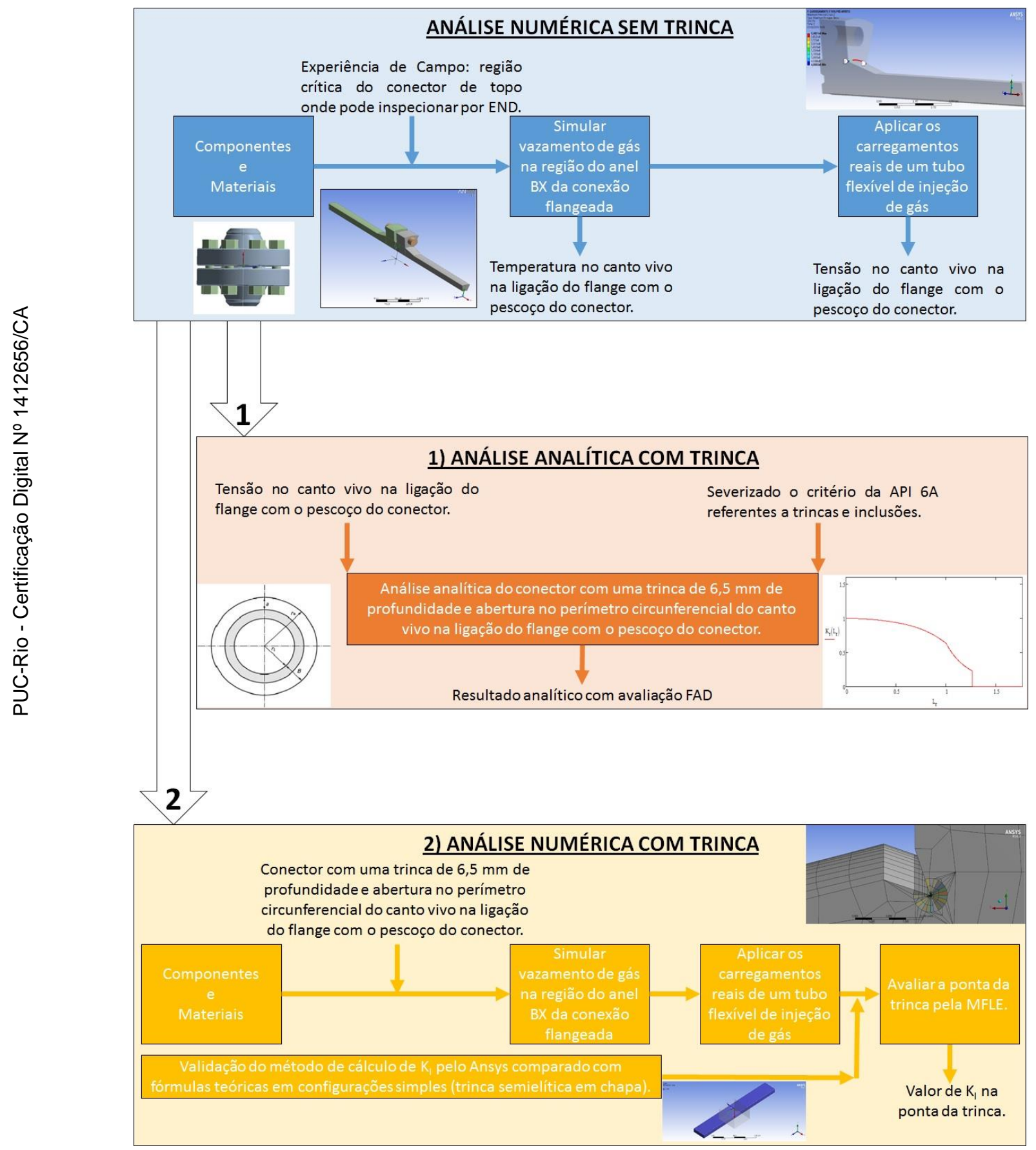

Figura 37: Esquema simplificado da metodologia usado na pesquisa. 


\subsection{Componentes}

Os componentes usados são estojos e porcas, anel BX e o flange 7 1/16" API 6BX 10.000 psi (Figura 38). A geometria deste seguiu a norma API 6A [53]. A norma de referência e os componentes são os mesmos usados no projeto das linhas flexíveis para injeção de gás nos reservatórios brasileiros. Para este flange com esta classe de pressão, são considerados 12 furos distribuídos a cada $30^{\circ}$ de modo que os mesmos 12 conjuntos de porcas e parafusos possam fazer a conexão entre dois flanges. $\mathrm{O}$ anel $\mathrm{BX}$ é posicionado no canal conhecido na indústria como groove e tem a finalidade de selagem entre as conexões.
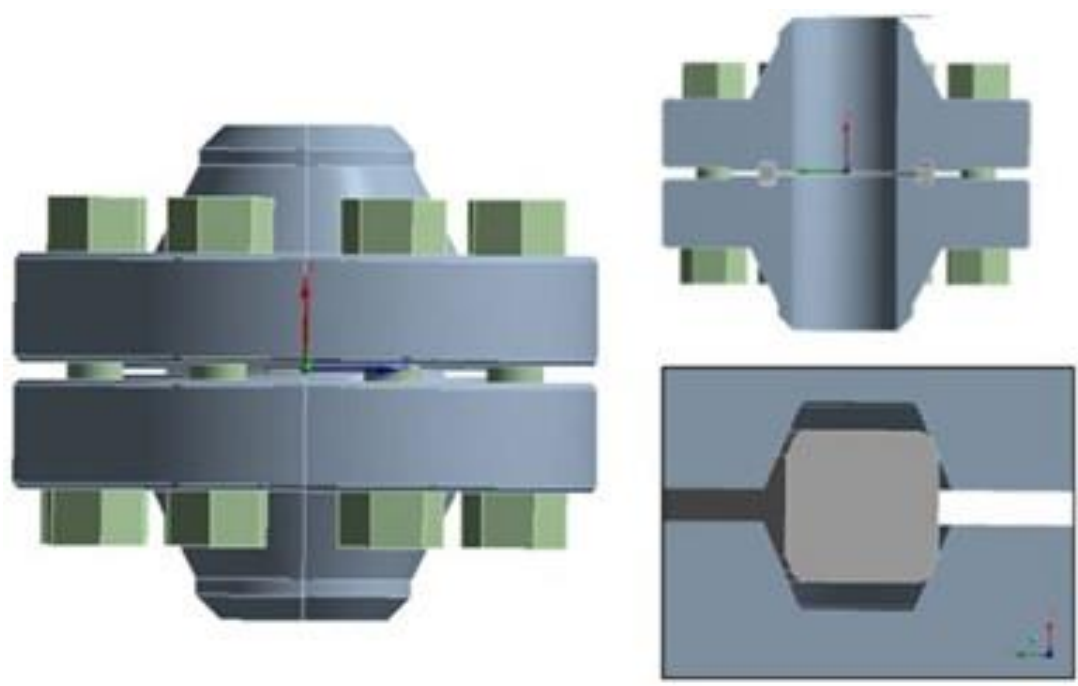

Figura 38: Esquema do flange 7 1/16" API 6BX 10.000 psi, anel BX e estojos e porcas

Na Figura 39 é demonstrada uma das 12 seções (a cada $30^{\circ}$ ) deste equipamento. Esta divisão de 12 seções se deu pelo fato da norma API 6A definir 12 conjuntos de estojos e porcas distribuído igualmente para este tipo de flange. Foi usado este método de simplificação geométrica de modo que as análises fossem mais rápidas. Esta simplificação, muito usada no ambiente acadêmico e industrial, não interfere nos dados obtidos. 


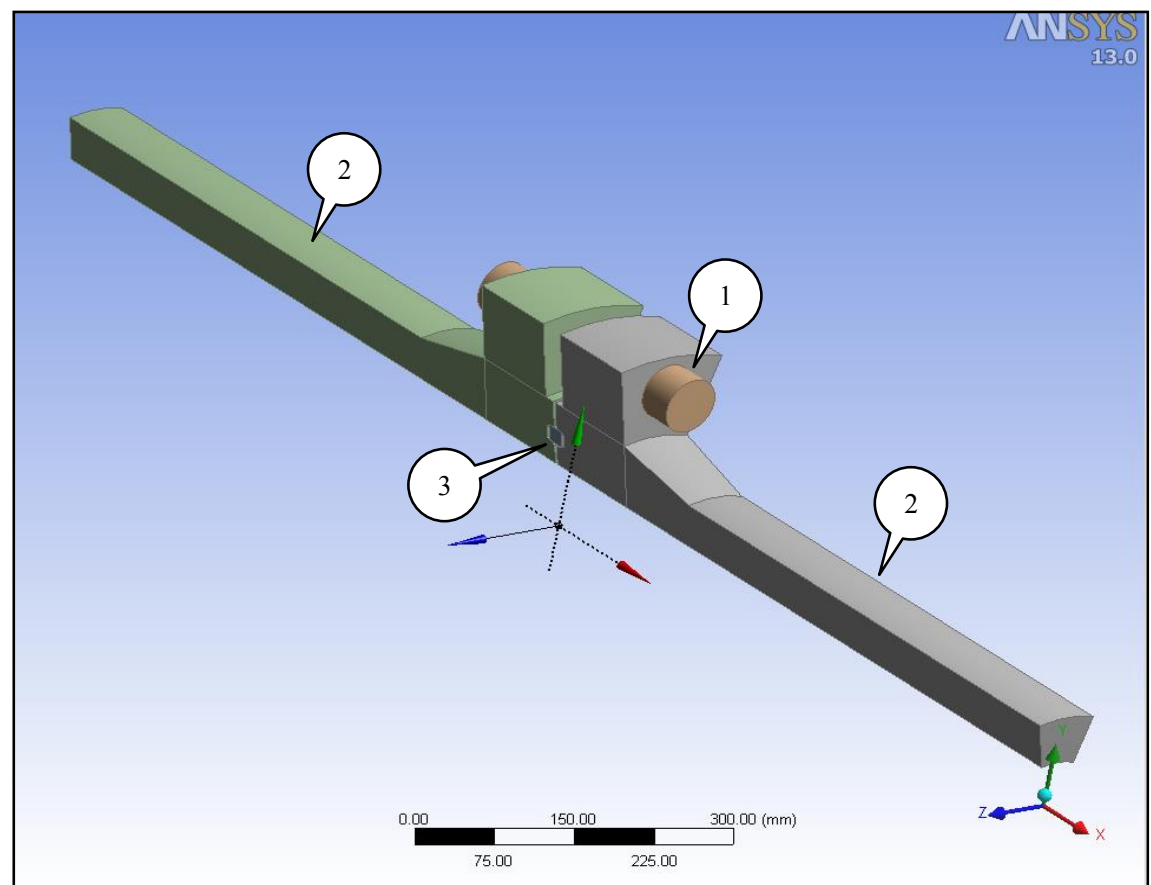

Figura 39: 1/12 da conexão flangeada de uma terminação de topo de um duto flexível de uma linha de injeção de gás, onde 1 é o estojo e porcas, 2 os flanges 7 1/16" API 6BX 10.000 psi e 3 o anel BX 156.

A Tabela 12 mostra os componentes e os materiais considerados. Nos capítulos posteriores serão mostradas as características destes materiais usadas na pesquisa.

Tabela 12: Materiais empregados e descrição dos equipamentos

\begin{tabular}{|l|l|l|l|}
\hline Item & Quantidade & Descrição & Materiais \\
\hline 1 & 1 & Estojo com porcas. & Inconel UNS N06625 \\
\hline 2 & 2 & Flange 7 1/16" API 6BX 10.000 psi & Aço 9\% Ni \\
\hline 3 & 1 & Anel BX 156 & Inconel UNS N06625 \\
\hline
\end{tabular}

\subsection{Materiais}

\subsubsection{Material dos Flanges}

Ao longo deste capítulo são demostradas as características do material dos flanges, aço $9 \% \mathrm{Ni}$, analisado no estudo, seguindo as normas ASTM A353 e ASTM 
A553 tipo I [25]. Nas

Figura 40, Figura 41, Figura 42 e Figura 43 são

apresentadas algumas propriedades mecânicas consideradas do material dos flanges.

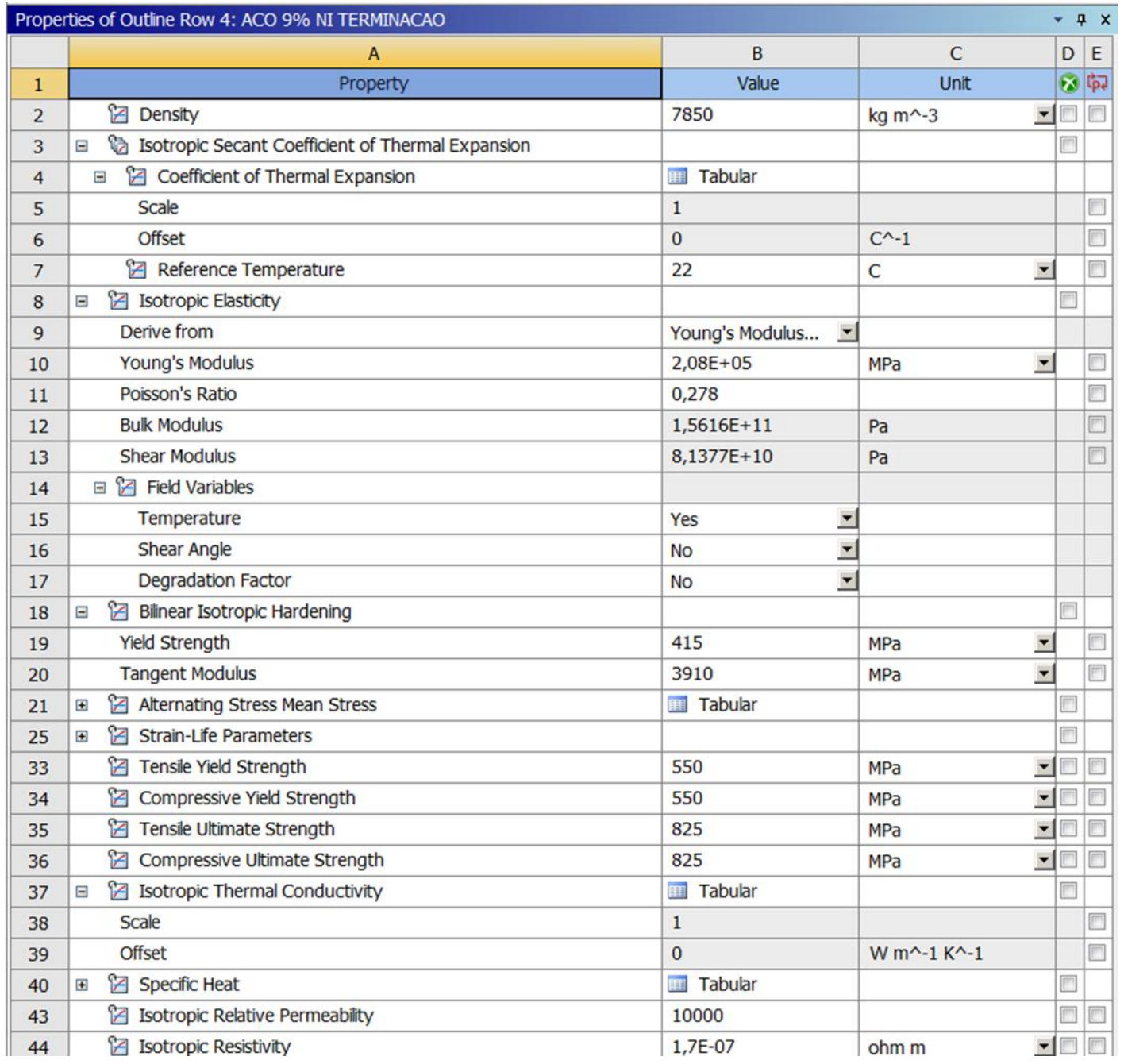

Figura 40: Propriedades do material Aço 9\%Ni [25].

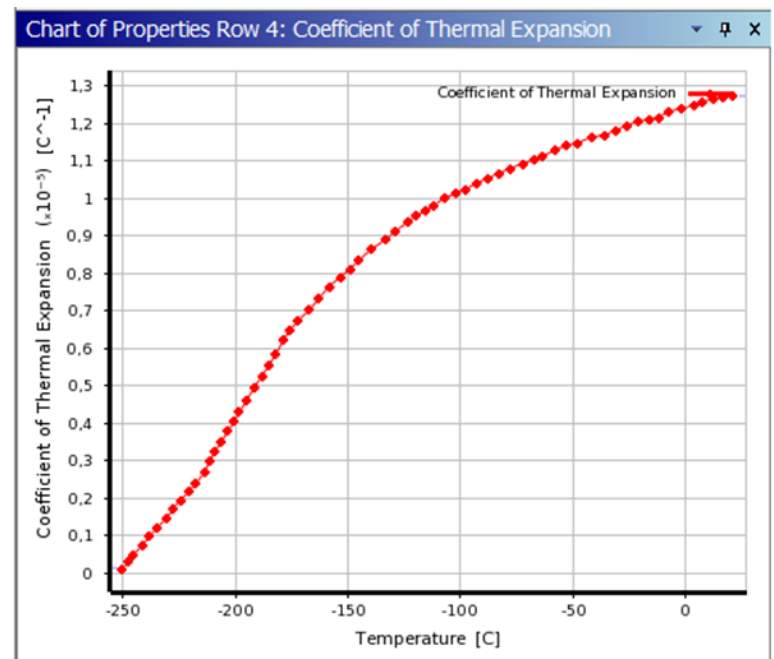

Figura 41: Coeficiente térmico de expansão do material Aço $9 \% \mathrm{Ni}$ [25]. 


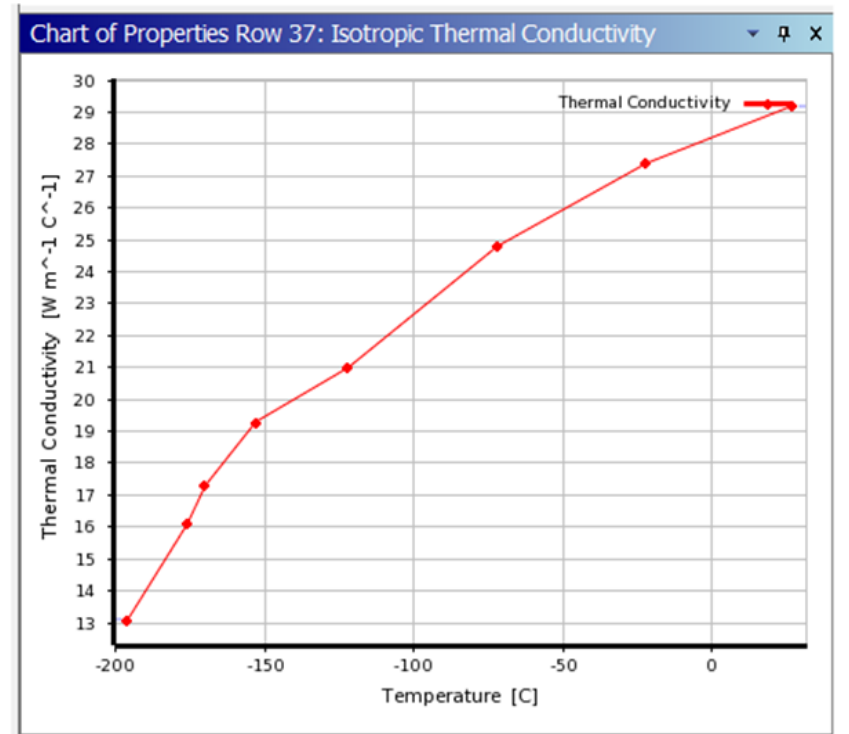

Figura 42: Variação da condutividade térmica em relação a temperatura do material Aço 9\% Ni [25].

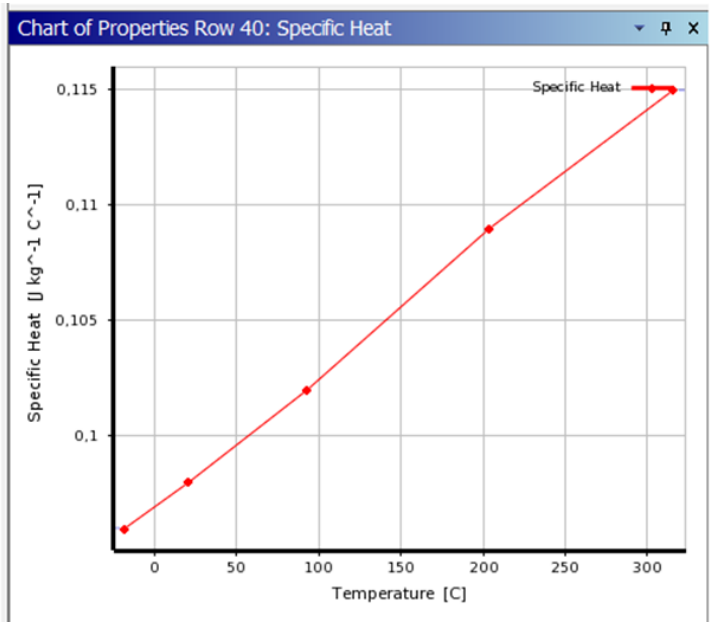

Figura 43: Variação de calor específico em relação a temperatura do material Aço 9\%Ni [25].

\subsubsection{Material do anel BX 156}

Nas Figura 44, Figura 45,Figura 46,Figura 47 e Figura 48 deste capítulo são mostradas as características do material do anel BX 156, o inconel UNS N06625, considerado no estudo. 


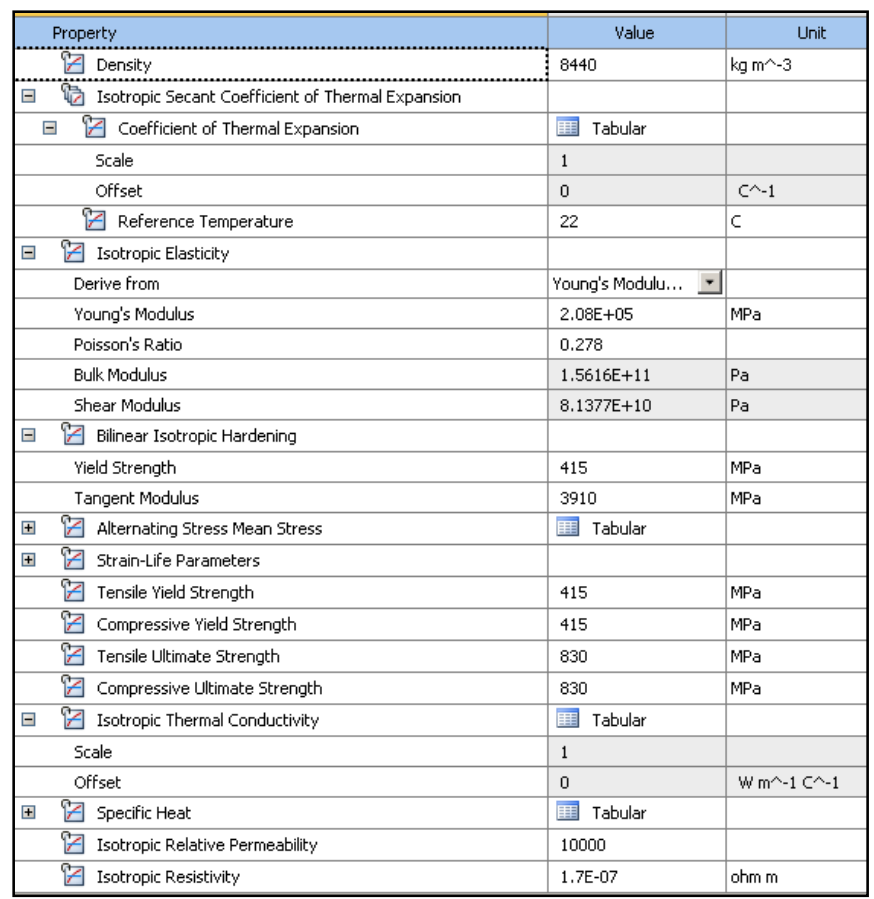

Figura 44: Propriedades do material Inconel UNS N06625 [12].

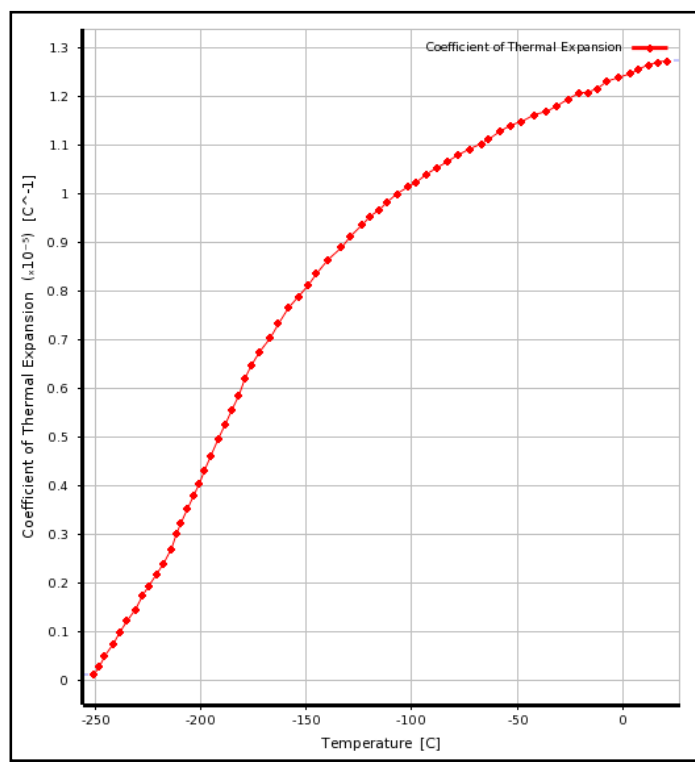

Figura 45: Coeficiente térmico de expansão do material Inconel UNS N06625 [12]. 


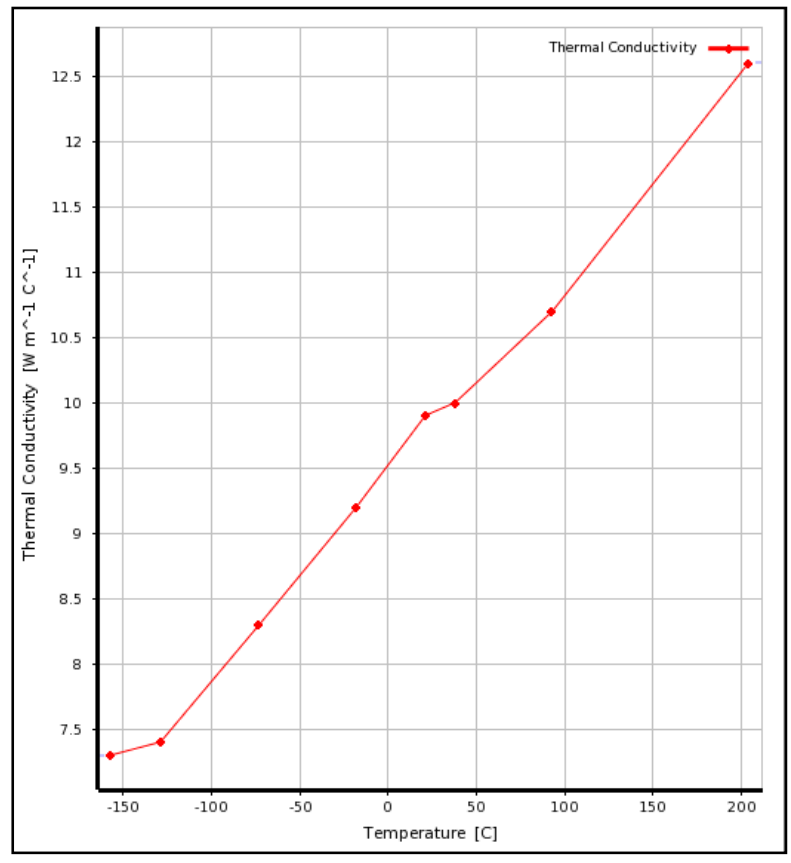

Figura 46: Variação da condutividade térmica em relação a temperatura do material Inconel UNS N06625 [12].

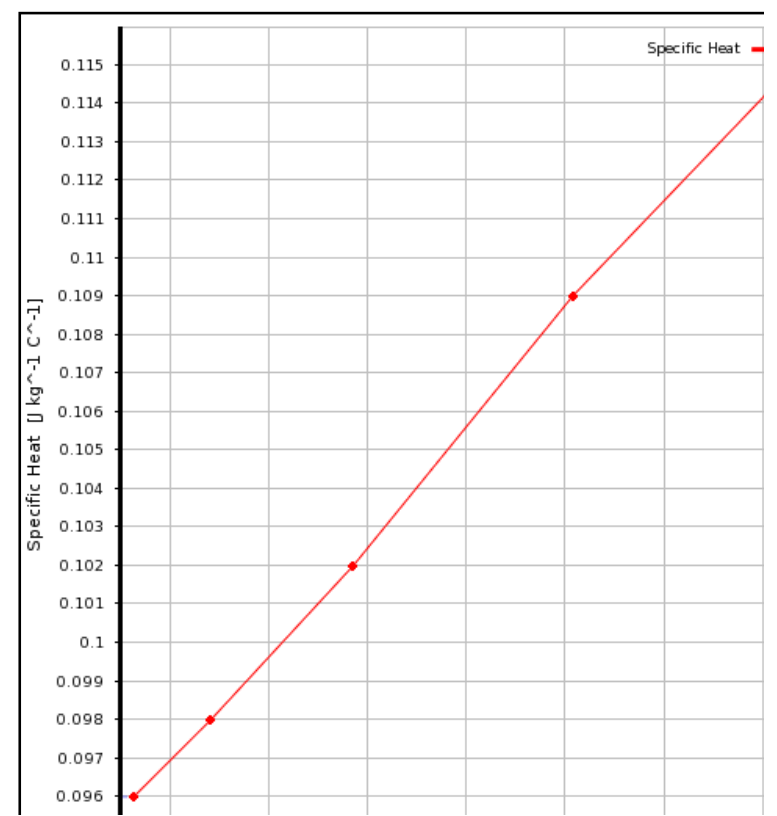

Figura 47: Variação do calor específico em relação a temperatura do material Inconel UNS N06625 [12]. 


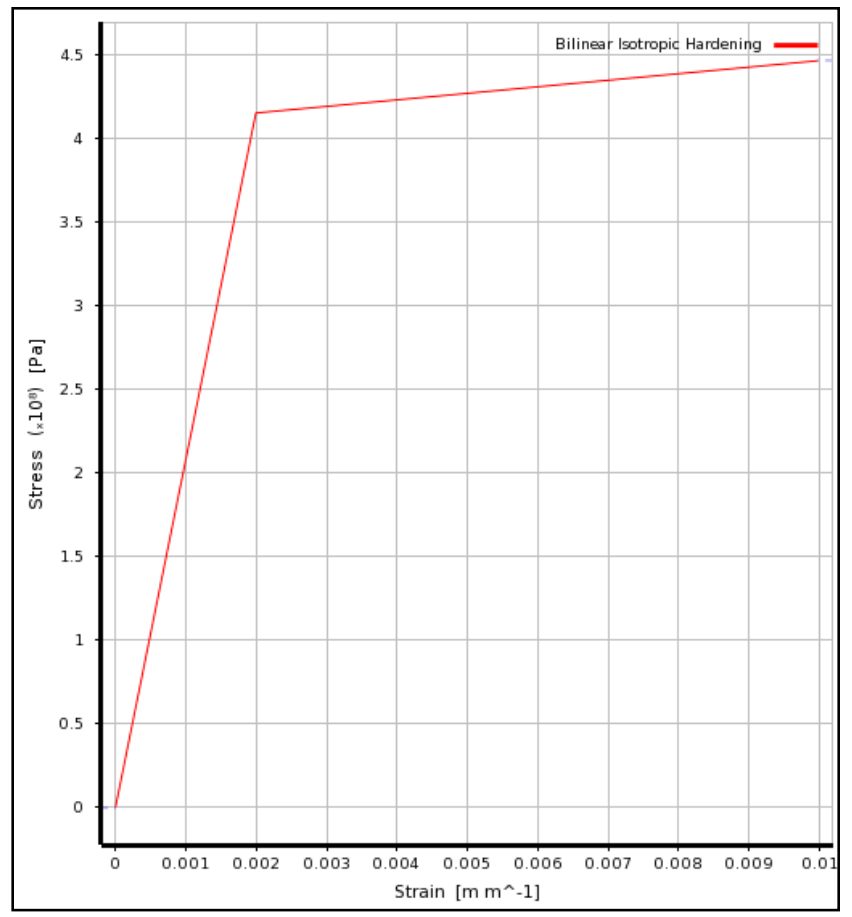

Figura 48: Curva Tensão $x$ Deformação do material Inconel UNS N06625 de forma simplificada [12].

\subsubsection{Material dos Estojos e porcas}

Nas Figura 49, Figura 50,Figura 51,Figura 52 e Figura 53 deste capítulo são mostradas as características do material dos estojos e porcas, o inconel UNS N06625, considerado no estudo.

\begin{tabular}{|c|c|c|c|}
\hline Property & \multirow{2}{*}{8440} & \multicolumn{2}{|l|}{ Unit } \\
\hline Density & & $\mathrm{kg} \mathrm{m} \wedge-3$ & $\dot{\sim}$ \\
\hline \multicolumn{4}{|l|}{ G 施 Isotropic Secant Coefficient of Thermal Expansion } \\
\hline$\square$ Coefficient of Thermal Expansion & 睓 Tabular & & \\
\hline Scale & 1 & & \\
\hline Offset & 0 & \multicolumn{2}{|l|}{$c^{\wedge}-1$} \\
\hline 7 Reference Temperature & 22 & \multirow[t]{2}{*}{ c } & 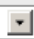 \\
\hline \multicolumn{3}{|l|}{$\square$ Isotropic Elasticity } & \\
\hline Derive from & \multicolumn{3}{|l|}{ Young's Modu... ت } \\
\hline Young's Modulus & $2.08 \mathrm{E}+05$ & $\mathrm{MPa}$ & 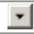 \\
\hline Poisson's Ratio & \multicolumn{3}{|l|}{0.278} \\
\hline Bulk Modulus & $1.5616 \mathrm{E}+11$ & \multicolumn{2}{|l|}{$\mathrm{Pa}$} \\
\hline Shear Modulus & $8.1377 \mathrm{E}+10$ & \multicolumn{2}{|l|}{$\mathrm{Pa}$} \\
\hline \multicolumn{4}{|l|}{$\square$ Bilinear Isotropic Hardening } \\
\hline Yield Strength & 725 & MPa & 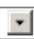 \\
\hline Tangent Modulus & 4062 & $\mathrm{MPa}$ & 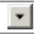 \\
\hline I A Alternating Stress Mean Stress & 圈 Tabular & & \\
\hline \multicolumn{4}{|l|}{ (1) Strain-Life Parameters } \\
\hline 7 Tensile Yield Strength & 725 & MPa & -1 \\
\hline 7 Compressive Yield Strength & 725 & MPa & 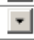 \\
\hline 7 Tensile Ultimate Strength & 1114 & $\mathrm{MPa}$ & 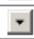 \\
\hline 7 Compressive Uttimate Strength & 1114 & $\mathrm{MPa}$ & 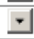 \\
\hline$\square$ Isotropic Thermal Conductivity & 圈 Tabular & & \\
\hline Scale & 1 & & \\
\hline Offset & 0 & $W m^{\wedge}-1 C^{\wedge}-1$ & \\
\hline Ð Specific Heat & 圈 Tabular & & \\
\hline 7 Isotropic Relative Permeability & 10000 & & \\
\hline 7 Isotropic Resistivity & $1.7 \mathrm{E}-07$ & ohm m & 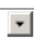 \\
\hline
\end{tabular}

Figura 49: Propriedades do material Inconel UNS N06625 [12]. 


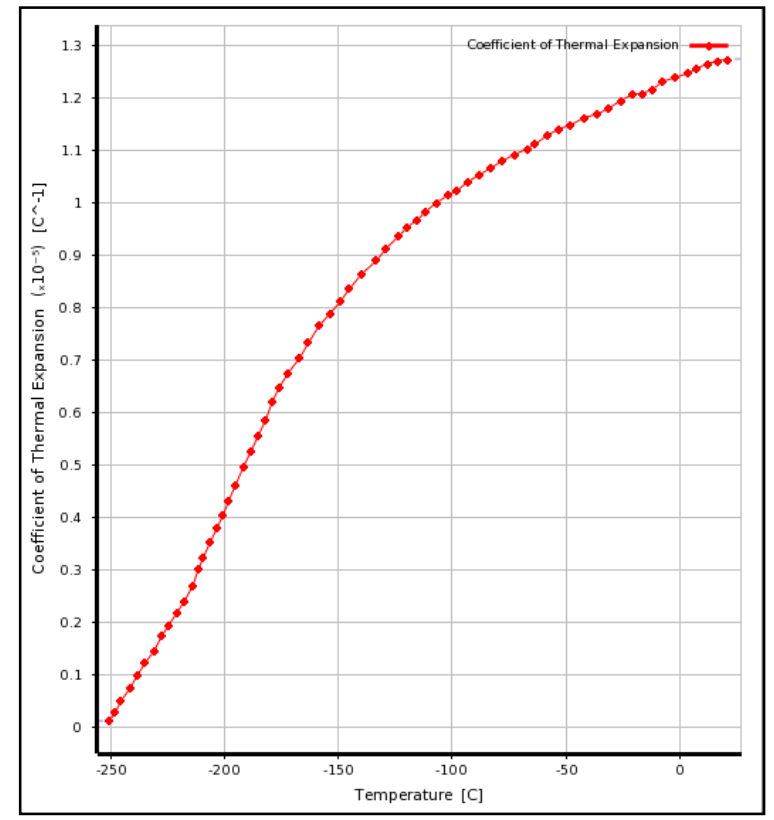

Figura 50: Coeficiente térmico de expansão do material Inconel UNS N06625 [12].

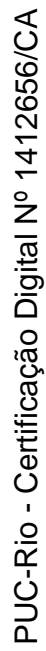

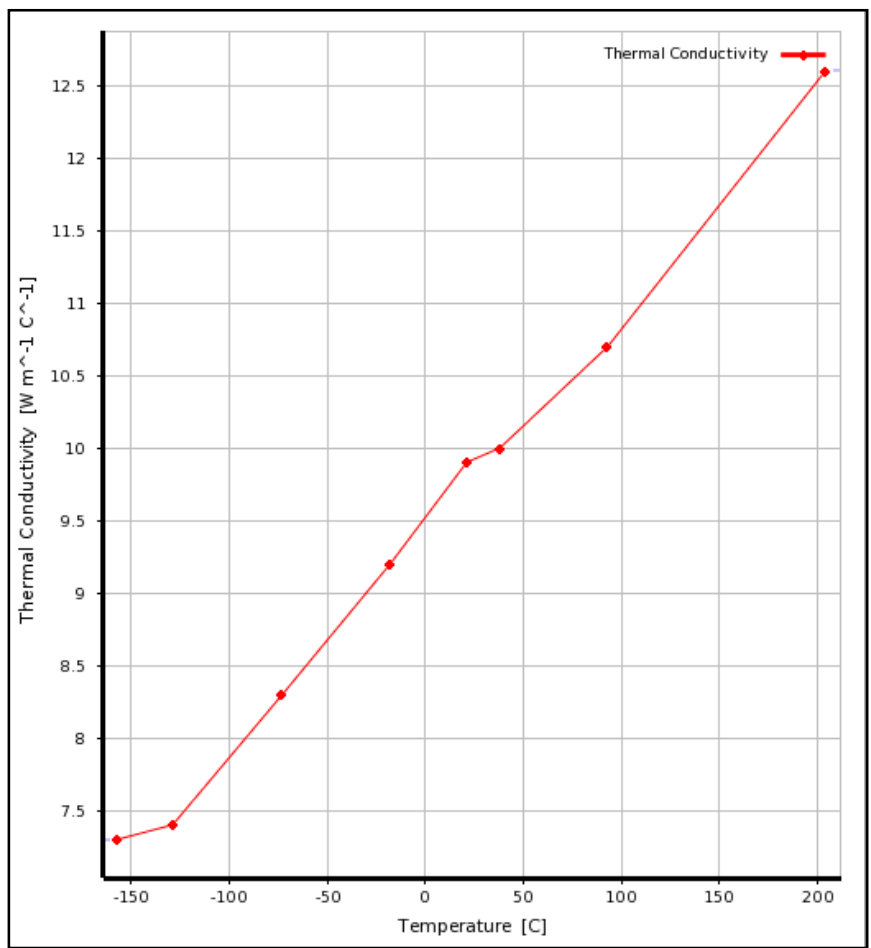

Figura 51: Variação da condutividade térmica em relação a temperatura do material Inconel UNS N06625 [12]. 


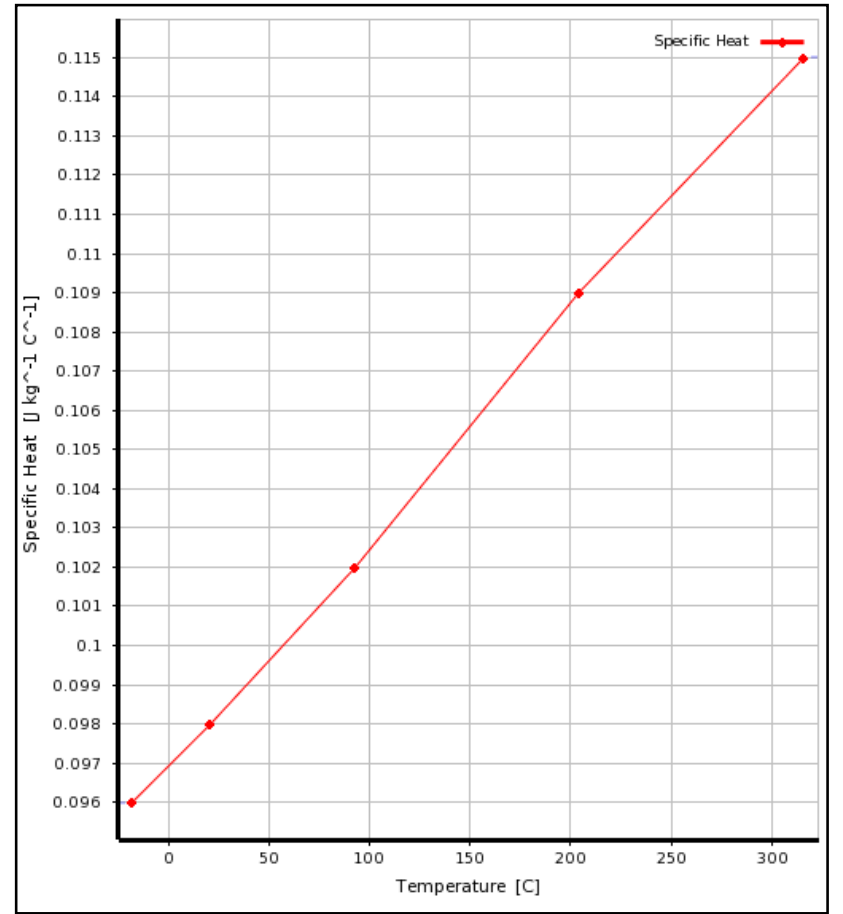

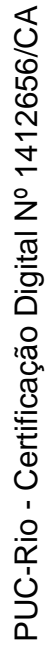

Figura 52: Variação do calor específico em relação a temperatura do material Inconel UNS N06625 [12].

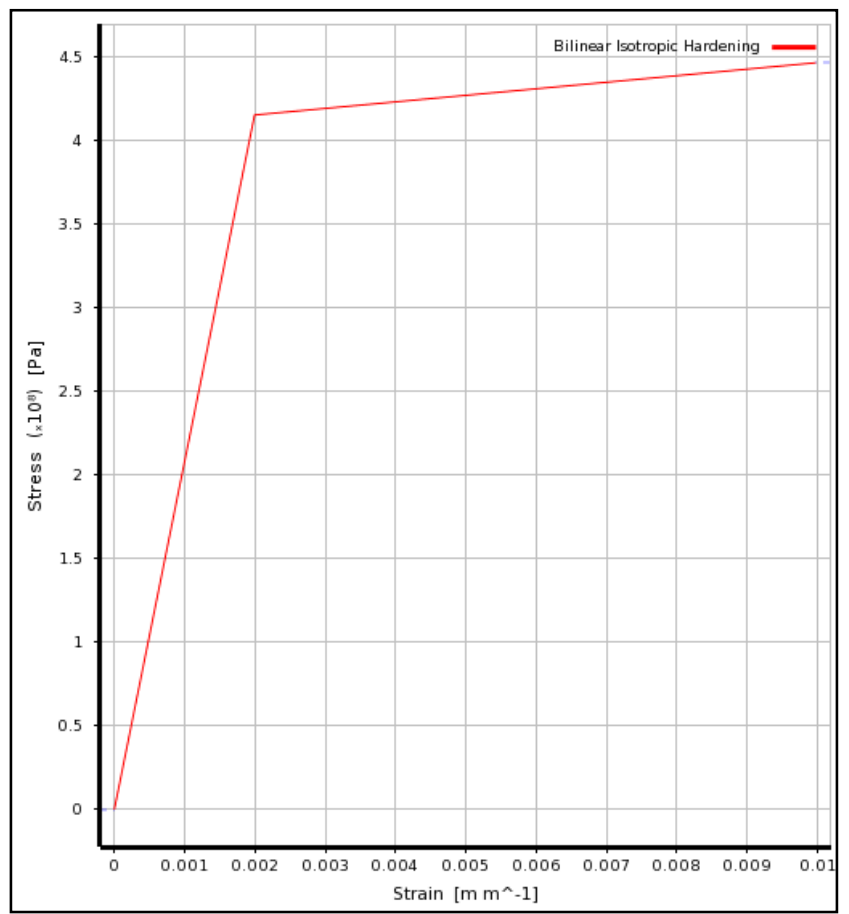

Figura 53: Curva Tensão x Deformação do material Inconel UNS N06625 de forma simplificada [12].

\subsection{Avaliação numérica do conjunto sem defeito}

Neste capítulo serão vistos o método de elaboração do modelo numérico na 
ferramenta ANSYS, as premissas utilizadas para que se obtenha a análise térmica e as tensões na região escolhida para a pesquisa.

O objetivo nesta etapa é desenhar os componentes na ferramenta ANSYS sem a presença de defeitos, obter uma malha com boa qualidade e avaliar as premissas consideradas. Depois destas avaliações executadas, obteremos os valores da tensão principal máxima, tensão de membrana e de curvatura no canto vivo presente na ligação entre o flange e o pescoço do conector (Figura 54). Estes valores são usados como dados de entrada na avaliação pelo método analítico na próxima fase da pesquisa.

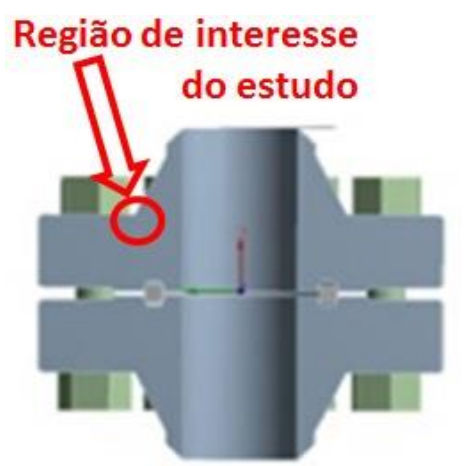

Figura 54: Região de interesse do estudo no flange 7 1/16" API 6BX 10.000 psi

\subsubsection{Malha}

A malha foi desenvolvida e refinada de modo que os resultados estivessem o mais próximo da realidade e com bom nível de qualidade (Figura 55, Figura 56 e Figura 57). 


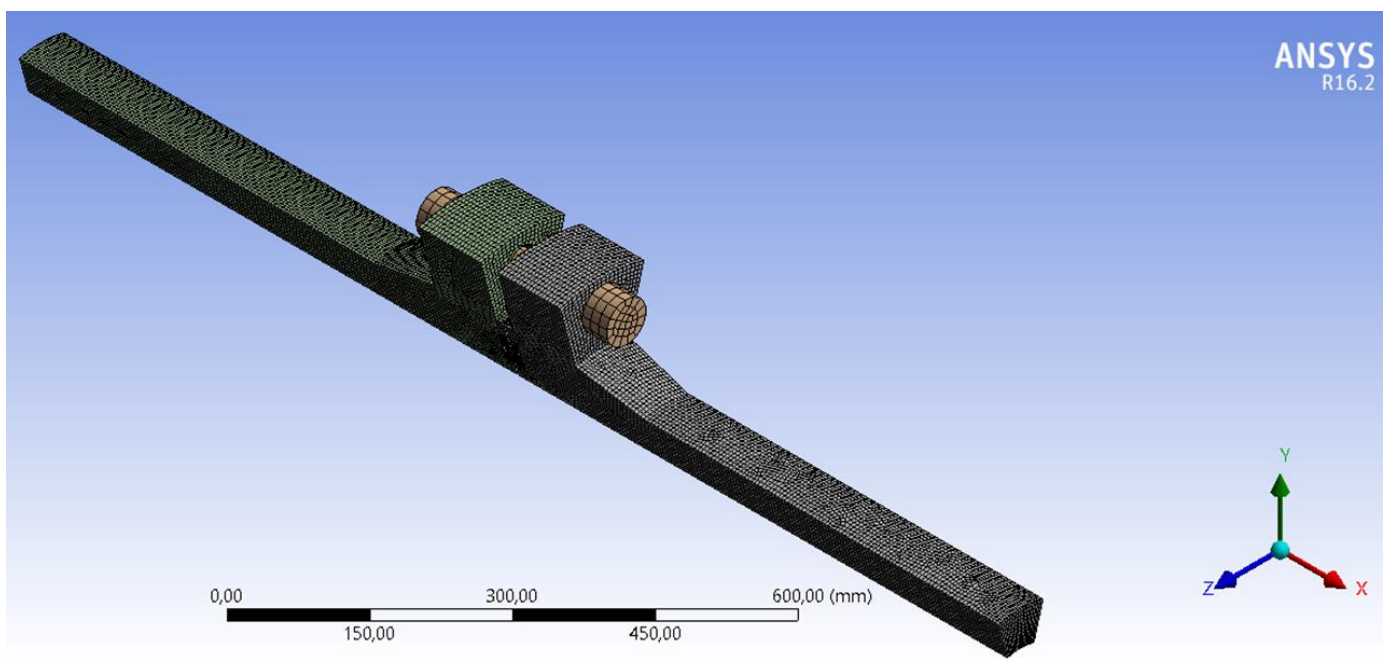

Figura 55: Modelo com a malha.

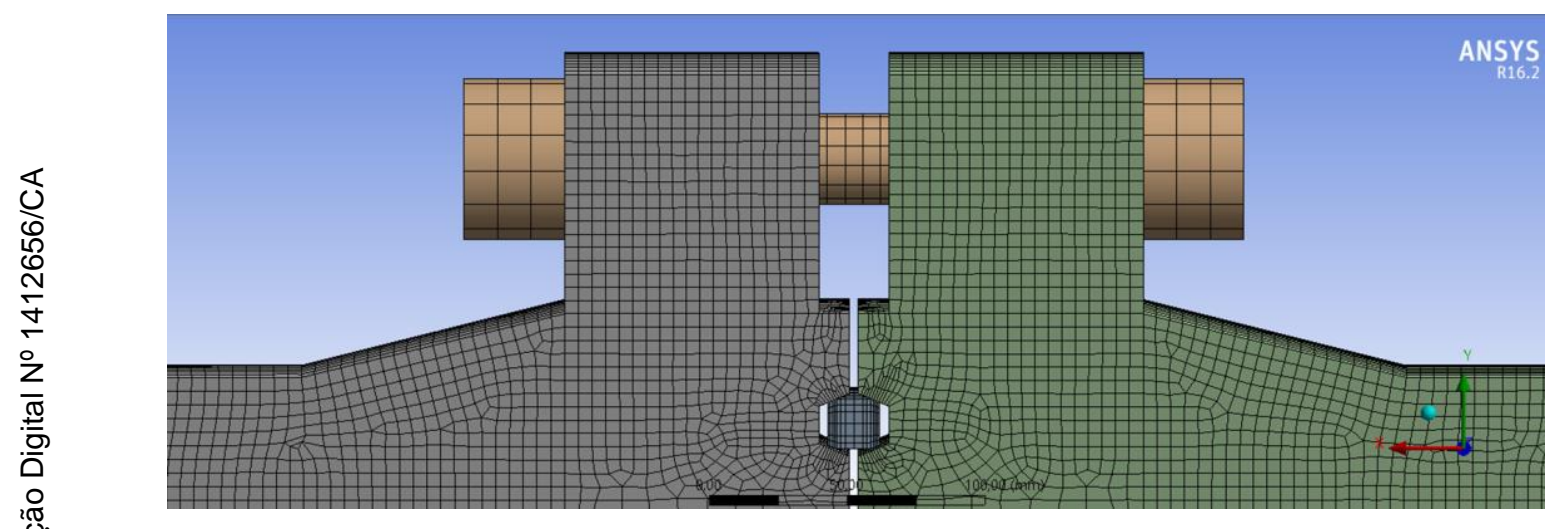

Figura 56: Modelo com a malha. 

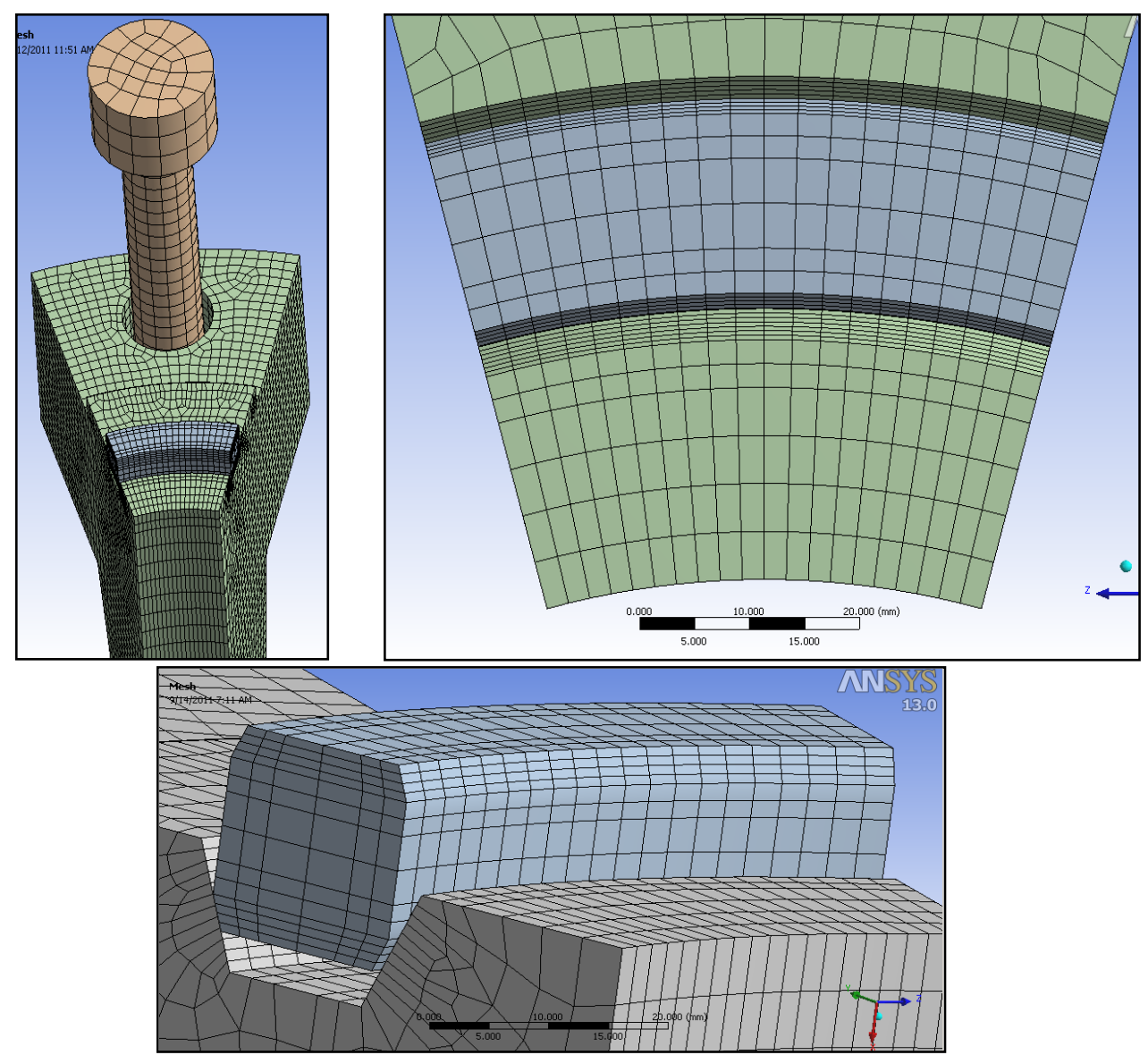

Figura 57: Modelo com a malha

A Figura 58 mostra que a grande maioria dos elementos tem uma boa qualidade da malha. A média Jacobiano Ration constituiu 1,67, o que reflete a boa qualidade da malha. 


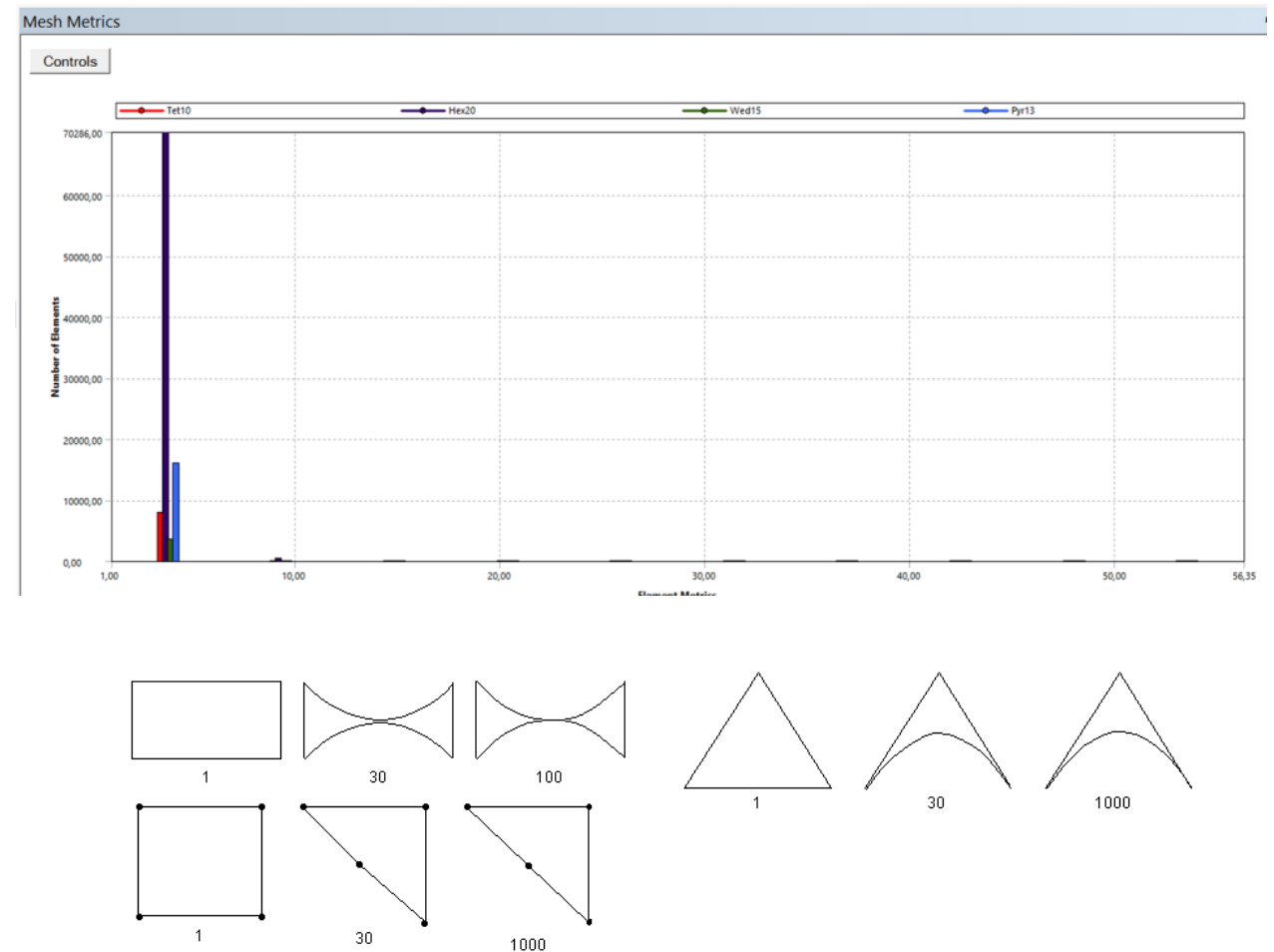

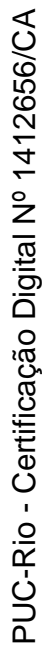

Figura 58: Qualidade da malha.

\subsubsection{Regiões de avaliações}

Nas Figura 59 e Figura 60 mostram as regiões consideradas para avaliações estruturais dos componentes ao longo do estudo. Nestas regiões serão analisados previamente a integridade dos componentes (tensões e deformações) de modo a refletir ao máximo o comportamento dos mesmos operando em campo.

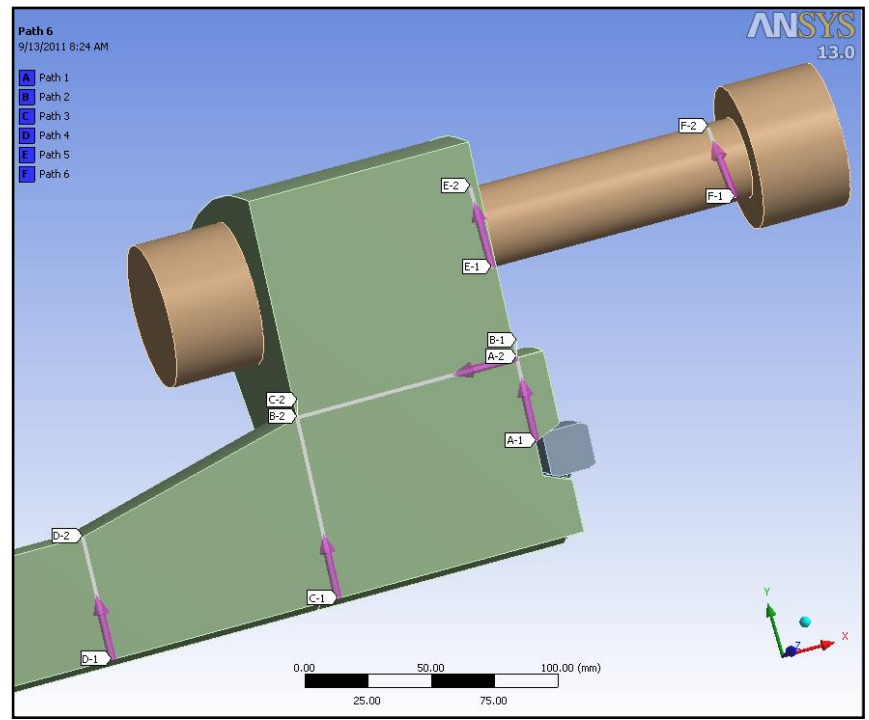

Figura 59: Regiões consideradas nas análises. 


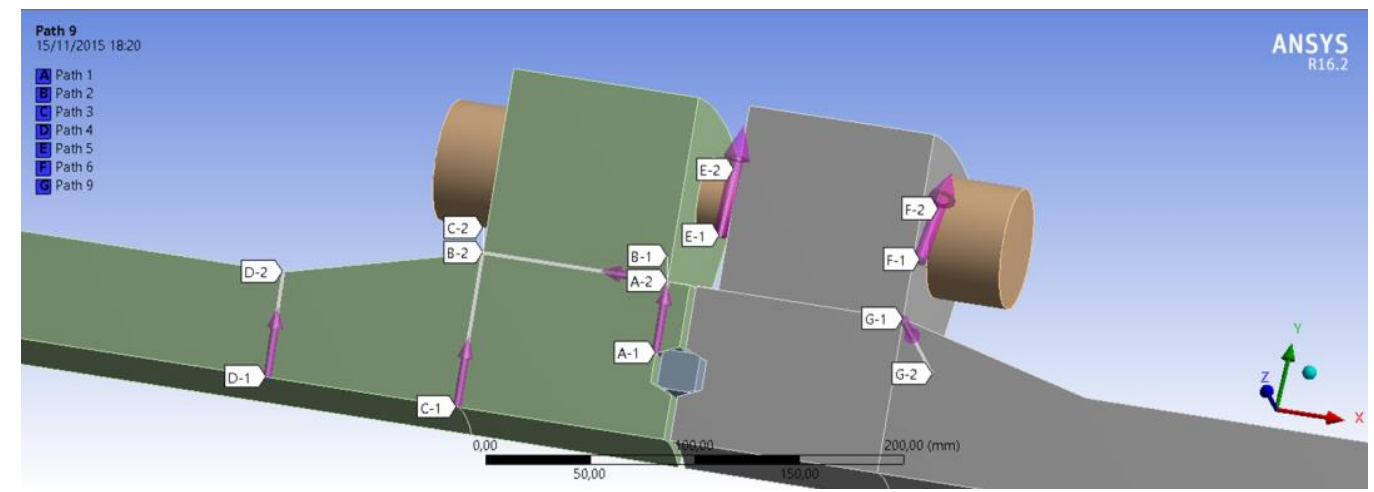

Figura 60: Regiões consideradas nas análises.

\subsubsection{Premissas térmicas}

As premissas térmicas (Figura 61) foram consideradas de modo que a região

da base do flange atingisse a temperatura próxima de $-196^{\circ} \mathrm{C}$. Esta temperatura foi escolhida em função da disponibilidade de dados obtidos em ensaios para avaliação pela INCO [26], além de se aproximar do resultado de estudos prévios realizados pela indústria.

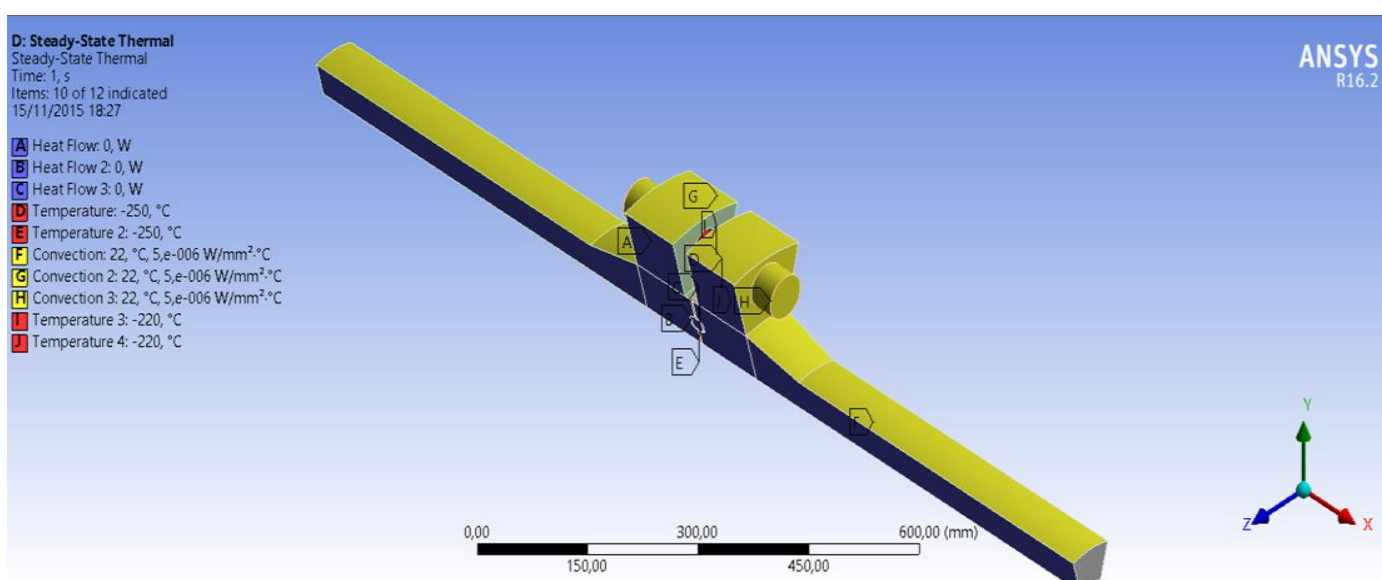

Figura 61: Condições de contorno térmico. 


\subsubsection{Premissas Estruturais}

A terminação do conector foi fixado apenas em uma das extremidades. $\mathrm{O}$ outro tem liberdade para deslocamento. Esta consideração representa a realidade destes equipamentos que são fixados nas plataformas de petróleo a partir de um sistema de travamento e sustentação (Figura 62 e Figura 63), não sofrendo flexão.

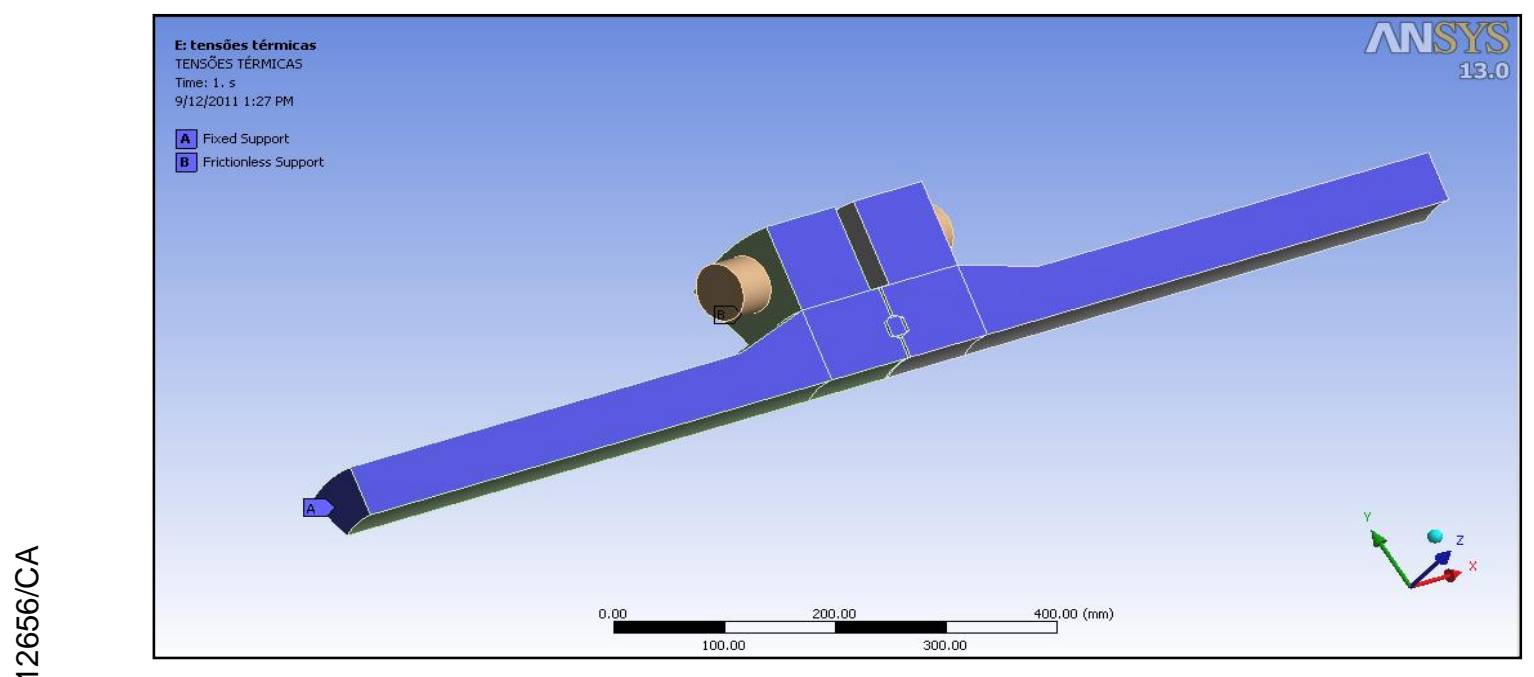

Figura 62: Condição de contorno estrutural.

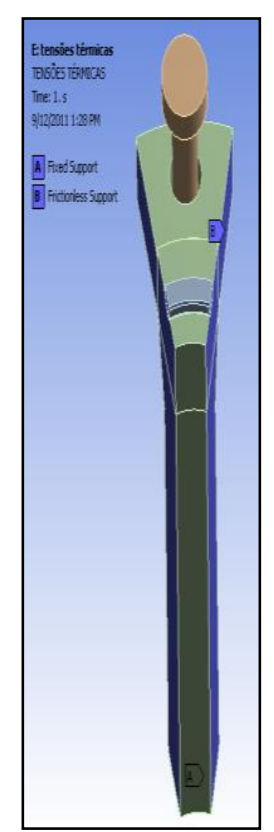

Figura 63: Condição de contorno estrutural. 
A pressão interna considerada foi de $69,8 \mathrm{MPa}$ (10.000 PSI) aplicado no flange (Figura 64 eFigura 65) e a força considerada dado a pressão interna dividida por 12 (em função da simetria da geometria) será igual a 104,81 kN. O pré-aperto dos estojos considerado foi de $50 \%$ da tensão de escoamento conforme visto na Tabela 13. Todos estes valores foram extraídos de dados reais de uma linha flexível de injeção de gás operando nos reservatórios de petróleo no Brasil.

Tabela 13: Pré-carregamento dos estojos

\begin{tabular}{|l|l|l|l|}
\hline Material do Estojo & $\boldsymbol{\sigma}_{\mathrm{y}}$ & $\begin{array}{l}\text { Pré-carregamento } \\
\left.\text { estojo [\% } \boldsymbol{\sigma}_{\mathrm{y}}\right]\end{array}$ & $\begin{array}{l}\text { Pré-carregamento do } \\
\text { estojo [kN] }\end{array}$ \\
\hline Inconel UNS N06625 & $725 \mathrm{MPa}$ & $50 \%$ & $346,50 \mathrm{kN}$ \\
\hline
\end{tabular}

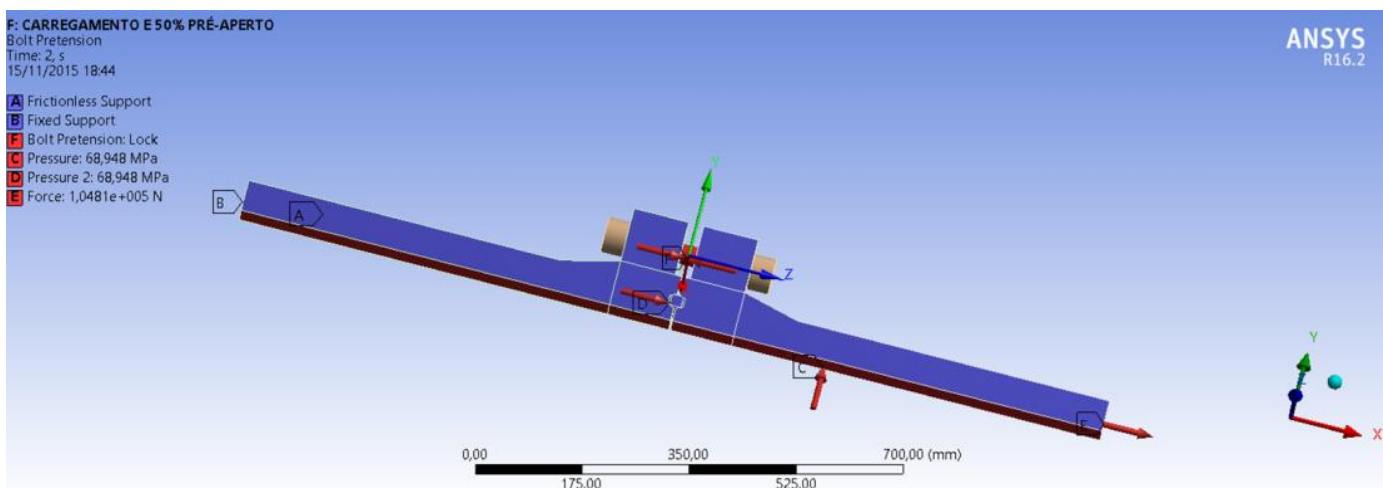

Figura 64: Condições de contorno da análise estrutural.

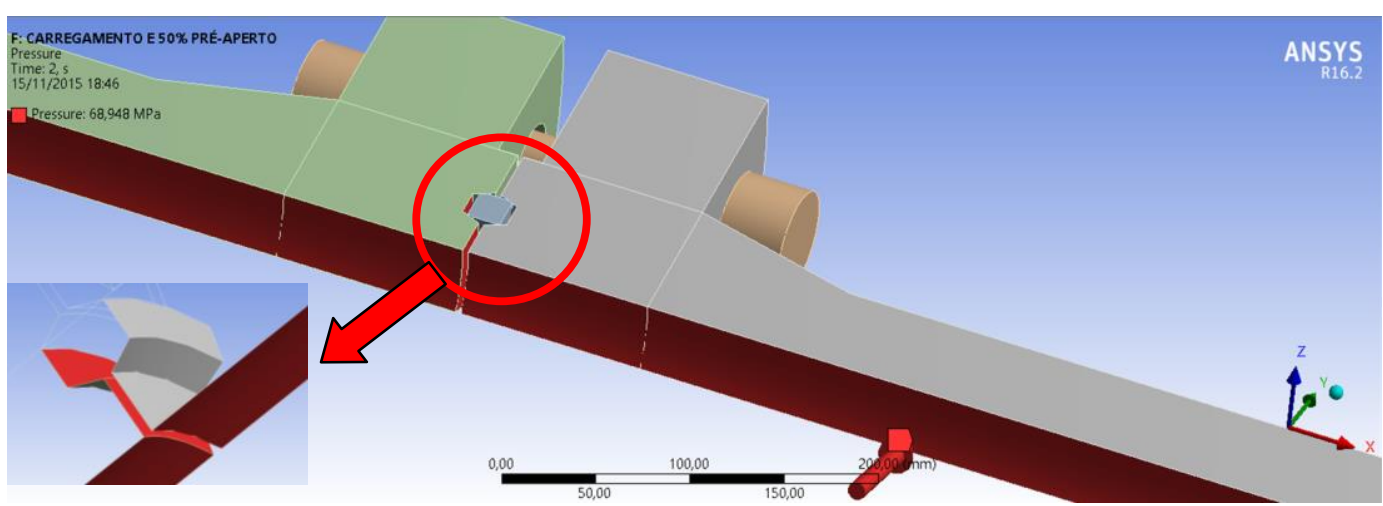

Figura 65: Pressão aplicada nos flanges.

Depois de todas as premissas estabelecidas no modelo numérico, o comando de cálculo é executado e obtém-se os valores de tensão principal máxima, tensão de membrana e de curvatura na interface entre o flange e o pescoço do conector. Estas tensões serão importantes para análise analítica seguindo a norma BS 7910. 


\subsection{Avaliação Analítica do Conjunto com o defeito}

A primeira avaliação do uso do aço $9 \% \mathrm{Ni}$ em flanges de conectores de linhas flexíveis de injeção de gás foi feita utilizando a metodologia de avaliação analítica conforme norma BS 7910 para nível 2. Para os cálculos será utilizada a ferramenta Mathcad R15. Foi determinado este nível intermediário de conservadorismo, em função dos dados que puderam ser obtidos na primeira fase da pesquisa. Usando a metodologia analítica desta norma, nesta etapa avalia-se como o material irá resistir às condições empregadas possuindo uma trinca superficial de $6,5 \mathrm{~mm}$ no perímetro do pescoço do conector de topo de um tubo flexível de injeção de gás.

O tamanho desta trinca se deu pela norma API 6A [53] determinar, além de outros critérios, que nos flanges dos equipamentos não possam haver trincas e que inclusões ou escórias não podem ter comprimentos superiores a 6,4 $\mathrm{mm}$. De forma conservadora, realizou-se análises nestes equipamentos considerando estas inclusões como sendo trincas e adotando o comprimento de $6,4 \mathrm{~mm}$ como sendo o limitante para aceitação de uma trinca.

Como a forma e o posicionamento típicos das possíveis trincas nestes equipamentos não são conhecidos, foi considerada uma trinca de $6,5 \mathrm{~mm}$ de abertura e profundidade em todo o perímetro do pescoço do flange.

Na Tabela 14 são apresentadas as propriedades mecânicas do material aço 9\% Ni que será avaliado. Para os valores de limite de escoamento e limite de resistência a temperatura de $-196^{\circ} \mathrm{C}$ foi usado a seção 7.1.3.4 da norma BS 7910 [52]. Estes valores transformados por equações se aproximam de resultados obtidos em ensaios mecânicos publicados pela INCO [26].

Tabela 14: Propriedades Mecânicas para análise analítica do material aço $9 \%$ Ni.

\begin{tabular}{|l|l|}
\hline Módulo de Young $\left(-196^{\circ} \mathbf{C}\right)$ & $\mathrm{E}=209 \mathrm{GPa}$ \\
\hline Coeficiente Poisson & $\mathrm{V}=0,3$ \\
\hline Limite de Escoamento de Engenharia(-196 $\left.{ }^{\circ} \mathbf{C}\right)$ & $\mathrm{Sye}=1084,589 \mathrm{MPa}$ \\
\hline Limite de Resistência de Engenharia(-196 $\mathbf{C})$ & $\mathrm{Sue}=1278,619 \mathrm{MPa}$ \\
\hline Limite de Escoamento Verdadeiro & $\mathrm{S}_{\mathrm{y}}=\mathrm{S}_{\mathrm{ye}}(1+\ln (1+0,002))$ \\
\hline Limite de Resistência Verdadeiro & $\mathrm{S}_{\mathrm{u}}=\mathrm{S}_{\mathrm{ue}}\left(1+\ln \left(1+\varepsilon_{\mathrm{u}}\right)\right)$ \\
\hline
\end{tabular}

A próxima etapa será avaliar a propriedade a tenacidade do material aço $9 \%$ Ni. Neste sentido, considerou-se o valor de CTOD deste material na temperatura de $-196{ }^{\circ} \mathrm{C}$ conforme publicação da INCO [26]. O valor de CTOD é de $\delta_{\mathrm{C}}=0,19 \mathrm{~mm}$. 
Depois de obtido o valor de m a partir da equação 3.1, deve-se obter o valor de tenacidade a fratura do material $\mathrm{K}_{\text {mat }}$ (equação 3.2).

$m=\mid 1,517\left(\frac{S_{y}}{S_{u}}\right)^{-0,3188}$

Eq. 3.1

se $0,3<\left(\frac{S_{y}}{S_{u}}\right)<0,98$

$K_{m a t}=\sqrt{\frac{m S_{y} \delta_{C} E}{1-v^{2}}}$

Considera-se a tensão principal máxima $\left(\mathrm{S}_{1.1}\right)$ e a tensão de membrana e curvatura $\left(\mathrm{S}_{\mathrm{mb} .1}\right)$ como aquela obtida na análise numérica sem a presença do defeito no canto vivo entre o flange e o pescoço do conector.

Ainda seguindo a norma BS 7910, determina-se a geometria da região estudada. Lembrando que a trinca considerada na pesquisa é superficial ao longo do perímetro do flange 7 1/16" API 6BX 10.000 psi, tem-se as dimensões consideradas conforme norma API 6A [53].

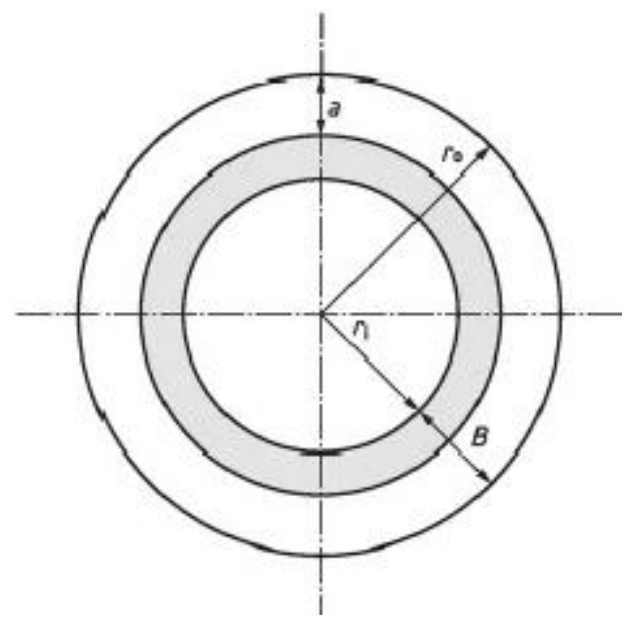

$$
\begin{aligned}
& \text { Tamanho da } \quad a_{1 . r 1}=6,5 \\
& \text { Trinca } \quad \mathrm{mm} \\
& \text { Espessura do } \quad \mathrm{B}_{\mathrm{r} 1}=60,7 \\
& \text { tubo } \mathrm{mm} \\
& \text { Raio interno } \quad r_{i . r 1}=90,1 \\
& \mathrm{~mm} \\
& \text { Raio Externo } \\
& \mathrm{r}_{0 . \mathrm{r} 1}=150,8 \\
& \mathrm{~mm} \\
& \lambda_{r 1}=\frac{r_{i . r 1}}{r_{0 . r 1}} \\
& \mu_{1 . r 1}=\frac{a_{1 . r 1}}{B_{r 1}}
\end{aligned}
$$


O fator de intensidade de tensões é dado conforme a equação 3.3.

$$
\begin{aligned}
& K_{1 . r 1}=M_{1} f_{w .1} M_{m b . r 1} S_{1.1} \sqrt{\pi a_{1 . r 1}} \quad \text { onde, } \\
& M_{m b . r 1}=\left[\frac{1-\lambda_{r 1}^{2}}{\left[1-\left(1-\lambda_{r 1}\right) \mu_{1 . r 1}\right]^{2}-\lambda_{r 1}^{2}}\right]\left[0,8+\left[\frac{\left(1-\lambda_{r 1}\right) \mu_{1 . r 1}}{1-\left(1-\lambda_{r 1}\right) \mu_{1 . r 1}}\right]\left[4+\frac{1,08 \lambda_{r 1}}{\left(1-\lambda_{r 1}\right)\left(1-\mu_{1 . r 1}\right)}\right]\right]^{-0,5}
\end{aligned}
$$

Por fim calcula-se a razão entre a tensão aplicada e a tensão dada pela equação 3.4 .

$$
L r_{r 1}=\frac{S_{m b .1}}{S_{y}}
$$

Eq. 3.4

Assim, já será possível verificar qual a região no gráfico FAD de nível 2 que a análise se encontra (Gráfico 1).

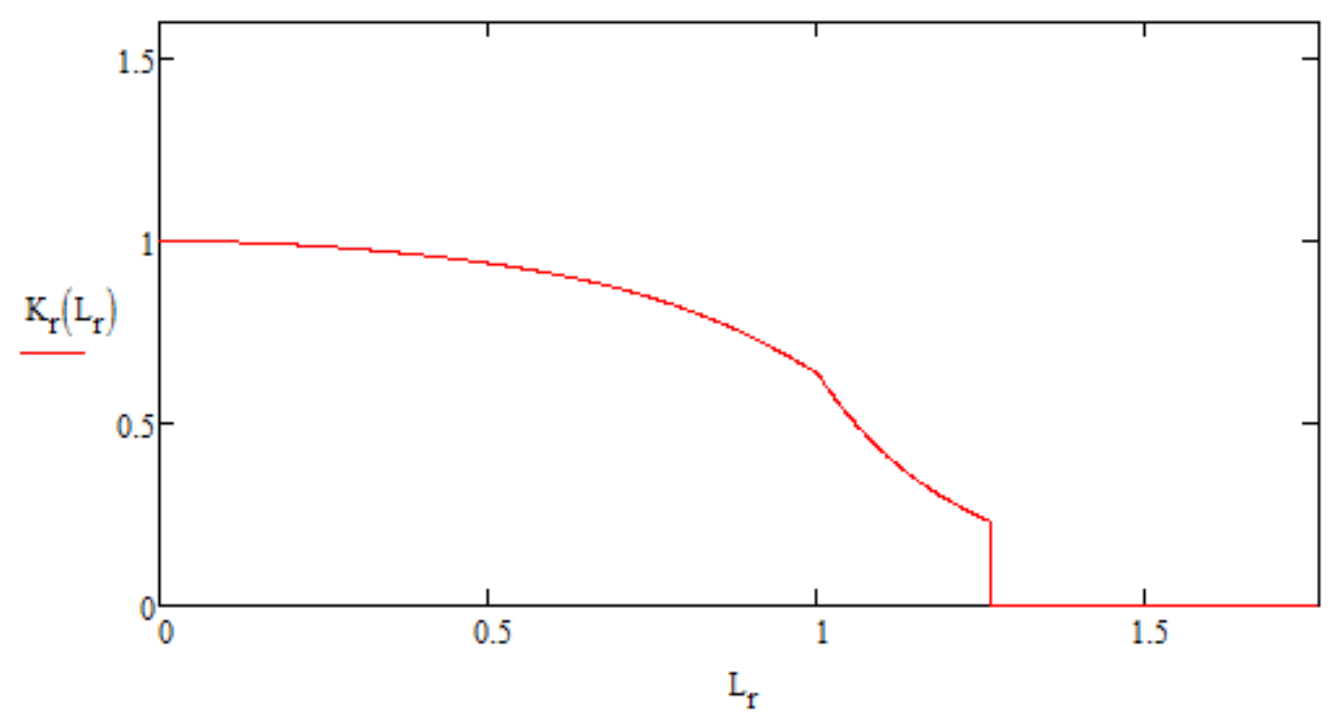

Gráfico 1 - Diagrama FAD Nível 2 (Lr x Kr)

Os pontos no gráfico $L_{r} \times K_{r}$ que se posicionarem dentro da região limitada pela linha vermelha estarão em uma região segura e pode-se afirmar que o material é apto para o uso em operação. Os pontos que se localizarem fora desta região mostram que o material não pode ser usado (região não segura do gráfico). 


\subsection{Avaliação Numérica do Conjunto com o defeito}

A segunda avaliação do uso do aço $9 \% \mathrm{Ni}$ em flanges de conectores de linhas flexíveis de injeção de gás foi feita utilizando a metodologia de avaliação numérica a partir do modelo na ferramenta ANSYS. Este foi desenvolvido a partir do mesmo desenho e modelo utilizado para obter as tensões principais máximas para avaliação analítica mostrado anteriormente. No entanto, nesta etapa, incluiu-se uma trinca no modelo.

A norma API 6A [53] determina, além de outros critérios, que nos flanges dos equipamentos não possam haver trincas e que inclusões ou escórias não podem ter comprimentos superiores a $6,4 \mathrm{~mm}$. De forma conservadora, realizou-se análises estruturais numéricas nestes equipamentos considerando estas inclusões como sendo trincas e adotando o comprimento de $6,4 \mathrm{~mm}$ como sendo de uma trinca.

Como a forma e o posicionamento típicos das possíveis trincas nestes equipamentos não são conhecidos, foi considerada uma trinca de $6,5 \mathrm{~mm}$ de abertura e profundidade em todo o perímetro do pescoço do flange.

Após a inclusão desta trinca superficial no perímetro do pescoço do conector com profundidade e abertura de $6,5 \mathrm{~mm}$, todo o modelo foi refinado e as mesmas premissas térmicas e estruturais foram conservadas. $\mathrm{O}$ posicionamento da trinca nesta região foi motivado por ser uma região estruturalmente crítica e onde se pudesse realizar ensaios de inspeção de modo que na prática pudesse ser identificada e avaliada com o duto flexível em operação.

\subsubsection{Malha}

A malha foi desenvolvida e refinada de modo que os resultados estivessem o mais próximo da realidade e com bom nível de qualidade (Figura 66, Figura 67, Figura, Figura 69 e Figura 70). 


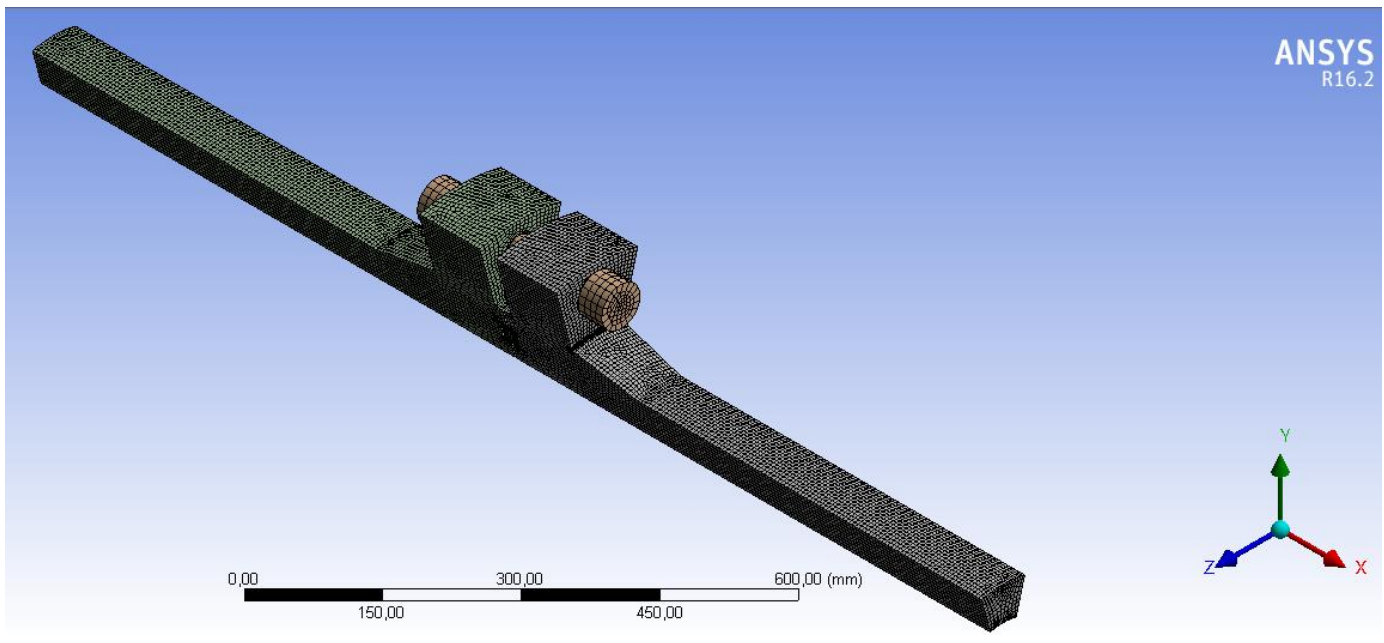

Figura 66: Malha.

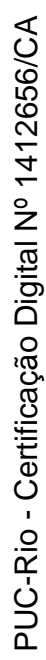

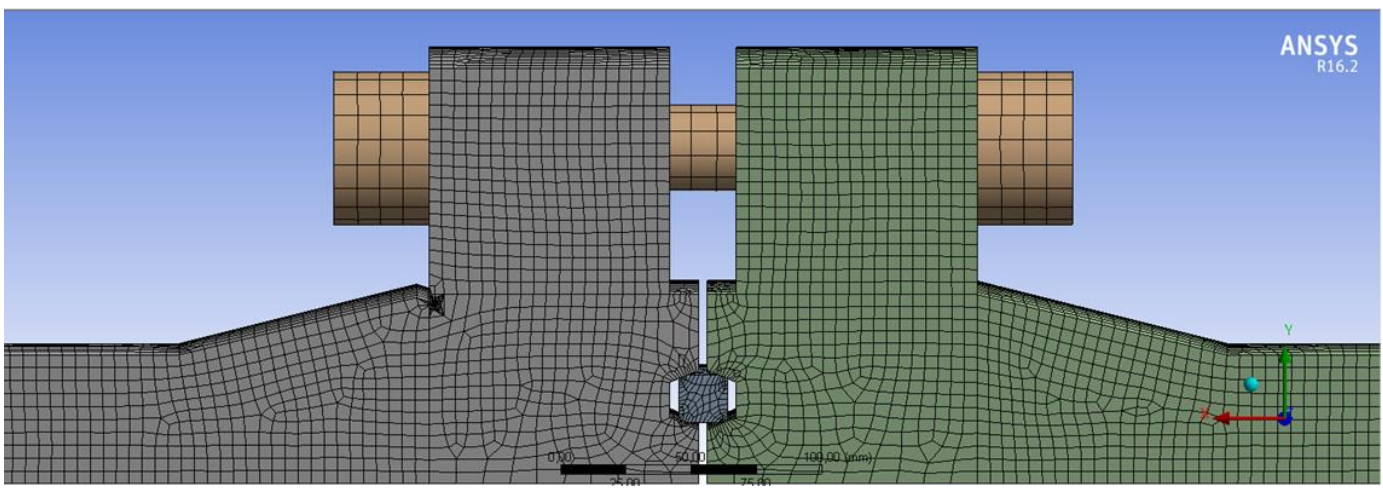

Figura 67: Malha.

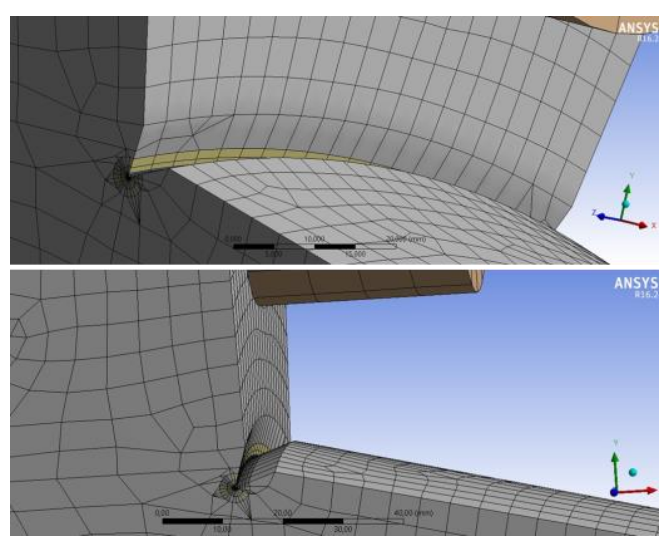

Figura 68: Malha na região da trinca. 


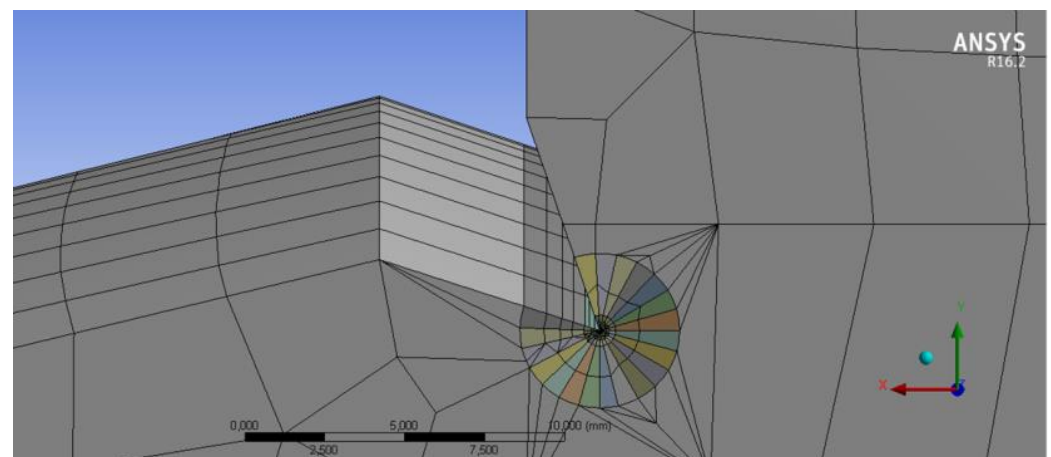

Figura 69: Malha na região da trinca.

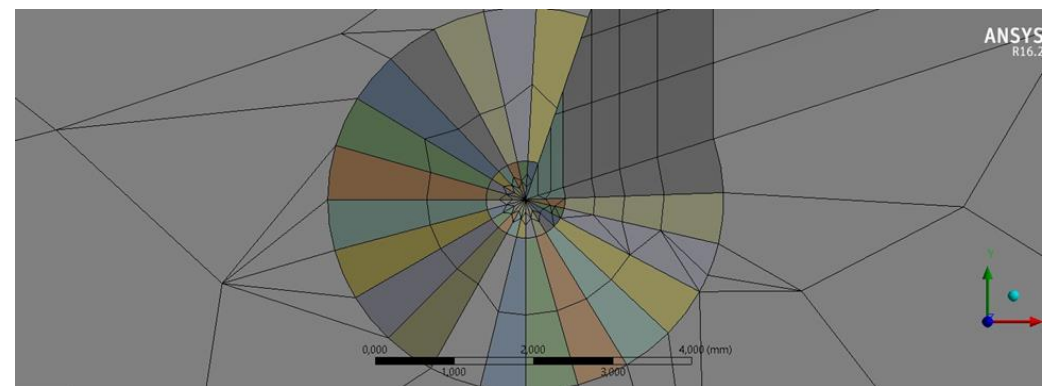

Figura 70: Malha na região da trinca.

A Figura 71 mostra que a grande maioria dos elementos tem uma boa qualidade da malha. A média Jacobiano Ration constituiu 1,65, o que reflete a boa qualidade para este tipo de modelo.

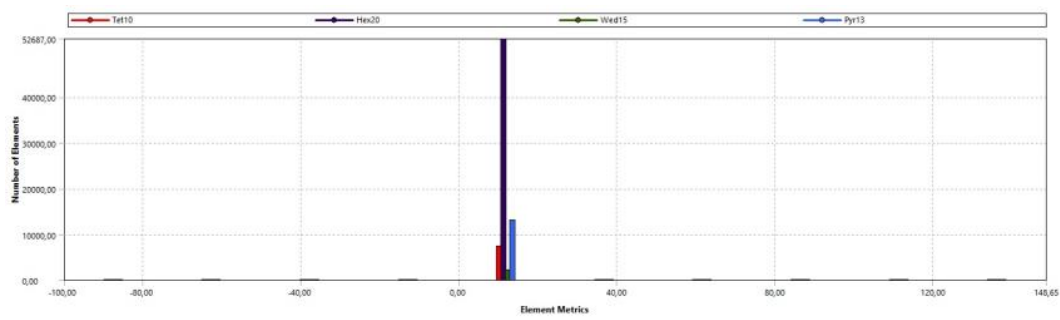

Figura 71: Qualidade da malha. 


\subsubsection{Regiões de Avaliação}

A Figura 72 mostra as regiões consideradas para avaliações estruturais dos componentes ao longo do estudo. Nestas regiões será analisada previamente a integridade dos componentes (tensões e deformações) de modo a refletir ao máximo o comportamento dos mesmos operando em campo.

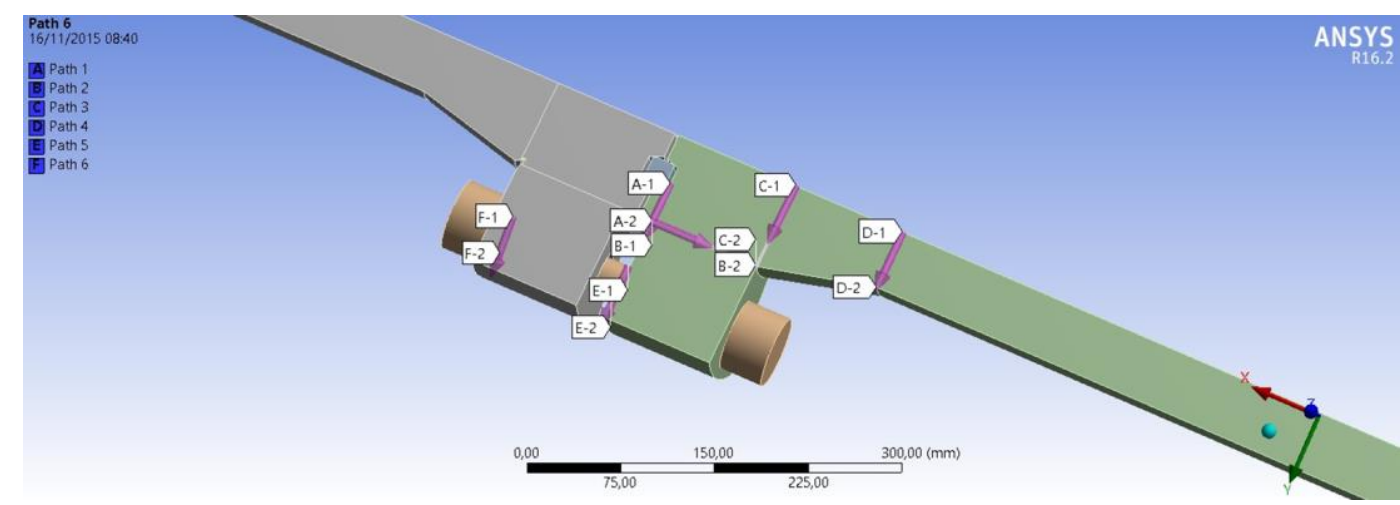

Figura 72: Definição dos caminhos.

\subsubsection{Premissas Térmicas}

As premissas térmicas (Figura 73) continuaram considerando que a região da base do flange atingisse a temperatura próxima de $-196^{\circ} \mathrm{C}$. Esta temperatura foi escolhida em função da disponibilidade de dados obtidos em ensaios realizados e publicados pela INCO [26] para avaliação. Além de se aproximar de estudos prévios realizados pela indústria.

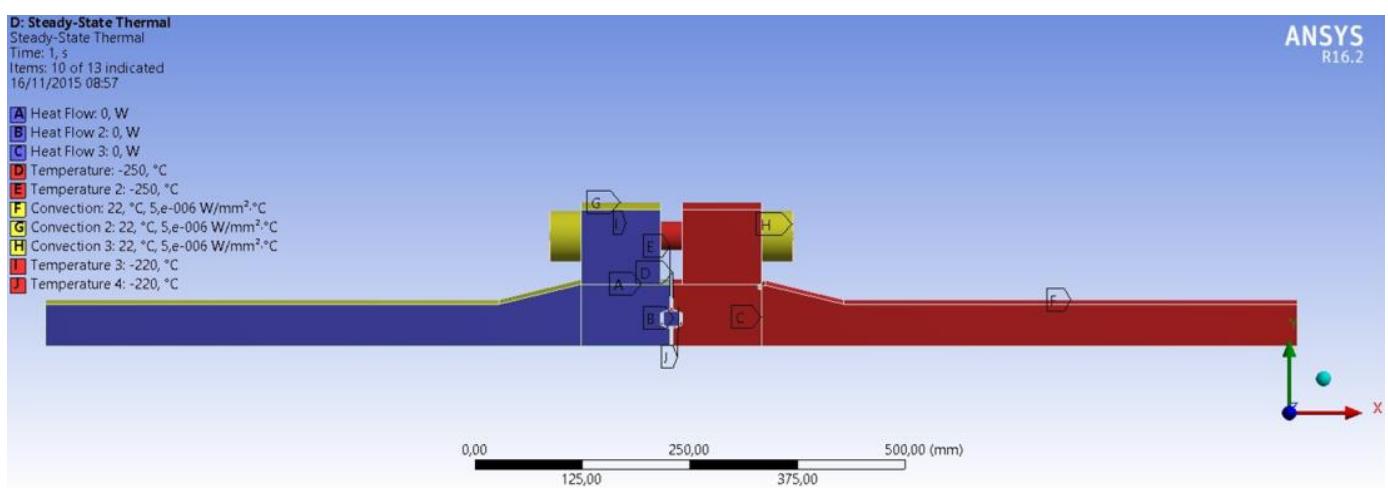

Figura 73: Condições de contorno térmico. 


\subsubsection{Premissas Estruturais}

O componente flange foi fixado apenas em um dos lados (Figura 74 eFigura 75). $\mathrm{O}$ outro tem liberdade para deslocamento. Isso representa a realidade destes equipamentos que são fixados nas plataformas de petróleo a partir de um sistema de travamento.

A pressão interna considerada foi de $69,8 \mathrm{MPa}$ (10.000 PSI) aplicado no flange (Figura 74 eFigura 75) e a força considerada dado a pressão interna dividida por 12 (em função da simetria da geometria) será igual a 104,81 kN. O pré-aperto dos estojos considerado foi de $50 \%$ da tensão de escoamento conforme visto na Tabela 15. Todos estes valores foram extraídos de dados reais de uma linha flexível de injeção de gás operando nos reservatórios de petróleo no Brasil.

Tabela 15: Pré-carregamento dos estojos.

\begin{tabular}{|l|l|l|l|}
\hline Material do Estojo & $\sigma_{\mathbf{y}}$ & $\begin{array}{l}\text { Pré-carregamento } \\
\left.\text { estojo [\% } \sigma_{\mathbf{y}}\right]\end{array}$ & $\begin{array}{l}\text { do } \\
\text { do estojo [kN] }\end{array}$ \\
\hline Inconel UNS N06625 & $725 \mathrm{MPa}$ & $50 \%$ & $346,50 \mathrm{kN}$ \\
\hline
\end{tabular}

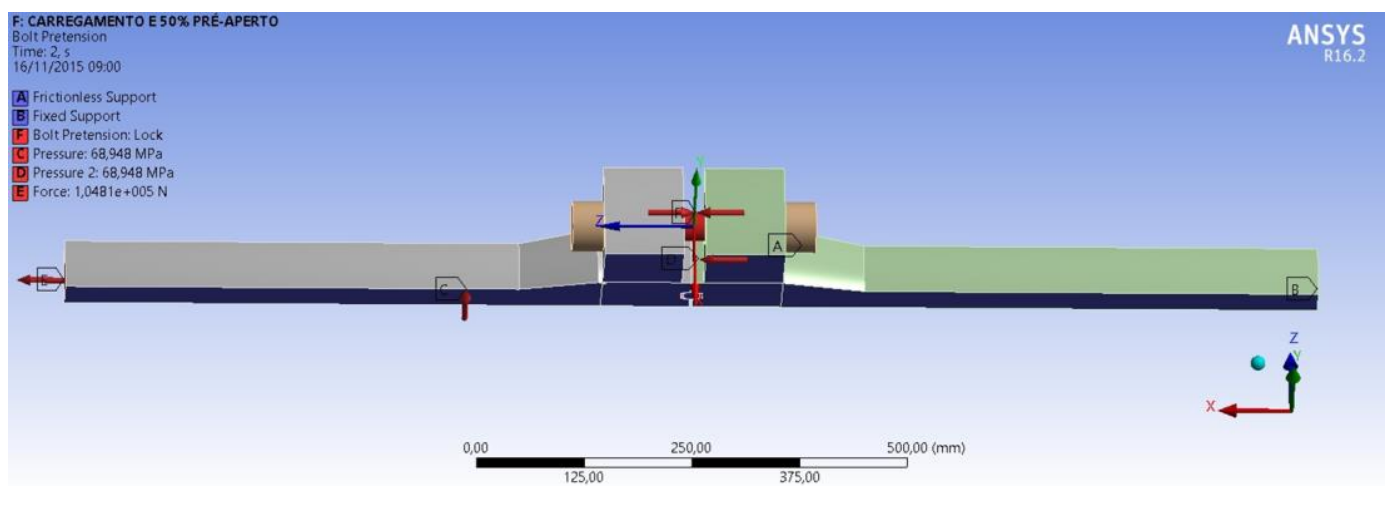

Figura 74: Premissas estruturais.

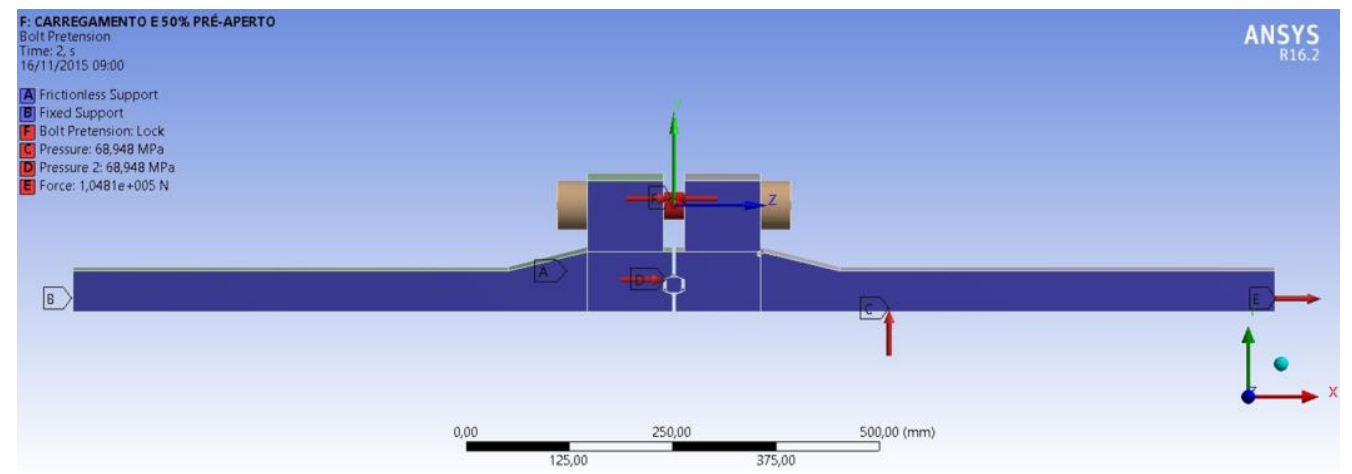

Figura 75: Premissas estruturais. 
Depois de todas as premissas estabelecidas no modelo numérico, o comando de cálculo é executado e obtém-se os valores para avaliação. A principal avaliação que se deseja obter nesta pesquisa é o valor de $\mathrm{K}_{\mathrm{I}}$ na ponta da trinca estudada. A validação do cálculo que o ANSYS executa para obter o valor de $\mathrm{K}_{\mathrm{I}}$ através do comando SIFS subtipo $\mathrm{K}_{\mathrm{I}}$ foi feita e será mostrada em seguida.

\subsubsection{ANSYS: Calcular o $\mathrm{K}_{\mathrm{I}}$}

Depois de todo o modelo desenvolvido e as premissas consideradas, avaliouse a partir do método de elementos finitos, com o emprego do programa ANSYS $16.2 \AA$, o comportamento à fratura do aço $9 \%$ Ni. Esta é a etapa que se pretende avaliar os efeitos de tensões de origem térmica e mecânica no comportamento à fratura do aço usando a metodologia de cálculo numérico do ANSYS.

O parâmetro considerado foi o fator de intensidade de tensões $\mathrm{K}$, usando o comando SIFS subtipo $\mathrm{K}_{\mathrm{I}}$. O comando de pós-processamento SIFS permite calcular o fator de intensidade de tensões para os três modos de carregamento (I, II, III), porém, a análise em pauta se limitou ao modo I. O objetivo é encontrar o valor de $\mathrm{K}_{\mathrm{I}}$ na ponta da trinca inserida no componente de modo a avaliar a integridade do mesmo quando comparado com dados de $\mathrm{K}_{\mathrm{IC}}$ obtidos na publicação da INCO [26].

De forma a validar os valores $\mathrm{K}_{\mathrm{I}}$ obtidos pelo ANSYS por esta metodologia de cálculo de $\mathrm{K}_{\mathrm{I}}$ através do comando SIFS $\mathrm{K}_{\mathrm{I}}$, simulou-se em uma chapa de

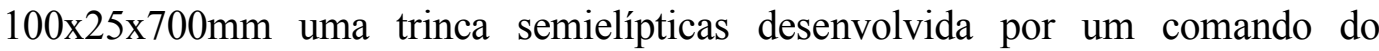
ANSYS (Fracture $\rightarrow$ Crack). Esta trinca foi inserida no centro da chapa com comprimento de $34,9 \mathrm{~mm}$ e profundidade de 6,5 $\mathrm{mm}$ (Figura 76, Figura 77 e Figura 78). A força aplicada para esta simulação foi de $104,81 \mathrm{kN}$ gerando uma tensão de 41,9 MPa longe da região da trinca. Na Figura 79Erro! Fonte de referência não encontrada. é mostrado o valor de tensão principal máxima e na Figura 80, o valor do fator de intensidade de tensão encontrado na ponta da trinca $\left(\mathrm{K}_{\mathrm{I}}=7,3401\right.$ MPa.m ${ }^{0,5}$ ). Para obter este valor, foi usado o mesmo comando do ANSYS (SIFS $\mathrm{KI})$ que será usado no modelo numérico para obter o valor de intensidade de tensão no flange do conector da linha flexível em estudo. O objetivo é conseguir validar os valores calculados automaticamente comparando-o com fórmulas conhecidas na 
literatura em geometrias e formas mais simples e conhecidas.

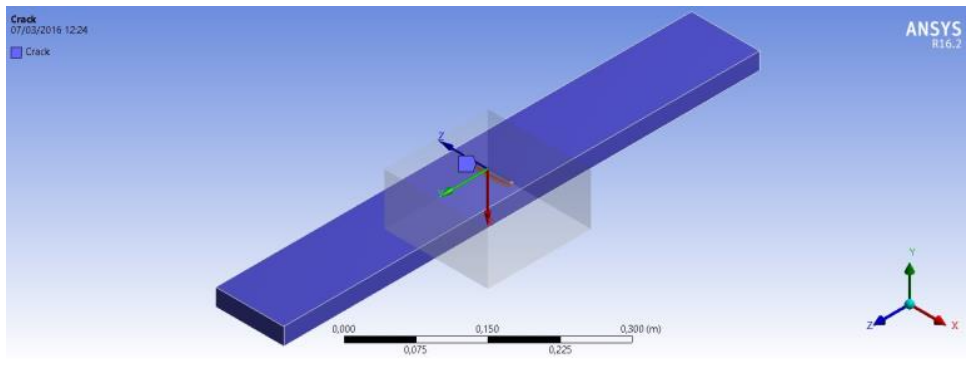

Figura 76: Trinca de $34,9 \mathrm{~mm}$ de abertura e $6,5 \mathrm{~mm}$ de profundidade em chapa de aço $9 \% \mathrm{Ni}$.

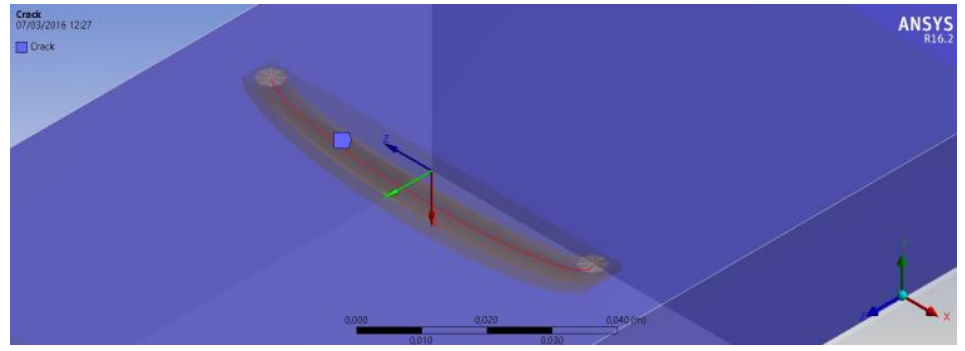

Figura 77: Trinca feita pelo comando Fracture $\rightarrow$ Crack de de 34,9 $\mathrm{mm}$ de abertura e $6,5 \mathrm{~mm}$ de profundidade em chapa de aço $9 \% \mathrm{Ni}$.

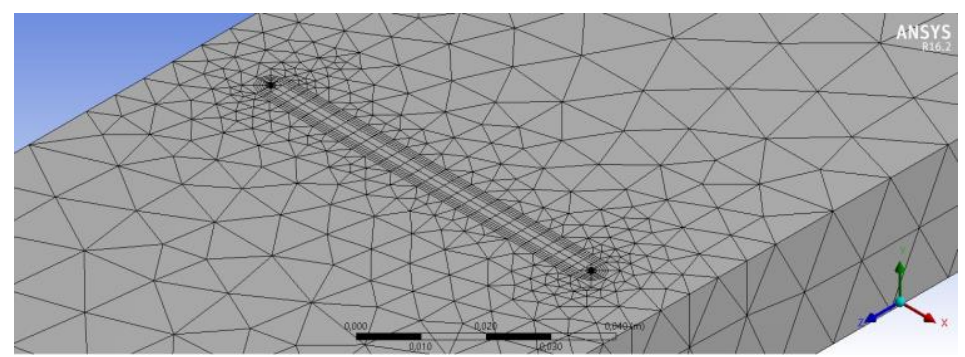

Figura 78: Malha da trinca feita pelo comando Fracture $\rightarrow$ Crack de de $34,9 \mathrm{~mm}$ de abertura e $6,5 \mathrm{~mm}$ de profundidade em chapa de aço $9 \% \mathrm{Ni}$.

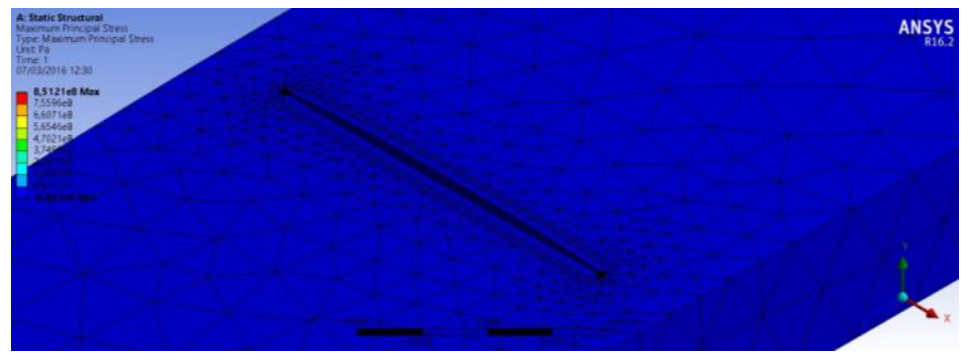

Figura 79: Tensão principal máxima na chapa (34,9x6,5mm). 


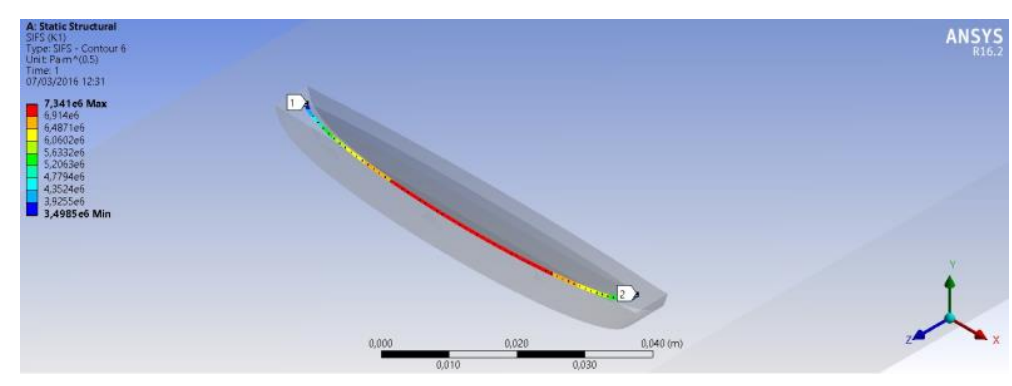

Figura 80: Fator Intensidade de Tensão na trinca $(34,9 \times 6,5 \mathrm{~mm})$.

Uma vez obtido os valores do fator de intensidade de tensão pelo método numérico na chapa 100x25x700 mm, calculou-se a partir da equação (Equação 3.5) sugeridas por Anderson, 2005 [27] (item 2.6.3) para trincas superficiais semielípticas em chapas (Figura 81) o valor de intensidade de tensão $\mathrm{K}_{\mathrm{I}}$. Em nosso exemplo os valores das variáveis da equação 3.5 são: $\mathrm{a}=6,5 \mathrm{~mm}, 2 \mathrm{c}=34,9 \mathrm{~mm}$ e $\sigma=41,9 \mathrm{MPa}$.

$$
K_{I}=\lambda_{s} \cdot \sigma \cdot \sqrt{\frac{\pi \cdot a}{Q} \cdot f(\phi)}
$$

\section{Eq. 3.5}

Onde,

$$
\begin{aligned}
& Q=1+1,464 \cdot\left(\frac{a}{c}\right)^{1,65} \\
& \lambda_{s}=\left\lfloor 1,13-0,09 \cdot\left(\frac{a}{c}\right) \mid \cdot\left[1+0,1(1-\operatorname{sen}(\phi))^{2}\right]\right. \\
& f(\phi)=\left[\operatorname{sen}^{2}(\phi)+\left(\frac{a}{c}\right)^{2} \cos ^{2}(\phi)\right]^{1 / 4}
\end{aligned}
$$

De modo a conhecer o valor de $\mathrm{K}_{\mathrm{I}}$ teórico para efeito de comparação, foi desconsiderado o valor de $\phi$. Assim, obteve o valor teórico de intensidade de tensão como sendo $\mathrm{K}_{\mathrm{I}}=5,5277 \mathrm{MPa} \cdot \mathrm{m}^{0,5}$. 


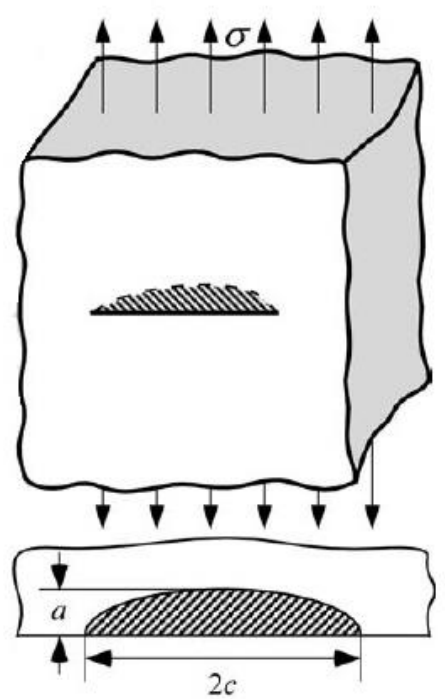

Figura 81: Esquema de trinca superficial semielíptica em chapa. Valores: a=6,5 mm, 2c=34,9 mm. [27]

Visto que o valor médio encontrado usando o comando SIFS (KI) do ANSYS na modelagem numérica da chapa e o valor teórico são muito próximos, podemos afirmar que o uso desta rotina é válido para avaliações onde se quer obter valores de intensidade de tensões. 


\section{RESULTADOS E DISCUSSÕES}

\subsection{Avaliação numérica do conjunto sem defeito}

\subsubsection{Análise Térmica}

A partir de um suposto vazamento de gás $\mathrm{CO}_{2}$ devido a falha da vedação do anel BX 156 na região do groove da conexão flangeada, observa-se nas Figura $82 \mathrm{e}$ Figura 83 que a temperatura de aproximadamente $-196^{\circ} \mathrm{C}$ é atingida na interface do flange com o corpo da terminação do conector. Esta é a região onde a pesquisa se concentrou.

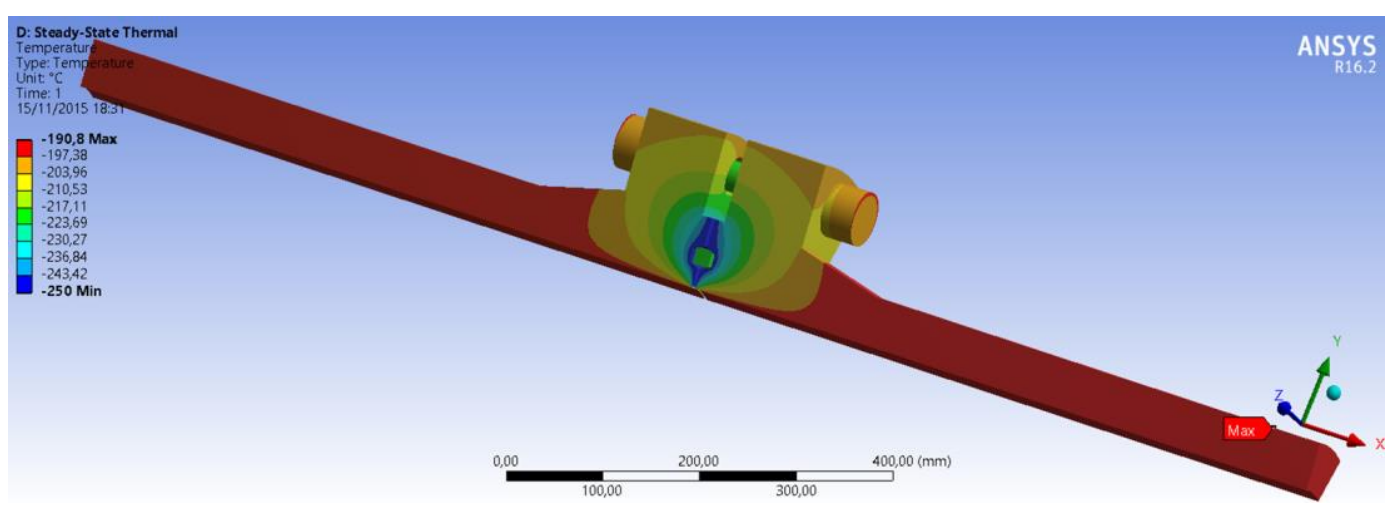

Figura 82: Resultado da Análise térmica.

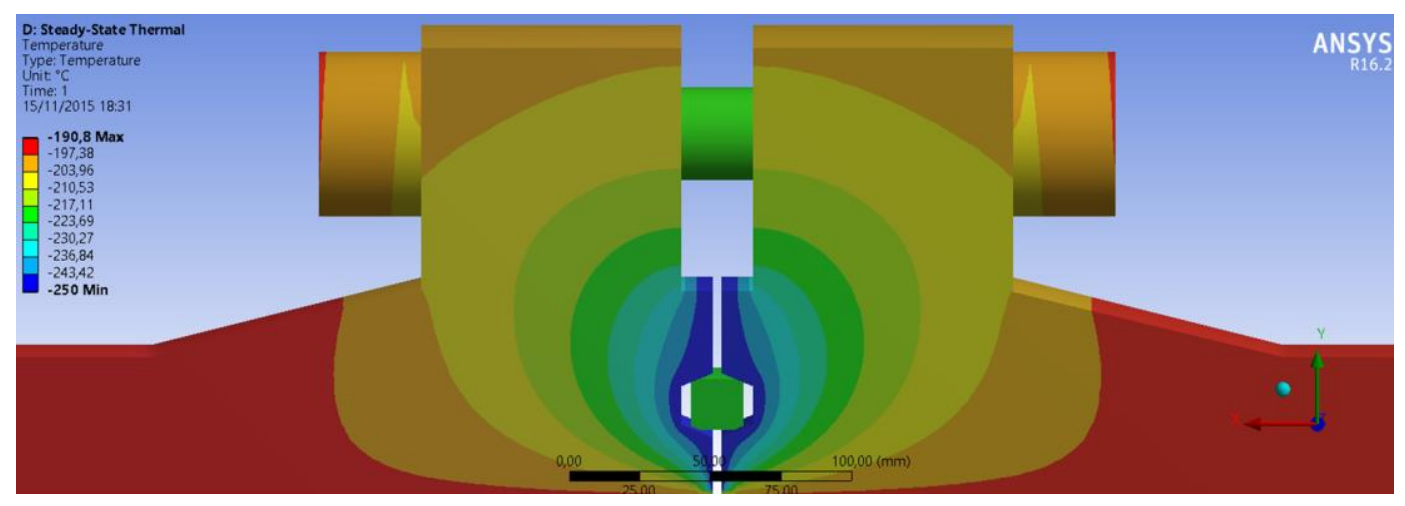

Figura 83: Resultado da Análise térmica.

\subsubsection{Análise Estrutural}

O resultado da análise estrutural na região do estudo mostrado nas Figura 84 e Figura 85 mostrou que a presença dos estojos e o pré-aperto considerado induz 
variações de tensões ao longo da região estudada. De forma conservadora foi considerada a maior tensão principal $(598,31 \mathrm{MPa})$ para avaliação analítica com a norma BS 7910 que serão vistos os resultados na seção em seguida. Já na Figura 86, vê-se o resultado das tensões de membrana e curvatura (336,4 MPa), importante para o cálculo no modelo analítico.

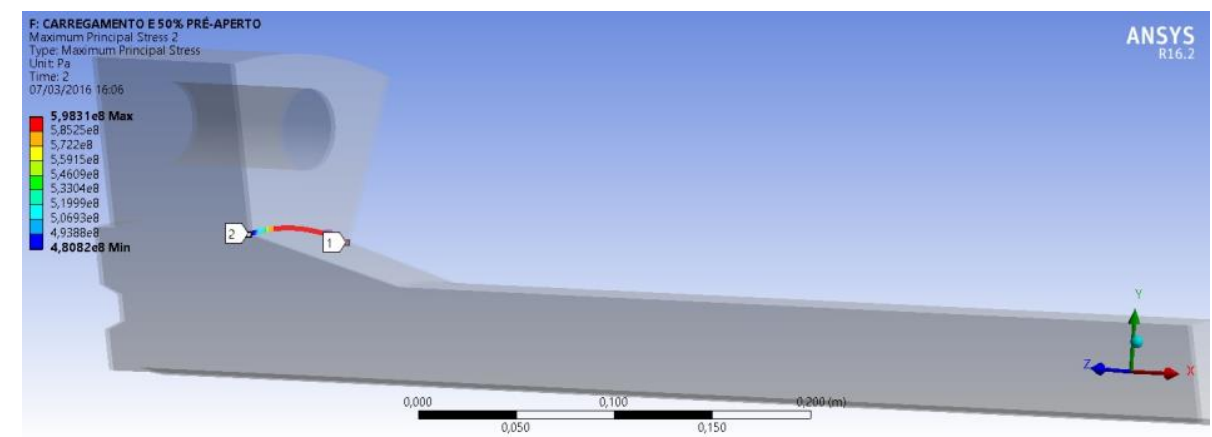

Figura 84: Resultado da análise estrutural.

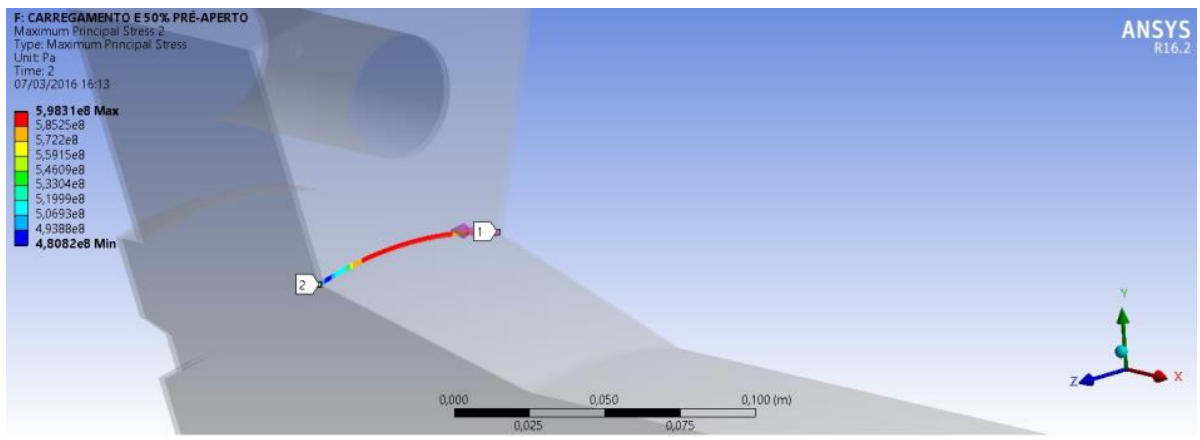

Figura 85: Resultado análise estrutural

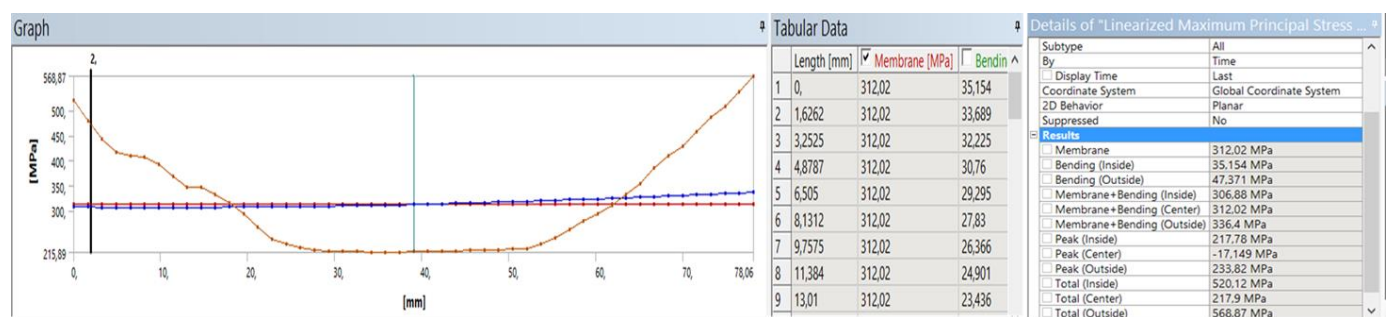

Figura 86: Resultado da análise estrutural (Tensão de Membrana e Curvatura) 


\subsection{Avaliação Analítica do Conjunto com o defeito}

A partir dos dados do material e os obtidos na avaliação numérica do componente sem a presença do defeito apresentados na seção acima, calculou-se a razão entre a intensidade de tensão do componente nas condições estudadas $\left(\mathrm{K}_{1 \mathrm{r} 1}=\right.$ 95,534 MPa.m $\left.{ }^{0,5}\right)$ e o do material $\left(\mathrm{K}_{\text {mat }}=283,334 \mathrm{MPa} \cdot \mathrm{m}^{0,5}\right)$, conhecido pelo símbolo $\mathrm{K}_{\mathrm{r} .1 \mathrm{rl}}$. O valor obtido foi $\mathrm{K}_{\mathrm{r} .1 \mathrm{rl}}=0,337$.

Outra informação importante para compor o ponto no gráfico FAD é a razão entre tensão principal na região de interesse $\left(\mathrm{S}_{1.1}=598,31 \mathrm{MPa}\right)$ e o limite de escoamento do material a $-196^{\circ} \mathrm{C}$ conforme a $\mathrm{BS} 7910\left(\mathrm{~S}_{\mathrm{ye}}=1084,589 \mathrm{MPa}\right)$, conhecido pelo símbolo $\mathrm{Lr}_{\mathrm{r} 1}$. O valor encontrado foi $\mathrm{Lr}_{\mathrm{r} 1}=0,31$.

Com estes dois valores calculados plotou os mesmos no gráfico FAD nível 2 (Gráfico 2). Pode-se observar que o ponto ficou dentro da região segura do gráfico, significando que a trinca com os carregamentos aplicados no componente podem continuar em operação. Os detalhes dos cálculos podem ser observados no Apêndice A.

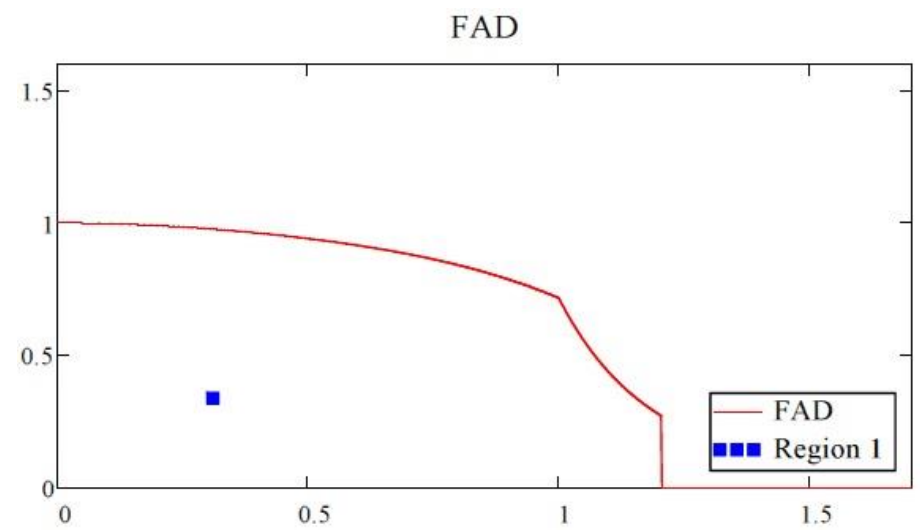

Gráfico 2: Resultado avaliação analítica através da ferramenta Mathcad para trinca de 6,5 $\mathrm{mm}(\mathrm{Lr} \times \mathrm{Kr})$.

De forma a conhecer a margem de segurança do componente nas condições de operação considerada na pesquisa, manteve-se o mesmo valor de $\operatorname{Lr}_{r 1}\left(\operatorname{Lr}_{r 1}=0,31\right)$ e variou o tamanho da trinca. O objetivo era conhecer quando o ponto irá ficar fora da região segura do gráfico (Gráfico 3). $\mathrm{O}$ valor máximo da trinca encontrado para esta condição limítrofe foi de $31,5 \mathrm{~mm}$ e a intensidade de tensão de $\mathrm{K}_{1 \mathrm{r} 1}=272,119$ MPa.m ${ }^{0,5}$. O valor da razão dos fatores de intensidade de tensão foi de $K_{\text {r.1r1 }}=0,96$. Os detalhes dos cálculos podem ser observados no Apêndice B. 
FAD

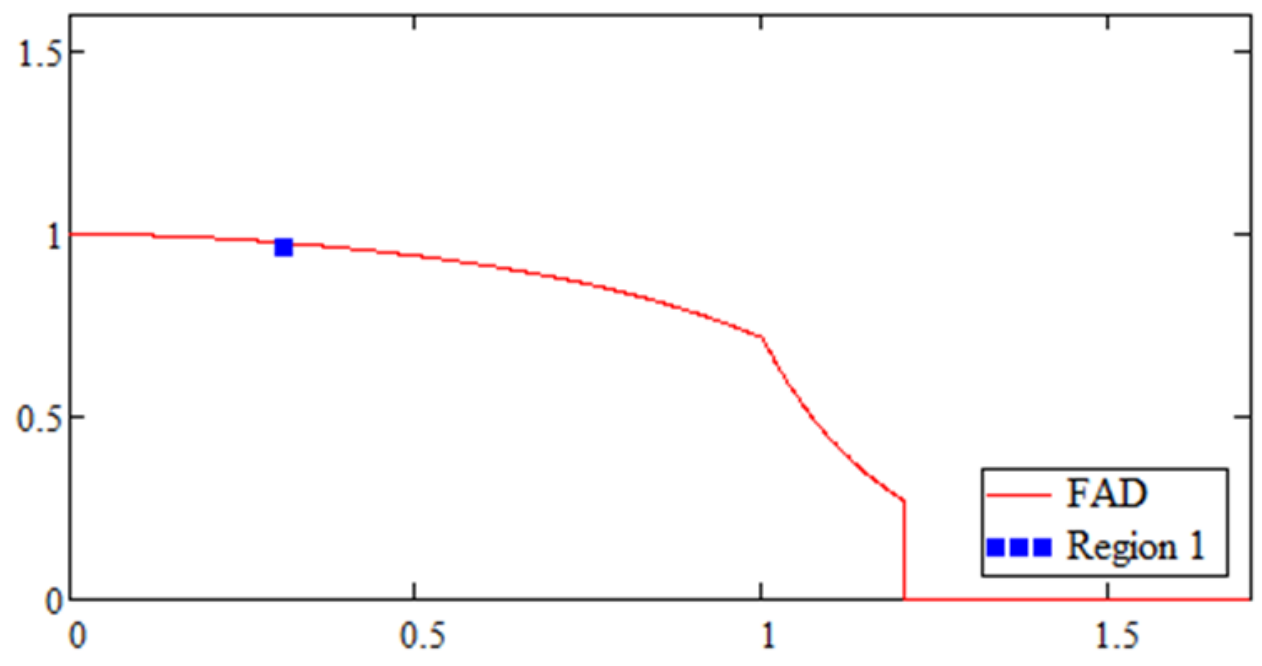

Gráfico 3: Resultado avaliação analítica através da ferramenta Mathcad para trinca de $31,5 \mathrm{~mm}(\mathrm{Lr} \times \mathrm{Kr})$.

Com os valores obtidos no caso da trinca estudada e a maior trinca aceitável para as condições operacionais, verificou-se que a trinca estudada é $20,6 \%$ do tamanho não aceitável e a razão dos fatores de intensidade tensão é $35,1 \%$ do aceitável.

\subsection{Avaliação Numérica do Conjunto com o defeito}

\subsubsection{Análise Térmica}

A partir de um suposto vazamento de gás $\mathrm{CO}_{2}$ devido a falha da vedação do anel BX 156 na região do groove da conexão flangeada, observa-se nas Figura 87 e Figura 88 que a temperatura de aproximadamente $-196^{\circ} \mathrm{C}$ é atingida na região da trinca, região esta, onde a pesquisa se concentrou. 


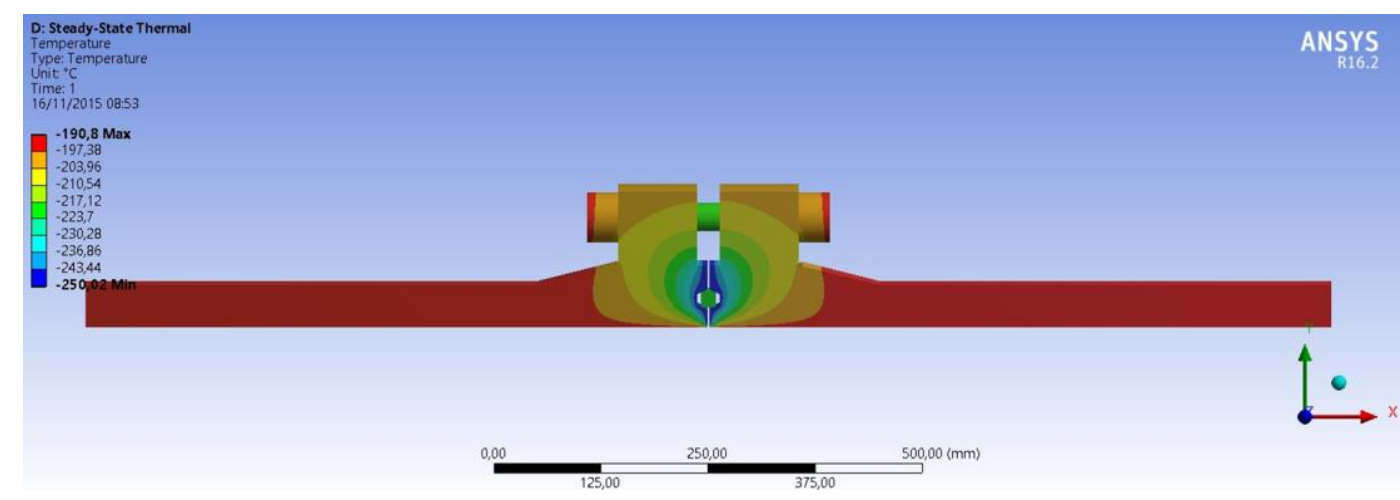

Figura 87: Resultado da análise térmica.

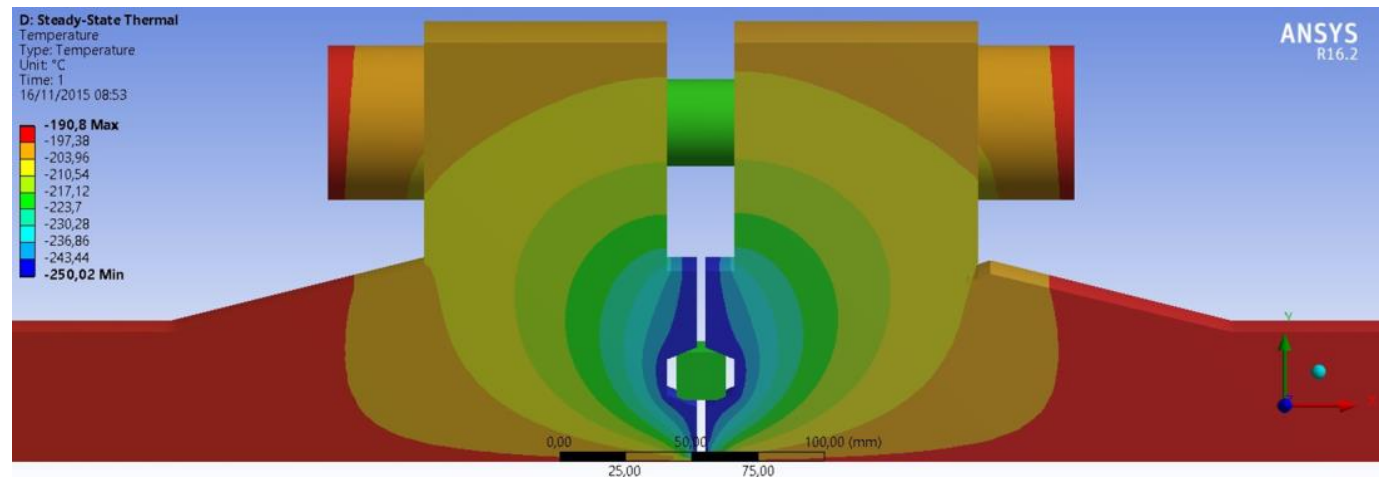

Figura 88: Resultado da análise térmica.

\subsubsection{Análise Estrutural}

O resultado da análise estrutural na região da trinca mostrado nas Figura 89, Figura , Figura 91, Figura 92 e Figura 93 mostrou que a presença dos estojos e o pré-aperto considerado induz variações de tensões ao longo da região estudada. A maior tensão está localizada no interior da trinca $(674,31 \mathrm{MPa})$. Comparando este valor com o obtido nesta mesma região sem a presença da trinca, observa-se que a presença da trinca intensificou a tensão por volta de $12 \%$ nesta região. 


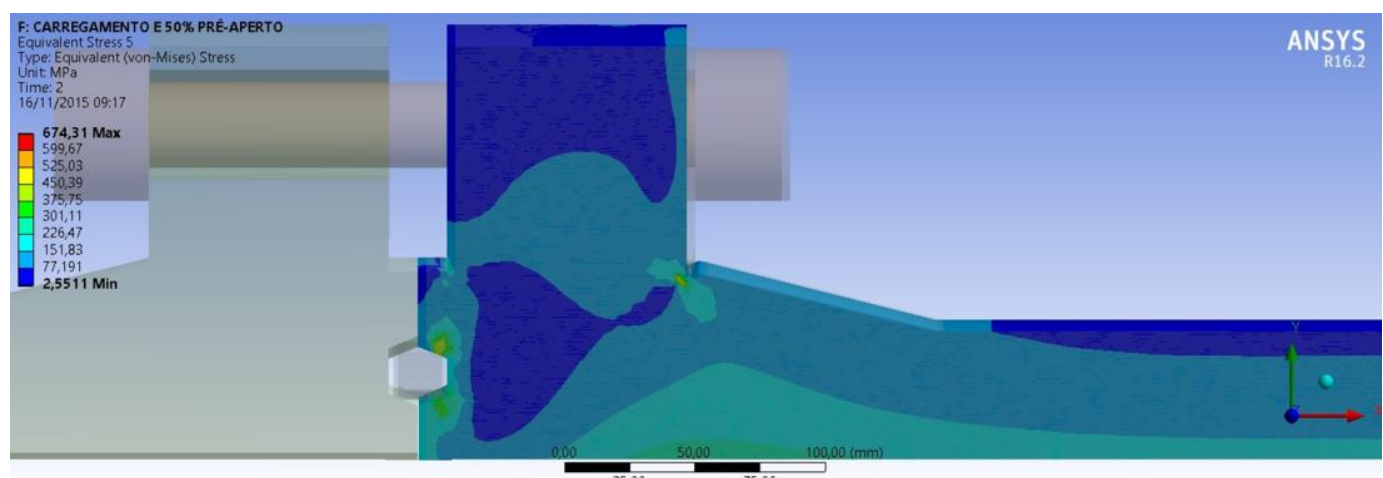

Figura 89: Resultado da Análise Estrutural.

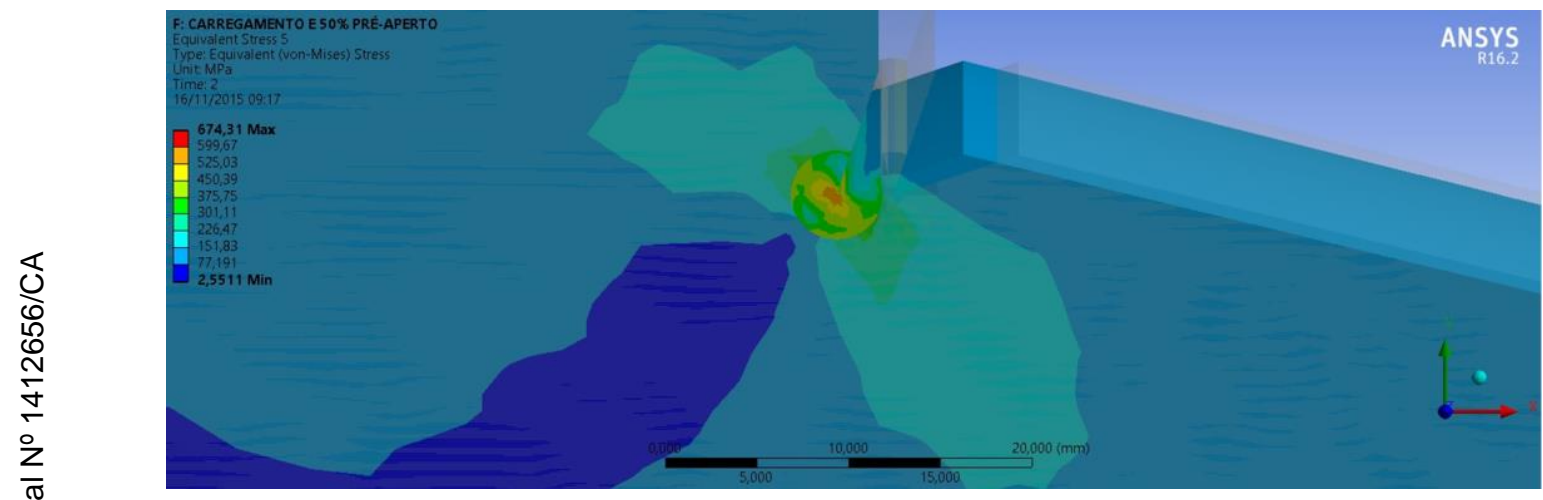

Figura 90: Resultado da Análise Estrutural.

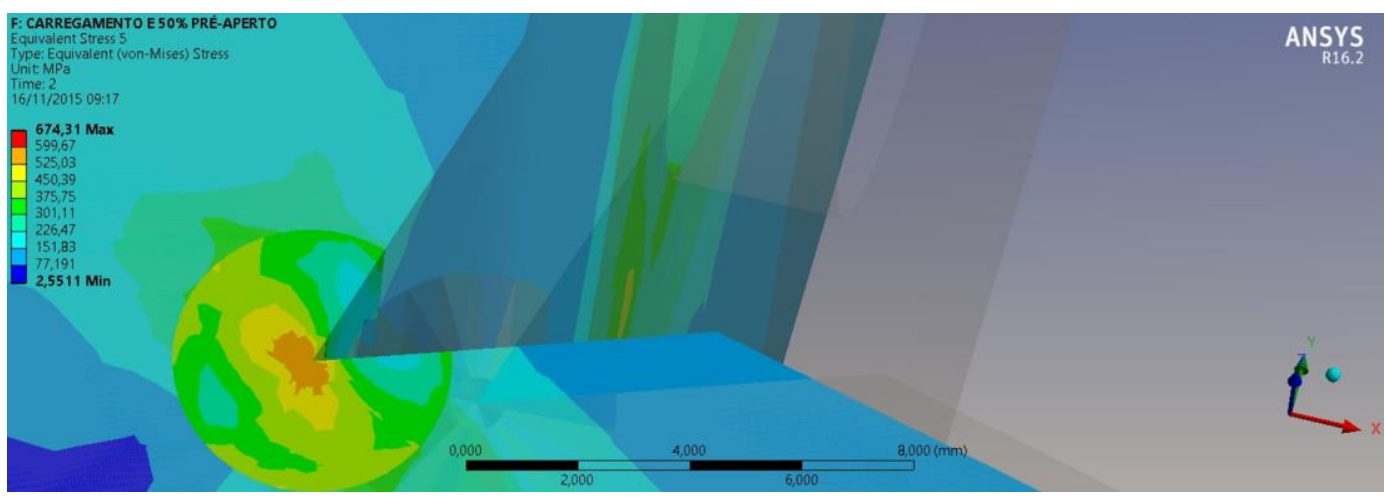

Figura 91: Resultado da Análise Estrutural. 


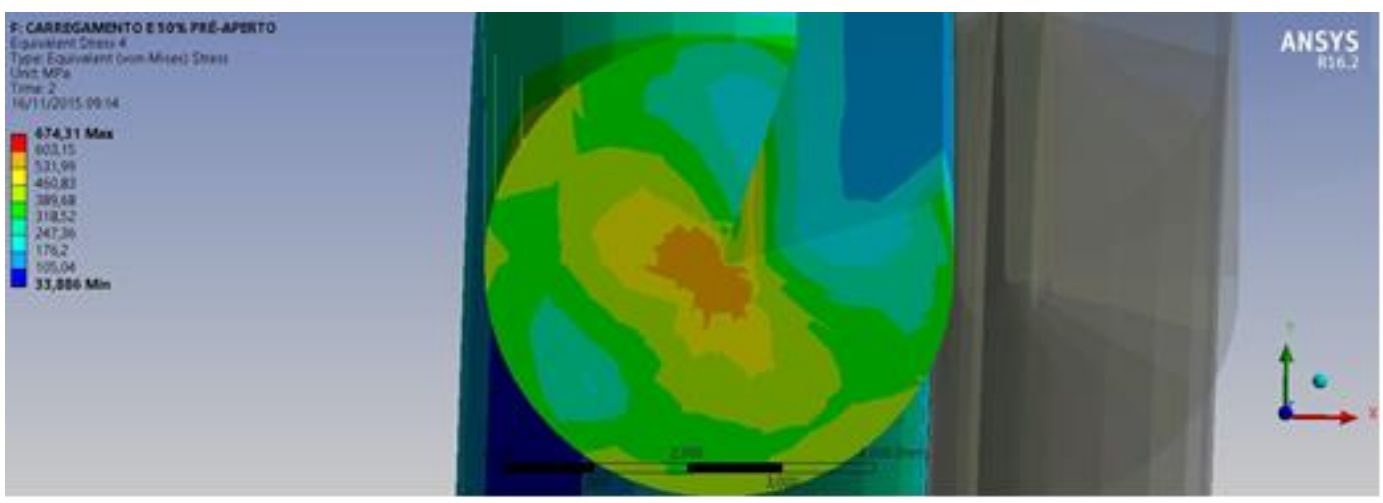

Figura 92: Resultado da Análise Estrutural.

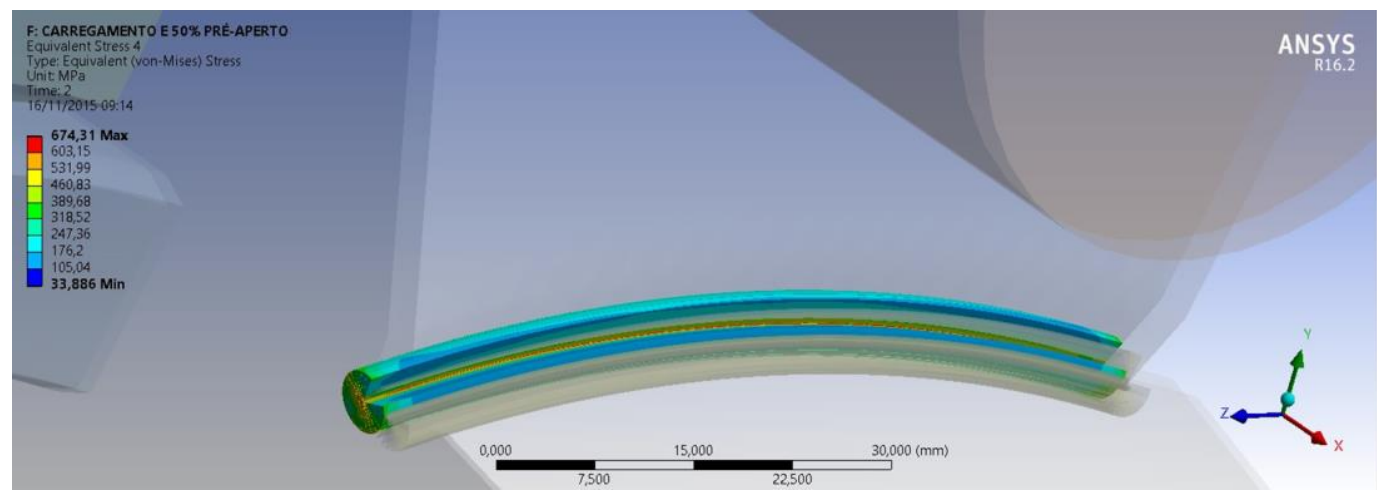

Figura 93: Resultado da Análise Estrutural.

\subsubsection{Análise Mecânica da Fratura}

Nesta etapa, temos o resultado da intensidade de tensão $\mathrm{K}_{\mathrm{I}}$ ao longo da aresta frontal da trinca calculado pelo comando SIFS (K1) da ferramenta ANSYS. No resultado mostrado nas Figura 94 e Figura 95 observa-se que a presença dos estojos e o pré-aperto considerado induziram variações da intensidade de tensão $K_{I}$ ao longo da ponta da trinca. Para a avaliação estrutural do componente, será considerado o maior valor encontrado $\left(\mathrm{K}_{\mathrm{I}}=111,3 \mathrm{MPa} \cdot \mathrm{mm}^{0,5}\right.$ ou $\left.\mathrm{K}_{\mathrm{I}}=3,52 \mathrm{MPa}^{0,5}\right)$. 


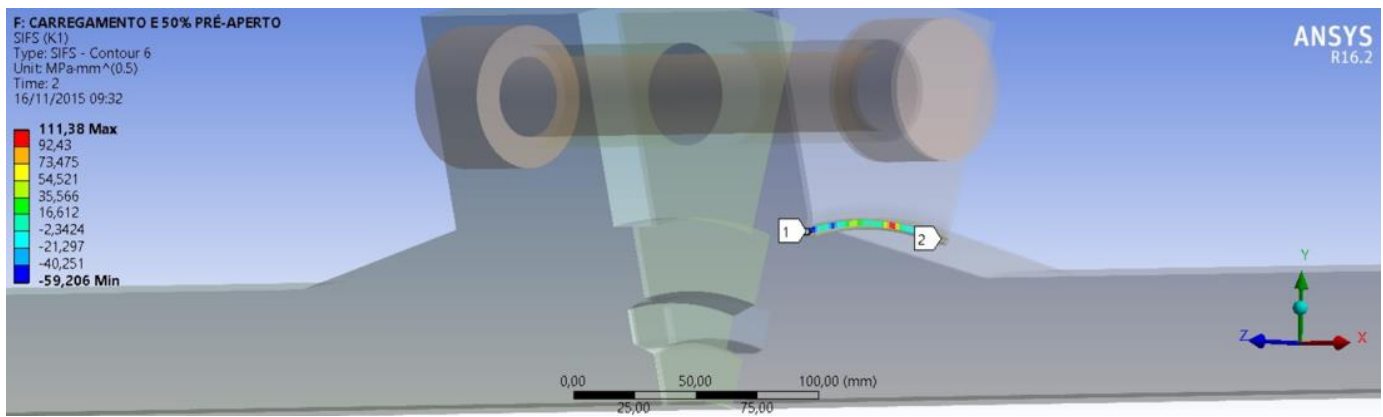

Figura 94: Resultado da análise mecânica de fratura.

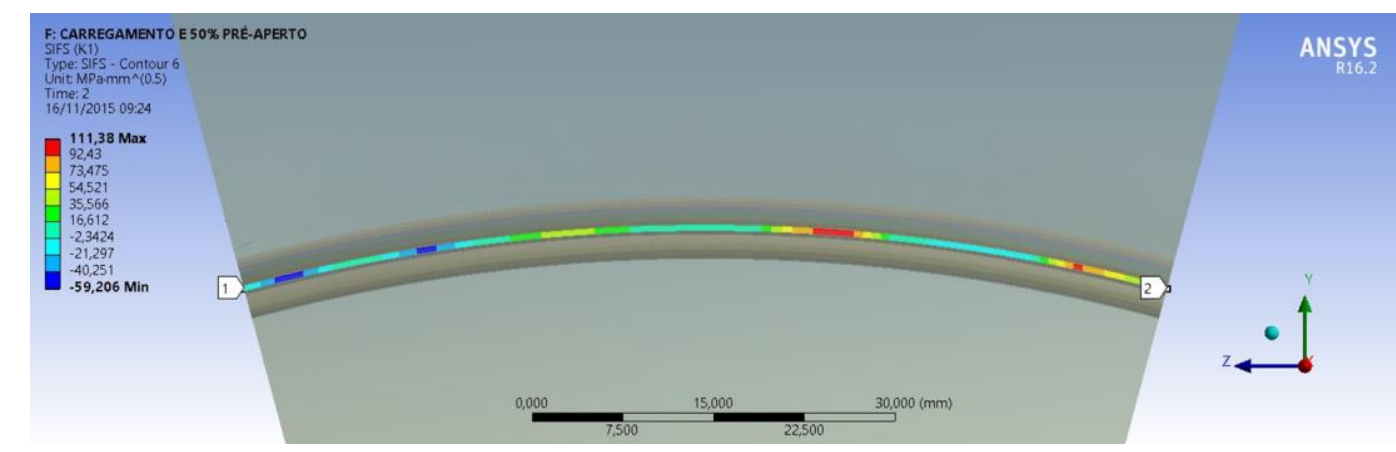

Figura 95: Resultado da análise mecânica de fratura.

$\mathrm{O}$ valor de $\mathrm{K}_{\mathrm{I}}$ encontrado por esta metodologia, que foi validada por modelos teóricos conforme Anderson, 2005 [27], mostra que o material aço 9\%Ni pode ser usado como material de conectores de topo de linhas flexíveis em condição operacional compatível com a estudada nesta pesquisa. Isso pode ser afirmado visto que os ensaios realizados pela INCO [26] mostram que o valor de $\mathrm{K}_{\mathrm{I}}$ crítico da liga $\mathrm{Fe}-\mathrm{C}-9 \% \mathrm{Ni}$ a $-196^{\circ} \mathrm{C}$ varia de 159 a $305 \mathrm{MPa} \cdot \mathrm{m}^{0,5}$. 


\section{CONCLUSÕES}

Esta pesquisa apresenta o estudo potencial de aplicação de uma liga metálica da família do aço $9 \% \mathrm{Ni}$, usualmente usada em tanques de armazenamento de Gás Natural Liquefeito, na fabricação de terminações de conectores de linhas flexíveis de injeção de gás $\mathrm{CO}_{2}$ comparando os valores da intensidade de tensão calculados por dois métodos: Método de Elementos Finitos (ANSYS 16.2 ®) e Método Analítico seguindo a norma BS 7910. Para tal, foram utilizados os dados relativos à geometria do componente em estudo, o comprimento de trinca de $6,5 \mathrm{~mm}$ de abertura e profundidade e os valores máximos da intensidade de tensão correspondente às situações extremas de carregamento e mínimas de temperatura, além das propriedades dos materiais.

$\mathrm{Na}$ primeira metodologia de análise usada na pesquisa, o cálculo analítico seguiu o nível 2 da norma BS 7910. A partir de avaliações numéricas realizadas na ferramenta ANSYS 16.2 ® em uma conexão flangeada sem a presença de defeitos entre uma linha flexível e os equipamentos da plataforma de petróleo chegou-se as tensões principais máximas (598,31 MPa), tensão de membrana e de curvatura (336,4 MPa) na interligação entre o flange 7 1/16" API 6BX 10.000 psi e o corpo da terminação do conector. As premissas operacionais como a pressão interna de 69,8 MPa e a temperatura mínima em caso de falha da selagem da conexão de $196^{\circ} \mathrm{C}$ foram obtidas de linhas flexíveis reais operando nos reservatórios de petróleo brasileiros.

Se o resultado obtido do fator de intensidade de tensão seguindo a norma BS $7910\left(\mathrm{~K}_{\mathrm{I}}=95 \mathrm{MPa}^{0} \mathrm{~m}^{0,5}\right)$ for comparado com a tenacidade a fratura do material aço 9\% $\mathrm{Ni}\left(\mathrm{K}_{\text {Imat }}=283 \mathrm{MPa} . \mathrm{m}^{0,5}\right)$ obtido na literatura pode-se concluir que nas condições operacionais estudadas, o aço $9 \% \mathrm{Ni}$ pode ser usado em flanges ou terminações de linhas flexíveis de injeção de gás $\mathrm{CO}_{2}$. De modo a conhecer o quanto que a trinca de $6,5 \mathrm{~mm}$ estudada no trabalho está em relação ao tamanho máximo de trinca admissível $(a=31,5 \mathrm{~mm})$ nas condições operacionais estudadas, a norma BS 7910 foi seguida novamente e chegou-se à conclusão que o tamanho da trinca considerada na pesquisa é $20,6 \%$ do tamanho crítico de trinca considerada na pesquisa. Isso mostra a grande margem de segurança para o uso deste material nas terminações de conectores das linhas flexíveis em aplicações de injeção de gás seguindo o método analítico da norma BS 7910. 
$\mathrm{Na}$ segunda metodologia de análise usada na pesquisa, o modelo numérico desenvolvido na ferramenta ANSYS 16.2® também considerou uma conexão flangeada entre uma linha flexível e os equipamentos da plataforma de petróleo. Foi considerado uma trinca de $6,5 \mathrm{~mm}$ ao longo do perímetro na interligação entre o flange 7 1/16" API 6BX 10.000 psi e o corpo da terminação do conector. As mesmas premissas operacionais usadas na primeira metodologia foram consideradas. A pressão interna de 69,8 MPa e a temperatura mínima em caso de falha da selagem da conexão de $-196^{\circ} \mathrm{C}$ foram obtidas de linhas flexíveis reais operando nos reservatórios de petróleo brasileiros.

De modo a validar os cálculos que a ferramenta ANSYS 16.2® utiliza para obter os valores do fator de intensidade de tensão a partir do comando SIFS subtipo KI, foi considerado uma chapa com uma trinca com tamanhos conhecidos. Comparou-se os valores obtidos através da ferramenta numérica $\left(\mathrm{K}_{\mathrm{I}}=7,3401\right.$ MPa.m $\left.{ }^{0,5}\right)$ e equações teóricas conforme Anderson, $2005\left(\mathrm{~K}_{\mathrm{I}}=5,5277 \mathrm{MPa}^{0,5}\right)$ e concluiu que os resultados dos cálculos utilizando o comando SIFS subtipo KI são válidos.

Assim, o modelo numérico na ferramenta ANSYS 16.2® foi executado e dados do fator de intensidade de tensão na ponta da trinca foram obtidos $\left(\mathrm{K}_{\mathrm{I}}=3,52\right.$ MPa.m ${ }^{0,5}$ ). $\mathrm{O}$ valor de $\mathrm{K}_{\mathrm{I}}$ encontrado por esta metodologia, que foi validada por modelos teóricos conforme Anderson, 2005 [27], mostra que o material aço 9\% $\mathrm{Ni}$ pode ser usado como material de conectores de topo de linhas flexíveis em condição operacional compatível com a estudada nesta pesquisa. Isso pode ser afirmado visto que os ensaios realizados pela INCO [26] mostram que o valor de $\mathrm{K}_{\mathrm{I}}$ crítico deste material a $-196^{\circ} \mathrm{C}$ varia de 159 a $305 \mathrm{MPa} \cdot \mathrm{m}^{0,5}$.

Os resultados obtidos mostraram que nas condições operacionais estudadas, usando tanto a metodologia analítica da norma BS 7910 quanto a metodologia numérica usando modelos e comandos na ferramenta ANSYS como o SIFS subtipo $\mathrm{K}_{\mathrm{I}}$, o aço $9 \%$ Ni pode ser usado em flanges ou terminações de linhas flexíveis de injeção de gás $\mathrm{CO}_{2}$. Desta maneira, esta pesquisa contribuiu para que a indústria offshore de petróleo tenha mais uma opção de material para ser adotado na fabricação de conectores de topo das linhas flexíveis que trabalhem em condição criogênica. 


\section{Referências bibliográficas}

[27] ANDERSON, T. L., Fracture Mechanics - Fundamentals and Applications, CRC Press, Boca Raton, $3^{\text {rd }}$ Edition, 2005.

[53] ANSI/API SPECIFICATION 6A, Specification for Wellhead and Christmas Tree Equipment. Twentieth edition, october 2010. Effective date: April 1, 2011.

[45] ANSYS ${ }^{\circledR}$, “Element Reference Library”. ANSYS Help.

[25] ARCELOR MITTAL USA, Nickel Steel: For use Cryogenic temperatures. Dezembro 2010 - Plate 9\%

[14] ASM INTERNATIONAL HANDBOOK COMMITTEE, Nickel, Cobalt and their Alloys, Davis \& Associates, 2000.

[35] ASTM E1820, 2001, "Standard Test Method for Measurement for Fracture Toughness", In: Annual Book of ASTM Standards, v. 03.01, pp. 1-45, ASTM, Philadelphia.

[46] ATLURI, A. N., NAKAGAKI, M., 1986, "Computation methods for Plane Problems of Fracture", In: ATLURI, A. N. (eds), Computational Methods in Mechanics - Computational methods in the Mechanics of Fracture, v. 2, chapter 6, New York, Elsevier Science Publishers.

[7] BACHU, STEFAN, et al. 2000. Suitability of the Alberta Subsurface for Carbon-Dioxide Sequestration in Geological Media. [Online] Alberta Energy and Utilities Board, Março 2000. [Cited: agosto 19, 2015.

[47] BARSOUM, R. S., 1974 "Application of Quadratic Isoparametric Finite Elements in Linear Fracture Mechanics", International Journal of Fracture, vol. 10, pp. 603-605. 
[42] BATHE, K-J, 1996, “An Introduction to the Use of Finite Element Procedures". Finite Element Procedures. 1 ed., chapter 1, United States, Prentice Hall.

[30] BASTIAN, F.L., CAMINHA, H.M., MORAES M., "Mecânica da Fratura Elasto Plástica", Apostila de Mecânica da Fratura, capítulo 4, EMM/COPPE/UFRJ, Rio de Janeiro, RJ, Brasil.

[38] BASTOS. J.P. A. Electromagnetic Modeling by Finite Element Methods. Florianopolis: Marcel Dekker, Inc. 2005.

[51] BROCKS, W., CORNEC, A., SCHEIDER, I., 2002, “Computational Aspects of Nonlinear Fracture Mechanics", Technical Note GKSS/WMS/02/05, Institute of Materials Research -GKSS research centre Geesthacht.

[48] BROCKS, W., CORNEC, A., SCHEIDER, I., 2002, "Computational Aspects of Nonlinear Fracture Mechanics", Technical Note GKSS/WMS/02/05, Institute of Materials Research-GKSS research centre Geesthacht.

[36] BROCKS, W., CORNEC, A., SCHEIDER, I., 2002, “Computational Aspects of Nonlinear Fracture Mechanics", Technical Note GKSS/WMS/02/05, Institute of Materials Research -GKSS research centre Geesthacht.

[50] BROCKS, W., MULLER, W., OLSCHEWSKI, J., 1985 "Experiences in Applying ADINA to the Analysis of Crack Tip Fields in Elastic-Plastic Fracture Mechanics", International Journal of Solids Structures, vol. 11, pp. 601616.

[52] BS 7910:2005 — Guide to Methods for Assessing Acceptability of Flaws in Metallic Structures, July/2005, BSI — British Standards Institution.

[4] BT 01-09 - ACIDENTE EM PLANTA DE GNL - SHANGHAI TRANSPETRO - BOLETIM TÉCNICO DGN/SMSOP/TIPSEG elaborado por 
Ana Paula Bahiense em 03/2009.

[5] CARDOSO, LUIS CLÁUDIO DOS SANTOS. LOGÍSTICA DO PETRÓLEO: TRANSPORTE E ARMAZENAMENTO. RIO DE JANEIRO: INTERCIÊNCIA, 2004. THOMAS, JOSÉ EDUARDO. FUNDAMENTOS DE ENGENHARIA DE PETRÓLEO. 2. ED. Rio de Janeiro: Interciência, 2004.

[41] COOK, R.D., 1995, “INTRODUCTION”. FINITE ELEMENT MODELLING FOR STRESS ANALYSIS. 1 ED., CHAPTER 1, United States, John Willey and Sons.

[44] COOK, R.D., 1995, “3D Solids and Solids of Revolution”. Finite Element Modelling for Stress Analysis. 1 ed., chapter 6, United States, John Willey and Sons.

[13] CRAIG, B. D., SMITH, L., Corrosion Resistent Alloys (CRAs) in the oil and gas industry - selection guidelines update, 3ed. Nickel Institute, 2011.

[32] DOWD, N. P.; Applications of Two Parameters Approaches in Elastic-Plastic Fracture Mechanics. Engineering Fracture Mechanics, Vol. 52, número 3. Pp. 445-465. 1995.

[33] EWALDS, H. L. \& WANHILL, R. J. H.; Fracture Mechanics. London New York Melbourme Auckland,1993, 304p.

[15] FLOREEN, S., FUCHS, G. E., YANG, W. J., “The Metallurgy of Alloy 625”, In: Superalloys 718, 625 and Various Derivatives, pp. 13 - 37, 1994.

[31] FONTES, O.H.P.M., 2014, Curvas de Resistência e Tenacidade à Fratura de Laminado Fibra-Mtela GLARE em Baixa Temperatura, Tese D.Sc., COPPE/UFRJ, Rio de Janeiro, RJ, Brasil.

[26] FRACTURE TOUGHNESS AND RELATED CHARACTERISTICS OF THE CRYOGENIC NICKEL STEELS - INCO, The International Nickel 
Company, INC. P.O. Box 200, Suffern, N.Y.10901.

[16] G.R.BROPHY : United States Patent, International Nickel Co., (1946), Serial No.687876.

[17] G.R.BROPHY AND A.J.MILLER : Trans. ASM, Vol.41, 1949, p11851203.

[28] HERTZBERG, R. W., Deformation and Fracture Mechanics of Engineering Materials; John Wiley \& Sons, 1989.

[22] H.MIYAKOSHI, N.ISHIKURA, T.SUZUKI AND K.TANAKA : Proceedings for Transmission Conf., Atlanta, 1981, American Gas Association, T155-T166.

[19] J.PITAUD : Rev. Metallurg, 60, (1963), p83.

[6] JOHNSON, FRED V. NYDEGGER, ROLAND R. Apparatus for handling strands. United States Patent 2106803, 01 fev. 1938.

[40] LAI, W.M, RUBIN, D., KREMPL, E., 2010, “Introduction", Introduction to Continuum Mechanics, 4 ed., chapter 1, United States, Elsevier.

[11] LOBIANCO, S.L.A., SIMÕES, F.S., FILHO, I.D.A.M., 2008 "Manual para Monitoramento/Inspeção de Linha Flexível Submarina - Inspeção Baseada em Risco-IBR”. Bol. téc. Petrobras, Rio de Janeiro, Setembro.

[49] MCMEEKING, R. M., RICE, J. R., 1975 "Finite-Element Formulations for Problems of Large Elastic-Plastic Formulations", International Journal of Solids Structures, vol. 11, pp. 601-616.

[10] MCS INTERNATIONAL AND UKOOA Guidance Note, 2002, "Monitoring Methods and Integrity Assurance for Unbonded Flexible Pipe". Doc No. 2-1-4-221/GN01 Revision 5, October , pp 06-52. 
[23] N.ISHIKURA, T.KOHNO, H.MAEDA, K.ARIMOCHI AND K.TANAKA : International Conference "Transport and Storage of LNG \& LPG", Brugge, Belgium, 1984, p1-11.

[20] N.J.CUPERUS, Proceedings for Tenth World Petroleum Congress, Heyden \& Son, London, 1979, Panel Discussion 17, Paper3, p119-129.

[2] POPP, JOSÉ HENRIQUE. Geologia Geral. 6. ed. Rio de Janeiro: LTC, 2010. p. 309.).

[24] R.D.STOUT AND S.J.WIERSMA, 8th International Conference of Liquefied Natural Gas, Session3, Paper No.5,(1986).

[43] RIBEIRO, F.L.B., "Introdução ao Método dos Elementos Finitos", Notas de aula do professor Fernando L. B. Ribeiro, capítulo 1, PEC/COPPE/UFRJ, Rio de Janeiro, RJ, Brasil.

[29] RICARDO, L. C. H.; Modelagem do Fenômeno de Abertura e Fechamento de Trincas em Fadiga Pelo Método de Elementos Finitos. Tese de Doutorado, Universidade de São Paulo, 2003. 129p.

[37] RICE, J.R., "A Path Independent Integral and the Approximative Analysis of Strains Concentrations by Notches and Cracks", 1968, Journal of Applied Mechanics - Transactions of the ASME, pp. 379-386.

[39] SEgERlind, L. J. Applied Finite Element Analysis. Nova lorque: John Wiley \& Sons, 1976.

[21] S.HONGO, N.KUBO : Journal of the Japan Welding Society, 63, 2(1994), p95. (in Japanese)

[8] SILVA, V. R. M.; Análise global de riser rígido vertical tracionado no 
topo para águas ultra-profundas, Rio de Janeiro: UFRJ/Escola Politécnica, 2011.

[9] SOLANO, R. F.; Flambagem Térmica de um Sistema Pipe-in-Pipe Dual em Águas profundas, Rio de Janeiro: UFRJ/COPPE, 2001.

[12] SPECIAL METALS, Propriedades metalúrgicas da liga Inconel 625. Disponível em: http://www.specialmetals.com/documents/Inconel\%20alloy\%20625.pdf Acessado em: 26/10/2015.

[1] THOMAS, JOSÉ EDUARDO. Fundamentos de engenharia de petróleo. 2. ed. Rio de Janeiro: Interciência, 2004.

[18] T.ITOU, et al. : Yawata Technical Report, No.252, 1965, pp.6120-6147.

[34] WELLS, A.A., "Unstable Crack Propagation in Metals: Cleavage and Fast Fracture.", 1961, Proceedings of the Crack Propagation Symposium, v. 1, Paper 84, Cranfield, UK.

[3]http://www.petrobras.com.br/pt/nossas-atividades/areas-deatuacao/exploracao-e-producao-de-petroleo-e-gas/pre-sal/).

http://www.ags.gov.ab.ca/publications/ESR/PDF/ESR_2000_11.PDF 
ANEXO A

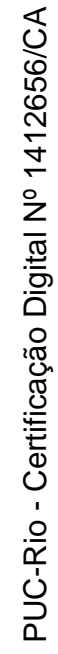




\section{1) Mechanical properties}

$\begin{array}{ll}\begin{array}{l}\text { Young Modulus } \\ \text { Poisson Ratio }\end{array} & \begin{array}{l}\mathrm{E}:=209 \mathrm{GPa} \\ \mathrm{v}:=0.3\end{array} \\ \text { Engineering Yield Strength } & \text { Sye }:=1084.589 \mathrm{MPa} \\ \text { Engineering Tensile Strength } & \text { Sue }:=1278.619 \mathrm{MPa} \\ \text { Engineering Tensile Strain } & \varepsilon_{\mathrm{u}}:=0.22 \\ \text { True Yield Strength } & \text { Sy }:=\text { Sye } \cdot(1+\ln (1+0.002)) \\ & \text { Sv }:=\text { Sye } \cdot(1+\ln (1+0.002)) \\ & \text { Sy }=1.087 \times 10^{3} \cdot \mathrm{MPa} \\ \text { True Ultimate Strength } & \mathrm{Su}:=\text { Sue } \cdot\left(1+\ln \left(1+\varepsilon_{\mathrm{u}}\right)\right) \\ & \mathrm{Su}=1.533 \times 10^{3} \cdot \mathrm{MPa}\end{array}$

\section{2) Toughness properties}
CTOD
$\delta_{\mathrm{c}}:=0.19 \mathrm{~mm}$
$\underset{m}{m}:=\left\{\begin{array}{l}1.517 \cdot\left(\frac{\mathrm{Sy}}{\mathrm{Su}}\right)^{-0.3188} \\ 1.5 \text { otherwise }\end{array}\right.$ if $0.3<\left(\frac{\mathrm{Sy}}{\mathrm{Su}}\right)<0.98$
$\mathrm{m}=1.693$ 
Fracture Toughness $\quad \mathrm{K}_{\mathrm{mat}}:=\sqrt{\frac{\mathrm{m} \cdot \mathrm{Sy} \cdot \delta_{\mathrm{c}} \cdot \mathrm{E}}{1-\mathrm{v}^{2}}} \quad \mathrm{~K}_{\text {mat }}=283.334 \mathrm{~m}^{0.5} \cdot \mathrm{MPa}$

Extend of the plastic zone $\quad a_{\mathrm{pl}}:=\left(\frac{1}{\pi}\right) \cdot\left(\frac{\mathrm{K}_{\mathrm{mat}}}{\mathrm{Sy}}\right)^{2} \quad \mathrm{a}_{\mathrm{pl}}=21.636 \cdot \mathrm{mm}$

\section{3) Stresses}

\section{@ critical region 1}

Maximum principal stress

Membrane + Bending stress (von Mises)

$$
\begin{aligned}
\mathrm{S}_{1.1} & :=598.31 \mathrm{MPa} \\
\mathrm{S}_{\mathrm{mb} .1} & :=336.4 \mathrm{MPa}
\end{aligned}
$$

\section{2) FAD}

$$
\begin{aligned}
& \mathrm{L}_{\text {r.max }}:=\frac{\mathrm{Sy}+\mathrm{Su}}{2 \cdot \mathrm{Sy}} \quad \mathrm{L}_{\text {r.max.I }}:=\frac{\mathrm{Sy}_{\mathrm{I}}+\mathrm{Su}_{\mathrm{I}}}{2 \cdot \mathrm{Sy}_{\mathrm{I}}} \\
& \mu:=\min \left(0.001 \cdot \frac{\mathrm{E}}{\mathrm{Sy}}, 0.6\right) \quad \mu_{\mathrm{I}}:=\min \left(0.001 \cdot \frac{\mathrm{E}_{\mathrm{I}}}{\mathrm{Sy}_{\mathrm{I}}}, 0.6\right) \\
& \mathrm{f} 1:=\left(1+\frac{1}{2} \cdot 1\right)^{\frac{-1}{2}} \cdot\left(0.3+0.7 \cdot \exp \left(-\mu \cdot 1^{6}\right)\right) \mathrm{fl}_{\mathrm{I}}:=\left(1+\frac{1}{2} \cdot 1\right)^{\frac{-1}{2}} \cdot\left(0.3+0.7 \cdot \exp \left(-\mu_{\mathrm{I}} \cdot 1^{6}\right)\right)
\end{aligned}
$$




$$
\begin{aligned}
& \quad \mathrm{N}:=0.3 \cdot\left(1-\frac{\mathrm{Sy}}{\mathrm{Su}}\right) \quad \mathrm{N}_{\mathrm{I}}:=0.3 \cdot\left(1-\frac{\mathrm{Sy}_{\mathrm{I}}}{\mathrm{Su}_{\mathrm{I}}}\right)
\end{aligned}
$$

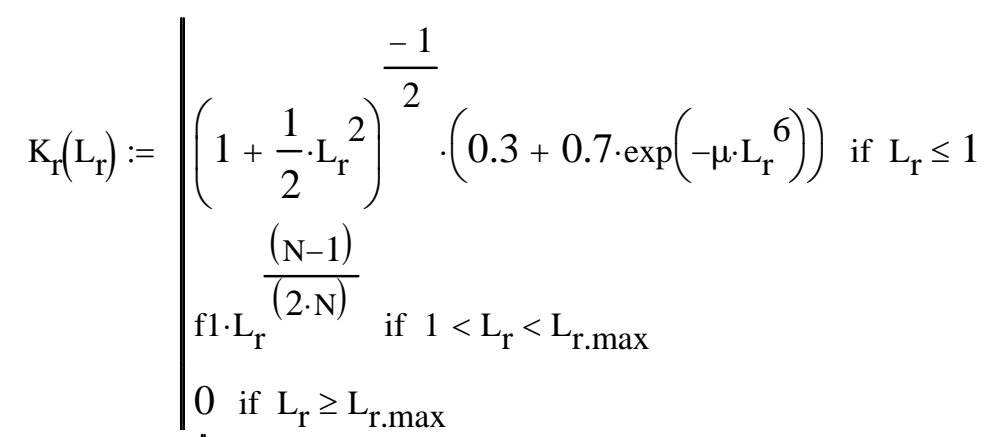

$$
\begin{aligned}
& \mathrm{K}_{\mathrm{r} . \mathrm{I}}\left(\mathrm{L}_{\mathrm{r}}\right)=\mid \begin{array}{l}
\left(1+\frac{1}{2} \cdot \mathrm{L}_{\mathrm{r}}^{2}\right)^{\frac{-1}{2}} \cdot\left(0.3+0.7 \cdot \exp \left(-\mu_{\mathrm{r}} \mathrm{L}_{\mathrm{r}}^{6}\right)\right) \text { if } \mathrm{L}_{\mathrm{r}} \leq 1 \\
\frac{\left(\mathrm{N}_{\mathrm{I}}-1\right)}{\left(2 \cdot \mathrm{N}_{\mathrm{I}}\right)} \text { if } 1<\mathrm{L}_{\mathrm{r}}<\mathrm{L}_{\text {r.max.I }} \\
\mathrm{fl}_{\mathrm{r}} \mathrm{L}_{\mathrm{r}} \\
0 \text { if } \mathrm{L}_{\mathrm{r}} \geq \mathrm{L}_{\mathrm{r} \text {.max.I }}
\end{array}
\end{aligned}
$$




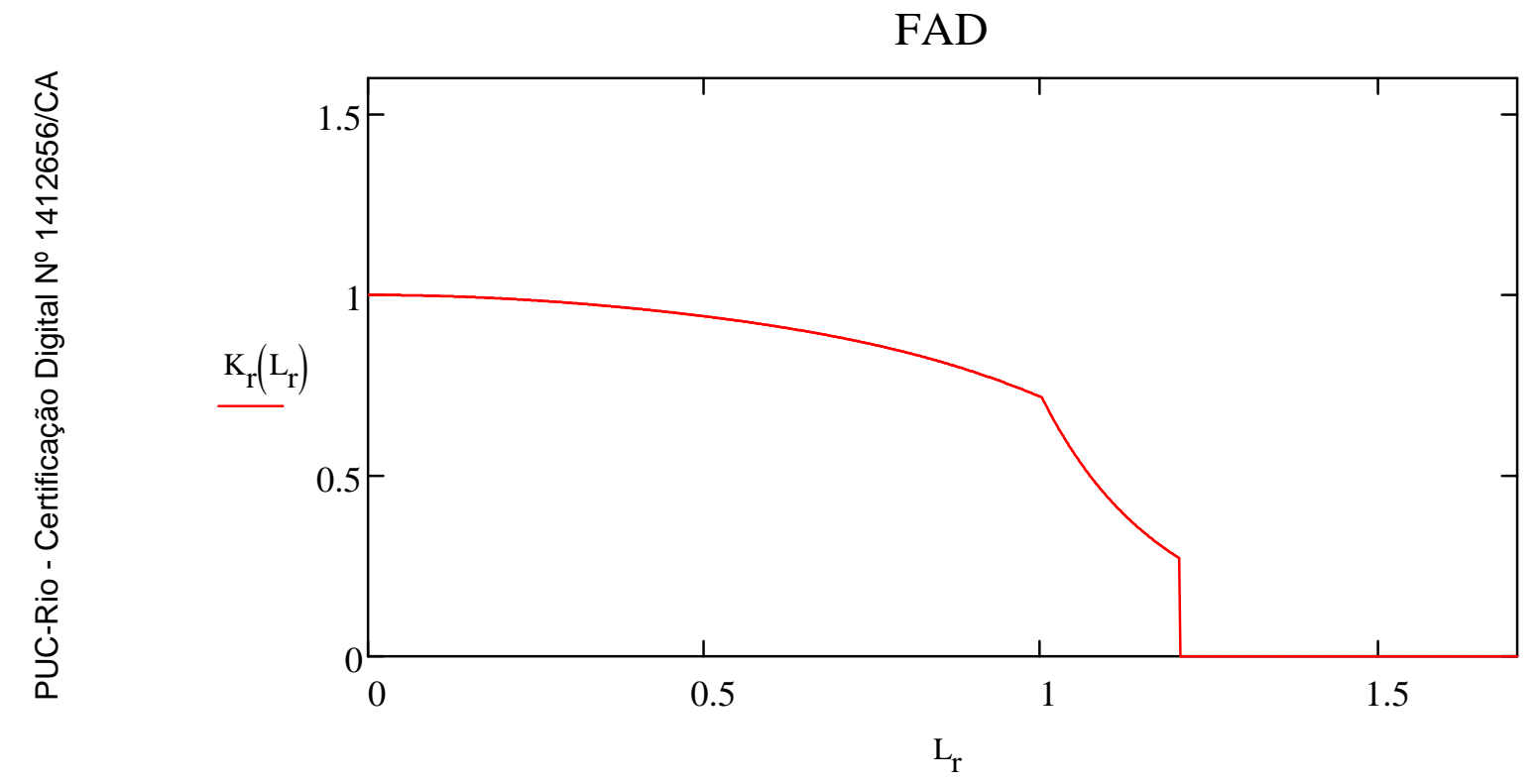

3) Intensity factor calculation and $\mathrm{Kr}$

3.1) Case - Fully circunferential external surface flaw - FLANGE 


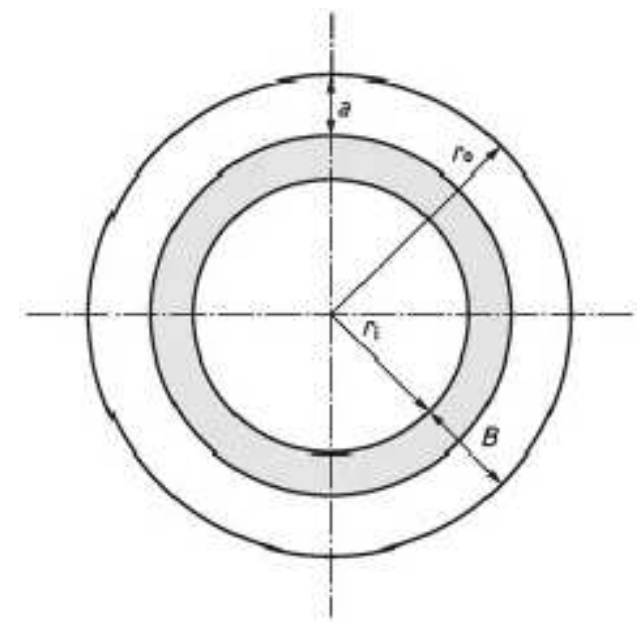

Flaw size

Tube thickness

Inside radius

External radius

$\lambda$ constant

$\mu$ constant

Stress intensity magnification factor
$\mathrm{M}_{1}:=1$

$\mathrm{f}_{\mathrm{w} .1}:=1$ $\mathrm{a}_{1 . \mathrm{rl}}:=31.5 \mathrm{~mm}$

$\mathrm{B}_{\mathrm{r} 1}:=60.7 \mathrm{~mm}$

$\mathrm{r}_{\mathrm{i} . \mathrm{r} 1}:=90.1 \mathrm{~mm}$

$\mathrm{r}_{0 . \mathrm{r} 1}:=150.8 \mathrm{~mm}$

$\lambda_{\mathrm{r} 1}:=\frac{\mathrm{r}_{\mathrm{i} . \mathrm{r} 1}}{\mathrm{r}_{0 \mathrm{r} 1}} \quad \lambda_{\mathrm{r} 1}=0.597$

$\mu_{1 . \mathrm{r} 1}:=\frac{\mathrm{a}_{1 . \mathrm{r} 1}}{\mathrm{~B}_{\mathrm{r} 1}} \quad \mu_{1 . \mathrm{r} 1}=0.519$ 


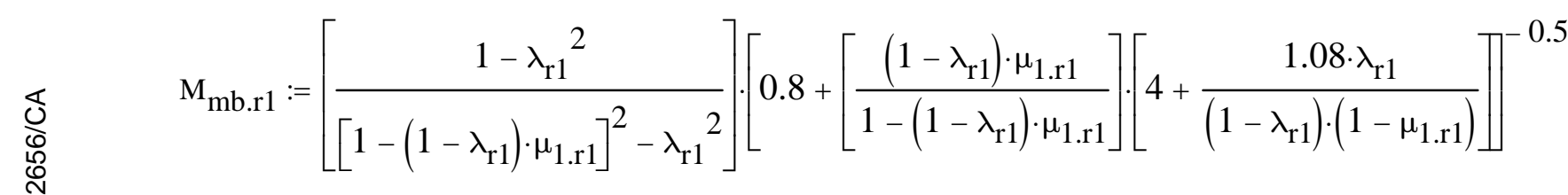

Stress intensity factor

$\mathrm{K}_{1 . \mathrm{r} 1}:=\mathrm{M}_{1} \cdot \mathrm{f}_{\mathrm{w} .1} \cdot \mathrm{M}_{\mathrm{mb} . \mathrm{r} 1} \cdot \mathrm{S}_{1.1} \cdot \sqrt{\pi \cdot \mathrm{a}_{1 . \mathrm{r} 1}}$

$\mathrm{K}_{1 . \mathrm{r} 1}=272.119 \mathrm{~m}^{0.5} \cdot \mathrm{MPa}$

@ Region 1

$$
\mathrm{K}_{\mathrm{r} .1 . \mathrm{rl}}:=\frac{\mathrm{K}_{1 . \mathrm{r} 1}}{\mathrm{~K}_{\mathrm{mat}}}
$$

$$
\mathrm{K}_{\mathrm{r} .1 . \mathrm{r} 1}=0.96
$$

@ Region 1

\section{4) Ratio of applied load to yield load (Lr)}

Lr@ Region 1

$$
\operatorname{Lr}_{\mathrm{r} 1}:=\frac{\mathrm{S}_{\mathrm{mb} .1}}{\mathrm{Sy}}
$$$$
\mathrm{Lr}_{\mathrm{r} 1}=0.31
$$

\section{5) Results}

$\mathrm{K}_{\mathrm{r} . \mathrm{r} 1}\left(\mathrm{Lr}_{\mathrm{r} 1}\right):=\mathrm{K}_{\mathrm{r} .1 . \mathrm{r} 1}$ 
FAD

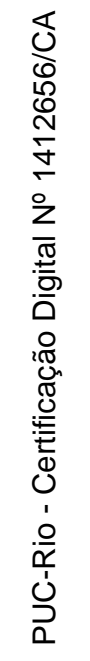

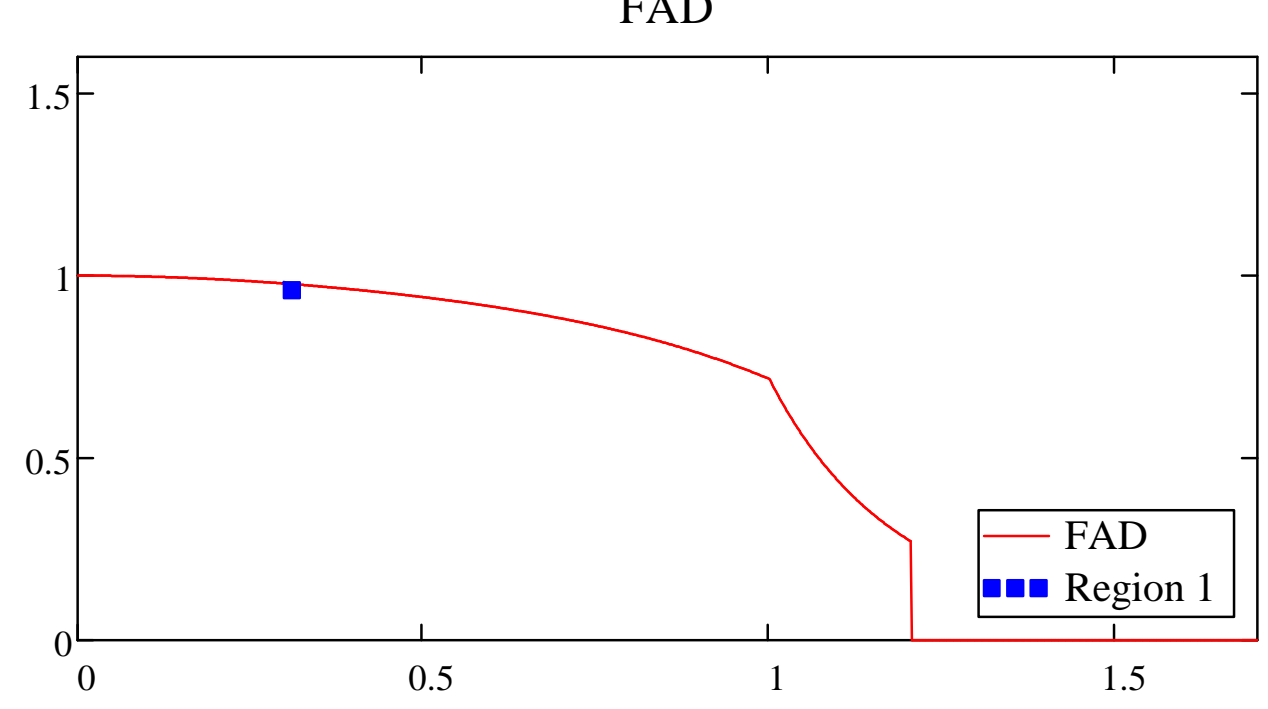


ANEXO B

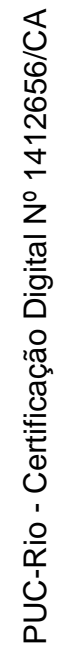




\section{1) Mechanical properties}

$\begin{array}{ll}\begin{array}{l}\text { Young Modulus } \\ \text { Poisson Ratio }\end{array} & \begin{array}{l}\mathrm{E}:=209 \mathrm{GPa} \\ \mathrm{v}:=0.3\end{array} \\ \text { Engineering Yield Strength } & \text { Sye }:=1084.589 \mathrm{MPa} \\ \text { Engineering Tensile Strength } & \text { Sue }:=1278.619 \mathrm{MPa} \\ \text { Engineering Tensile Strain } & \varepsilon_{\mathrm{u}}:=0.22 \\ \text { True Yield Strength } & \text { Sy }:=\text { Sye } \cdot(1+\ln (1+0.002)) \\ & \text { Sv }:=\text { Sye } \cdot(1+\ln (1+0.002)) \\ & \text { Sy }=1.087 \times 10^{3} \cdot \mathrm{MPa} \\ \text { True Ultimate Strength } & \mathrm{Su}:=\text { Sue } \cdot\left(1+\ln \left(1+\varepsilon_{\mathrm{u}}\right)\right) \\ & \mathrm{Su}=1.533 \times 10^{3} \cdot \mathrm{MPa}\end{array}$

\section{2) Toughness properties}
CTOD
$\delta_{\mathrm{c}}:=0.19 \mathrm{~mm}$
$\underset{m}{m}:=\left\{\begin{array}{l}1.517 \cdot\left(\frac{\mathrm{Sy}}{\mathrm{Su}}\right)^{-0.3188} \\ 1.5 \text { otherwise }\end{array}\right.$ if $0.3<\left(\frac{\mathrm{Sy}}{\mathrm{Su}}\right)<0.98$
$\mathrm{m}=1.693$ 
Fracture Toughness $\quad \mathrm{K}_{\mathrm{mat}}:=\sqrt{\frac{\mathrm{m} \cdot \mathrm{Sy} \cdot \delta_{\mathrm{c}} \cdot \mathrm{E}}{1-\mathrm{v}^{2}}} \quad \mathrm{~K}_{\text {mat }}=283.334 \mathrm{~m}^{0.5} \cdot \mathrm{MPa}$

Extend of the plastic zone $\quad a_{\mathrm{pl}}:=\left(\frac{1}{\pi}\right) \cdot\left(\frac{\mathrm{K}_{\mathrm{mat}}}{\mathrm{Sy}}\right)^{2} \quad \mathrm{a}_{\mathrm{pl}}=21.636 \cdot \mathrm{mm}$

\section{3) Stresses}

\section{@ critical region 1}

Maximum principal stress

Membrane + Bending stress (von Mises)

$$
\begin{aligned}
\mathrm{S}_{1.1} & :=598.31 \mathrm{MPa} \\
\mathrm{S}_{\mathrm{mb} .1} & :=336.4 \mathrm{MPa}
\end{aligned}
$$

\section{2) FAD}

$$
\begin{aligned}
& \mathrm{L}_{\text {r.max }}:=\frac{\mathrm{Sy}+\mathrm{Su}}{2 \cdot \mathrm{Sy}} \quad \mathrm{L}_{\text {r.max.I }}:=\frac{\mathrm{Sy}_{\mathrm{I}}+\mathrm{Su}_{\mathrm{I}}}{2 \cdot \mathrm{Sy}_{\mathrm{I}}} \\
& \mu:=\min \left(0.001 \cdot \frac{\mathrm{E}}{\mathrm{Sy}}, 0.6\right) \quad \mu_{\mathrm{I}}:=\min \left(0.001 \cdot \frac{\mathrm{E}_{\mathrm{I}}}{\mathrm{Sy}_{\mathrm{I}}}, 0.6\right) \\
& \mathrm{f} 1:=\left(1+\frac{1}{2} \cdot 1\right)^{\frac{-1}{2}} \cdot\left(0.3+0.7 \cdot \exp \left(-\mu \cdot 1^{6}\right)\right) \mathrm{fl}_{\mathrm{I}}:=\left(1+\frac{1}{2} \cdot 1\right)^{\frac{-1}{2}} \cdot\left(0.3+0.7 \cdot \exp \left(-\mu_{\mathrm{I}} \cdot 1^{6}\right)\right)
\end{aligned}
$$




$$
\begin{aligned}
& \quad \mathrm{N}:=0.3 \cdot\left(1-\frac{\mathrm{Sy}}{\mathrm{Su}}\right) \quad \mathrm{N}_{\mathrm{I}}:=0.3 \cdot\left(1-\frac{\mathrm{Sy}_{\mathrm{I}}}{\mathrm{Su}_{\mathrm{I}}}\right)
\end{aligned}
$$

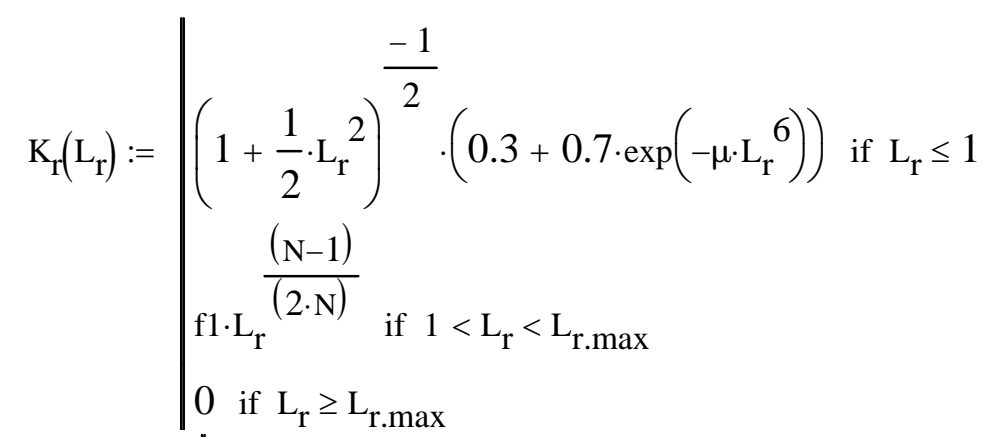

$$
\begin{aligned}
& \mathrm{K}_{\mathrm{r} . \mathrm{I}}\left(\mathrm{L}_{\mathrm{r}}\right)=\mid \begin{array}{l}
\left(1+\frac{1}{2} \cdot \mathrm{L}_{\mathrm{r}}^{2}\right)^{\frac{-1}{2}} \cdot\left(0.3+0.7 \cdot \exp \left(-\mu_{\mathrm{r}} \mathrm{L}_{\mathrm{r}}^{6}\right)\right) \text { if } \mathrm{L}_{\mathrm{r}} \leq 1 \\
\frac{\left(\mathrm{N}_{\mathrm{I}}-1\right)}{\left(2 \cdot \mathrm{N}_{\mathrm{I}}\right)} \text { if } 1<\mathrm{L}_{\mathrm{r}}<\mathrm{L}_{\text {r.max.I }} \\
\mathrm{fl}_{\mathrm{r}} \mathrm{L}_{\mathrm{r}} \\
0 \text { if } \mathrm{L}_{\mathrm{r}} \geq \mathrm{L}_{\mathrm{r} \text {.max.I }}
\end{array}
\end{aligned}
$$




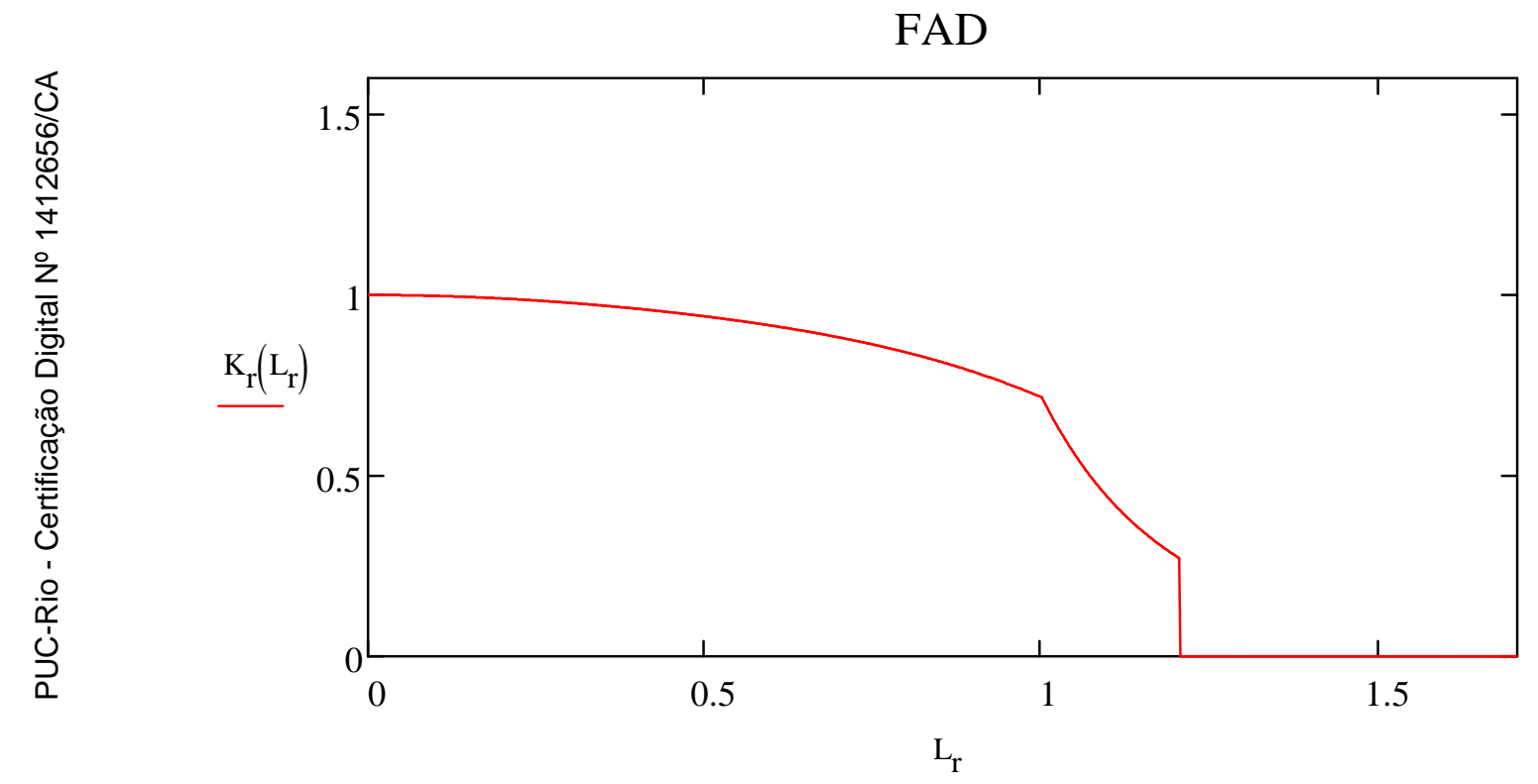

3) Intensity factor calculation and $\mathrm{Kr}$

3.1) Case - Fully circunferential external surface flaw - FLANGE 


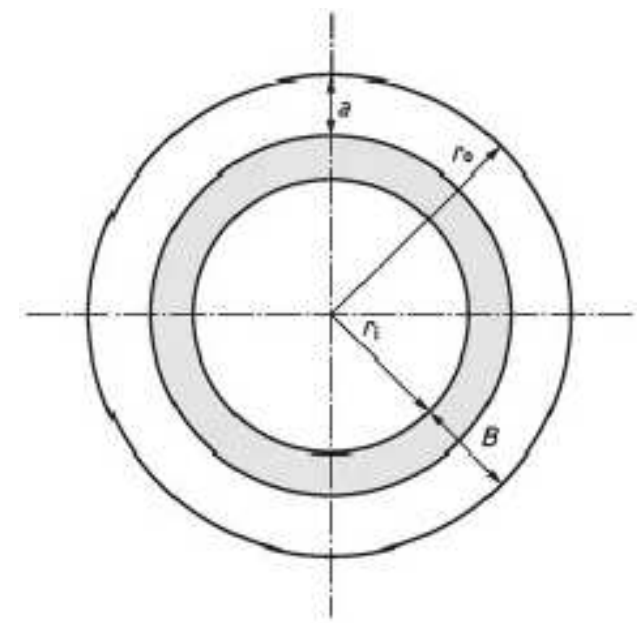

$$
\begin{aligned}
& \mathrm{M}_{1}:=1 \\
& \mathrm{f}_{\mathrm{w} .1}:=1
\end{aligned}
$$

Flaw size

Tube thickness

Inside radius

External radius

$\lambda$ constant

$\mu$ constant

Stress intensity magnification factor

$$
\mathrm{a}_{1 . \mathrm{rl}}:=6.5 \mathrm{~mm}
$$$$
\mathrm{B}_{\mathrm{r} 1}:=60.7 \mathrm{~mm}
$$$$
\mathrm{r}_{\mathrm{i} . \mathrm{r} 1}:=90.1 \mathrm{~mm}
$$$$
\mathrm{r}_{0 . \mathrm{rl}}:=150.8 \mathrm{~mm}
$$$$
\lambda_{\mathrm{r} 1}:=\frac{\mathrm{r}_{\mathrm{i} . \mathrm{r} 1}}{\mathrm{r}_{0 \mathrm{r} 1}} \quad \lambda_{\mathrm{r} 1}=0.597
$$

$\mu_{1 . \mathrm{r} 1}:=\frac{\mathrm{a}_{1 . \mathrm{r} 1}}{\mathrm{~B}_{\mathrm{r} 1}} \quad \mu_{1 . \mathrm{r} 1}=0.107$




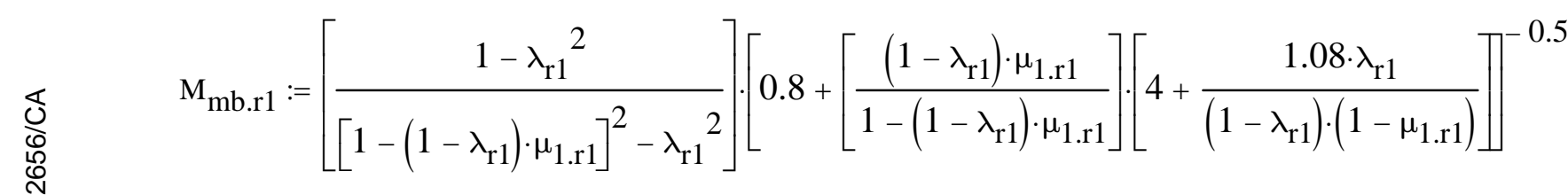

Stress intensity factor

$\mathrm{K}_{1 . \mathrm{rl}}:=\mathrm{M}_{1} \cdot \mathrm{f}_{\mathrm{w} .1} \cdot \mathrm{M}_{\mathrm{mb} . \mathrm{r} 1} \cdot \mathrm{S}_{1.1} \cdot \sqrt{\pi \cdot \mathrm{a}_{1 . \mathrm{r} 1}}$

$\mathrm{K}_{1 . \mathrm{r} 1}=95.534 \mathrm{~m}^{0.5} \cdot \mathrm{MPa}$

@ Region 1

$$
\mathrm{K}_{\mathrm{r} .1 . \mathrm{r} 1}:=\frac{\mathrm{K}_{1 . \mathrm{r} 1}}{\mathrm{~K}_{\mathrm{mat}}}
$$

$$
\mathrm{K}_{\mathrm{r} .1 .1 \mathrm{r}}=0.337
$$

@ Region 1

\section{4) Ratio of applied load to yield load (Lr)}

Lr@ Region 1

$$
\mathrm{Lr}_{\mathrm{r} 1}:=\frac{\mathrm{S}_{\mathrm{mb} .1}}{\mathrm{Sy}}
$$$$
\mathrm{Lr}_{\mathrm{r} 1}=0.31
$$

\section{5) Results}

$\mathrm{K}_{\mathrm{r} . \mathrm{r} 1}\left(\mathrm{Lr}_{\mathrm{r} 1}\right):=\mathrm{K}_{\mathrm{r} .1 . \mathrm{r} 1}$ 
FAD

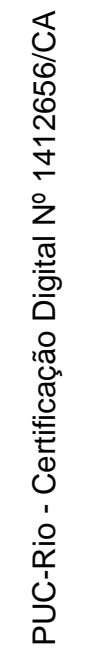

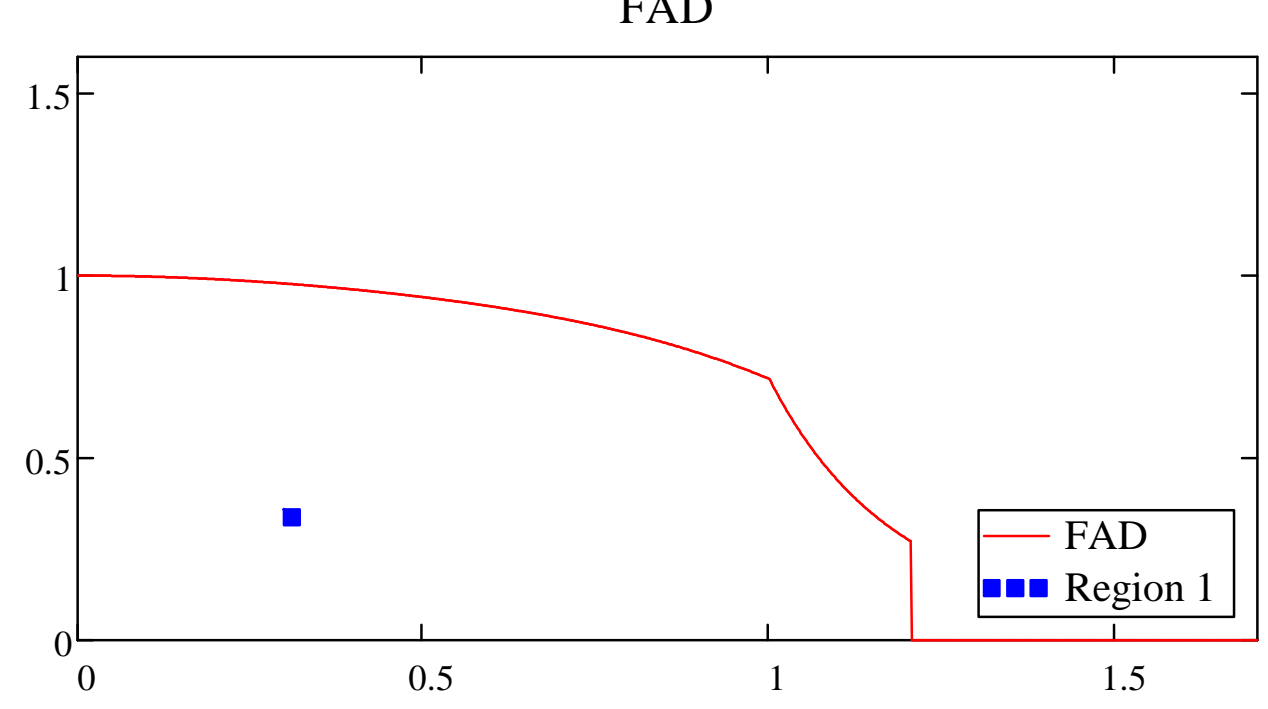

